\title{
Naturalis
}

\section{Efectos de la contaminación difusa sobre el perifiton de arroyos}

\section{Vilches, Carolina}

Doctor en Ciencias Naturales

Dirección: Giorgi, Adonis

Co-dirección: Casco, María Adela

Facultad de Ciencias Naturales y Museo

2012

Acceso en:

http://naturalis.fcnym.unlp.edu.ar/id/20120418001218

\section{(c) (1) (2) (2) \\ BY NC SA}

Esta obra está bajo una Licencia Creative Commons

Atribución-NoComercial-Compartirlgual 4.0 Internacional

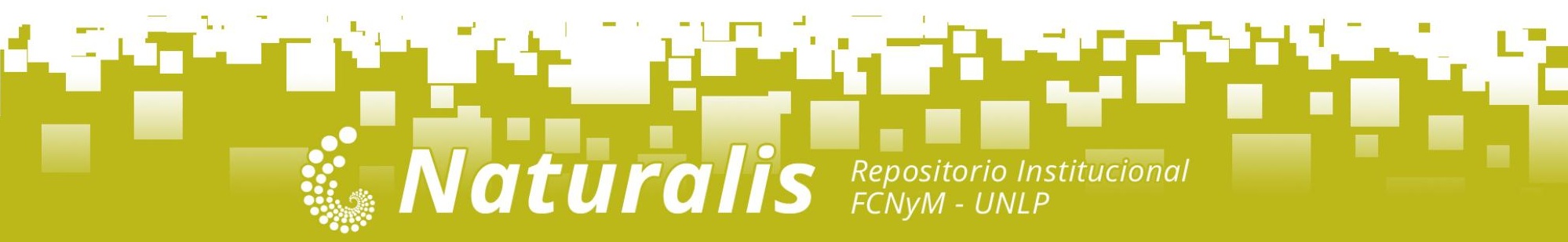




\section{Universidad Nacional de La Plata}

Facultad de Ciencias Naturales y Museo

\section{Efectos de la contaminación difusa sobre el perifiton de arroyos}

\section{Carolina Vilches}

Director: Adonis Giorgi

Codirector: María Adela Casco

Tesis para optar por el título de Doctor en

Ciencias Naturales 


\section{Agradecimientos}

Mi agradecimiento a todas aquellas personas que han hecho posible la realización de este trabajo de tesis.

Adonis por haber confiado en mi desde un primer momento y por seguir confiando, por todos sus consejos y acompañamiento, porque además de un excelente director es un compañero que mete las patas en el agua y se queda filtrando hasta la madrugada, porque escucha todas las locas teorías que se me ocurren cada día y me sostiene cada vez que creo bajar los brazos, por estar constantemente ocupado en mi formación profesional, por tener todas las respuestas o saber dónde buscarlas.

MAC, por los consejos y guía en la realización de este trabajo.

A los compañeros de muestreos, Martina Mastrángelo, Paola Scarcia, Natalia Ossana, Lucrecia Ferrari, Patricia Castagné, Fernando de la Torre, María Andrea Casset, Agustín Somma y Luciana Rocha.

A la colaboración imprescindible en las determinaciones de metabolismo de Juan Francisco Asad y Carolina Rodríguez Castro.

A Martina Mastrángelo por las DBO.

A Leonardo Leggieri por la colaboración en el registro de las curvas de variación de oxígeno.

A los pasantes que colaboraron en diferentes instancias de este trabajo, Lucrecia Pearson y Martín Da Silva.

Gracias a los diferentes cursos y sus docentes en las determinaciones de las algas, Silvia Sala, MAC, Tatty, Guillermo Tell, Haydeé Pizarro, Irina Izaguirre, Nora Maidana. Y a Visitación Conforti por la ayuda con los euglenoideos.

A los compañeros del PRODEA por el aguante, los consejos, los mates, los asados y locros y gracias por tolerar los "turnos de María".

Al PEP por la silla y el escritorio tan necesarios para acabar de escribir, por la paz del campo y la ventana sin igual. Y a los miembros del PEP por todo el aguante. 
Al sector ecología, a los PRH y a tormenta de ideas por estar ahí, por prestar la mano y el hombro y la oreja y todo lo que haga falta.

Al apoyo y los sabios consejos de mis compañeros, Leonardo Leggieri, Nicolás Ferreiro, Gabriela Campana y Laura Rigacci.

A Vicenç Acuña por los consejos en el diseño de los arroyos artificiales, consejos con la escritura de artículos y sus muchas "críticas constructivas" que me llevaron a plantear y replantear varias veces la mejor forma de realizar este trabajo.

A mis padres, por la contención, el aliento, la confianza y el apoyo constantes.

A los amigos que me siguen escuchando aunque no se entienda lo que digo, por aceptar mis "no tengo tiempo" y esperar con paciencia y sobre todo por el apoyo y contención, Taty, Marimar, Gre, Ale, Lucre, Ara, Flor,Vic, a todos gracias por estar. Y a Taty por su excelente hospitalidad y compañía durante nuestras convivencias en VU.

Al Xino, por el aguante y el rock!

A MINCyT (PICT 2004- N 26-165), CONICET y a la Universidad de La Plata por haber subvencionado este trabajo a través del otorgamiento de becas y subsidios. Y a la Universidad de Luján que me dio mi lugar de trabajo. 


\section{Resumen}

El perifiton puede considerarse una comunidad clave en los cuerpos de agua lóticos pequeños ya que tiene alta producción y se considera responsable de sostener gran parte de su red trófica. Las algas que lo componen provocan cambios a nivel físicoquímico en el agua, intervienen en el almacenamiento temporario de fósforo, en la formación de sedimentos y en la reducción de la erosión de los lechos. Por otro lado, las algas constituyen refugios y favorecen la construcción del sustrato a través de las secreciones y restos de la comunidad.

El perifiton responde predictiva y rápidamente a los cambios en las condiciones ambientales en un gran rango de escalas espaciales. Es una comunidad sésil que se modifica por los impactos del lugar y tiene la capacidad de absorber y concentrar sustancias contaminantes mostrando cambios en su composición y en sus características estructurales y funcionales. Por ello, puede utilizarse esta comunidad como un indicador biológico del cual se obtiene información complementaria a la suministrada por variables físicas y químicas.

La actividad agropecuaria genera desechos que se originan a partir de fuentes puntuales (ensilado, purines, cámaras sépticas) o difusas (plaguicidas, fertilizantes, sedimentos, materia orgánica y nutrientes aportados por el ganado). Mientras que las primeras son más fáciles de detectar y controlar, las difusas son más difíciles de evaluar y manejar ya que llegan al arroyo como un complejo.

Nuestra hipótesis fue que los cambios producidos por actividades agropecuarias repercutirán en las características estructurales y/o funcionales de la comunidad perifítica de acuerdo a la intensidad y tipo de contaminación difusa. El principal objetivo propuesto fue: Evaluar las modificaciones producidas por la contaminación difusa en el perifiton, considerando tanto parámetros estructurales como funcionales y elaborar un marco predictivo que describa el efecto que las distintas actividades agropecuarias producen en la comunidad perifítica.

Este estudio se realizó principalmente en las cabeceras de los arroyos que dan origen al río Reconquista. La geología de la región se vincula esencialmente con los depósitos sedimentarios Cenozoicos. Las pendientes de los arroyos son sumamente bajas $(0,02 \%)$ y sus aguas poseen altos contenidos de nutrientes. El río Reconquista está situado al noroeste de la región metropolitana de Buenos Aires, en una zona templada en la región pampeana. 
En este estudio se trabajó tanto con perifiton desarrollado sobre sustrato natural como con el colonizado en sustratos artificiales en ambiente natural y también se estudió la respuesta del perifiton en un ambiente completamente artificial. El uso de sustratos artificiales permitió la incorporación de la determinación de parámetros funcionales que aportan medidas sensibles y eficientes para detectar el impacto sobre el perifiton sin que se viese afectado por la interacción con el sustrato natural. Por otro lado, la realización de experimentos en un ambiente artificial posibilitó aislar factores que habían demostrado su importancia en los resultados del trabajo de campo. De este modo se pudo estudiar su efecto separado de cualquier interacción y contrastarlo con el hallado en el ambiente natural. Se realizó primero un relevamiento de la cuenca superior en ocho sitios seleccionados de acuerdo al uso agropecuario predominante (ganaderoagrícola) donde se analizaron variables fisicoquímicas del agua y se estudió el perifiton sobre sustrato natural (Ludwidgia peploides). Luego se concentró el trabajo en tramos seleccionados de acuerdo a la intensidad de su uso agropecuario y se analizó el perifiton colonizado en sustratos artificiales. Además de las características estructurales se evaluaron las funcionales (producción y respiración de la comunidad, actividad de exoenzimas). Finalmente, se realizaron tres experimentos en arroyos artificiales para evaluar la relación de las sustancias húmicas con la concentración de fósforo, la de un fertilizante y la de un herbicida de uso comercial.

Nuestros resultados revelaron que los parámetros que mejor indican el efecto de la contaminación difusa sobre el perifiton fueron la concentración de clorofila $a$, el contenido de fósforo total en el perifiton, la composición taxonómica, la producción neta y la actividad de la fosfatasa alcalina. Sin embargo, sería necesaria una combinación de ellos para interpretar los cambios acerca de los que nos informan. Podría decirse que los parámetros funcionales serían sistemas de alerta temprana de contaminación debida al uso agropecuario de la tierra, mientras que los estructurales informarían acerca de situaciones sostenidas de buena o mala calidad del agua. Además, se observó que los ácidos húmicos deben ser tenidos en cuenta como una variable clave en los arroyos pampeanos por las repercusiones que tienen tanto en el desarrollo de las comunidades como en la atenuación en la captación de nutrientes.

Finalmente, se elaboró un esquema general predictivo en base a las respuestas posibles en la comunidad perifítica desarrollada en arroyos con ganadería o agricultura. Se tuvo en cuenta el estado trófico del sistema, el tipo e intensidad de uso de la tierra para diferenciar los posibles impactos. 


\begin{abstract}
Periphyton can be considered a key community in small lotic water bodies because its high production and because is consider of being responsible of the maintenance of much of their food web. The algae which compose it causes changes to the physico-chemical water, interceding in the temporary phosphorus storage, in the sediment formations, and in the beds erosion reduction. On the other hand, algae provide refuges and facilitate the construction of the substrate through secretions and community remains.

Periphyton has predictable and quick response to changes in environmental conditions in a large range of spatial scales. It is a sessile community that changes by local impacts and has the ability to absorb and concentrate pollutants showing changes in its composition as well as in its structural and functional characteristics. Therefore, this community can be used as a biological indicator in order to obtain complementary information from the provided by physical and chemical variables.

Agricultural and livestock activities generate wastes that are originated from point sources (silage, manure, septic tanks) or diffuse sources (pesticides, fertilizers, sediment, organic matter and nutrients from livestock). While the former ones are easier to detect and control, the diffuse ones are more difficult to evaluate and manage as they reaches the stream as a complex.

Our hypothesis was that changes produced by agricultural and livestock activities have an impact on the structural and/or functional characteristic of the periphytic community according to the intensity and type of diffuse pollution. The main objective was: To evaluate the modifications produced by diffuse pollution in the periphyton, taking into account both structural and functional parameters, and develop a predictive framework that describes the effect of different agricultural and livestock activities in the periphytic community.

This study was carried out mainly in the headwaters of the streams that origins the Reconquista River. The geology of the region is essentially related to Cenozoic sedimentary deposits. The streams slopes are extremely low $(0.02 \%)$ and their water have high content of nutrients. The Reconquista River is located northwest of the metropolitan region of Buenos Aires, in a temperate zone in the Pampean region.
\end{abstract}


The study was carried out with both natural periphyton and artificial substrates colonized on natural environment and also with periphyton on a completely artificial environment. The use of artificial substrates allowed the incorporation of functional parameters that provide sensitive and effective measures to detect the impact on the periphyton avoiding its interaction with the natural substrate. On the other hand, the experiments in an artificial environment made possible to isolate factors that had demonstrated to be important on fieldwork results. As a result, it was possible to study its effect independently from any interaction and to make a comparison against the natural environment results. At the beginning, it was conducted a survey of the upper basin at eight sites selected according to the predominant agricultural and livestock management where physico-chemical variables were analyzed and periphyton on natural substrate (Ludwidgia peploides) was studied. Then, work was concentrated on reaches that were selected according to the intensity of farming use and the periphyton colonized on artificial substrates was analyzed. In addition to the structural characteristics, functional variables were evaluated (production and community respiration, activity of exoenzymes). Finally, three experiments were carried out in artificial streams to assess the relationship of humic substances and the concentration of phosphorus, of a fertilizer, and of an herbicide for commercial use.

Our results revealed that the parameters that best indicate the effect of diffuse pollution on periphyton were the concentration of chlorophyll a, total phosphorus content in the periphyton, the taxonomic composition, net production and alkaline phosphatase activity. However, a combination of them is necessary to interpret the changes that we reported about. It is arguably the functional parameters serve as early warning systems of pollution due to agricultural and livestock land use, whereas the structural conditions would report the sustained good or bad water quality. In addition, it was observed that humic acids should be taken into account as a key variable in Pampean streams for the impact on the development of the communities as well as on the attenuation in the nutrients uptake.

Finally, a general predictive scheme was made based on the possible responses of the periphytic community developed in streams with livestock or crops. The trophic status of the system, the type and the intensity of land use was taken into account to differentiate the possible impacts. 


\section{ÍNDICE}

Capítulo 1: Introducción 1

Objetivos 6

Capítulo 2: Metodología 9

$\begin{array}{ll}\text { Ambiente } & 10\end{array}$

$\begin{array}{ll}\text { Sitios de muestreo } & 19\end{array}$

$\begin{array}{ll}\text { Materiales y Métodos } & 27\end{array}$

Parámetros Fisicoquímicos $\quad 28$

Parámetros del Perifiton $\quad 31$

Análisis Estadísticos $\quad 35$

Capítulo 3: Efectos de la contaminación difusa en arroyos sobre el perifiton en sustratos naturales 36

Introducción $\quad 37$

Materiales y Métodos $\quad 39$

Resultados 43

$\begin{array}{ll}\text { Discusión } & 67\end{array}$

Capítulo 4: Efectos de la contaminación difusa en arroyos sobre el $\begin{array}{ll}\text { perifiton en sustratos artificiales } & 74\end{array}$

Introducción $\quad 75$

Materiales y Métodos $\quad 77$

$\begin{array}{ll}\text { Resultados } & 80\end{array}$

Discusión $\quad 92$

Capítulo 5: Efecto de la contaminación difusa sobre el perifiton en arroyos artificiales 96

Introducción $\quad 97$

Materiales y Métodos 99

$\begin{array}{ll}\text { Resultados } & 106\end{array}$

Discusión 119

Capítulo 6: Discusión y Conclusiones $\quad 125$

Conclusiones 135

Epílogo 136

Capítulo 7: Bibliografía 139

$\begin{array}{ll}\text { Anexo } & 156\end{array}$ 
Capítulo 1

Introducción 
El perifiton es la comunidad constituida por el conjunto de organismos que viven asociados a plantas u objetos sumergidos en el agua (Wetzel 1983). En ese sentido el término perifiton es más amplio que el de epifiton ya que engloba los organismos adheridos sobre sustratos naturales y artificiales. Además, se refiere a comunidades totalmente desarrolladas a diferencia del término biofilm que designa comunidades en proceso de colonización o crecimiento (Ringuelet 1962). De todos modos, estos últimos años ha cobrado importancia el término biofilm utilizándose como sinónimo de perifiton (por ejemplo, Sabater et al. 2002)

El perifiton puede considerarse una comunidad clave en los cuerpos de agua lóticos pequeños ya que tiene alta producción y se considera responsable de sostener gran parte de su red trófica (Sand Jensen et al. 1989, Vilches y Giorgi 2010). También es importante su papel dentro de la red de detritos, como productores de materia orgánica y en menor medida como consumidores de sustratos orgánicos simples (Stevenson et al. 1996). Las algas epifitas que lo constituyen provocan cambios a nivel físico-químico en el agua que incluyen: procesos de oxigenación (fotosíntesis) así como también de desoxigenación (descomposición y respiración nocturna de las floraciones de algas), incremento del $\mathrm{pH}$, disminución de la concentración de dióxido de carbono e iones carbonato, y aumento de la materia orgánica disuelta y nitrógeno (por asimilación del nitrógeno molecular por cianofitas). También intervienen en el almacenamiento temporario de fósforo a partir de sustratos vivos o muertos, en la formación de sedimentos a través de la precipitación de calcita, y en la reducción de la erosión de los lechos (por ejemplo por crecimiento de matas de algas mucilaginosas). Por otro lado, constituyen refugios para el zooplancton, invertebrados y anfibios y favorecen la construcción del mismo sustrato a través de las secreciones y restos de la comunidad (Stevenson et al. 1996).

El perifiton responde predictiva y rápidamente a los cambios en las condiciones ambientales en un gran rango de escalas espaciales (Gaiser 2009). Es una comunidad compacta y de ciclos de vida cortos que al desarrollarse en un sitio determinado, se modifica por los impactos producidos por contaminantes u otro tipo de perturbaciones sobre ese lugar. Esta comunidad además tiene la capacidad de absorber y concentrar sustancias contaminantes que estén disueltas en el agua. La acción de los contaminantes sobre el perifiton se traduce en cambios en su composición y en sus características estructurales y funcionales (Aizaki 1985, Blanck 1985). Es una comunidad rica en 
especies y cada especie tiene sus tolerancias y preferencias ambientales. Por ello, puede utilizarse esta comunidad como un indicador biológico del cual se obtiene información complementaria a la suministrada por variables físicas y químicas (Cairns et al. 1993).

La utilidad del perifiton para mostrar las consecuencias ecológicas de la contaminación se debe según Gaiser (2009) a que presenta varias de las características más deseables de un indicador ecológico fiable que incluyen: (1) se distribuye en todo el sistema de estudio, (2) tiene una respuesta rápida a los cambios ambientales, (3) son cuantificables en varios niveles de organización biológica (especie, División, forma de vida), (4) con consecuencias en la red trófica.

El perifiton ha sido muy utilizado como comunidad indicadora tanto en lagos (Crossey y LaPoint 1998, Desrosiers et al. 2006) como ríos (Stewart 1995, Žižec et al. 2011) y arroyos (Economou-Amilli 1980, Giorgi y Malacalza 2002). En cada caso, para referirse a los efectos de los contaminantes, se estudiaron los cambios producidos en cada comunidad local, demostrándose que existen cambios en la comunidad perifítica provocados directamente por los contaminantes mientras que otros se explican por la interacción con otros factores como la velocidad del agua, la herbivoría o la sedimentación. En ambientes pampeanos, el perifiton ha sido utilizado como indicador de perturbaciones naturales y antropogénicas (Giorgi y Malacalza 2002, Gómez y Licursi 2003, Gómez et al. 2003, Gómez et al. 2008, Licursi y Gómez 2004, Pizarro y Alemanni 2005, Sierra y Gómez 2007, 2010).

De acuerdo con lo demostrado por distintos autores el perifiton es una comunidad sensible a los cambios producidos en los ecosistemas acuáticos por contaminación difusa. Aizaki (1985) indica la capacidad de absorción de sustancias orgánicas por parte del perifiton y Blanck (1985) estudiando el efecto de algunos plaguicidas indica que estos afectan primeramente a los parámetros funcionales y luego a los estructurales. Según Steiman y Mc Intire (1990) la materia orgánica incrementa en una primera etapa el perifiton heterotrófico, y a medida que la comunidad se recupera se va transformando en autotrófica. Estos autores agregan que esta recuperación es más lenta en el caso de una comunidad perifítica con más tiempo de colonización o más madura y aún más si recibe el efecto de sustancias tóxicas. En caso de ingreso directo de nutrientes, es esperable que se incremente la clorofila $a$ (Delong y Bruswen 1992). 
En líneas generales se podría decir que el hombre a través de su actividad promueve los flujos de transporte horizontal de materia y energía. En el caso de los ecosistemas adyacentes (campo cultivado-cuerpo de agua / campo ganadero-cuerpo de agua) los intercambios de materia y energía entre ellos son acelerados por esta acción humana (Margalef y Prat 1979).

Dado que los arroyos tienen una gran interrelación con las tierras adyacentes, las modificaciones de uso que en estas se producen pueden impactar directamente sobre estos ecosistemas por ingreso de sustancias al cuerpo de agua (Margalef 1994). En el caso que estas sustancias sean contaminantes o interfieran en el funcionamiento de los arroyos pueden provocarse cambios en su biodiversidad. Un ecosistema con una producción neta más alta, una biodiversidad menor y una alta tasa de renovación como son los sistemas cultivados, produce un flujo neto de energía hacia otro ecosistema de organización más compleja como serían los ecosistemas acuáticos (Margalef 1991). Junto con ese flujo de exceso de producción son trasladados parte de los insumos de la actividad pecuaria, como ser, pesticidas, fertilizantes, alimento y desechos metabólicos y orgánicos. El conocimiento de los cambios en los sistemas complejos pueden informarnos tempranamente sobre problemas relacionados con el manejo en la explotación, tales como sobrepastoreo, erosión, etc.

Por otro lado, los sistemas ganaderos producen desechos básicamente heterotróficos (incremento de la turbidez, la conductividad, compuestos nitrogenados y fosforados) que aceleran los procesos de consumo de materiales y descomposición y que repercutirán tanto en la estructura como en el funcionamiento de la comunidad perifítica (Steinman y Mc Intire 1990, Hooda et al. 2000). A su vez, cambios en la biomasa algal y su composición taxonómica pueden causar cascadas tróficas que tienen efectos irreversibles sobre la estructura y función de la comunidad acuática (Chase 2003).

La región pampeana se distingue de otros paisajes del mundo por abarcar un extenso territorio predominantemente llano de suelos muy fértiles, excelentes para usos agropecuarios. Por este motivo ha sufrido el impacto de la actividad agrícola desde el siglo XIX y de la ganadería desde los tiempos coloniales (S. XIV) (Gómez y Toresani 1999). Los arroyos pampeanos son parte de este paisaje y mantienen una interrelación y 
dependencia con este medio por lo que son altamente vulnerables al uso antrópico de los recursos tanto propios como los de las riberas (Quirós 2000).

La actividad agropecuaria genera desechos que son vertidos a cuerpos de agua cercanos originando fenómenos de contaminación. Los mismos se originan a partir de fuentes puntuales (ensilado, purines, cámaras sépticas) o difusas (plaguicidas, fertilizantes, sedimentos, materia orgánica y nutrientes aportados por el ganado). Mientras que las primeras son fáciles de detectar y controlar, las difusas (pérdidas de nutrientes por lixiviación y escorrentía superficial) son más difíciles de evaluar y manejar (Hooda et al. 2000).

Los aportes a los cuerpos de agua por contaminación difusa han sido escasamente registrados en nuestro país (Arreghini et al. 2005, Jergentz et al. 2005) Por otro lado, han sido más numerosas las investigaciones sobre este tema referidas a las comunidades planctónicas, debido a que el perifiton es una comunidad con una distribución altamente heterogénea que se desarrolla únicamente donde hay sustratos disponibles para la colonización. A su vez su distribución en el sustrato suele ser también heterogénea (Morin y Cattaneo 1992).

No obstante, el estudio del perifiton tiene la ventaja de representar los eventos que históricamente han ocurrido en el sitio estudiado por su característica de sésil y la consiguiente incapacidad de tomar distancia de la fuente contaminante (Stevenson et al. 1996)

El uso de sustratos artificiales o naturales para la evaluación del perifiton depende de los objetivos del trabajo y de las preguntas que se planteen. Los sustratos naturales ofrecen un mayor realismo que los artificiales ya que la comunidad mantiene la heterogeneidad propia del lugar, y presenta la variabilidad poblacional y ambiental natural. Los sustratos artificiales permiten una evaluación de la calidad del agua a una escala de tiempo más amplia que la ofrecida por el sustrato natural. Los sustratos artificiales se utilizan para biomonitoreo ya que la superficie disponible para la colonización por los microorganismos no cambia a lo largo del estudio como sucede cuando el sustrato natural es una hidrófita. En ese aspecto, el sustrato artificial constituye una ventaja para el biomonitoreo respecto al sustrato natural (Gómez et al. 2003). 


\section{OBJETIVOS GENERALES y PARTICULARES. HIPOTESIS}

En la llanura pampeana hay numerosos arroyos y ríos que están sufriendo fuerte deterioro físico y químico por el efecto de la contaminación (Feijoó et al. 1999, Gómez y Licursi 2001, O’Farrell et al. 2002, Rodrigues Capítulo et al. 2010). Sin embargo se posee escasa información de los efectos reales que tienen estos impactos sobre la biota así como de la capacidad de reacción de las comunidades (Bauer 2009, Cortelezzi 2010, Licursi 2005, Loez y Topalián 1999; Sierra y Gómez 2007, 2010; Sierra 2009).

Las actividades agropecuarias generan diversos tipos de contaminantes cuyo impacto es de difícil evaluación debido a que constituyen una fuente de contaminación difusa, es decir, que ingresa por varios sitios al cuerpo de agua. Este tipo de contaminación puede afectar a las características de los suelos y de las aguas subterráneas y superficiales a la vez que compromete a la biodiversidad presente en los ecosistemas terrestres y acuáticos (Meybeck y Helmer 1989).

En la contaminación difusa los contaminantes suelen llegar a los cuerpos de agua como un complejo conformado por materia orgánica, nutrientes y biocidas en los que se hace difícil distinguir el efecto particular de cada uno, a la vez que separarlos de la acción de factores biológicos como la herbivoría o físicos como la velocidad del agua (Novotny 2003).

Tanto los aportes por contaminación difusa a los cuerpos de agua como las modificaciones en la zona ribereña han sido escasamente registrados en nuestro país. Sin embargo, estos procesos son importantes: en Europa se conoce que las zonas de ribera se han reducido en un $70 \%$ debido a la ganadería (Wiley et al. 1990) y en Estados Unidos se calcula que el $80 \%$ del suelo erosionado en áreas rurales se debe a cultivos mientras que la agricultura es responsable del $46 \%$ de los sedimentos, $47 \%$ del fósforo total y 52 \% del nitrógeno total descargado a los cuerpos de agua (Allan 1995).

\section{Hipótesis y Predicciones}

De acuerdo con estos antecedentes, podemos esperar que se incremente el perifiton heterotrófico y la biomasa total en arroyos con predominio de actividades ganaderas; que haya predominio de perifiton autotrófico en zonas eminentemente agrícolas y que el crecimiento y la recuperación sean más lentos cuando se presentan 
sustancias tóxicas como metabolitos de biocidas. Si bien esta respuesta es la predicha por Steiman y Mc Intire (1990), posteriormente, Underwood y Paterson (1993) hallan que los valores de clorofila de una comunidad bentónica, se recuperan luego de la aplicación de un biocida y exceden el valor de los controles. Atribuyen este resultado a la recuperación más lenta por parte de los invertebrados. Posteriormente, Gustavson et al. (2003) destacan la relación entre el efecto de sustancias tóxicas utilizadas en sistemas agropecuarios sobre el perifiton y el tiempo de exposición al tóxico. Estos autores también aseveran que el efecto más directo de los herbicidas es la exclusión e inhibición de especies sensibles promoviendo cambios tanto en la disponibilidad como calidad de alimentos para pastoreadores que afectarían a toda la red trófica.

Por ello nuestra Hipótesis general fue que la contaminación difusa provoca cambios en la estructura y/o funcionamiento de las comunidades perifíticas de arroyos aledaños a las explotaciones agrícolas y ganaderas. En particular, la hipótesis sobre la que se trabajó fue que los cambios producidos por estas actividades agropecuarias repercutirán en las características estructurales y/o funcionales de la comunidad perifítica de acuerdo con la intensidad y tipo de contaminación difusa producida. Se propone que la contaminación difusa afectará primariamente a los parámetros funcionales y sólo cuando su intensidad sea mayor a los parámetros estructurales de la comunidad.

Para responder a la demanda urgente de gestión y control de los recursos acuáticos, necesitamos modelos de gran alcance que puedan predecir la respuesta de las comunidades acuáticas a los cambios ambientales (Cattaneo et al. 1993, Danilov y Ekelund 2000). Aunque no nos resultaba posible predecir cuáles serían los cambios más esperados en las distintas situaciones pretendimos mediante la realización de este estudio, analizar las distintas respuestas posibles y a partir de ello tener mayor capacidad predictiva.

\section{Los objetivos generales de la tesis fueron:}

* Evaluar las modificaciones producidas por la contaminación difusa en el perifiton, considerando tanto parámetros estructurales como funcionales. 
* Elaborar un esquema general predictivo en base a las respuestas posibles de la comunidad perifítica desarrollada en arroyos pampeanos en respuesta a la ganadería o la agricultura.

Los objetivos particulares consistieron en indagar si existen respuestas diferenciales al utilizar distintos parámetros estructurales o funcionales del perifiton cuando:

a. Es afectado por distintos tipos de contaminantes provenientes de las actividades agrícolas y ganaderas, cómo nutrientes, materia orgánica y biocidas.

b. Hay una marcada interacción entre estos contaminantes y un factor fisicoquímico de importancia para estos sistemas (ácidos húmicos). 
Capítulo 2

Metodología 


\section{Ambiente - Área de estudio}

Este trabajo se realizó principalmente en las cabeceras de los arroyos que dan origen al río Reconquista. El área de estudio se describe siguiendo dos niveles de detalle: a) Caracterización de la cuenca del río Reconquista con énfasis en su cuenca superior; b) Descripción de los sitios de muestreo.

\section{Caracterización del Río Reconquista}

\section{Ubicación geográfica}

La cuenca del río Reconquista forma la parte de la Cuenca del Plata que se halla comprendida dentro de la Región Metropolitana de Buenos Aires. Abarca al menos parcialmente, 18 partidos: General Las Heras, General Rodríguez, General San Martín, Hurlingham, Ituzaingó, José C. Paz, Luján, Malvinas Argentinas, Marcos Paz, Merlo, Moreno, Morón, San Fernando, San Isidro, San Miguel, Tigre, Tres de Febrero y Vicente López (fig. 2.1). 


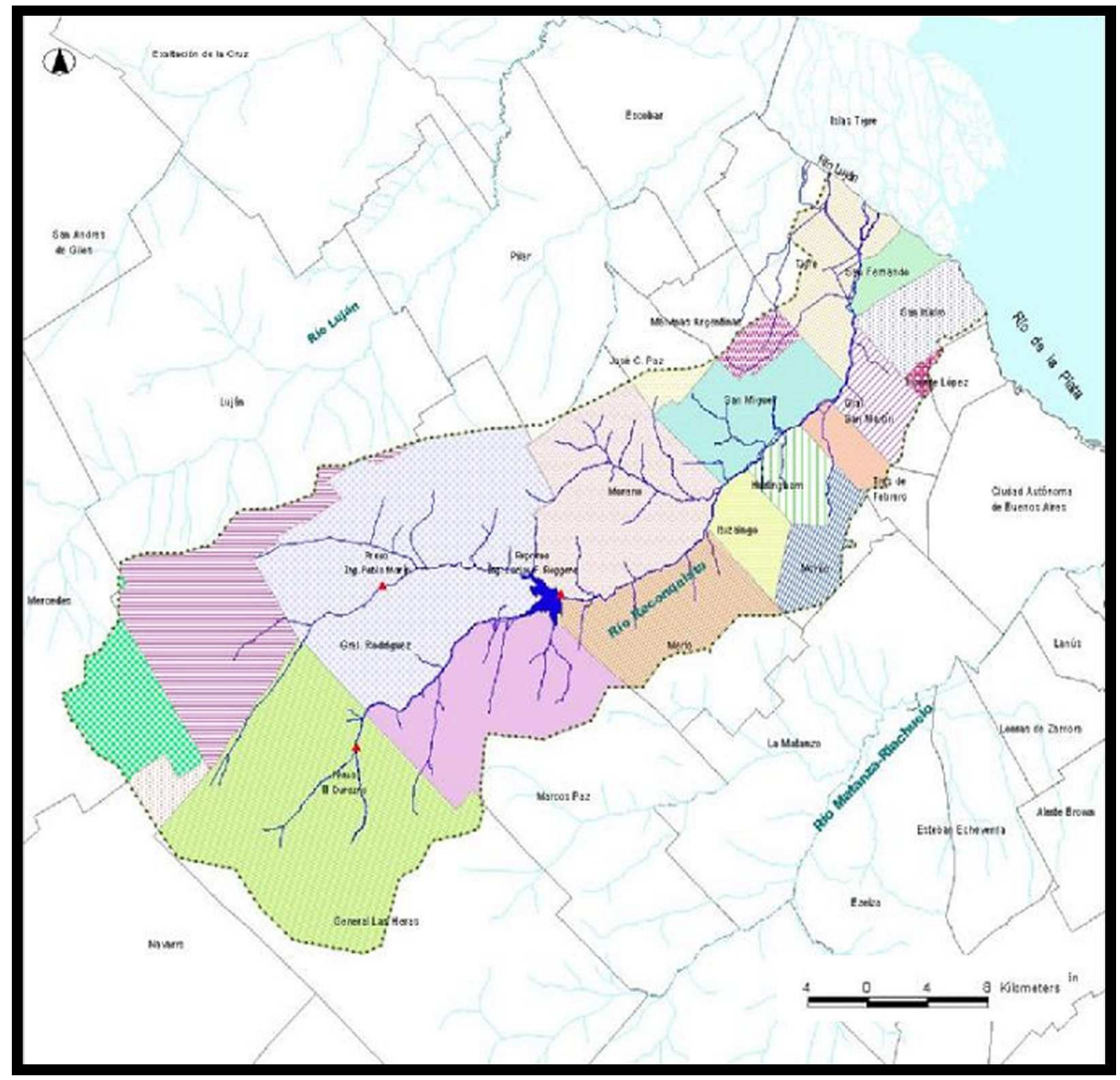

Figura 2.1. Mapa de la cuenca del Río Reconquista. Se marca en colores los partidos.

(Extraído de Sadañiowsky 2003)

\section{Geomorfología y edafología}

Toda la cuenca del río Reconquista se desarrolla sobre la "Pampa Ondulada", que es la subregión de la llanura pampeana comprendida entre las cuencas de los ríos Paraná y Salado. El relieve característico de la región es suavemente ondulado con la presencia de ríos, arroyos y cañadas que han sido excavados a partir del ascenso diferencial de los bloques de su basamento. Posteriormente la erosión y sedimentación de loess pampeano, determinaron la fisonomía típica del paisaje actual, la Planicie Loéssica (Sala y Auge 1970). 
En la cuenca se destacan dos geoformas: terraza intermedia y terraza baja. Solamente se encuentra terraza alta en dos zonas aisladas, una en la cuenca alta y la otra coincidente con los terrenos de Campo de Mayo (Lastra 2007). La pendiente media de la cuenca está comprendida en el rango entre 0 y $1 \%$.

La matriz física de la región es el resultado de complejos procesos morfogenéticos. La deposición fluvial y eólica de sedimentos loéssicos y las ingresiones marinas, generaron el relieve actual de la región, que es básicamente una llanura con suaves ondulaciones incluida en la unidad morfoestructural del Cratón del Río de La Plata (Pereyra 2002).

Lastra (2007) en base a estudios realizados previamente por otros autores describe los sedimentos de la región y menciona que pueden agruparse en dos grandes unidades: pampeanos y postpampeanos. El primero, más antiguo, fue conformado en un período de lluvias y está constituido predominantemente por limos loéssicos y corresponde a las zonas de recarga de los acuíferos; el segundo, de origen epipluvial, se caracteriza por depósitos de loess eólicos. Los sedimentos pampeanos de la cuenca comprenden las formaciones Ensenadense y Bonaerense. En el valle del río se han depositado los sedimentos post-pampeanos cuya base la constituye la Formación Luján. Estos sedimentos ocupan el fondo del cauce del río Reconquista en su tramo medio y superior y están constituidos por limos, a menudo arcillosos de colores verdes y grises con intercalaciones de limos pardos y amarillentos.

Como consecuencia de la acción abrasiva de las aguas marinas y las embalsadas en las cuencas interiores, se desarrolló una zona intermedia entre el borde del llano de los depósitos viejos pampeanos, no afectados por las aguas (Terraza Alta) y el de los depósitos nuevos pospampeanos (Terraza Baja). Esta zona intermedia se encuentra sobre las costas y sobre los bordes de los cursos actuales, constituyendo un escalón.

Los suelos originales de la región, desarrollados sobre el loess pampeano, tienen una textura limosa y una composición mineralógica rica en nutrientes. Son suelos con un horizonte superficial de color oscuro, formados bajo una vegetación herbácea de gramíneas, ricos en bases, con una buena estructura y elevada porosidad, lo que les da una consistencia blanda. Corresponden al orden taxonómico de los molisoles. 
En el sector superior de la cuenca los suelos varían dentro del paisaje, con predominio de molisoles en zonas drenadas y acuoles y acualfes (alfisoles) en sectores de régimen ácuico. En las subcuencas media e inferior existe un predominio de argiudoles y un sector importante de la cuenca media corresponde a suelos del gran grupo de los hapludoles. Los suelos adyacentes al cauce del río de la Reconquista y los principales tributarios de éste en la cuenca media, corresponden al gran grupo de los natracualfes (Basilico 2008). Esto significa que son suelos habitualmente inundables, con alto contenido de sodio y escasamente estructurados.

\section{Hidrología}

La cuenca del río Reconquista tiene una superficie de $1670 \mathrm{~km}^{2}$ y comprende unos 134 cursos de agua que recorren un total de $606 \mathrm{~km}$ de los que cerca de $55 \mathrm{~km}$ corresponden al cauce principal. El río Reconquista se origina con la confluencia de los arroyos La Choza y Durazno en el partido de General Rodríguez, sumándose aguas abajo el arroyo La Horqueta en la presa de embalse "Ingeniero C. Roggero", que constituye el límite de la cuenca superior. El río transcurre en dirección Suroeste a Noreste y desemboca en el río Luján, quien a su vez lo hace en el Río de la Plata. La presa "Ingeniero C. Roggero" fue construida entre los años 1967 y 1972, con el principal objetivo de regular el caudal de agua del río Reconquista durante las crecidas (Sadañiowsky 2003). La retención de las aguas se completa con dos presas de arcilla y tierra consolidada construidas sobre los arroyos La Choza y Durazno, de 75 y $55 \mathrm{hm}^{3}$ de capacidad de embalse, respectivamente (Lastra 2007).

El arroyo La Choza tiene una longitud aproximada de $30 \mathrm{~km}$ y drena un área de aproximadamente $440 \mathrm{~km}^{2}$, la que incluye la subcuenca de su principal afluente, el arroyo Arias. El arroyo Durazno, de una longitud de $32 \mathrm{~km}$, drena un área de $360 \mathrm{~km}^{2}$. El drenaje de los suelos varía de imperfecto, en gran parte de la subcuenca del Arroyo Durazno a moderado en parte de la superficie de la subcuenca Arias-La Choza.

La cota media de las divisorias en las nacientes resulta aproximadamente de 30 m.s.n.m. siendo la cota media del valle inferior aproximadamente de 3 m.s.n.m. 
(Sadañiowsky 2003). El cauce principal se vuelve algo sinuoso en el sector medio e inferior; su fondo es plano y el perfil longitudinal posee una baja inclinación. Su caudal medio es de $259.200 \mathrm{~m}^{3} /$ día (Lastra 2007).

El principal recurso hídrico subterráneo del área es el denominado Acuífero Puelche, el cual es explotado para consumo humano, para riego y para la industria (Lastra 2007). Desde el punto de vista hidráulico se comporta como un acuífero semiconfinado debido a la presencia de un limo arcilloso gris que conforma su techo (Ensenadense basal). Por encima del Puelche, existe una formación llamada genéricamente Epipuelche, constituida por el Acuífero Freático y el Acuífero Pampeano. Por debajo del Puelche, se encuentra el acuífero Hipopuelche, de mayor salinidad, conformado por el Acuífero Paraná.

\section{Clima}

La región se halla caracterizada por un clima templado húmedo, según la clasificación de Köppen. La temperatura media anual es de $17^{\circ} \mathrm{C}$, el mes más frío es julio, con una media de $11{ }^{\circ} \mathrm{C}$ y el más cálido es enero con $23{ }^{\circ} \mathrm{C}$ de media (Ereño 2002).

Las precipitaciones están distribuidas regularmente a lo largo del año. Las precipitaciones promedio son de $1.100 \mathrm{~mm}$ anuales, siendo el invierno la estación más seca y el verano la más húmeda. La frecuencia de tormentas es baja y tiene un marcado componente estacional con muy baja ocurrencia durante los meses de invierno. El drenaje, debido a las características morfológicas y geológicas, se ve dificultado cuando se exceden los promedios mensuales de lluvias o simplemente éstos se desplazan aún dentro de las estaciones, por lo que se pasa de épocas de inundaciones a épocas de sequia con suma facilidad y a veces con frecuencia (Fidalgo 1983).

La región se encuentra sujeta a la influencia de los vientos provenientes del anticiclón del Atlántico Sur. El viento dominante en la cuenca es del este-noreste. 


\section{Paisaje y Flora}

Cabrera (1978) describe el paisaje original de la región pampeana como una llanura en la que dominaban gramíneas de distinto porte con elementos aislados del espinal, principalmente en un cordón paralelo a la costa del Río de la Plata que se internaba, en ocasiones, varios kilómetros tierra adentro.

Debido a los usos de la tierra tradicionales de la región y a la presencia permanente del hombre en el lugar, el paisaje de la mayor parte de la cuenca ha sido drásticamente modificado. Faggi et al. (1999) describen la variación de la composición florística de las riberas del río Reconquista a lo largo del cauce principal. Sobre la base de la vegetación vascular de las riberas puede dividirse al río Reconquista en tres sectores: 1) ambientes rurales con flechillares de Stipa hyalina; 2) áreas suburbanas con comunidades ruderales de Sonchus oleraceus, Amaranthus quitensis y Urtica urens, con un cauce modificado por aterraplenado; y 3) ambientes suburbanos y urbanos con menor riqueza florística y mayor proporción de leñosas.

En la cuenca alta se pueden encontrar macrófitas como juncos (Schoenoplectus californicus), duraznillos (Solanum glaucophyllum), totoras (Thypha spp.), Eryngium spp., Althernanthera spp., Ludwigia peploides, Pistia stratiotes entre otras (Burgueño 2003).

\section{Fauna}

En el sector superior de la cuenca aún pueden encontrarse cerca de 190 especies de aves donde las lacustres más importantes son garza blanca (Ardea alba), garza bruja (Nycticorax nycticorax), la garcita (Butorides striata), pato maicero (Anas georgica) y Biguá (Phalacrocorax olivaceus), 26 especies de peces entre los que podemos mencionar a vieja del agua (por ej. Loricaria anus), dientudo (Cynopotamus kincaidi), varias especies de bagres, pejerrey lacustre (Basilichthys bonariensis), sábalo (Prochilodus platensis), chanchita (Gymnogeophagus australis), limpiavidrio (por ej. Otocinclus flexilis), limpiafondo (Corydoras spp. entre otros), mojarra (por ej. Astyanax fascitus), tararira (Hoplias malabaricus), anguila (Synbranchus marmoratus) y varias 
especies de madrecitas (Cnesterodon spp. entre otros). También 22 especies de mamíferos como por ejemplo cuis (Microcavia australis), coipo (Myocastor coypus), comadreja colorada (Lutreolina crassicaudata) y overa (Didelphis albiventris), hurón (Galictis cuja), zorrino (Conepatus chinga), ratas y lauchas, 13 especies de reptiles (tortugas de río y de laguna, lagartos verde y overo Tupinambis teguixin, lagartijas y culebras) y 8 especies de anfibios (ranas, sapos y ranitas de zarzal) (Burgueño 2003).

\section{Población}

Según datos preliminares del censo 2010, la cuenca contiene más de 4,6 millones de habitantes, aproximadamente el 12\% de la población del país (INDEC 2010).

La ocupación del territorio y los usos del suelo carecen de una planificación efectiva y se han desarrollado en forma espontánea o anárquica, desconociéndose las potencialidades y restricciones del territorio en los planos social y ecológico. La densidad de población de la cuenca superior presenta niveles bajos, de 0 a 3.700 $\mathrm{hab} / \mathrm{km}^{2}$ mientras que en la cuenca media e inferior la densidad aumenta llegando incluso a valores mayores a $7.000 \mathrm{hab} / \mathrm{km}^{2}$ (Lastra 2007).

\section{Calidad de las aguas superficiales}

El río Reconquista es el segundo río más contaminado de la Argentina (Salibian 2006). A lo largo de toda la cuenca el río recibe los aportes de distintas fuentes de contaminación principalmente de tipo doméstica e industrial. Sumados a la gestión deficiente o directamente inexistente de los residuos sólidos, estos factores generan un impacto negativo significativo. Este deterioro ambiental alcanza su máxima expresión en el sector inferior de la cuenca.

Diversos estudios (Arreghini et al. 2007, Lastra 2007, Mondino 2007) señalan a la cuenca superior como la que presenta los niveles de contaminación más bajos de toda la cuenca, situación relacionada probablemente con las prácticas predominantemente 
ganadera y agrícola y la baja densidad de población en dicha región. Sin embargo, estas prácticas ganaderas y agrícolas podrían constituir una fuente difusa de contaminantes, relacionada con la escorrentía superficial que arrastra sales y agroquímicos durante y posteriormente a precipitaciones hasta el cauce de los arroyos y el embalse Roggero. Algunos estudios sobre la subcuenca del A $A^{\circ}$ Durazno (Arreghini et al. 2005, 2007) proponen a esta zona como de referencia en cuanto a mejor calidad de agua de toda la cuenca debido al uso predominante del suelo (agricultura y ganadería), la baja densidad poblacional, los bajos niveles de nutrientes y elevados niveles de oxígeno disuelto en el agua y la escasa movilidad de los metales pesados presentes debido a las condiciones de $\mathrm{pH}$ y el tipo de sedimento, entre otros factores.

\section{Arroyo Las Flores}

En el capítulo 4 de este trabajo se seleccionó además un tramo sobre el arroyo Las Flores, tributario del río Luján por su margen norte, en la subcuenca media. El río Luján se desarrolla en la misma región que el río Reconquista por lo que sus características geomorfológicas, climáticas y de paisaje son similares (fig. 2.2).

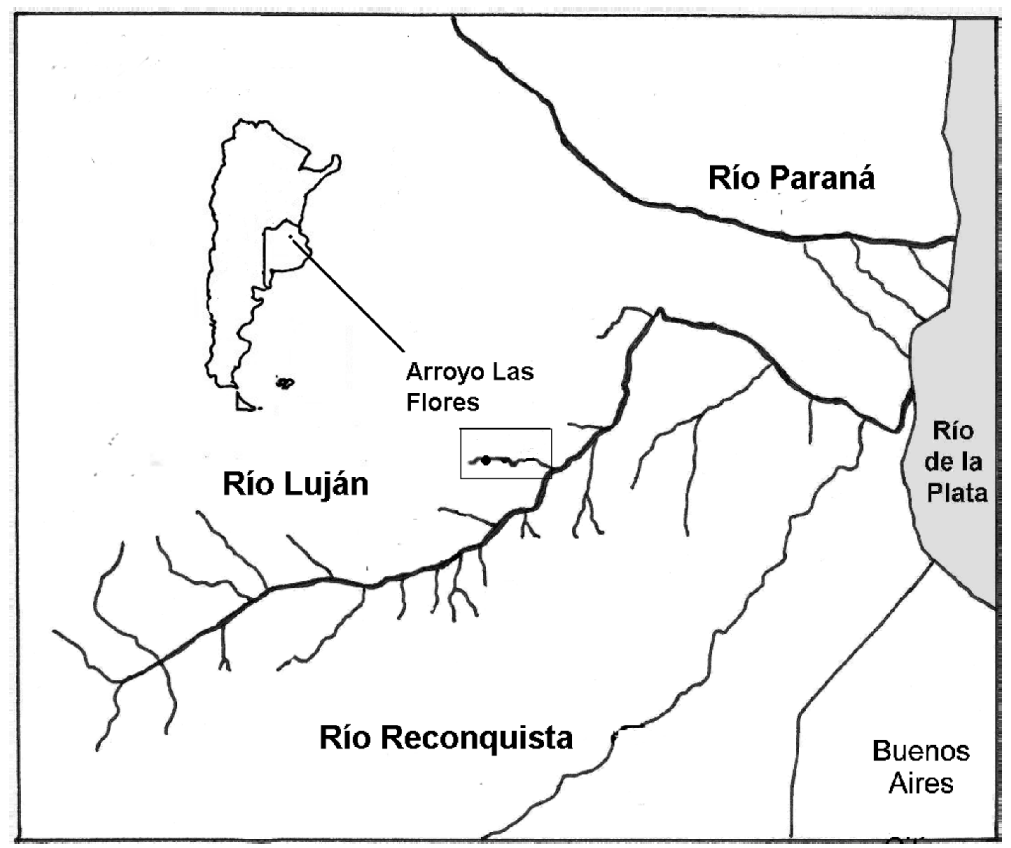

Figura 2.2. Esquema de la ubicación del arroyo Las Flores sobre el río Luján. También se observa el recorrido del río Reconquista 
El arroyo Las Flores se encuentra ubicado entre las localidades de Los Cardales $\left(34^{\circ} 29^{\prime} \mathrm{S}\right.$ y $\left.59^{\circ} 7^{\prime} \mathrm{O}\right)$ y Manzanares ( $34^{\circ} 28^{\prime} \mathrm{S}$ y $\left.58^{\circ} \mathrm{O}\right)$, aproximadamente a unos $20 \mathrm{~km}$ de la ciudad de Luján. Se inicia a partir del desagüe de un bañado. Su longitud total es de $12 \mathrm{~km}$. Su ancho varía entre 0,5 y $11 \mathrm{~m}$, y su profundidad entre 9 y $100 \mathrm{~cm}$ aproximadamente. El pH es menos alcalino y la conductividad es menor que en el promedio de los arroyos de la cuenca. En cambio, el material particulado en suspensión y la materia orgánica particulada son superiores al promedio. Es uno de los arroyos con más alto contenido natural de nutrientes (fósforo y nitrógeno) dentro de toda la cuenca (Feijoó et al. 1999). 


\section{Sitios de muestreo}

El estudio se llevó a cabo durante más de dos años en cinco arroyos pertenecientes a la cuenca superior del Río Reconquista: el arroyo La Choza y sus dos tributarios, los arroyos Arias y Nutrias, y en el arroyo Durazno junto a su tributario Durazno chico. Se seleccionaron un total de ocho tramos de $100 \mathrm{~m}$ de longitud sobre estos arroyos cuyos predios adyacentes tenían una superficie aproximada de 300 a 500 Ha. (fig. 2.1). Para esta selección se tuvo en cuenta su uso agropecuario predominante e intensidad del mismo. Esto se estableció mediante visitas con frecuencia mensual (para registrar posibles cambios entre estaciones del año), encuestas realizadas a los productores de cada predio, la existencia o no de alambrados, el ancho de la zona de ribera y la conservación de las márgenes (Tabla 2.1). Estos ocho sitios se muestrearon durante la primer etapa del trabajo de tesis (Cap. 3), luego se enfocó el estudio en cinco de estos sitios (La Choza II, La Choza III, Nutrias, Durazno I y Durazno II) para la etapa siguiente (Cap.4) y se agregó el arroyo Las Flores perteneciente a la cuenca del Río Luján. Finalmente, para el trabajo en arroyos artificiales (Cap. 5) se utilizó agua y perifiton del sitio La Choza III (fig. 2.3).

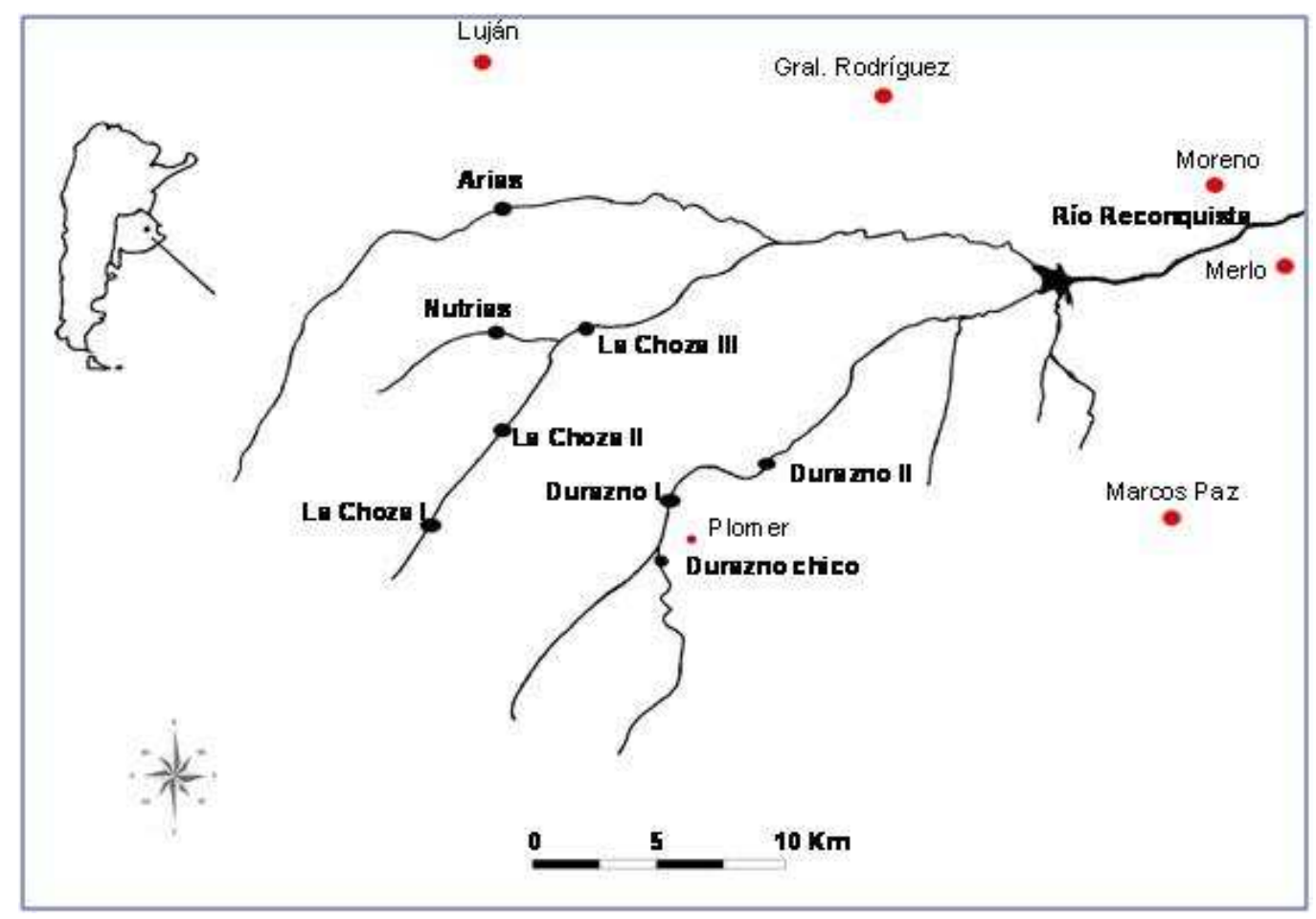

Figura 2.3. Esquema con la ubicación de los sitios de muestreo 


\section{Arroyo La Choza}

El arroyo La Choza es uno de los tres arroyos que al desembocar en la represa Roggero dan inicio al Río Reconquista. Tiene una longitud de $30 \mathrm{~km}$ y drena un área de aproximadamente $440 \mathrm{~km}^{2}$. El paisaje forma parte de una llanura aluvial plano-cóncava, y el suelo está formado por un complejo indiferenciado de suelos alcalinos, salinos e hidromórficos. Está sujeto a anegamientos e inundación, y se puede observar sodio a partir de los $50 \mathrm{~cm}$ de profundidad (Troitiño 2008). Sobre este arroyo se seleccionaron tres sitios (fig. 2.4):

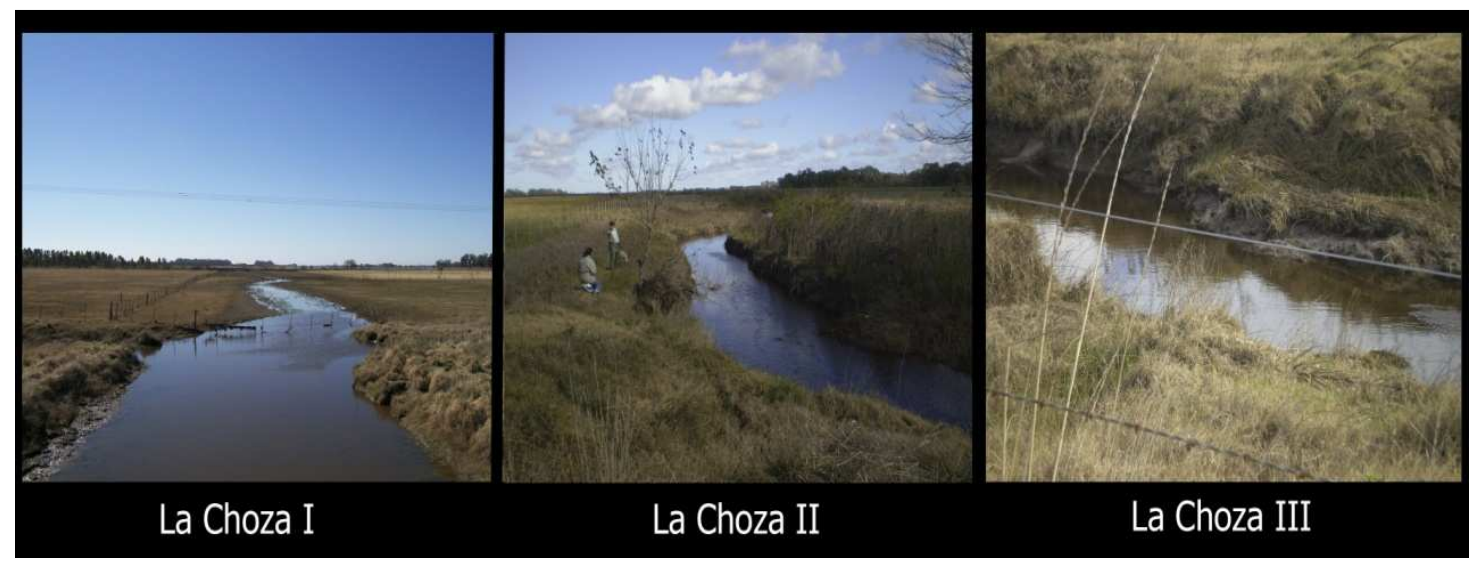

Figura. 2.4 Fotos de los tres sitios de muestreo sobre el arroyo La Choza

La Choza I (Ch I): Ubicado entre $34^{\circ} 46,586^{`} \mathrm{~S}, 5^{\circ}$ 08,506` O con una elevación de 36 m.s.n.m. Nacientes del arroyo, poca profundidad, llanura aluvial amplia. Uso ganadero extensivo $(80 \%)$ en pradera natural. Un alambrado transversal no permite el ingreso del ganado al tramo estudiado. Pequeño lote agrícola (20\%). Aguas arriba la actividad es similar.

La Choza II (Ch II): Se encuentra a 33 m.s.n.m. entre $34^{\circ} 44,451^{\prime}$ S, 59 06,489’0. Barrancas más evidentes. Uso agrícola-ganadero con muy escaso laboreo, márgenes conservadas con alambrado que impide el ingreso del ganado al arroyo. Se lo consideró en este trabajo como uso agrícola (50\%) de intensidad baja. Se destaca que esta zona se encuentra en transición ya que está siendo ocupada por emprendimientos urbanísticos que modificarán el estado de uso a futuro. 
La Choza III (Ch III): Con $31 \mathrm{~m}$ de elevación, se encuentra entre $34^{\circ} 42,182^{\prime} \mathrm{S}, 5^{\circ}$ 04,717`O. Este sitio de márgenes en barranca bien conservadas se encuentra cultivado con soja-trigo por siembra directa (100\%). La zona arable deja un ancho de franja de vegetación ribereña de más de $25 \mathrm{~m}$. La actividad entre los sitios La Choza II y La Choza III es ganadería y cultivos de uso familiar (muy baja intensidad).

\section{Tributarios del arroyo La Choza}

Ambos tributarios tienen uso ganadero (100\% pastoreo extensivo) sin exclusión de las márgenes, lo que ha degradado profundamente la geomorfología del cauce (fig 2.5).

Arias (Ar): Principal tributario del arroyo La Choza. El sitio seleccionado se ubica a 29 m.s.n.m. entre $34^{\circ} 38,932^{\prime} \mathrm{S}, 59^{\circ} 06,201^{\prime} \mathrm{O}$. Hay una amplia llanura aluvial sin barranca y sus márgenes están fuertemente pastoreadas y pisoteadas por lo que tiene un lecho inestable y poco profundo. La actividad aguas arriba es ganadería.

Nutrias (Nu): Ubicado entre $34^{\circ} 42,135^{\prime} \mathrm{S}, 59^{\circ} 06,602^{\prime} \mathrm{O}$ con una elevación de $34 \mathrm{~m}$. Al igual que el Arias se encuentra fuertemente pastoreado pero las márgenes en barranca sólo permiten el ingreso del ganado en las interrupciones de la misma. Aguas arriba, ganadería.

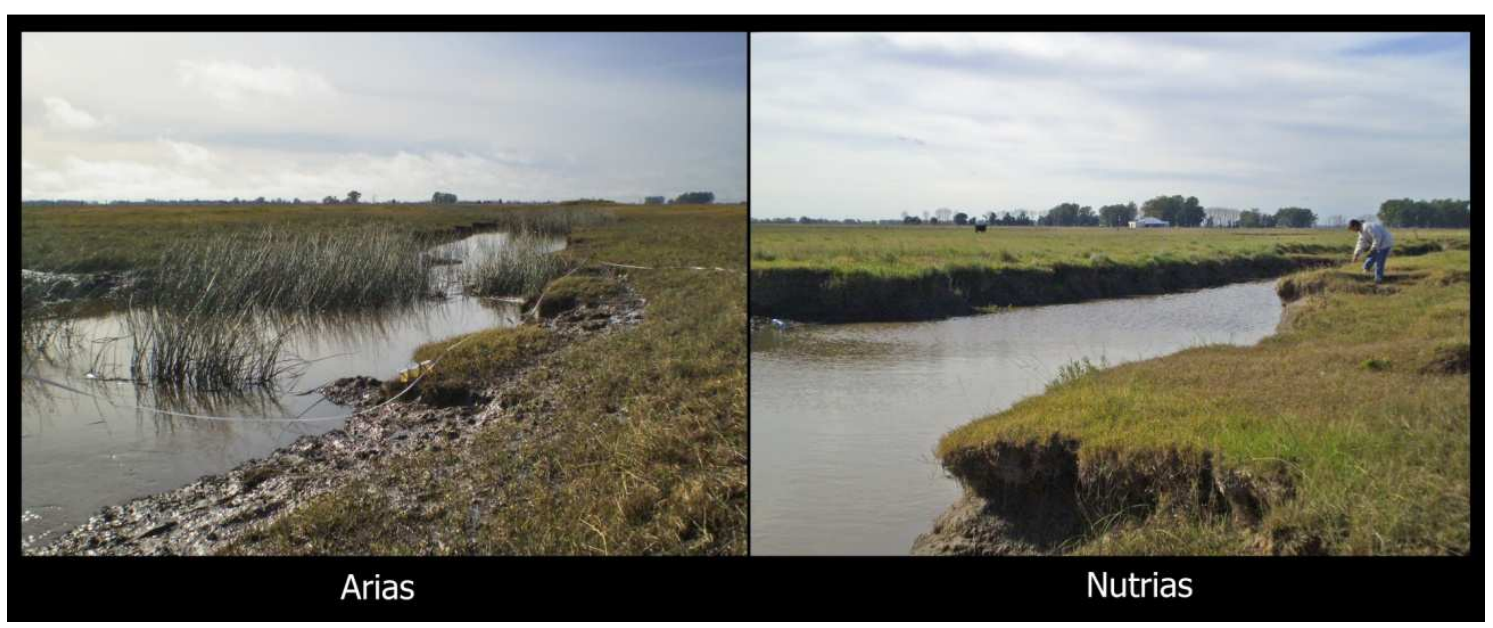

Figura 2.5 Fotos de los sitios de muestreo sobre los arroyos Arias y Nutrias 


\section{Arroyo Durazno}

El arroyo Durazno, de una longitud de $32 \mathrm{~km}$ drena un área de $360 \mathrm{~km}^{2}$ y es también uno de los arroyos que dan inicio al Río Reconquista. Al igual que en la microcuenca de La Choza los suelos son sódicos y poco estructurados, pobremente drenados y con baja permeabilidad (Troitiño 2008). Se seleccionaron 2 sitios para su estudio (fig. 2.6).

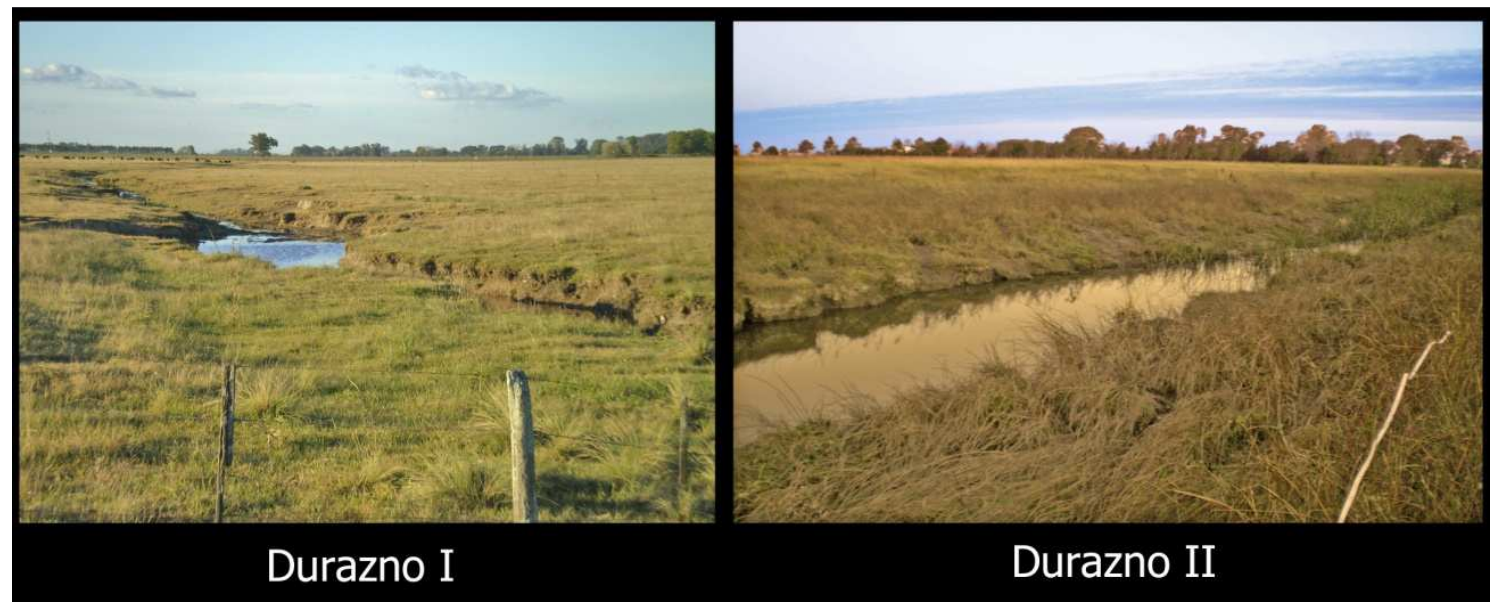

Figura 2.6 Fotos de los dos sitios de muestreo sobre el arroyo Durazno

Durazno I (D I): Se encuentra a 24 m.s.n.m. entre $34^{\circ} 48,385^{\prime} \mathrm{S}, 58^{\circ} 58,937^{\prime} \mathrm{O}$. Cauce encajonado con riberas pisoteadas. Uso ganadero extensivo $(100 \%)$ sobre pastura natural sin alambrado que limite el ingreso del ganado con el consecuente sobrepastoreo de las márgenes. Aguas arriba, ganadería

Durazno II (D II): Con una elevación de $22 \mathrm{~m}$, este sitio se ubica entre $34^{\circ} 46,562^{\prime} \mathrm{S}, 58^{\circ}$ $58,299^{\prime}$ O. Llanura aluvial amplia con uso agrícola en su margen derecha y pradera natural no pastoreada en la otra durante el primer año (50\%). Durante el 2008 se cultivó en ambas márgenes (100\%). Aguas arriba, ganadería. 


\section{Tributario del Arroyo Durazno}

Durazno chico (Dch): A 26 m.s.n.m., sus coordenadas son $34^{\circ} 47,476^{\prime} \mathrm{S}, 5^{\circ}$ 02,387’O. Este sitio tenía una fisonomía similar a los otros arroyos seleccionados y el tramo seleccionado estaba cerca de un frigorífico desactivado. Poco antes de comenzados los muestreos el arroyo fue canalizado por lo que sus márgenes tuvieron una pendiente de $45^{\circ}$ sin cobertura vegetal durante dichos muestreos. Además, meses después de comenzados los muestreos el frigorífico volvió a funcionar descargando su afluente aguas abajo del sitio de toma de muestras. El uso de los campos aledaños es ganadería $(100 \%)$ en baja intensidad (< 3 cabezas/Ha) sin ingreso de los vacunos al agua (fig. 2.7).

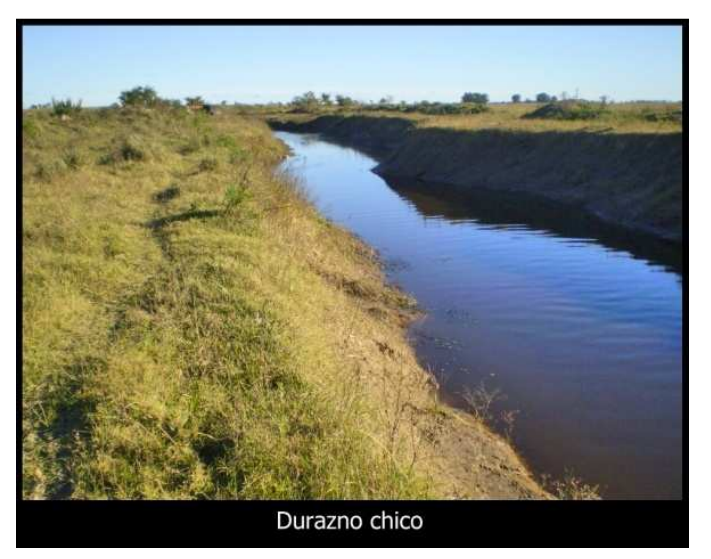

Figura 2.7 Foto del sitio de muestreo sobre el arroyo Durazno chico

Para la parte del estudio que se describe en el Capítulo 4 se seleccionó además un tramo en el arroyo Las Flores, tributario por su margen norte de la cuenca media del río Luján. Este arroyo posee un elevado estado de conservación de los lotes adyacentes y ausencia de ganado vacuno que ingrese a las márgenes. En la zona se realiza cría de caballos de polo (no más de un animal por hectárea) por lo que se consideró a este sitio como ganadero de baja intensidad (Fig. 2.8). Se eligió este sitio perteneciente a la cuenca del río Luján porque no se contaba con otro sitio en situación de baja intensidad agrícola o ganadera en la cuenca superior del río Reconquista. 


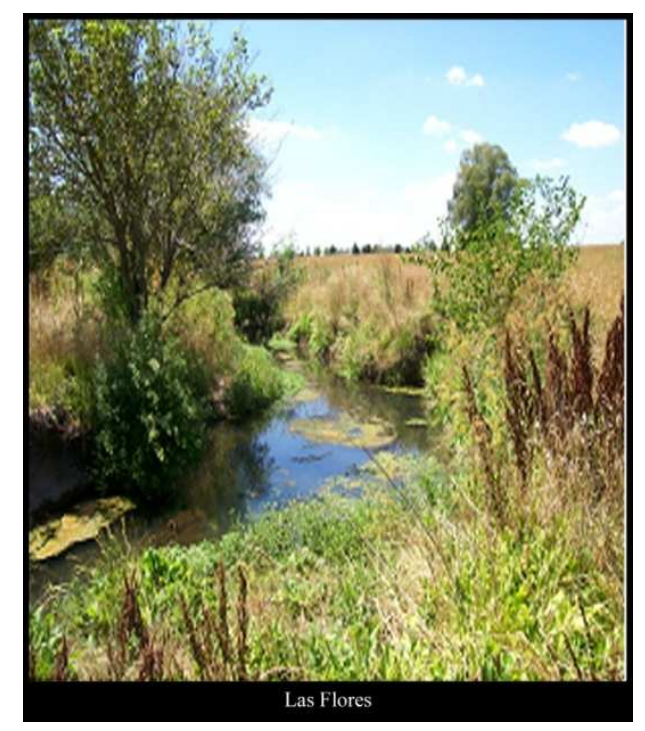

Figura 2.8 Foto del sitio de muestreo sobre el arroyo Las Flores

A modo de síntesis, en la tabla 2.1 se detallan los usos e intensidades considerados en este trabajo de tesis para cada uno de los sitios de muestreo. En la misma tabla se encuentran las características principales de la actividad en cada sitio resultado de la observación directa (uso y conservación de las márgenes) y respuestas de los productores del lugar. Para discriminar entre baja y alta intensidad se consideró: en los predios agrícolas, el tipo y la frecuencia de cultivo (trigo-soja, todo el año; forrajes, en temporadas), la presencia de un área de ribera sin cultivar, se apuntó el uso de fertilizantes y glifosato; en los predios ganaderos, la densidad de ganado, la rotación, la presencia de alambrado y la conservación de las márgenes. 
Tabla 2.1. Uso e intensidad de cada sitio de muestreo junto a las características utilizadas para definirlos.

$\begin{array}{lllll}\text { Sitios Uso Intensidad } & \text { Características } & \text { Márgenes Zona de ribera }\end{array}$

\begin{tabular}{|c|c|c|c|c|c|c|}
\hline La Choza I & Ganadero & Baja & Sin rotación. < 1 cabeza/Ha & $\begin{array}{l}\text { Llanura aluvial } \\
\text { amplia }\end{array}$ & Alambrado & Nacientes del arroyo. \\
\hline La Choza II & Agrícola & Baja & Forrajes. Urea y Glifosato & Barrancas & $10 \mathrm{~m}$ sin cultivar & \\
\hline La Choza III & Agrícola & Alta & $\begin{array}{l}\text { Trigo-soja. Superfosfato triple, } \\
\text { fosfatodiamonico, urea y glifosato }\end{array}$ & $\begin{array}{l}\text { Barrancas bien } \\
\text { conservadas }\end{array}$ & $25 \mathrm{~m}$ sin cultivar & \\
\hline Arias & Ganadero & Alta & Sin rotación. 5 cabezas/Ha & $\begin{array}{l}\text { Llanura aluvial } \\
\text { amplia }\end{array}$ & $\begin{array}{l}\text { Pastoreado y } \\
\text { pisoteado }\end{array}$ & $\begin{array}{l}\text { Lecho inestable y poco } \\
\text { profundo }\end{array}$ \\
\hline Nutrias & Ganadero & Alta & Sin rotación. 5 cabezas/Ha. & Barranacas & $\begin{array}{l}\text { Pastoreado y } \\
\text { pisoteado }\end{array}$ & $\begin{array}{c}\text { Las barrancas permiten el } \\
\text { acceso de ganado sólo en } \\
\text { algunos puntos }\end{array}$ \\
\hline Durazno I & Ganadero & Alta & Sin rotación. 7 cabezas/Ha & $\begin{array}{l}\text { Barrancas } \\
\text { degradadas }\end{array}$ & $\begin{array}{l}\text { Pastoreado y } \\
\text { pisoteado }\end{array}$ & \\
\hline Durazno II & Agrícola & Alta & $\begin{array}{l}\text { Soja. Superfosfato triple y } \\
\text { glifosato }\end{array}$ & $\begin{array}{l}\text { Llanura aluvial } \\
\text { amplia }\end{array}$ & $10 \mathrm{~m}$ sin cultivar & \\
\hline $\begin{array}{l}\text { Durazno } \\
\text { chico }\end{array}$ & Ganadero & Baja & Con rotación. $<1$ cabeza/Ha & $45^{\circ}$ de pendiente & $\begin{array}{l}\text { Modificada por } \\
\text { canalización }\end{array}$ & Canalizado \\
\hline Las Flores & Ganadero & Baja & Con rotación. $\ll<1$ cabeza/Ha. & $\begin{array}{l}\text { Barrancas } \\
\text { conservadas }\end{array}$ & Alambrado & \\
\hline
\end{tabular}


De modo que en el primer año de trabajo se desarrolló el estudio en dos sitios ganaderos de baja intensidad (Choza I, no canalizado, y Durazno Chico, canalizado), tres sitios con uso ganadero de mayor intensidad (Arias, Nutrias y Durazno I) y tres sitios con uso agrícola (Choza II, Choza III y Durazno II).

Durante el segundo año se utilizó un sitio de baja intensidad ganadera (Las Flores) y otro con baja intensidad agrícola (La Choza II), dos sitios con alta intensidad de ganado (Nutrias y Durazno I) y dos con actividad agrícola intensiva (Durazno II y Choza III).

Finalmente en el tercer año se utilizó únicamente agua y perifiton del sitio agrícola La Choza III para desarrollar los distintos experimentos en laboratorio. 


\section{Materiales y Métodos}

En este capítulo se presentan las técnicas generales que se utilizaron en el estudio y en los siguientes capítulos se detallarán las utilizadas particularmente en cada uno de ellos además de la frecuencia de muestreo y tipo de sustrato. En el primer año (2006-2007) (Cap. 3) se caracterizaron los sitios hidrológicamente, se muestreó en los arroyos y se tomaron muestras de perifiton desarrollado sobre Ludwidgia sp. (sustrato natural). En el segundo año (2008-2009) (Cap. 4) se estudiaron características fisicoquímicas del agua de los sitios muestreados y en ellos se colocaron cuerdas de nylon como sustratos artificiales. En el tercer año se trabajó en arroyos artificiales (descriptos en el Capítulo 5) utilizando vidrios esmerilados como sustrato artificial.

El esquema siguiente (fig. 2.9) resume la extracción de muestras de los parámetros estimados. En cada sitio de muestreo (tramo de arroyo o arroyo artificial) se midió utilizando sondas el oxígeno disuelto (OD), $\mathrm{pH}$, conductividad y temperatura. Se tomaron tres réplicas de muestra de agua y tres réplicas de muestras de perifiton en su sustrato correspondiente por cada determinación a realizar y se trasladaron al laboratorio en oscuridad. En el laboratorio se estimó en cada réplica de agua cloruros, $\mathrm{DBO}_{5}$ y DQO. El resto de la muestra fue filtrada y se analizó fósforo reactivo soluble (PRS), amonio, nitrito, nitrato, alcalinidad y ácidos húmicos. El filtro utilizado se destinó a la estimación del material particulado en suspensión. El perifiton desarrollado en los sustratos se extrajo en forma diferente de acuerdo a la determinación. Se cepilló el sustrato en $300 \mathrm{ml}$ aproximadamente de agua corriente no clorada. En la resuspensión del perifiton así obtenida se estimó nitrógeno total, polisacáridos y riqueza específica. Parte del volumen de resupensión se filtró. Los filtros utilizados se destinaron a la estimación de clorofila $a$, feopigmentos y peso seco. Además, para la estimación de fósforo total y exoenzimas los sustratos fueron sonicados y no cepillados. Finalmente, para la estimación del metabolismo se utilizó el perifiton sobre su sustrato sin separarlo del mismo. Cada una de las técnicas aquí mencionadas se detallan a continuación y las especificaciones de acuerdo al sustrato, frecuencia de muestreo, etc. se explican en cada capítulo. 

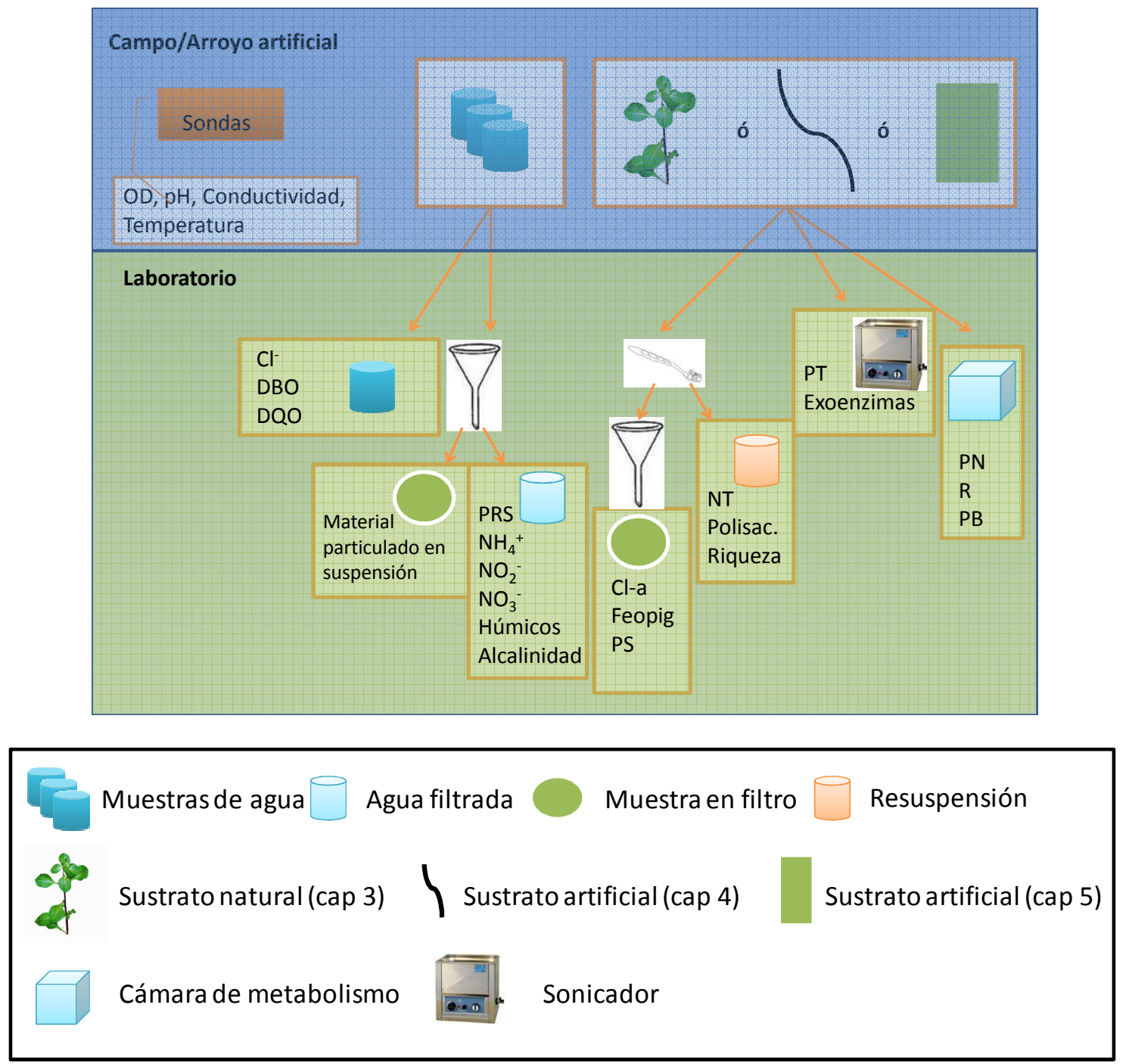

Figura 2.9 Esquema de la metodología empleada en este estudio. Fondo celeste, pasos realizados en los arroyos; fondo verde, pasos realizados en laboratorio.

\section{Parámetros físico-químicos}

Se midieron en los arroyos o en los arroyos artificiales sumergiendo los sensores en una zona central de los arroyos los siguientes parámetros del agua:

Temperatura: Se expresa en ${ }^{\circ} \mathrm{C}$. Se utilizó un termómetro digital incorporado al peachímetro Hanna HI 9023 con $0,1{ }^{\circ} \mathrm{C}$ de precisión.

Velocidad de corriente: se utilizó un velocímetro General Oceanics 2030R (General Oceanics, Miami, Florida, USA). Se expresa en m/seg.

pH: se midió con un peachímetro portátil Hanna HI 9023 con sensibilidad +/- 0,01 
Conductividad: se registró con conductímetro portátil Hanna HI 9033 con sensibilidad de $+/-0,1$. Se expresa en $\mu \mathrm{S} / \mathrm{cm}$

Oxígeno disuelto: con oxímetro portátil Hanna HI9142 (Hanna instruments, Woonsocket, Rhode Island, USA.) para las mediciones a campo. Sensibilidad +/- 0,1.

Se midieron en el laboratorio los siguientes parámetros del agua:

Se tomaron en el campo o en los arroyos artificiales tres réplicas de agua para los análisis fisicoquímicos. En el laboratorio se estimaron cloruros, demanda bioquímica de oxígeno $\left(\mathrm{DBO}_{5}\right)$ y demanda química de oxígeno (DQO). Por otro lado se filtraron las muestras con filtros de fibra de vidrio Munkell ${ }^{\circledR} \mathrm{MF} / \mathrm{C}$ (similares a Whatman $\left.{ }^{\circledR} \mathrm{GF} / \mathrm{C}\right)$ para las técnicas de obtención de valores de alcalinidad, fósforo reactivo soluble, amonio, nitrito, nitrato y ácidos húmicos, destinando los filtros utilizados a la estimación del material particulado en suspensión (fig. 2.9). En los casos de métodos colorimétricos (fosfatos, amonio, nitrito y nitratos) la absorbancia propia de la muestra se descontó en la expresión final de los resultados. Para las curvas de calibración y diluciones se utilizó agua miliQ. Se utilizaron tres réplicas en cada caso.

Fosfatos: se utilizó el método del ácido ascórbico (APHA 2005). Este método estima el Fósforo Reactivo Soluble (fosfatos más otras formas en las que se encuentra el fósforo de manera aprovechable para las algas) que a diferencia del Fósforo Total (que incluye el PRS) puede ser aprovechado en forma inmediata por las algas. Se expresa en mg P$\mathrm{PO}_{4}^{-3} / \mathrm{L}$

Amonio: se estimó por el método del indofenol (APHA 2005). Este compuesto coloreado se forma por la reacción, catalizada por una sal manganosa, de amonio con hipoclorito de sodio y fenol en medio alcalino. Se expresa en $\mu \mathrm{g} \mathrm{N}-\mathrm{NH}_{4}{ }^{+} / \mathrm{L}$

Nitritos: se realizó por el método de Shinn (APHA 2005) con sulfanilamida en medio ácido. Este reactivo forma con los nitritos del agua un compuesto complejo que se colorea al agregarle $\mathrm{N}\left(1-\right.$ naftil) etilendiamina. Se expresa en $\mathrm{mg} \mathrm{N}-\mathrm{NO}_{2}{ }^{-} / \mathrm{L}$

Nitratos: su estimación se realizó a través del método de la columna reductora (APHA 2005) que consiste en estimar inicialmente la cantidad de nitritos de una muestra según el método de Shinn, para luego reducir los nitratos presentes en la muestra haciéndola 
pasar a través de una columna con limaduras de cadmio recubiertas de cobre metálico. Se expresa en $\mathrm{mg} \mathrm{N}-\mathrm{NO}_{3}{ }^{-} / \mathrm{L}$

Alcalinidad: se determinó la reserva alcalina a la fenoftaleína y la reserva alcalina total según Golterman (APHA 2005). Este método evalúa el exceso de cationes sobre aniones fuertes, desplazando ácidos débiles $\left(\mathrm{HCO}_{3}^{-}, \mathrm{CO}_{3}^{-}, \mathrm{HO}^{-}\right)$con ácido sulfúrico $0,02 \mathrm{~N}$. Al añadir fenolftaleína como indicador, se produce un viraje de rosa a incoloro a $\mathrm{pH} 8,2$ que mide la alcalinidad producida por $\mathrm{OH}^{-}$y $\mathrm{CO}_{3}{ }^{-}$. Si se le agrega indicador mixto (rojo de metilo y verde de bromocresol), la solución toma un color azul. Al seguir valorando con ácido, la reacción se lleva a pH 5 donde vira nuevamente a rosado. Los $\mathrm{ml}$ de solución ácida consumida sirven para realizar el cálculo de la alcalinidad total (incluye $\mathrm{HCO}_{3}{ }^{-}$). Se expresa en $\mathrm{mg} \mathrm{CO} \mathrm{Ca}_{3} \mathrm{Ca} / \mathrm{L}$

Cloruros: consiste en valorar la muestra, a la que previamente se le agrega cromato de potasio, con nitrato de plata lo que produce un viraje a una coloración a rojo ladrillo (APHA 2005). El volumen de solución de nitrato de plata utilizado tiene relación directa con la cantidad de cloruros presentes. Se expresa en $\mathrm{mg} / \mathrm{L}$

Demanda Química de Oxígeno (DQO): se estimó por método fotométrico utilizando el kit SQ 118 Spectroquant ${ }^{\circledR}$ Merk

Demanda Biológica de Oxígeno $\left(\mathrm{DBO}_{5}\right)$ : se estimó por el método de dilución (APHA 2005) utilizando el método de Winkler con la modificación de azida sódica para las medidas de oxígeno.

Material particulado en suspensión: se determinó filtrando la muestra (volumen mínimo $200 \mathrm{ml}$ ) con filtros de fibra de vidrio Munkell® MF/C calcinados y prepesados. Luego el filtro se secó a $60^{\circ} \mathrm{C}$ hasta peso constante para obtener el peso seco. Posteriormente el filtro se calcinó a $480^{\circ} \mathrm{C}$ durante 4 horas y se estimó el peso seco inorgánico. El peso seco orgánico (peso seco libre de cenizas) se calculó por diferencia de los dos anteriores. Todas las pesadas fueron realizadas con una balanza analítica Mettler +/0,0001g. Los resultados se expresan en mg/L (Strickland y Parsons 1972).

Ácidos Húmicos: se estimaron por método espectrofotométrico (Absorbancia a $365 \mathrm{~nm}$ ) (Lavado et al. 1982). 


\section{Parámetros del Perifiton}

Las muestras de perifiton se obtuvieron a partir del raspado o sonicado (de acuerdo al protocolo de cada técnica) del sustrato natural (Hidrófita) durante la primera etapa del estudio (Cap. 3) o de sustratos artificiales como cuerdas de nylon en la etapa de campo (Cap. 4) y vidrios esmerilados en arroyos artificiales (Cap. 5). Los detalles sobre cada sustrato se presentan en los capítulos correspondientes. Las muestras de perifiton desarrollado en cada sustrato se trasladaron al laboratorio en oscuridad en recipientes herméticos con agua corriente no clorada. En el caso de los cálculos de metabolismo se colocó el sustrato artificial directamente en la cámara de metabolismo (fig. 2.9). Se utilizó agua miliQ como control cuando fue necesario para la técnica. Se utilizaron tres réplicas en cada caso.

\section{Parámetros estructurales:}

Clorofila a y feopigmentos: se utilizó el método de Lorenzen (Aminot 1983). Los sustratos naturales o artificiales se rasparon con un cepillo de cerda suave y se lavaron hasta obtener la resuspensión de muestra (Fig. 2.9). La filtración se realizó mediante un embudo Sartorius utilizando filtros de fibra de vidrio Munkell@ MF/F. Luego de filtrado, las muestras se conservaron en freezer a $-20^{\circ} \mathrm{C}$ durante un corto lapso (nunca superior a 15 días) hasta la realización de los análisis. Se realizó una extracción en frío sumergiendo los filtros con la muestra durante 20 horas en acetona $90 \%$. Posteriormente el material se machacó para completar la extracción, se centrifugó (20 min. a 700 revoluciones/min) y se leyó la absorbancia del sobrenadante en espectrofotómetro Hitachi UV-visible, en las longitudes de onda de $750 \mathrm{~nm}$ y $665 \mathrm{~nm}$, antes y después de acidificar con ácido clorhídrico 0,03M. El valor registrado a $665 \mathrm{~nm}$ es considerado como el pico de absorción de la clorofila $a$, mientras que la lectura a $750 \mathrm{~nm}$ permite descontar la turbidez a los valores registrados a $665 \mathrm{~nm}$. Se puede realizar el cálculo de la cantidad de clorofila $a$ presente en la muestra mediante la siguiente fórmula:

$$
\begin{aligned}
\operatorname{Biomasa}_{C l a}( & \left.m g C l a / m^{2}\right) \\
= & \frac{26,7 *\left(A b s_{665}-A b s_{750}-\left(A b s_{665 a c}-A b s_{750 a c}\right)\right) * v}{S * D} * \frac{V}{V_{2}}
\end{aligned}
$$

Donde: 
26,7: constante de proporcionalidad

$A b s_{665}:$ Absorbancia antes de acidificar

$A b s_{665 a c}$ : Absorbancia luego de acidificar

$v$ : Volumen del extracto de acetona (1)

$S$ : Superficie del sustrato $\left(\mathrm{m}^{2}\right)$ o Volumen de la muestra extraída.

$D$ : Longitud del trayecto óptico $(\mathrm{cm})$

$V$ : Volumen total o volumen de resuspensión

$V_{2}$ : Volumen de la muestra o volumen filtrado

Peso seco orgánico e inorgánico: se determinó filtrando la muestra (sustrato lavado en $300 \mathrm{ml}$ ) con filtros de fibra de vidrio Munkell® $\mathrm{MF} / \mathrm{C}$ calcinados y prepesados. Luego el filtro se secó a $60^{\circ} \mathrm{C}$ hasta peso constante para obtener el peso seco. Posteriormente el filtro se calcinó a $480^{\circ} \mathrm{C}$ durante 4 horas y se estimó el peso seco inorgánico. El peso seco orgánico (peso seco libre de cenizas) se calcula por diferencia de los dos anteriores (Aloi 1990). Todas las pesadas fueron realizadas con una balanza analítica Mettler +/$0,0001 \mathrm{~g}$. Los resultados se expresan en $\mathrm{mg} / \mathrm{m}^{2}$

Fósforo total: se estimó por el método de digestión con peroxidisulfato (APHA 2005) que consiste en digerir completamente el material en una solución oxidante y luego estimar fosfatos por el método del ácido ascórbico (descripto más arriba).

Nitrógeno Total: se determinó por el método de Kjeldahl (APHA 2005) que consiste en digerir completamente el material en una solución reductora para luego estimar el amonio resultante por el método descripto en parámetros fisicoquímicos del agua.

Polisacáridos Totales: se estimó por el método fenol/ácido sulfúrico (DuBois et al. 1956) que se basa en la capacidad reductora de los polisacáridos que al ser tratados con fenol y concentrados en ácido sulfúrico adquieren una coloración naranja-amarilla cuantificable espectrofotométricamente.

Riqueza específica: se observó únicamente la fracción autotrófica de las comunidades. Las muestras extraídas por cepillado (fig. 2.9) fueron fijadas con solución de formol al 1-2 \% y los organismos se identificaron a nivel genérico o específico, utilizando un microscopio Reichert con objetivo de inmersión a una magnificación de 1000X. Las determinaciones taxonómicas se hicieron de acuerdo con la bibliografía específica de 
cada grupo pero siguiendo básicamente los criterios de Cox (1996) y Patrick y Reimer (1966 y 1975) para la División Bacillariophyta, Komárek y Anagnostidis (1999, 2005) para las Cyanophyta, Van Den Hoek et al. (1995) y Graham y Wilcox 2000 para la División Chlorophyta y, Tell y Conforti (1986) para la División Euglenophyta. La determinación de Bacillariophyta requirió la limpieza previa de los frústulos según técnica de Patrick y Reimer (1966) y la fijación con resina de elevado índice de refracción (Hirax $®)$. Una vez identificadas las distintas especies de algas se contaron en microscopio Reichert con una magnificación de 40X. Se contó un número mínimo de 300 individuos (células, colonias o filamentos) en campos al azar y los resultados se expresaron como medidas de abundancia relativa.

Índices: Se aplicaron diversos índices que sintetizan la estructura y la composición de la comunidad. Ellos son:

- Índice autotrófico (IA) que evalúa la biomasa algal presente en la biomasa total perifítica. Se calcula como:

$$
I A=\frac{\text { Peso Seco libre de cenizas }}{\text { Clorofila } a}
$$

Valores mayores a 200 indican una comunidad heterotrófica (APHA 2005).

- Lakatos (1989) en referencia a su contenido de cenizas y concentración de clorofila $a$ siguiendo el esquema:

\begin{tabular}{|c|l|c|l|l|}
\hline TIPO & \multicolumn{1}{|c|}{ CENIZAS } & $\mathbf{\%}$ & \multicolumn{1}{|c|}{ CLOROFILA $\boldsymbol{~}$} & \multicolumn{1}{c|}{$\%$} \\
\hline I & Perifiton inorgánico & $>75$ & Perifiton autotrófico & $>0,6$ \\
\hline II & Perifiton inorgánico-orgánico & $>50-75$ & Perifiton auto-hetrotrófico & $>0,25-0,6$ \\
\hline III & Perifiton orgánico-inorgánico & $>25-50$ & Perifiton hetero-autotrófico & $>0,1-0,25$ \\
\hline IV & Perifiton orgánico & $<25$ & Perifiton heterotrófico & $<0,10$ \\
\hline
\end{tabular}

- Riqueza específica (S) se estimó como el total de especies presentes en cada sitio (Washington 1984). 
- Abundancia relativa de especies (pi) como (Washington 1984):

$$
p i=\frac{n i}{N}
$$

Donde: $\quad$ pi: abundancia relativa de la especie i

ni: número de individuos de la especie $\mathrm{i}$

$\mathrm{N}$ : número de todos los individuos de todas las especies

- Diversidad de Shannon (H') como (Washington 1984):

$$
H^{\prime}=-\sum_{i=1}^{S} p i \log _{2} p i
$$

- Equitatividad de Pielou (J') como (Magurran 1994):

$$
J^{\prime}=\frac{H^{\prime}}{\log S}
$$

\section{Parámetros funcionales:}

Estos parámetros se estimaron únicamente en sustratos artificiales. Se utilizaron también tres réplicas en cada caso.

Metabolismo (Producción y Respiración): se determinó por el método de cámaras claras y oscuras (Bott et al. 1985, Roberts et al. 2007) utilizando como cámara de metabolismo (unidad experimental) botellas de DBO o cajas plásticas herméticas de acuerdo con el sustrato utilizado. Las determinaciones se realizaron en una habitación cerrada con regulación de temperatura $\left(25^{\circ} \mathrm{C}\right.$ aprox.) donde se expuso a las cámaras de metabolismo durante una hora a luz artificial $\left(100 \mu \mathrm{mol} / \mathrm{seg} . \mathrm{m}^{2}\right)$ y se las mantuvo dos horas en oscuridad total. En cada cámara se colocó el sustrato artificial con la comunidad en estudio con agua corriente no clorada y se midió el oxígeno disuelto con un oxímetro HQ 40d (con sensibilidad de +/- 0,01) al inicio y al final de cada etapa lumínica. Como estimación de la producción y respiración se calculó la variación de oxígeno disuelto en cada cámara con relación a la superficie colonizada por el perifiton. Se expresa como g $\mathrm{O}_{2}$ (producidos o consumidos)/h. $\mathrm{m}^{2}$. La producción neta (PN) se estimó como la variación de oxígeno disuelto en las cámaras expuestas a la luz, mientras que la respiración (R) se estimó con las expuestas a la oscuridad. La producción bruta se calculó como la suma de PN y R en cada cámara. En los métodos de cada capítulo se detallarán estas metodologías ya que varían los sustratos y por lo tanto las 
características de la cámara de metabolismo utilizada y el cálculo de la superficie colonizada. Para estimar la radiación fotosintéticamente activa (PAR) se utilizó un sensor esférico quantum sumergible (sensor LI-193 instalado en LI-250 Quantum Meter, ambos LICOR Inc., Lincoln, NA, U.S.A) con sensibilidad $1 \mu \mathrm{mol} / \mathrm{seg} . \mathrm{m}^{2}$. Complementariamente, se registró la curva de variación diaria de oxígeno en algunos de los experimentos realizados en arroyos artificiales para evaluar los cambios metabólicos del perifiton. En el capítulo 5 se detalla la metodología utilizada.

Actividad de exoenzimas: se determinaron las actividades de Celobiohidrolasa (cataliza la ruptura de enlaces glucosídicos produciendo celobiosa), Fosfatasa alcalina (responsable de la desfosforilación) y $\beta$-glucosidasa (catalizala ruptura de enlaces glucosídicos produciendo glucosa) por la medición en espectrofluorómetro de un extracto de la comunidad perifítica. Cada sustrato artificial fue sonicado durante tres intervalos de un minuto para extraer el perifiton colonizado. A dos mililitros de cada muestra sonicada se le adicionó el sustrato fluorogénico (4-metilumbeliferona) específico para la enzima en estudio y se incubó en oscuridad a la temperatura que la muestra fue extraída en el arroyo muestreado. La reactivación de las enzimas extracelulares se detuvo con glicerina $1 \%$ y se midió en espectrofluorómetro Shimadzu RF-540. La actividad enzimática fue calculada como la máxima velocidad de hidrólisis desde la ecuación Lineweaver-Burk sobre la base de la ecuación de Michaelis-Menten (Romaní y Sabater 1999, Romaní 2001).

\section{Análisis estadísticos}

Para los análisis estadísticos se utilizaron: los paquetes informáticos Statistica $6.0{ }^{\circledR}$; PRIMER 5.2® y CANOCO 4.5® y para los gráficos los programas Microsoft Office Excel $2007 \circledR$ y Sigma Plot $11.0{ }^{\circledR}$.

En los casos en que se realizaron análisis paramétricos, la normalidad de las variables fue puesta a prueba usando el test de Kolmogorov-Smirnov. Las variables que no cumplieron con este supuesto fueron transformadas para lograr su normalidad. En cada capítulo se describirán detalladamente los análisis estadísticos realizados. 


\section{Capítulo 3}

Efectos de la contaminación difusa en arroyos sobre el perifiton en sustratos naturales 


\section{Introducción}

El estudio de las algas sobre sustratos naturales (plantas, rocas, sedimento) para la evaluación del efecto de la contaminación tiene mayor realismo ecológico que el proporcionado por sustratos artificiales porque mantiene la heterogeneidad propia del lugar (disponibilidad de luz, temperatura, contenido de nutrientes, pastoreo, nivel hidrométrico) y las relacionas alga-sustrato. En el ambiente natural, los diferentes niveles tróficos interaccionan para dar respuesta a los contaminantes. Por ello, el sustrato natural que se desarrolla en un ambiente natural está expuesto a otras variables que también se deben tener en cuenta, como son el herbivorismo y el tipo y grado de desarrollo de la planta. El resultado de la interacción planta-epifito dependerá de la estación del año, de la disponibilidad de nutrientes en la columna de agua, de las condiciones físicas y edad de la planta soporte, entre otros factores (Stevenson et al. 1996).

La interacción con el sustrato es más importante cuando la disponibilidad de nutrientes en el agua es menor (Eminson y Moss 1980), ya que algunos sustratos pueden proveer de nutrientes a las algas epífitas (Cattaneo y Kalff 1979). Asimismo la edad de la planta hospedadora condiciona su capacidad de liberar nutrientes (Stevenson et al. 1996). Algunos de ellos como amonio, fosfatos y azúcares simples son liberados por los tejidos vegetales durante su senescencia en las primeras etapas de descomposición (Wetzel 1981).

La presencia de epífitos puede tener efectos negativos en el crecimiento de la planta hospedadora, tales como reducción en la disponibilidad de la luz, interferir en la captación de nutrientes o causar el desprendimiento de las hojas de la planta debido a su peso (Vermaat 2005). Por otro lado, la presencia de epífitos podría tener también efectos positivos sobre las hidrófitas, como por ejemplo actuando de filtro y atenuando la radiación ultravioleta (Brandt y Koch 2003). Las plantas a su vez pueden liberar sustancias alelopáticas (alcaloides, fenoles, taninos) que inhiben el crecimiento algal del perifiton (Anthoni et al. 1980).

La agricultura se ha expandido en la región pampeana argentina en los últimos 50 años a expensas de los paisajes naturales y de las grandes extensiones de pasturas con escaso laboreo (Viglizzo et al. 2011). Estos autores destacan además el incremento en el uso de fertilizantes y pesticidas y la necesidad del estudio de su impacto. Más aún, 
las condiciones económicas globales conjuntamente con el reciente desarrollo tecnológico agroindustrial han promovido un notorio aumento de la superficie cultivada con soja en la Argentina. Dichas nuevas tecnologías agrarias aumentan la rentabilidad de los suelos (Lanson et al. 2009) con el consecuente desplazamiento del ganado vacuno hacia tierras cada vez menos productivas (ej. zona de ribera de los arroyos). Esto lleva a una intensificación en el uso de la tierra donde un gran número de animales convive en un área reducida, habitualmente cerca de los cuerpos de agua, o en pasturas implantadas con fertilizaciones periódicas (Hooda et al. 2000).

Cada vaca bebe 48 litros de agua al día por lo que se reducen los costos y el trabajo si el ganado tiene acceso a los cuerpos de agua (arroyos, lagunas) (Middleton 2010). Los vacunos son atraídos hacia esas áreas y pueden permanecer largo tiempo dentro o en los alrededores de los arroyos bebiendo y pastoreando. El pastoreo sin control por parte del ganado sobre áreas ribereñas puede ser causa de degradación en la calidad del agua, la morfología del canal, la hidrología, la estructura del suelo adyacente y la vegetación. Las causas de estos impactos negativos incluye ingreso de orina y fecas por escorrentia, el pisoteo, con incremento de bancos de erosión y reducción de la vegetación, destrucción de las márgenes y compactación del suelo (Trimble y Mendel 1995).

Nuestra principal área de estudio, la cuenca superior del río Reconquista, ha sido y es poco estudiada. Para tener una caracterización general y actualizada del área en este capítulo se presenta un estudio extensivo que se realizó abarcando toda la cuenca superior del Rio Reconquista. Este tipo de estudio permite una caracterización general del área, facilitando detectar distintas problemáticas ambientales a las que están sometidas las redes hídricas involucradas (Gómez et al. 2003).

La composición del agua está influenciada por las características de los ecosistemas terrestres y su grado de conservación. Margalef (1994) afirmó que la interacción entre las aguas continentales y los ecosistemas terrestres refleja el estado general de las cuencas, e hizo una analogía entre el drenaje del agua en los ríos y el sistema renal: el riñón recoge las sustancias tóxicas de la sangre, mientras que el río recibe los residuos de los alrededores. Por ello, en esos tramos se registraron las características hidrológicas y fisicoquímicas del agua así como también se describió las comunidades de hidrófitas que habita en ella y las algas epífitas desarrolladas sobre las 
hidrófitas considerando que la estructura de esta comunidad debía estar influenciada por la calidad del agua en cada sitio.

No se conocen estudios florísticos del perifiton en el área de este trabajo aunque se han estudiado el plancton y el bentos cerca de uno de los sitios de muestreo (Gómez et al. 2009). También hay estudios previos del fitoplancton del Río Reconquista (Loez 1995) donde se observó que disminuye la riqueza de especies en respuesta al estrés producto de la contaminación industrial (Loez y Topalián 1999).

Por ello, uno de los objetivos de esta etapa de la tesis fue relevar la ficoflora presente en el perifiton de los arroyos estudiados pertenecientes a la cuenca superior del río Reconquista. El otro objetivo consistió en evaluar el impacto de la contaminación difusa proveniente de actividades ganaderas y agrícolas sobre los parámetros estructurales del perifiton, principalmente los relacionados con la biomasa y la riqueza de especies.

\section{Materiales y métodos}

Se seleccionaron tres predios con actividad agrícola (La Choza II, La Choza III y Durazno II) y cinco con actividad ganadera (Arias, Nutrias, La Choza I, Durazno I y Durazno chico) ubicados cerca de arroyos de la cuenca superior del río Reconquista (Ver fig 2.2). Los arroyos La Choza y Durazno presentan tanto actividades ganaderas como agrícolas mientras que, en las cuencas del arroyo Arias y del arroyo Durazno Chico sólo se desarrolla ganadería. Este último presenta menor porcentaje de vegetación ribereña y márgenes con mayor pendiente.

En ellos se realizaron seis muestreos (diciembre 2006, febrero, mayo, agosto y noviembre 2007 y marzo 2008) donde se estudiaron características hidrológicas como profundidad (promedio de medidas tomadas con vara graduada cada $0,5 \mathrm{~m}$ ), ancho (considerando el ancho mojado medido con cinta métrica) velocidad del agua (Ver cap. 2), y caudal por el método de Velocidad/ Área (Gordon et al. 1994) representando cada una de las estaciones del año. Utilizando estos parámetros se estimó también la Rugosidad Relativa (RR) como:

$$
R R=\frac{\text { Profundidad máxima }}{\text { Profundidad media }}
$$


y la Forma del cauce como:

$$
\text { Forma }=\frac{\text { Ancho medio }}{\text { Profundidad media }}
$$

Se registraron las concentraciones de material particulado, conductividad y sales disueltas así como nutrientes (fósforo reactivo soluble, amonio, nitrito y nitrato), temperatura, $\mathrm{pH}$, cloruros, alcalinidad y se realizaron estimaciones de ácidos húmicos, oxígeno disuelto, DQO y $\mathrm{DBO}_{5}$ (Ver cap. 2).

A cada valor de Fósforo (PRS), Nitrógeno (Nitrito + Nitrato + Amonio), Material particulado en suspensión, Sales disueltas y Oxígeno Disuelto se lo multiplicó por el caudal estimado en cada sitio de muestreo para obtener el valor de las cargas transportadas y la proporción de nutrientes de cada arroyo aportada al total de la cuenca superior. Para esta estimación se consideró por separado el muestreo del mes de diciembre por ser el de mayor caudal. En el caso de la $\mathrm{DBO}_{5}$ se realizó el mismo cálculo. $\mathrm{La} \mathrm{DBO}_{5}$ multiplicada por el caudal informa acerca de cuanto oxígeno necesita esa masa de agua para degradar la materia orgánica que posee en suspensión o en solución. De ese modo, la carga del oxígeno disuelto es una medida del oxígeno transportado por el agua mientras que la carga de $\mathrm{DBO}_{5}$ es una medida del oxígeno consumido por el agua. La expresión de kg oxígeno/día transportado o consumido es una forma de expresión convencional, no está indicando el balance de oxígeno a lo largo del día sino una medida relativa a las concentraciones de $\mathrm{OD}$ y $\mathrm{DBO}_{5}$ estimadas puntualmente.

Se mapearon las hidrófitas mediante un muestreo areal sistemático a lo largo de un tramo total de $50 \mathrm{~m}$ con intervalos de cinco metros considerando las variaciones en el ancho total del arroyo. Para ello se tuvo en cuenta la presencia de las hidrófitas, su forma de vida (flotante, emergente, sumergida) y abundancia (\% de cobertura) de cada una de las especies presentes. Se realizaron correlaciones no paramétricas de Spearman entre las distintas variables hidráulicas y el uso de la tierra aledaña y el porcentaje de cobertura y la riqueza de especies de hidrófitas.

Se seleccionó Ludwidgia peploides (Hunth) Raven (fig 3.1) como sustrato natural para minimizar la influencia de la heterogeneidad derivada de los distintos tipos de planta sobre la comunidad perifítica, debido a que esta especie se encontró en todos 
los sitios y durante todo el año. Como unidad muestral se cortaron porciones de $10 \mathrm{~cm}$ de vástago de planta evitando los ápices jóvenes y las partes erectas situadas fuera del agua. Cada porción se colocó en un frasco con agua corriente no clorada. Se tomaron tres réplicas por sitio. En el laboratorio las plantas se limpiaron con un cepillo de cerdas finas en un lapso menor a ocho horas desde la extracción en el campo. Las muestras de perifiton así obtenidas se separaron en porciones correspondientes a cada tipo de determinación mediante la homogeneización y la separación en volúmenes conocidos. Además, la planta limpia se secó en estufa a $60^{\circ} \mathrm{C}$ hasta peso constante para obtener el peso seco de la planta y así estandarizar las estimaciones de perifiton a gramo (g) de peso seco de planta.

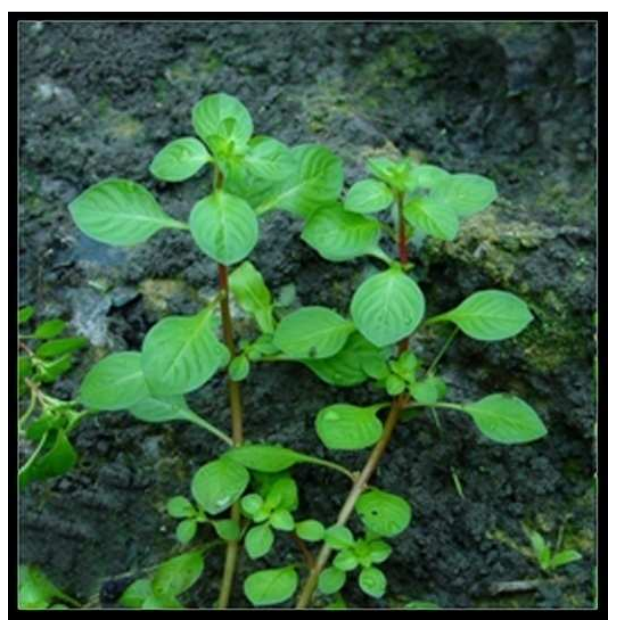

Figura 3.1. Ludwidgia peploides

Los parámetros estructurales que se utilizaron para evaluar la respuesta del perifiton fueron: Biomasa total, estimada como peso seco (orgánico e inorgánico) y concentración de Clorofila $a$ y Feopigmentos. Además, con estos parámetros se calcularon índices descriptores de la comunidad como el índice autotrófico y el índice de Lakatos (ver cap. 2). Luego del análisis florístico se estimó la abundancia relativa de cada División de las algas encontradas y se calculó riqueza de taxa algales (S), diversidad de Shannon $\left(\mathrm{H}^{\prime} \log\right.$ en base 2$)$ y equitatividad de Pielou ( $\left.\mathrm{J}^{\prime}\right)$ con el paquete DIVERSE del programa Primer 5 ®. Finalmente se estimó el Índice de Diatomeas Pampeanas (IDP) según Gómez y Licursi (2001).

Se realizó la toma de muestras durante más de un año en las distintas estaciones del año: primavera (19/12/06), verano (20/02/07), otoño $(22 / 5 / 07)$, invierno (06- 
07/8/07), primavera (06-07/11/07) y verano (11-12/03/08). El primer muestreo se llevó a cabo luego de una lluvia de $100 \mathrm{~mm}$. Los suelos de los campos en esa época ya estaban anegados por lluvias previas. Esta situación no volvió a repetirse en ningún otro muestreo (fig 3.2).

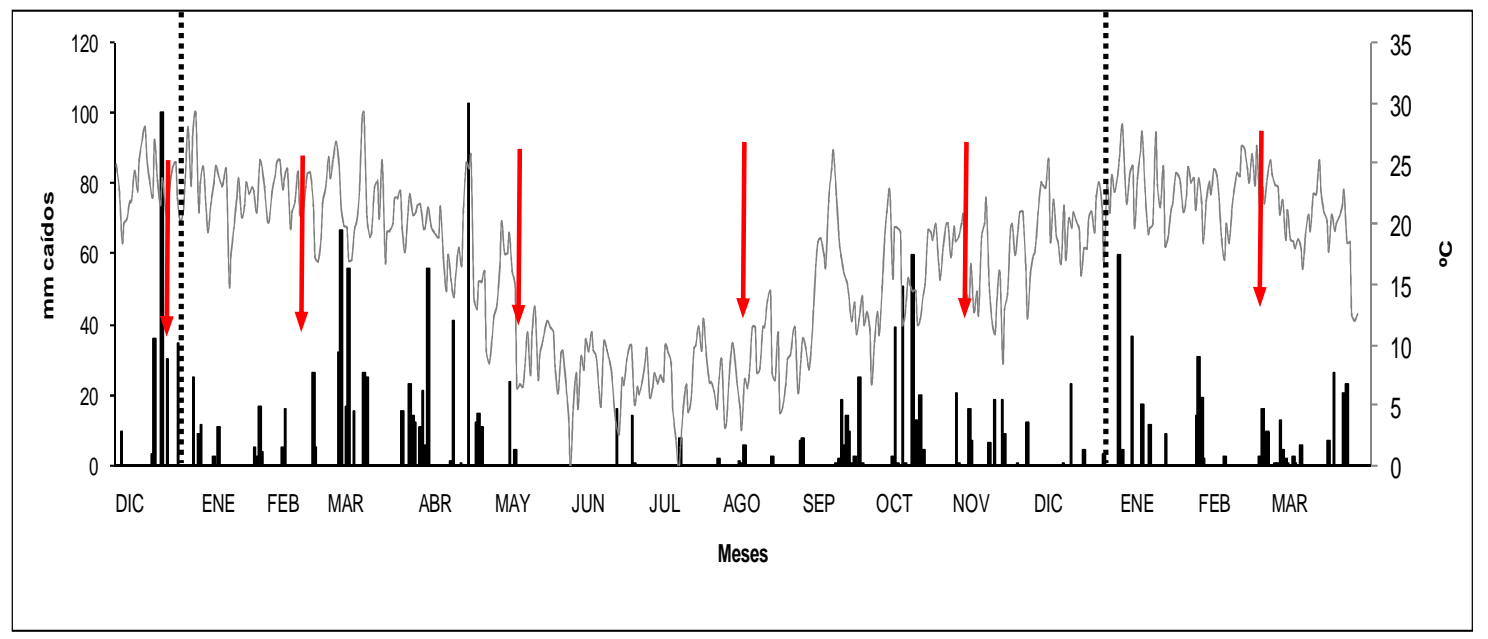

Figura 3.2. Precipitaciones (Eje primario) y temperatura media (Eje secundario) durante el período de muestreos. Las flechas rojas indican las fechas de cada muestreo y las líneas de puntos delimitan el año 2007

Se realizaron dos análisis multivariados de ordenamiento (análisis de componentes principales), uno con las variables fisicoquímicas (caudal, $\mathrm{DBO}_{5}, \mathrm{DQO}$, $\mathrm{pH}$, conductividad, peso seco total y orgánico, alcalinidad total y las concentraciones de cloruros, oxígeno disuelto, amonio, nitrito, nitrato, PRS y ácidos húmicos) y el segundo con las variables del perifiton (clorofila $a$, feopigmentos, peso seco total y orgánico, abundancias relativas de Bacillariophyta, Euglenophyta, Chlorophyta y Cyanophyta y los índices autotrófico, Lakatos clorofila, Lakatos cenizas, S, $\mathrm{H}^{\prime} \mathbf{y}^{\prime} \mathrm{J}^{\prime}$ ). Las diferencias observadas en cuanto a la composición taxonómica fueron evaluadas a través de análisis no paramétricos ANOSIM. Este análisis de similitud se basa en cálculos de permutaciones simples aplicados a una matriz de silmilitud que utiliza como índice al coeficiente de correlación por rangos de Spearman. 


\section{Resultados}

\section{Hidrófitas}

Durante el período analizado se halló un mínimo de 4 especies de hidrófitas (Arias) y un máximo de 10 especies (Durazno II). Las especies presentes pertenecían a distintos tipos biológicos: macrófitas emergentes que son las más abundantes y con mayor variedad: Scirpus sp, Typha sp, Sagitaria sp, Hidrochleis sp, Hidrocotyle ranunculoides, Senecio bonariensis, Narcissus junquilla, Solanum glaucophyllum, Cyperus sp, macrófitas sumergidas en forma total o parcial: Ludwidgia peploides, Miriophyllum sp, Ceratophyllum demersum, una macrófita flotante (Azolla sp) y clorofitas filamentosas. La cobertura máxima fue del $80 \%$ (fig. 3.3). Ludwidgia peploides fue muy abundante (40-80 \%) en algunos arroyos (La Choza, Nutrias) y en otros estuvo llegó a estar representada por el $5 \%$. Este organismo presenta dimorfismo foliar así como épocas del año con toda la planta sumergida y otras con parte de la planta emergiendo del agua. Si bien se encontraron variaciones estacionales de abundancias de hidrófitas, estas no fueron las mismas en todos los arroyos. La tabla 3.1 muestra las correlaciones no paramétricas de Spearman realizadas entre distintas variables hidráulicas y el uso de la tierra aledaña (agrícola o ganadero), el porcentaje de cobertura y la riqueza de especies de hidrófitas.

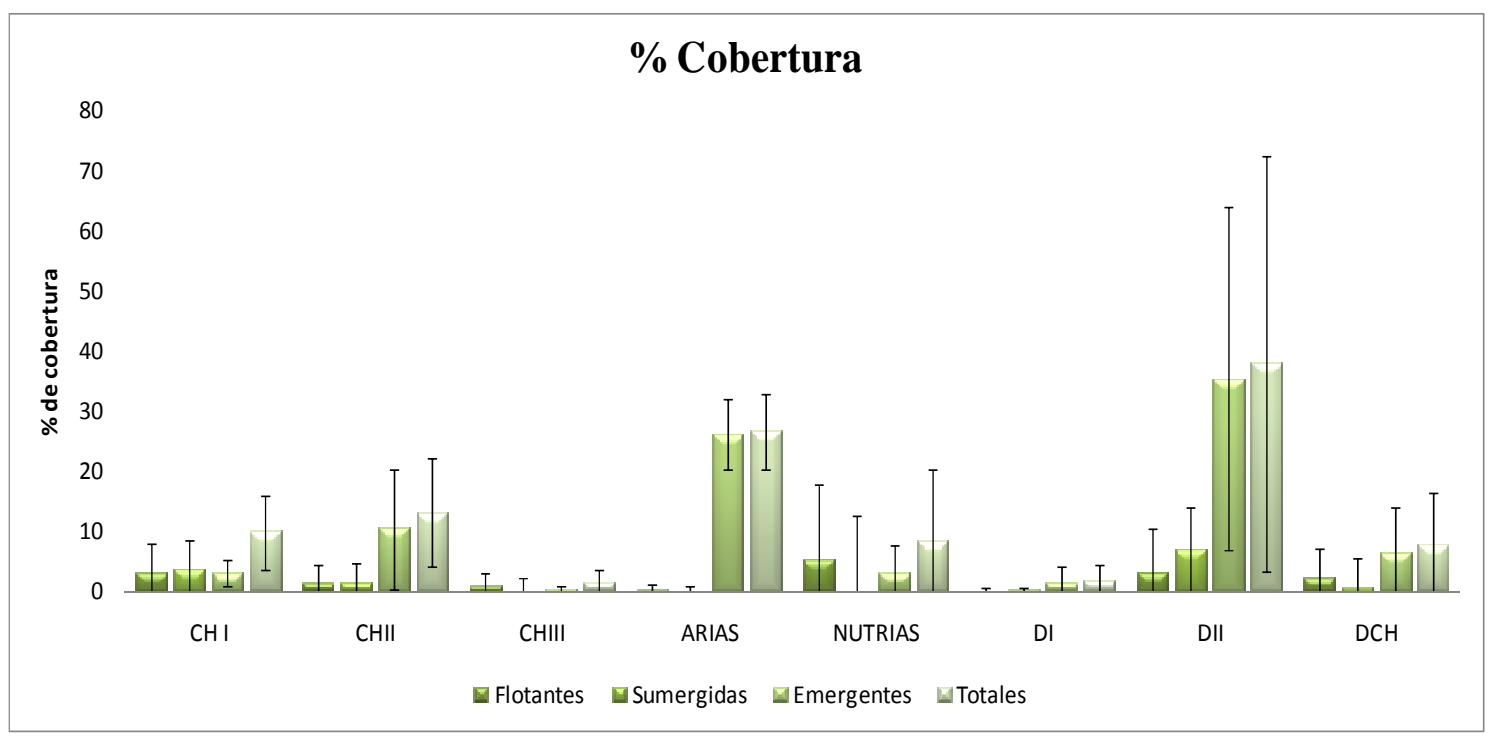

Figura 3.3. Porcentaje de cobertura de macrófitas para el período 2006-2008. CH I, La Choza I, CH II, La Choza II, CH III, La Choza III, D I, Durazno I, D II, Durazno II, DCH, Durazno chico 
Tabla 3.1 Correlaciones Spearman. En negrita se señala la correlación significativa $\mathrm{p}<0,01$

\begin{tabular}{l|cc|} 
& Cobertura de Hidrófitas\% & Riqueza Hidrófitas \\
\hline Velocidad & $-0,08$ & 0,08 \\
Profundidad & $-0,18$ & 0,09 \\
Ancho & 0,02 & $-0,13$ \\
Caudal & $-0,14$ & 0,07 \\
Forma & 0,23 & $-0,15$ \\
Rugosidad relativa & 0,11 & 0,06 \\
Uso & 0,00 & $\mathbf{0 , 6 3}$ \\
\hline
\end{tabular}

La única relación significativa fue entre el número de especies de hidrófitas y el uso de la tierra (tabla 3.1) donde la mayor riqueza se asocia a los tramos con uso agrícola.

\section{Parámetros fisicoquímicos:}

En la tabla 3.2 se muestran los valores medios junto a su rango de variación de los parámetros fisicoquímicos registrados durante todo el período de muestreo. El detalle de los valores medios y desvíos para cada fecha de muestreo se muestran en el anexo. El pH tuvo valores circumneutrales $(6,8-8,7)$ en todos los sitios y durante todo el período de muestreo. Cada sitio presentó una gran variación estacional asociada al régimen de lluvias tanto de la conductividad eléctrica (172 a $1753 \mu \mathrm{S} / \mathrm{cm}$ ) como del caudal $(0,07$ a 145 1/s) y de sus parámetros relacionados (profundidad, velocidad, ancho). La temperatura del agua varió entre 7 y $24{ }^{\circ} \mathrm{C}$ de acuerdo con la estación del año. El oxígeno disuelto presentó desde valores deficitarios $(0,8 \mathrm{mg} / \mathrm{l} ; 9,4 \%$ de saturación) hasta valores de sobresaturación (16,6 mg/l; $208 \%$ de saturación). Por otro lado, los valores máximos hallados para $\mathrm{DBO}_{5}$ y DQO fueron de $18 \mathrm{mg} / \mathrm{l}$ y $165 \mathrm{mg} / \mathrm{l}$ respectivamente. Los valores de $\mathrm{DBO}_{5}$ se encontraron siempre por encima de los niveles guía para la calidad del agua en función de cualquiera de los usos del recurso según la Secretaría de Recursos Naturales y Desarrollo Sustentable $(<3$ mg/l).

En los sólidos totales en suspensión también se observó una gran variación estacional (1,5 a $1.011 \mathrm{mg} / \mathrm{l})$. El fósforo reactivo disuelto alcanzó valores mayores en otoño y primavera $(0,47 \mathrm{mg} / \mathrm{l})$ asociado al régimen de lluvias mientras que los nitratos, nitritos y amonio presentaron promedios de 0,$9 ; 0,02$ y $0,024 \mathrm{mgN} / 1$ respectivamente y alcanzaron valores mayores en períodos de menores precipitaciones. 
Tabla 3.2. Valores medios y desvíos estándar $(n=18)$ de las variables estimadas en los distintos sitios de muestreo durante el período $2006-2008$. MPS, Material Particulado en Suspensión

\begin{tabular}{|c|c|c|c|c|c|c|c|c|}
\hline Sitio & La Choza I & La Choza II & $\begin{array}{c}\text { La Choza } \\
\text { III }\end{array}$ & Arias & Nutrias & Durazno I & Durazno II & $\begin{array}{c}\text { Durazno } \\
\text { chico }\end{array}$ \\
\hline $\mathrm{PRS} \mathrm{mgP}-\mathrm{PO}_{4}{ }^{-3} / 1$ & $0,17 \pm 0,11$ & $0,18 \pm 0,15$ & $0,14 \pm 0,11$ & $0,20 \pm 0,19$ & $0,18 \pm 0,17$ & $0,13 \pm 0,14$ & $0,12 \pm 0,12$ & $0,13 \pm 0,09$ \\
\hline Amonio $\mu \mathrm{gN}-\mathrm{NH}_{4}{ }^{+} / 1$ & $12,8 \pm 15,2$ & $17,8 \pm 26,5$ & $26,0 \pm 21,6$ & $33,8 \pm 35,9$ & $31,2 \pm 40,8$ & $22,0 \pm 24,6$ & $17,4 \pm 14,2$ & $9,01 \pm 11,2$ \\
\hline Nitrito $\mu \mathrm{gN}-\mathrm{NO}_{2}{ }^{-} / 1$ & $7 \pm 9$ & $36 \pm 44$ & $35 \pm 23$ & $16 \pm 17$ & $18 \pm 16$ & $11 \pm 17$ & $22 \pm 14$ & $18 \pm 11$ \\
\hline Nitrato $\mathrm{mgN}-\mathrm{NO}_{3}^{-} / \mathrm{l}$ & $0,23 \pm 0,33$ & $1,01 \pm 0,88$ & $1,65 \pm 1,01$ & $1,05 \pm 1,24$ & $0,85 \pm 0,93$ & $1,07 \pm 1,39$ & $1,50 \pm 0,95$ & $0,82 \pm 0,55$ \\
\hline Cloruro $\mathrm{mgCl}^{-} / 1$ & $31,7 \pm 28,2$ & $37,8 \pm 15,9$ & $77,0 \pm 35,3$ & $24,9 \pm 15,5$ & $19,9 \pm 13,1$ & $8,93 \pm 4,90$ & $29,0 \pm 18,0$ & $36,6 \pm 16,9$ \\
\hline Alc. Fen $\mathrm{mgCaCO}_{3} / 1$ & $3,10 \pm 3,43$ & $9,4 \pm 7,60$ & $8,60 \pm 4,01$ & $4,2 \pm 2,97$ & $7,3 \pm 7,00$ & $4,1 \pm 5,78$ & $3,43 \pm 2,29$ & $9,1 \pm 5,52$ \\
\hline Alcalinidad $\mathrm{mgCaCO}_{3} / 1$ & $43,2 \pm 16,0$ & $83,48 \pm 56,0$ & $79,4 \pm 51,8$ & $50,0 \pm 21,8$ & $50,4 \pm 25,2$ & $39,3 \pm 17,9$ & $54,2 \pm 22,4$ & $74,9 \pm 42,9$ \\
\hline DQO $\mathrm{mgO}_{2} / 1$ & $97,5 \pm 23,9$ & $47,17 \pm 28,9$ & $45,5 \pm 30,4$ & $90,8 \pm 47,4$ & $73,2 \pm 48,0$ & $89,0 \pm 43,6$ & $52,5 \pm 39,7$ & $53,5 \pm 38,7$ \\
\hline $\mathrm{DBO}_{5} \mathrm{mgO}_{2} / \mathrm{l}$ & $6,43 \pm 3,25$ & $5,23 \pm 6,3$ & $5,17 \pm 4,07$ & $8,00 \pm 4,67$ & $7,92 \pm 5,17$ & $6,35 \pm 5,78$ & $6,74 \pm 3,72$ & $7,05 \pm 5,41$ \\
\hline Ácidos Húmicos Abs & $0,34 \pm 0,12$ & $0,18 \pm 0,10$ & $0,12 \pm 0,12$ & $0,28 \pm 0,16$ & $0,19 \pm 0,13$ & $0,30 \pm 0,25$ & $0,18 \pm 0,15$ & $0,20 \pm 0,12$ \\
\hline $\mathrm{OD} \mathrm{mgO}_{2} / 1$ & $6,05 \pm 3,4$ & $6,63 \pm 3,07$ & $5,80 \pm 3,45$ & $5,35 \pm 2,40$ & $5,90 \pm 2,86$ & $9,40 \pm 4,04$ & $6,00 \pm 2,70$ & $8,42 \pm 4,5$ \\
\hline Temperatura ${ }^{\circ} \mathrm{C}$ & $20,8 \pm 8,5$ & $19,3 \pm 6,6$ & $19,2 \pm 6,6$ & $18,1 \pm 6,81$ & $19,0 \pm 6,9$ & $22,2 \pm 9,95$ & $19,21 \pm 7,1$ & $23,3 \pm 9,20$ \\
\hline $\mathrm{pH}$ & $7,74 \pm 0,7$ & $7,69 \pm 0,69$ & $7,80 \pm 0,52$ & $7,57 \pm 0,64$ & $7,73 \pm 0,72$ & $7,63 \pm 0,78$ & $7,74 \pm 0,69$ & $7,88 \pm 0,49$ \\
\hline Conductividad $\mu \mathrm{S} / \mathrm{cm}$ & $591 \pm 413$ & $1009 \pm 506$ & $894 \pm 583$ & $689 \pm 410$ & $641 \pm 368$ & $401 \pm 299$ & $759 \pm 386$ & $974 \pm 497$ \\
\hline Velocidad media $\mathrm{cm} / \mathrm{seg}$ & $0,2 \pm 0,1$ & $3,8 \pm 4,1$ & $3,3 \pm 2,7$ & $1,8 \pm 2,1$ & $0,2 \pm 0,2$ & $0,7 \pm 1,1$ & $0,2 \pm 0,1$ & $2,2 \pm 2,6$ \\
\hline Profundidad media m & $0,38 \pm 0,11$ & $0,17 \pm 0,12$ & $0,31 \pm 0,19$ & $0,19 \pm 0,18$ & $0,25 \pm 0,10$ & $0,34 \pm 0,09$ & $0,28 \pm 0,03$ & $0,28 \pm 0,06$ \\
\hline Ancho medio m & $11,34 \pm 1,2$ & $4,0 \pm 0,48$ & $4,57 \pm 0,41$ & $6,87 \pm 1,84$ & $6,42 \pm 0,63$ & $4,72 \pm 0,28$ & $4,15 \pm 0,71$ & $6,43 \pm 0,36$ \\
\hline Caudal 1/seg & $10,75 \pm 6,78$ & $49,3 \pm 73,9$ & $72,0 \pm 100$ & $62,60 \pm 119$ & $5,22 \pm 8,10$ & $16,6 \pm 30,0$ & $2,83 \pm 1,31$ & $50,95 \pm 64,2$ \\
\hline MPS g/l & $71,4 \pm 69,7$ & $35,9 \pm 42,1$ & $24,3 \pm 17,9$ & $304 \pm 289$ & $93,15 \pm 72,5$ & $67,7 \pm 51,88$ & $35,7 \pm 41,7$ & $76,8 \pm 57,3$ \\
\hline MPS orgánico g/l & $12,1 \pm 10,7$ & $4,90 \pm 6,70$ & $2,96 \pm 1,98$ & $38,6 \pm 35,7$ & $13,1 \pm 9,3$ & $9,07 \pm 5,88$ & $5,15 \pm 5,95$ & $8,27 \pm 6,551$ \\
\hline \% inorgánico & $78,7 \pm 18,0$ & $88,9 \pm 5,46$ & $84,9 \pm 9,08$ & $85,7 \pm 3,45$ & $84,38 \pm 3,85$ & $85,49 \pm 3,51$ & $86,26 \pm 3,1$ & $90,0 \pm 3,47$ \\
\hline \% orgánico & $21,3 \pm 18,0$ & $13,06 \pm 5,47$ & $15,0 \pm 9,08$ & $14,3 \pm 3,44$ & $15,6 \pm 3,86$ & $14,51 \pm 3,5$ & $13,7 \pm 3,1$ & $10,08 \pm 3,47$ \\
\hline
\end{tabular}


La proporción de caudal, fósforo, nitrógeno, material particulado en suspensión y oxígeno disuelto de cada arroyo aportada al total de la cuenca superior se esquematizan en la figura 3.4. La estimación se consideró por separado los valores base (verde) y los estimados para el mes de diciembre por ser el de mayor caudal (azul). Lo que se destaca en este análisis es que la importancia relativa de los arroyos no es la misma en épocas de caudal base que en épocas de alto caudal y por otro lado no todos los arroyos son igualmente importantes en el transporte de materiales incluidos aquellos contaminantes.

Los arroyos que aportan un mayor caudal en promedio son La Choza y Arias (alrededor de 70 1/s). La Choza transporta el mayor porcentaje de nitrógeno (38\%) y sales disueltas (46\%). El Arias, en cambio transporta el mayor porcentaje de fósforo (47\%). El material particulado en suspensión es transportado principalmente por el Durazno chico (52\%). Los arroyos Durazno chico y La Choza transportan una mayor carga de oxígeno disuelto (alrededor de $21 \mathrm{Kg} /$ día) que generalmente satisface la $\mathrm{DBO}_{5}$ del cuerpo de agua. Durante el momento de alto caudal estas importancias relativas en general no cambian, destacándose las disminuciones en Durazno chico y el aumento en el aporte relativo del arroyo Arias en todas las cargas transportadas. 


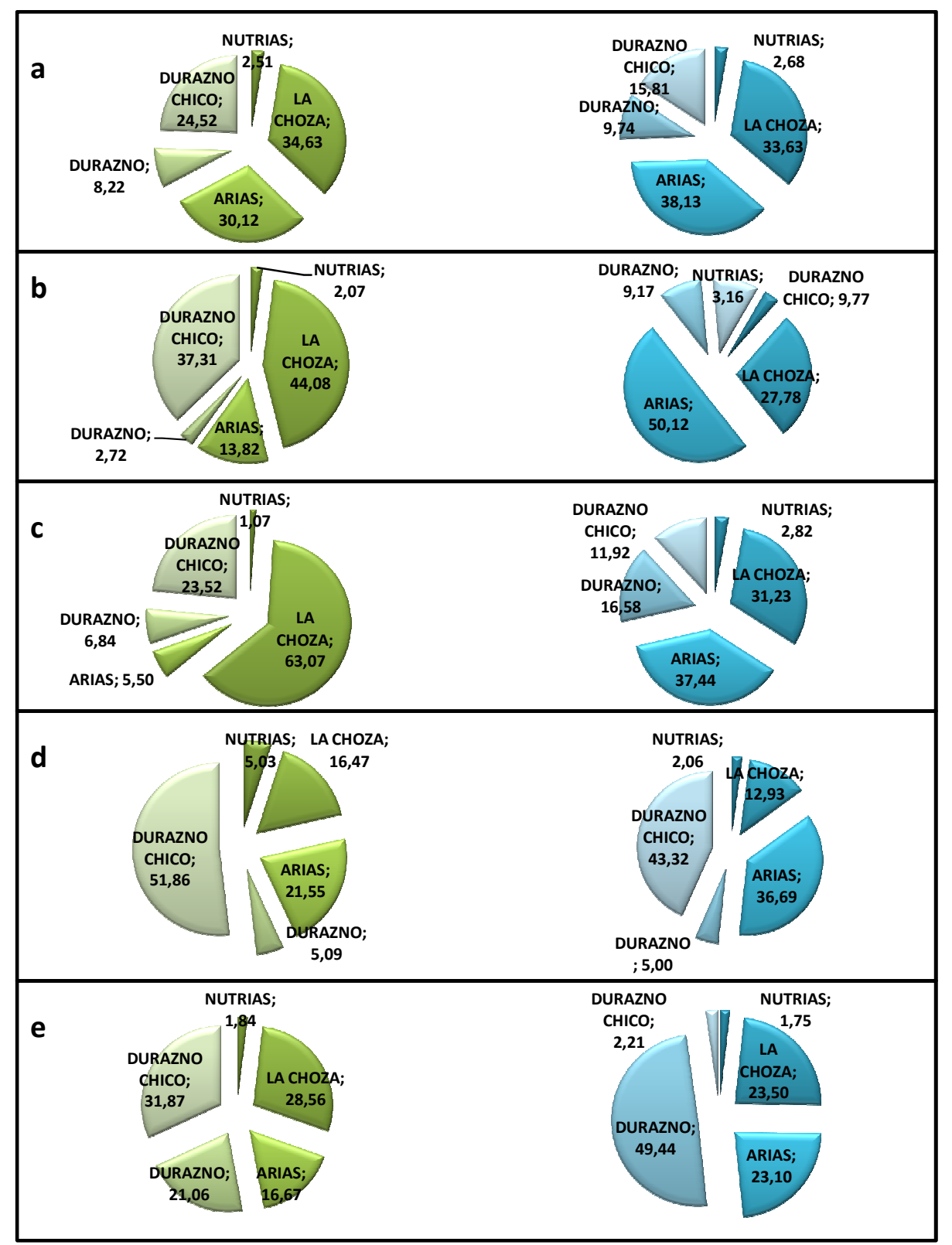

Figura 3.4 Aporte porcentual de las cargas de distintos materiales transportados en un año promedio (verde) y en una situación de alto caudal (azul). a- Caudal, b- Fósforo, c-

Nitrógeno, d- Material particulado en suspensión, e- Oxígeno disuelto

Aunque los usos del suelo son diferentes en cada tramo no se observaron diferencias significativas en las variables físico-químicas entre ellos (ANOVA). Sólo aquellos tramos adyacentes a campos con uso ganadero tendieron a presentar mayor cantidad de ácidos húmicos y sólidos en suspensión. Un análisis de las distintas variables consideradas se llevó a cabo mediante un análisis multivariado de ordenamiento (ACP). 
Los dos primeros componentes del Análisis de Componentes Principales (ACP) realizado con las variables físico-químicas del agua explican el 31,5\% y 19,19\% respectivamente del total de la varianza. El primer componente (autovalor: 4,72) se correlaciona positivamente con el contenido de ácidos húmicos (coeficiente: 0,83) y con la DQO $(0,80)$ y se correlaciona negativamente con la conductividad $(-0,82)$, la alcalinidad total $(-0,80)$, el pH $(-0,73)$ y la concentración de cloruros $(-0,72)$. El segundo componente (autovalor: 2,88) se correlaciona positivamente con el material particulado en suspensión estimado como peso seco $(0,93)$ y como peso seco orgánico $(0,9)$, y se correlaciona negativamente con el caudal $(-0,78)$ (fig. 3.5). Estos resultados indican que algunos de los sitios de muestreo se caracterizan por altos niveles de ácidos húmicos y DQO mientras que otros por altos niveles de sólidos disueltos. Los arroyos suelen transportar muchos sólidos en suspensión, incluso bajo condiciones de caudal normal.

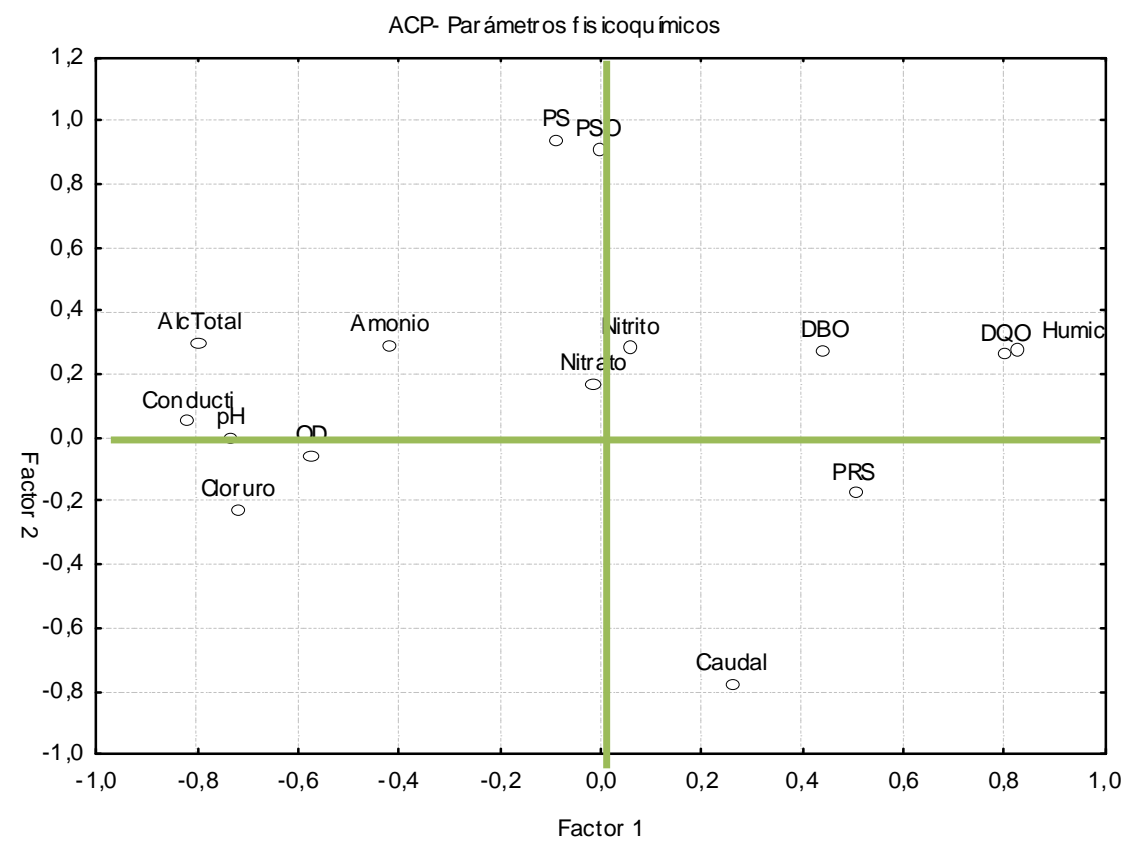

Figura 3.5 Análisis de componentes principales a través del cual se observa el ordenamiento de las variables analizadas: MPS, alcalinidad conductividad, $\mathrm{pH}$, cloruros, OD, amonio, nitrito, nitrato, $\mathrm{DBO}_{5}$, Caudal, PRS, DQO y ácidos húmicos.

La representación de cada uno de los casos en los dos primeros componentes principales fueron graficados (fig. 3.6) para visualizar la distribución de los sitios. Se observa que los sitios bajo condiciones de alto caudal (Dic-06) se ubican en el gráfico más cercanos entre si y alejados de los otros los cuales no se agrupan por sitios ni tampoco por fechas. 


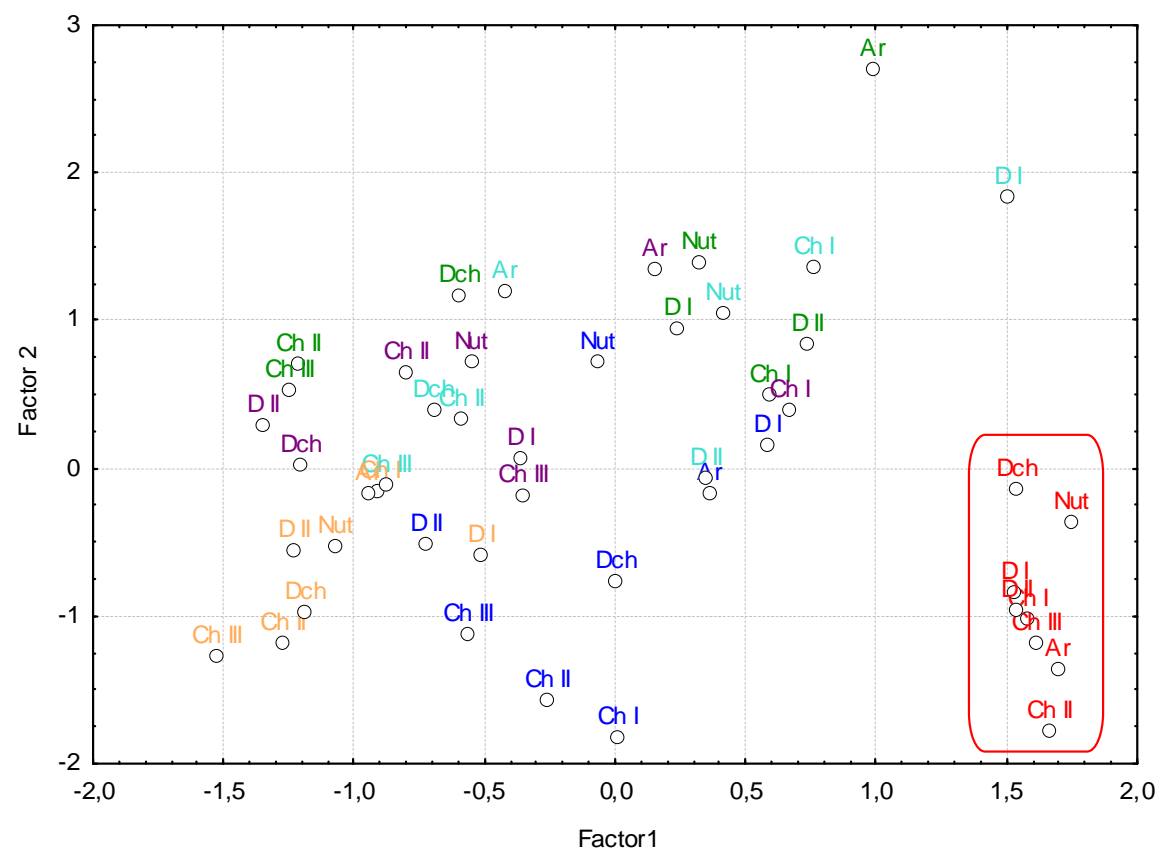

Figura 3.6 Representación de cada uno de los casos en el espacio que determinan los dos primeros componentes principales. La Choza I (Ch I), La Choza II (Ch II), La Choza III (Ch III), Arias (Ar), Nutrias (Nut), Durazno I (D I), Durazno II (D II), Durazno chico (Dch). Los colores indican la fecha de muestreo: rojo-Diciembre, verdeFebrero, azul-Mayo, naranja-Agosto, violeta-Noviembre y celeste-Marzo

\section{Parámetros del perifiton}

En la tabla 3.3 se muestran los rangos de variación de los parámetros estructurales del perifiton registrados durante todo el período de muestreo.

La concentración de clorofila $a$ fluctuó entre 0,03 y $1,0 \mathrm{mg} / \mathrm{g}$ planta durante todo el año con excepción del mes de agosto donde una floración de metafiton y un incremento en la densidad de diatomeas elevó la concentración de clorofila $a$ a valores cercanos a los $9 \mathrm{mg} / \mathrm{g}$ planta en algunos casos. El arroyo Arias sin embargo, nunca superó los $0,86 \mathrm{mg} / \mathrm{g}$ planta. Los arroyos agrícolas tienen valores relativos de clorofila $a$ mayores a los ganaderos (fig. 3.7) 
Tabla 3.3. Rango de variación de los parámetros estructurales del perifiton

\begin{tabular}{l|cccccccc} 
Sitio & La Choza I & La Choza II & La Choza III & Arias & Nutrias & Durazno I & Durazno II & Durazno chico \\
\hline Número de muestras & 6 & 18 & 18 & 16 & 18 & 18 & 15 \\
Clorofila $a$ mg/gplanta & $0,05-1,27$ & $0,08-12,75$ & $0,03-8,78$ & $0,001-0,86$ & $0,08-3,14$ & $0,09-2,09$ & $0,03-8,79$ & $0,12-1,69$ \\
Feopigmentos mg/g planta & $0,0-0,13$ & $0,0-0,07$ & $0,0-0,29$ & $0,0-0,12$ & $0,0-0,30$ & $0,01-0,59$ & $0,0-0,90$ & $0,0-0,04$ \\
Peso Seco g/gplanta & $0,09-0,75$ & $0,06-2,24$ & $0,09-1,54$ & $0,04-0,91$ & $0,03-3,61$ & $0,21-3,2$ & $0,08-4,69$ & $0,35-1,16$ \\
PS Orgánico g/gplanta & $0,03-0,1$ & $0,02-0,46$ & $0,01-0,81$ & $0,008-0,14$ & $0,003-0,55$ & $0,03-0,45$ & $0,01-0,54$ & $0,04-0,14$ \\
Índice Autotrófico & $80,9-674,1$ & $35,2-478,1$ & $40,9-464,9$ & $161,0-26752$ & $25,0-426,0$ & $107,3-607,3$ & $45,3-362,7$ & $40,7-381,1$ \\
Lakatos \%Cenizas & $65,5-87,8$ & $58,2-83,8$ & $71,5-87,5$ & $67,7-89,3$ & $64,5-98,3$ & $77,1-91,0$ & $67,5-88,4$ & $86,3-88,8$ \\
Lakatos \%Cl- $a$ & $0,15-1,23$ & $0,21-2,84$ & $0,21-2,44$ & $0,003-0,62$ & $0,23-4,0$ & $0,16-0,93$ & $0,27-2,2$ & $0,26-2,45$ \\
Riqueza (S) & $27-67$ & $23-53$ & $10-49$ & $14-38$ & $15-63$ & $20-50$ & $18-63$ & $42-59$ \\
Equitatividad (J') & $0,51-0,83$ & $0,28-0,90$ & $0,51-0,89$ & $0,43-0,83$ & $0,48-0,90$ & $0,39-0,89$ & $0,23-0,91$ & $0,55-0,74$ \\
Diversidad (H') & $2,44-4,92$ & $1,29-4,81$ & $1,99-4,76$ & $2,0-4,28$ & $2,35-5,08$ & $1,8-4,77$ & $0,98-5,26$ & $3,13-4,22$ \\
Bacillariophyta (\%) & $8,7-38,86$ & $14,05-97,73$ & $7,0-98,45$ & $0,0-59,27$ & $2,64-87,56$ & $1,22-93,66$ & $29,65-99,49$ & $6,90-34,09$ \\
Chlorophyta (\%) & $1,24-26,83$ & $1,98-45,45$ & $1,54-56,78$ & $5,63-62,93$ & $11,15-54,42$ & $3,52-64,08$ & $0,25-24,26$ & $29,0-49,09$ \\
Cyanophyta (\%) & $12,2-89,75$ & $0,0-64,32$ & $0,0-62,22$ & $11,21-86,71$ & $0,59-43,48$ & $2,46-74,24$ & $0,0-46,54$ & $17,04-49,53$ \\
Euglenophyta (\%) & $0,31-33,11$ & $0,0-16,90$ & $0,0-8,91$ & $0,0-48,15$ & $0,25-78,01$ & $0,0-42,86$ & $0,0-13,48$ & $1,52-19,55$ \\
\cline { 3 - 7 } & & & & & & &
\end{tabular}




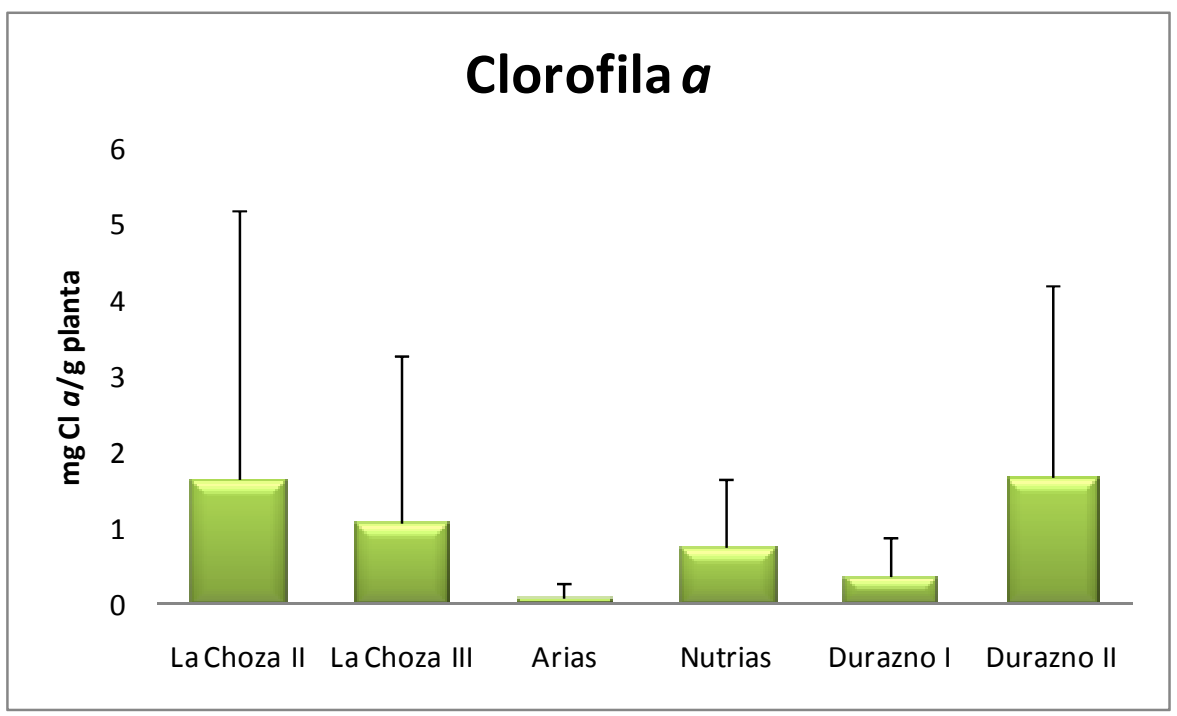

Figura 3.7. Concentraciones promedio y desvío estándar de clorofila $a$ para cada sitio de muestreo. La Choza II, La Choza III y Durazno II, agrícolas; Arias, Nutrias y Durazno I, ganaderos.

Durante el período de estudio el IA mostró valores en general heterotróficos para todos los sitios. En el mes de agosto al aumentar los valores de clorofila $a$ los valores de IA disminuyeron a niveles autotróficos salvo en los arroyos Arias y Durazno I que permanecieron con valores sobre o muy cercanos a 200. De acuerdo al sistema de Lakatos el perifiton podría clasificarse, en relación al \% de cenizas, como inorgánico en la mayoría de los casos. En relación al \% de clorofila $a$ en el PS puede clasificarse como un perifiton de tipo II (Auto-heterotrófico) en la mayoría de los sitios. El del arroyo Durazno I sin embargo, se mantuvo como un perifiton de tipo Hetero-autotrófico y el perifiton del arroyo Arias como netamente heterotrófico. Salvo durante el mes de agosto en que todos los sitios fueron clasificados como Autotróficos.

La riqueza específica fue muy variable. Sin embargo, se encontraron los menores valores para todos los sitios durante el mes de agosto. El Índice de equitatividad de Pielou mide la proporción de la diversidad observada con relación a la máxima diversidad esperada. El valor 1 corresponde a situaciones donde todas las especies son igualmente abundantes. En este estudio se encontraron valores cercanos a 1 en la mayoría de los casos lo que implica ausencia de una marcada dominancia por parte de las especies integrantes del perifiton. También se encontraron valores menores a 0,5 pero sin seguir ningún patrón temporal ni se relacionó con los usos de la tierra. 
La diversidad de Shannon fue alta en todos los sitios (entre 3 y 4 bytes). Los menores valores corresponden al muestreo del mes de agosto. Se encontraron valores cercanos al máximo teórico sin seguir ningún patrón temporal ni de uso de la tierra. El sitio Durazno II por ejemplo presenta tanto la diversidad más baja como la más alta.

La composición porcentual de la comunidad perifítica en grupos algales (Divisiones) presentó los valores mayores en Bacillariophyta para los sitios La Choza II, La Choza III, El Durazno I y El Durazno II. Los sitios La Choza I y Arias mostraron mayores valores en Cyanophyta mientras que el Nutrias estuvo representado por valores semejantes de Bacillariophyta y Euglenophyta y el Durazno chico de Chlorophyta y Cyanophyta. De las cuatro divisiones representadas la de menor proporción en general fue Euglenophyta, aunque es muy abundante en el sitio Nutrias.

Para facilitar la observación de la variación temporal de estas proporciones se graficaron las abundancias relativas por División separadas por el uso predominante de la tierra adyacente (fig. 3.8). Las Bacillariophyta tienen un gran predominio durante el otoño y el invierno. Las Euglenophyta tienen una mayor proporción en los meses cálidos en los sitios ganaderos. En cambio las Cyanophyta predominaron durante el verano en los sitios agrícolas.

a-

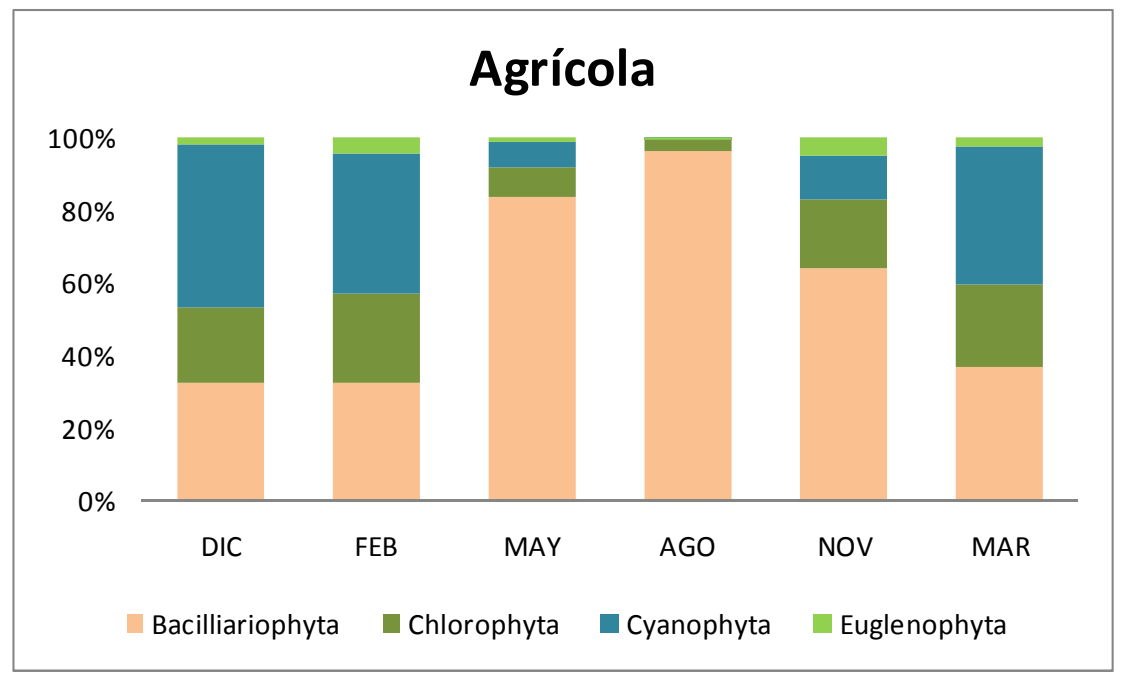


b-

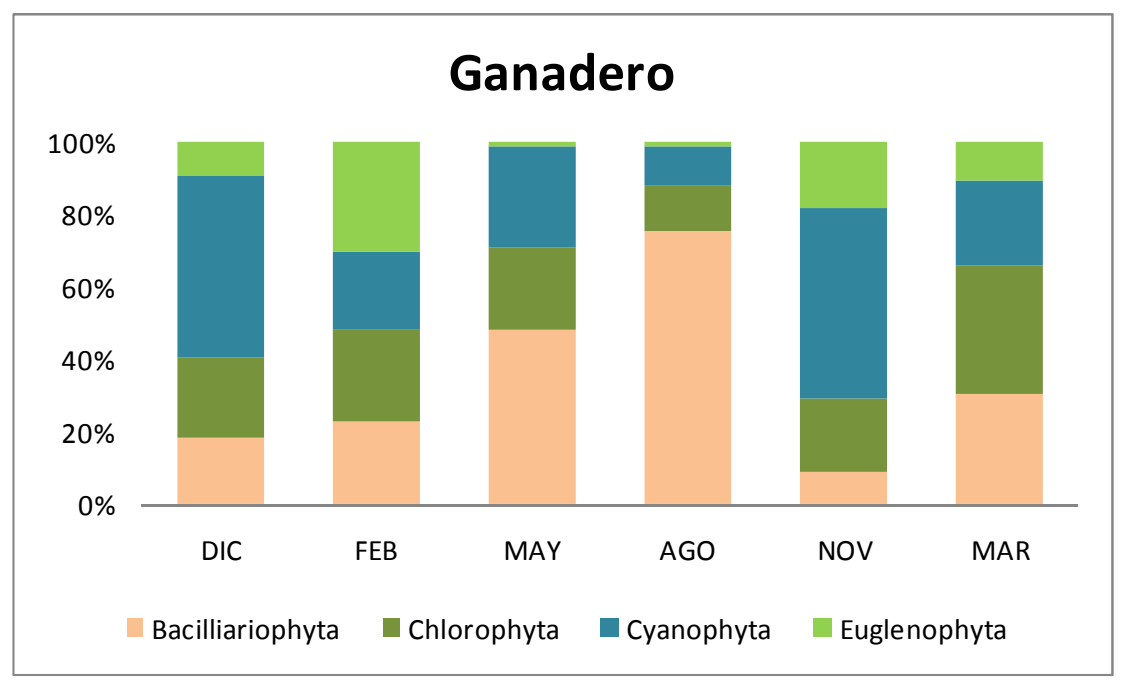

Figura 3.8. Composición de grupos algales a lo largo del tiempo para los sitios agrícolas (a) y para los sitios ganaderos (b). Período 2006-2008

Para los análisis estadísticos no se tuvo en cuenta el sitio La Choza I ni el Durazno chico debido a que no se muestreó el perifiton en todas las fechas y por lo tanto se poseía menor número de muestras (tabla 3.3). El sitio La Choza I permaneció interrumpido del cauce del arroyo por falta de lluvias a partir de abril del 2007 y el Durazno chico al haber sido canalizado no aportaba datos fieles sobre la relación con el uso de la tierra adyacente.

La relación entre los distintos parámetros estructurales del perifiton presentados en la Tabla 3.3 se exploró mediante un análisis multivariado de ordenamiento.

Los dos primeros componentes del Análisis de Componentes Principales (ACP) explican el $31,85 \%$ y $19,62 \%$ respectivamente del total de la varianza. El primer componente (autovalor: 4,46) se correlaciona negativamente con el Peso Seco Orgánico $(-0,74)$, la concentración de Clorofila $a(-0,90)$, el \% de clorofila $(-0,70)$ y la abundancia relativa de Diatomeas $(-0,78)$. El segundo componente (autovalor: 2,75) se correlaciona positivamente tanto con el índice de diversidad como con sus componentes: Riqueza $(0,74)$, Equitatividad $(0,74)$ y Diversidad de Shannon $(0,87)$ (Figura 3.9). Estos resultados indican que la abundancia de Bacillariophya está asociada a altas concentraciones de clorofila $a$ mientras que la abundancia de Cyanophyta está asociada a condiciones de heterotrofia y de menor riqueza y diversidad de especies. 


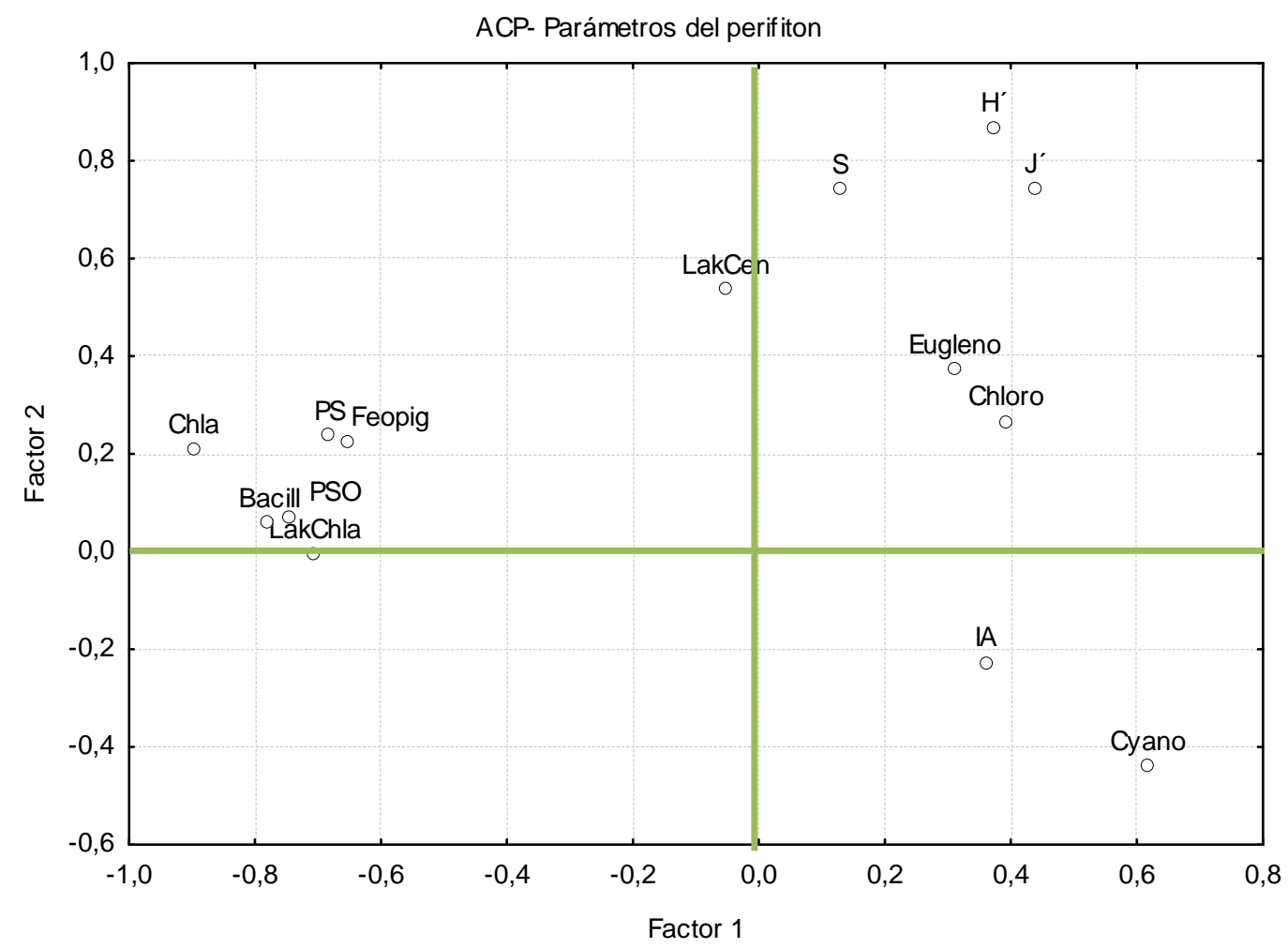

Figura 3.9. Ordenamiento de las variables del perifiton desarrollado sobre sustrato natural en período 2006-2008 en un ACP

La representación de cada uno de los casos en los dos primeros componentes principales se graficaron (fig. 3.10) para visualizar la distribución de los sitios en cada fecha de muestreo. Se observa comparando la representación de los puntajes de los sitios (fig. 3.10) con la de las variables (fig. 3.9) que el sitio Arias está asociado a una mayor abundancia de Cyanophyta. Los sitios ubicados en el margen izquierdo del gráfico (asociados a una mayor concentración de clorofila $a$ y abundancia de Bacillariophyta) corresponden al mes de agosto. 


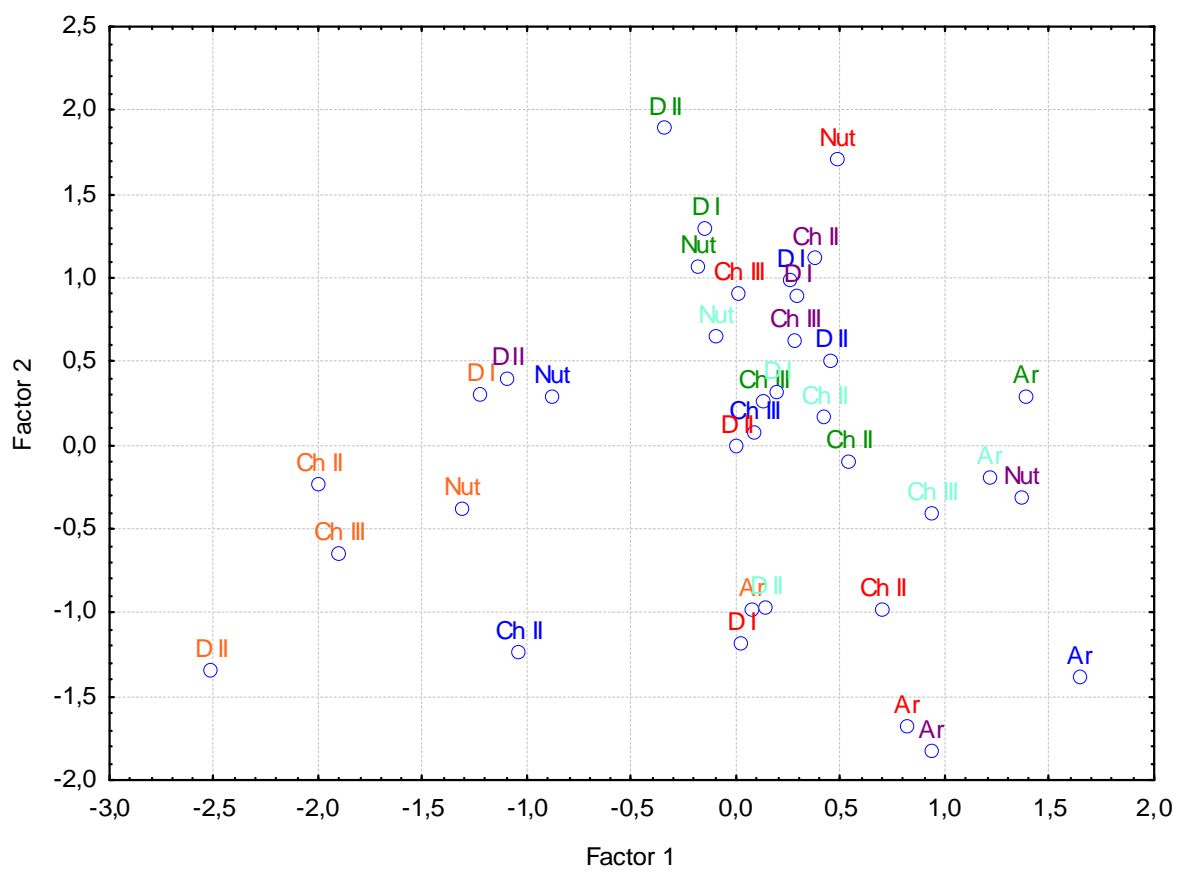

Figura 3.10. Representación de cada uno de los casos en el espacio que determinan los dos primeros componentes principales. La Choza II (Ch II), La Choza III (Ch III), Arias (Ar), Nutrias (Nu), Durazno I (D I), Durazno II (D II). Los colores indican la fecha de muestreo: rojo-Diciembre, verde-Febrero, azul-Mayo, naranja-Agosto, violeta-

Noviembre y celeste-Marzo

Con el objeto de relacionar las variables fisicoquímicas con las estructurales del perifiton se realizó una regresión simple según el Modelo Lineal General. Para ello se utilizó como variable sintética a los scores de los dos primeros factores del ACP de las variables fisicoquímicas.

En la tabla 3.4 se detallan los valores de pendiente, coeficiente de regresión (R), estadístico de Fisher (F) y el nivel de significación (p) para los parámetros que resultaron con una regresión significativa. Las variables con una regresión significativa con el primer componente (FQ1) muestran una relación con los ácidos húmicos y la DQO por un lado pero también con la conductividad y el $\mathrm{pH}$. Las regresiones significativas con el segundo componente (FQ2) se relacionan con el material particulado en suspensión y el caudal. 
Tabla 3.4: Regresiones simples significativas entre las variables del perifiton y los valores de ordenamiento de cada caso en los dos primeros factores del ACP para las variables fisicoquímicas. $\mathrm{N}=108$

Regresión con FQ1

\begin{tabular}{l|cccc|} 
Parámetro & Pendiente & R & F & p \\
\hline Riqueza (S) & 4,68 & 0,38 & 11,44 & $<0,01$ \\
Bacillariophyta (\%) & $-7,97$ & 0,30 & 6,68 & $<0,01$ \\
Cyanophyta (\%) & 5,93 & 0,26 & 4,93 & $<0,05$ \\
\hline
\end{tabular}

Regresión con FQ2

\begin{tabular}{l|cccc|} 
Parámetro & Pendiente & $\mathbf{R}$ & $\mathbf{F}$ & $\mathbf{p}$ \\
\hline PS (g/g planta) & 0,3 & 0,28 & 6,03 & $<0,05$ \\
IA & 1475,5 & 0,28 & 6,0 & $<0,05$ \\
Lakatos cenizas & 2,72 & 0,40 & 13,28 & $<0,01$ \\
Lakatos Cl $a$ & $-0,089$ & 0,31 & 7,45 & $<0,01$ \\
Bacillariophyta (\%) & $-6,72$ & 0,25 & 4,63 & $<0,05$ \\
Chlorophyta (\%) & 4,19 & 0,31 & 7,33 & $<0,01$ \\
Euglenophyta (\%) & 0,73 & 0,46 & 17,97 & $<0,01$ \\
\hline
\end{tabular}

\section{Análisis florístico:}

La lista taxonómica de organismos junto a su presencia en al menos uno de los muestreos se encuentra en la Tabla 3.5. Se identificaron un total de 159 especies incluyendo los ocho sitios de muestreo. De las especies registradas, 75 pertenecen a la división Bacillariophyta (47,2\%), 46 a la división Chlorophyta (28,9\%), 24 a la división Cyanophyta $(15,1 \%)$ y 14 a la división Euglenophyta $(8,8 \%)$.

Tabla 3.5. Lista de algas identificadas. Se señala con una cruz los sitios en que fueron encontradas al menos una vez durante el período de muestreo.

\begin{tabular}{|c|c|c|c|c|c|c|c|c|}
\hline & Chl & zhll & ChIII & $\mathrm{Ar}$ & Nut & DI & D II & Dch \\
\hline \multicolumn{9}{|l|}{ División Bacillariophyta } \\
\hline Achnanthes inflata (Kütz)Grun. & & $x$ & & & & & & \\
\hline Amphora ovalis Kütz & $x$ & $x$ & $x$ & $x$ & $x$ & $x$ & $x$ & $x$ \\
\hline Anomoeoneis sphaerophora O.Müll & & $x$ & $x$ & $x$ & $x$ & & $x$ & $x$ \\
\hline $\begin{array}{l}\text { Aulacoseira granulata v. } \\
\text { angustissima (O.Müll.) Simonsen }\end{array}$ & & $x$ & & $x$ & $x$ & & & \\
\hline Bacillaria paxillifer (O. F. Müller) & & & $x$ & & & & $x$ & $x$ \\
\hline Hendey & & & & & & & & \\
\hline Caloneis Cleve sp. & & & & & & & & $x$ \\
\hline Cocconeis pediculus Ehr. & $x$ & $x$ & $x$ & $x$ & $x$ & $x$ & $x$ & $x$ \\
\hline Cocconeis placentula Ehr. & $x$ & $x$ & $x$ & $x$ & $x$ & $x$ & $x$ & $x$ \\
\hline Craticula ambigua (Ehr.)D.G.Mann & $x$ & $x$ & $x$ & & & $x$ & & \\
\hline
\end{tabular}




\begin{tabular}{|c|c|c|c|c|c|c|c|c|}
\hline Cyclostephanos Round sp & $x$ & $\mathrm{x}$ & $x$ & $\mathrm{x}$ & $\mathrm{x}$ & $\mathrm{x}$ & $\mathrm{x}$ & $\mathrm{x}$ \\
\hline Cylindrotheca closterium (Ehr.) & & $\mathrm{X}$ & & $\mathrm{x}$ & $\mathrm{X}$ & $\mathrm{X}$ & $\mathrm{x}$ & \\
\hline Reiman \& Lewin & & & & & & & & \\
\hline Cymbella minuta Hilse ex Rabh. & $x$ & $x$ & $x$ & & $x$ & $\mathrm{x}$ & $x$ & \\
\hline Cymbella Agardh sp & & & & & & $x$ & & \\
\hline Denticula kuetzingii Grun. & $x$ & $x$ & $x$ & $x$ & $x$ & & $x$ & \\
\hline Diploneis puella (Schum.) Cleve. & & & & & $x$ & & $x$ & \\
\hline Entomoneis Ehr. sp & & & & & & & & $x$ \\
\hline Epithemia sorex Kütz. & & $x$ & & & & $x$ & $x$ & \\
\hline Eunotia pectinalis (O.F.Mull)Ralphs. & $x$ & $x$ & $x$ & $x$ & $x$ & $x$ & $x$ & $x$ \\
\hline Eunotia Ehr. sp & & $x$ & $x$ & & $x$ & $x$ & $x$ & \\
\hline Fragilaria capucina Desm. & & & $x$ & & & $\mathrm{x}$ & & \\
\hline Gomphonema affine Kütz. & $x$ & $x$ & $x$ & & $x$ & $\mathrm{x}$ & $x$ & $x$ \\
\hline $\begin{array}{l}\text { Gomphonema angustatum } \\
\text { (Kütz)Rabh. }\end{array}$ & & $x$ & $x$ & & $x$ & $x$ & & $x$ \\
\hline Gomphonema brasiliense Grun. & $x$ & $x$ & $x$ & $x$ & $x$ & $\mathrm{x}$ & $x$ & $x$ \\
\hline Gomphonema aff. clavatum Ehr. & $x$ & $x$ & $x$ & & $x$ & $x$ & $x$ & \\
\hline Gomphonema parvulum Kütz. & $x$ & $x$ & $x$ & $x$ & $x$ & $x$ & $x$ & $x$ \\
\hline Gomphonema truncatum Ehr. & & $x$ & & & & & $x$ & \\
\hline Halamphora veneta (Kütz)Levkov & $x$ & $x$ & $x$ & & $x$ & $x$ & $x$ & $x$ \\
\hline Hantzschia amphioxis (Ehr.)Grun. & $x$ & $x$ & $x$ & $x$ & $x$ & $\mathrm{x}$ & $x$ & $x$ \\
\hline Hantzschia elongata (Hantzsch) & & & & & & $\mathrm{x}$ & & \\
\hline Grunow & & & & & & & & \\
\hline $\begin{array}{l}\text { Hippodonta capitata (Ehr.) Lange- } \\
\text { Bert. et al }\end{array}$ & & $x$ & $x$ & & $x$ & $x$ & $x$ & $x$ \\
\hline Melosira varians C.A.Ag. & $x$ & $x$ & $x$ & $x$ & $x$ & $x$ & & $x$ \\
\hline Navicula Bory sp1 & & $x$ & $x$ & & & & $x$ & $x$ \\
\hline Navicula Bory sp2 & & & $x$ & & $x$ & $x$ & $x$ & $x$ \\
\hline Navicula Bory sp3 & & $x$ & $x$ & $x$ & & $x$ & $x$ & \\
\hline Navicula Bory sp4 & & & & & & & $x$ & $x$ \\
\hline Navicula Bory sp5 & & $x$ & $x$ & & & & & \\
\hline Navicula Bory sp6 & & $x$ & & & & $x$ & $x$ & \\
\hline Navicula cryptocephala Kütz. & $x$ & $x$ & $x$ & $x$ & $x$ & $x$ & $x$ & $x$ \\
\hline Navicula peregrina Ehr. & $x$ & $x$ & $x$ & $x$ & $x$ & $x$ & $x$ & $x$ \\
\hline Navicula radiosa Kütz. & $x$ & $x$ & $x$ & $x$ & $x$ & $x$ & $x$ & $x$ \\
\hline Navicula veneta Kütz. & & $x$ & & & & & $x$ & \\
\hline Neidium iridis (Ehr.)Cleve & $x$ & $x$ & $x$ & $x$ & $x$ & $x$ & $x$ & $x$ \\
\hline Nitzschia Hassal sp1 & $x$ & $x$ & $x$ & & $x$ & $x$ & $x$ & \\
\hline Nitzschia Hassal sp2 & $x$ & $x$ & $x$ & $x$ & $x$ & $x$ & $x$ & $x$ \\
\hline Nitzschia amphibia Grun. & $x$ & $x$ & $x$ & & $x$ & $x$ & $x$ & $x$ \\
\hline Nitzschia commutata Grun. & & $x$ & & $x$ & $x$ & $x$ & $x$ & \\
\hline Nitzschia gracilis Hantzsch. & & & $x$ & $x$ & & $x$ & $x$ & \\
\hline Nitzschia palea (Kütz.)W. Smith & $x$ & $x$ & $x$ & $x$ & $x$ & $x$ & $x$ & $x$ \\
\hline Nitzschia parvula Levis & $x$ & $x$ & $x$ & & $x$ & $x$ & $x$ & \\
\hline Nitzschia recta Hantzsch. & $x$ & $x$ & $x$ & $x$ & $x$ & $x$ & $x$ & $x$ \\
\hline Nitzschia scalpelliformis Grun. & $x$ & $x$ & $x$ & $x$ & $x$ & $x$ & $x$ & $x$ \\
\hline Nitzschia sigma (Kütz.)W.Smith & & & & & & & $x$ & \\
\hline
\end{tabular}


Nitzschia sigmoidea (Ehr.)W.Smith Nitzschia subacicularis Hust.

Pinnularia Ehr. sp1

Pinnularia Ehr. sp2

Pinnularia Ehr. sp3

Pinnularia braunii Grun.

Pinnularia gibba Ehr.

Pinnularia viridis (Nitz.)Ehr.

Placoneis Meresch. sp

Planothidium Round $\mathrm{sp}$

Pleurosira laevis (Ehr.)Comère

Rhoicosphenia abbreviata (Ag.)

Lange-Bertalot

Rhopalodia gibba (Ehr.)O.Müller.

Rhopalodia gibberula (Ehr.)O.Müller

Sellaphora pupula (Kütz.) Mereschk.

Stauroneis phoenicenteron

(Nitz.)Ehr.

Stephanocyclus meneghiniana

(Kütz.) Skabitschevsky

Surirella angustata Kütz.

Surirella ovalis Breb.

Surirella robusta Ehr.

Surirella rorata Frenguelli

Surirella tenera Gregory

Synedra ulna (Nitz.)Ehr.

\section{División Chlorophyta}

Actinastrum hantzschii Lager.

Ankistrodesmus acicularis

(A.Braun)Korshikov

Ankistrodesmus angustus Bernard

Characium Braun sp.

Chlamydomonas Ehr. sp.

Chodatella Lem. sp.

Cladophora glomerata (L.)Kütz.

Closterium acus (O.Müller)Kütz.

Closterium intermedium Ralfs.

Closterium parvulum Nägeli

Closterium Nitzsch. sp.

Coelastrum Nagüeli sp

Coleochaete Breb. sp.

Cosmarium botrytis Meneghini ex

Ralfs

Cosmarium Corda ex Ralf sp.

Dicellula Swirenko sp.

Dictyococcus Gerneck sp

\begin{tabular}{|c|c|c|c|c|c|c|c|}
\hline$X$ & $X$ & $X$ & $X$ & $x$ & $X$ & & $X$ \\
\hline$X$ & $x$ & $x$ & $x$ & $x$ & $X$ & $X$ & $x$ \\
\hline \multirow[t]{3}{*}{$X$} & $x$ & $X$ & & $x$ & $X$ & $X$ & $x$ \\
\hline & $x$ & $X$ & $x$ & $x$ & $X$ & $X$ & $x$ \\
\hline & $x$ & & & & & $X$ & \\
\hline \multirow[t]{3}{*}{$X$} & $x$ & $X$ & & $x$ & $X$ & $X$ & $x$ \\
\hline & $x$ & $X$ & $X$ & $x$ & $X$ & $X$ & \\
\hline & $x$ & $X$ & $X$ & $x$ & $X$ & $X$ & $x$ \\
\hline$X$ & $x$ & $X$ & $x$ & & & & \\
\hline \multirow[t]{2}{*}{$x$} & $x$ & $X$ & & $X$ & $X$ & $X$ & $x$ \\
\hline & $X$ & $X$ & & $X$ & & $X$ & \\
\hline \multirow[t]{2}{*}{$X$} & $x$ & $X$ & & & $X$ & $X$ & $x$ \\
\hline & $x$ & & & & & & \\
\hline \multirow[t]{2}{*}{$x$} & & $X$ & $X$ & & & $X$ & $x$ \\
\hline & & $X$ & & $X$ & & $X$ & \\
\hline$X$ & & & $X$ & & $x$ & $X$ & \\
\hline \multirow[t]{6}{*}{$X$} & $x$ & $x$ & $x$ & $X$ & $x$ & $X$ & $x$ \\
\hline & & $X$ & & & $X$ & $x$ & \\
\hline & $x$ & $X$ & & $X$ & & $X$ & $X$ \\
\hline & $x$ & $X$ & & $X$ & $x$ & $X$ & $x$ \\
\hline & & & & & & & $X$ \\
\hline & $X$ & $X$ & & $X$ & & $X$ & $x$ \\
\hline$X$ & $x$ & $x$ & $x$ & $X$ & $x$ & $x$ & \\
\hline$X$ & $x$ & & $x$ & $x$ & $x$ & $x$ & $x$ \\
\hline$X$ & $x$ & $X$ & $x$ & $x$ & $x$ & $X$ & $x$ \\
\hline$X$ & $x$ & $x$ & $x$ & $x$ & $x$ & $x$ & $X$ \\
\hline$X$ & $x$ & $X$ & $X$ & $X$ & $X$ & $X$ & $x$ \\
\hline \multirow[t]{4}{*}{$x$} & $X$ & $X$ & $X$ & $X$ & $x$ & $x$ & $x$ \\
\hline & & $X$ & $X$ & $X$ & & & \\
\hline & $X$ & & & & & & \\
\hline & $X$ & & $X$ & & $x$ & $x$ & \\
\hline$X$ & $x$ & & & $x$ & $x$ & $x$ & $X$ \\
\hline$X$ & & $X$ & & $x$ & & & $x$ \\
\hline$X$ & $x$ & $X$ & $X$ & & & & \\
\hline \multirow[t]{2}{*}{$X$} & $x$ & $X$ & $X$ & $X$ & $x$ & $X$ & $x$ \\
\hline & $x$ & $X$ & $x$ & $x$ & $x$ & $x$ & \\
\hline$X$ & $x$ & & & $x$ & $x$ & & $X$ \\
\hline$X$ & $X$ & $X$ & $X$ & $X$ & $x$ & $x$ & $X$ \\
\hline \multirow[t]{2}{*}{$x$} & $x$ & $X$ & $X$ & $X$ & & & $x$ \\
\hline & & & $x$ & & & $x$ & \\
\hline
\end{tabular}




\section{Euastrum ansatum Ehr. ex Ralfs}

Euastrum oblongum (Greville)Ralfs ex Ralfs

Eudorina Ehr. sp.

Kirchneriella lunaris

(Kirchner)K.Möbius

Korschikoviella gracilipes

(Lambert)Silva

Micractinium pussillum Fres.

Monoraphidium irregulare

(G.M.Smith) Komárková-Legnerová Netrium Nägeli sp.

Oedogonium Link. sp.

Oocystis Braun sp

Pandorina morum (O.Müller)Bory

Pediastrum duplex Meyen

Pediastrum tetras (Ehr.) Ralfs

Scenedesmus armatus Chodat.

Scenedesmus armatus v. bicauda

Scenedesmus falcatus Chodat.

Scenedesmus flexuosus

(Lem.)Ahlstrom

Schizomeris Kütz sp

Schroederia setigera (Sch.) Lem.

Spirogyra Link sp.

Staurastrum Meyen ex Ralph sp.

Staurastrum teliferum Reinsch

Stigeoclonium tenue Kütz.

Tetraedron minimum (Braun) Hansg.

Tetrastrum Chodat sp.

Ulotrix Kütz sp.

Xanthidium Ehr. ex Ralf $s p$

Zignema Ag. sp

\section{Division Cyanophyta}

Anabaena Bory sp1.

Anabaena Bory sp2

Aphanocapsa Nägeli sp

Calotrix Ag. sp.

Chrooccocus Nägeli sp

Chrooccocus minutus (Kütz.)Nägeli

Gomphosphaeria Kütz.sp

Leptolyngbia Anag. sp

Lyngbia Ag. sp1

Lyngbia Ag. sp2

Lyngbia Ag. sp3

Merismopedia Meyen sp1.

$x \quad x$

$\begin{array}{llllllll}x & x & x & x & x & x & x & x\end{array}$

$x \quad x \quad x \quad x$

$\begin{array}{llllllll} & x & x & x & x & x & & x \\ x & x & x & x & x & x & x & x\end{array}$

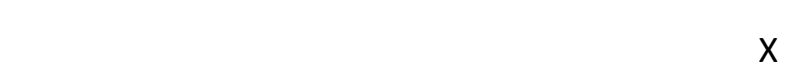

$\begin{array}{llllllll}x & x & x & x & x & x & x & x\end{array}$

$\begin{array}{lllll}x & x & x & x & x\end{array}$

$\begin{array}{lllllll}x & x & x & x & x & x & x\end{array}$

$x \quad x \quad x$

$x$

$\begin{array}{llllllll}X & X & X & X & X & X & X & X\end{array}$

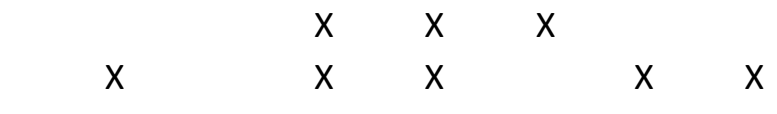

$\begin{array}{llllllll}x & x & x & x & x & x & x & x\end{array}$

$\begin{array}{llllllll}x & x & x & x & x & x & x & x \\ & x & x & & x & x & & x \\ x & x & x & x & x & x & x & x \\ & & & & & x & & \end{array}$

$\begin{array}{llllllll}x & x & x & x & x & x & x & x\end{array}$

$\begin{array}{llll}x & x & x & x\end{array}$

$\begin{array}{llll}x & x & x \\ x & x & x\end{array}$

$\begin{array}{llllllll}X & x & X & X & x & x & x & x\end{array}$

$x$

$X$

$\begin{array}{cccccccc}x & x & x & x & x & x & x & x \\ & & x & & x & & x & x \\ x & x & x & & x & x & & \\ & & & & & x & x & \\ & & & & & x & x & \\ & & & & & & x & \end{array}$

$\begin{array}{llll}x & x & x \\ x & x & x & x\end{array}$

$\begin{array}{llllllll}x & x & x & x & x & x & x & x\end{array}$

$\begin{array}{llllllll}x & x & x & x & x & x & x & x\end{array}$

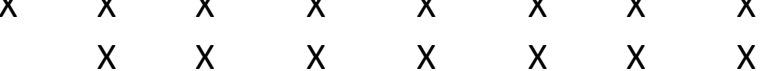

$x \quad x$

$\begin{array}{lllll}X & X & X & X & X\end{array}$ 


\begin{tabular}{|c|c|c|c|c|c|c|c|c|}
\hline Merismopedia Meyen sp2 & $x$ & $x$ & $x$ & $\mathrm{x}$ & $x$ & $x$ & & \\
\hline Microcystis aeruginosa Kütz. ex Lem. & & & & & & $x$ & & $x$ \\
\hline Oscillatoria limnetica Lem. & $x$ & $x$ & $x$ & $\mathrm{x}$ & $x$ & $x$ & $x$ & $x$ \\
\hline Oscillatoria princeps Vaucher & $x$ & & $x$ & & $x$ & & & $x$ \\
\hline Oscillatoria tenuis Ag. & $x$ & & $x$ & $x$ & $x$ & $x$ & $x$ & $x$ \\
\hline Oscillatoria Vaucher sp & $x$ & $x$ & & $x$ & $x$ & $x$ & $x$ & $x$ \\
\hline Phormidium Kütz. Ex Gomont sp & & $x$ & $x$ & $x$ & $x$ & $x$ & $x$ & $x$ \\
\hline Planktothrix Anag. sp & $x$ & & $x$ & $x$ & & $x$ & $x$ & $x$ \\
\hline $\begin{array}{l}\text { Pseudanabaena limnetica (Lemm.) } \\
\text { Komárek }\end{array}$ & $x$ & $x$ & $x$ & $\mathrm{x}$ & $x$ & $x$ & $x$ & $x$ \\
\hline Raphidiopsis mediterranea Skuja. & & & & $x$ & & & & \\
\hline Spirulina Turpin sp. & $x$ & $x$ & $x$ & $x$ & $x$ & $x$ & $x$ & $x$ \\
\hline Synechococcus Nägeli sp & & $x$ & $x$ & & $x$ & & & $x$ \\
\hline \multicolumn{9}{|l|}{ División Euglenophyta } \\
\hline Colacium epiphyticum Fritsch. & & & & $x$ & $x$ & & $x$ & \\
\hline Euglena Ehr sp1 & $x$ & $x$ & $x$ & $x$ & $x$ & $x$ & $x$ & $x$ \\
\hline Euglena acus Ehr. & $x$ & $x$ & $x$ & $x$ & $x$ & $x$ & $x$ & $x$ \\
\hline Euglena ehrembergii Klebs & $x$ & $x$ & $x$ & $x$ & $x$ & $x$ & $x$ & $x$ \\
\hline Euglena Ehr sp2 & $x$ & $x$ & $x$ & $x$ & $x$ & $x$ & $x$ & $x$ \\
\hline Lepocinclis salina Fritsch & $x$ & $x$ & $x$ & $x$ & $x$ & $x$ & $x$ & $x$ \\
\hline Lepocinclis caudata Cunha & $x$ & $x$ & $x$ & $x$ & $x$ & $x$ & & $x$ \\
\hline Phacus sp1 & $x$ & $x$ & $x$ & $x$ & $x$ & $x$ & $x$ & $x$ \\
\hline Phacus sp2 & $x$ & $x$ & $x$ & $x$ & $x$ & $x$ & $x$ & $x$ \\
\hline Strombomonas sp & $x$ & $x$ & $x$ & $x$ & $x$ & $x$ & $x$ & $x$ \\
\hline Trachelomonas sp1 & $x$ & & $x$ & $x$ & $x$ & $x$ & $x$ & $x$ \\
\hline Trachelomonas sp2 & $x$ & & $x$ & $x$ & $x$ & $x$ & $x$ & $x$ \\
\hline Trachelomonas sp3 & $x$ & $x$ & $x$ & $x$ & $x$ & $x$ & $x$ & $x$ \\
\hline Trachelomonas sp4 & $x$ & $x$ & & $x$ & $x$ & $x$ & $x$ & $x$ \\
\hline
\end{tabular}

La riqueza específica promedio de algas epífitas fue mayor en los sitios agrícolas (113) que en los ganaderos (101). El sitio con mayor riqueza fue La Choza II con 116 especies y los de menor riqueza La Choza I y Arias, ambos con 91 especies. De todas las especies halladas la mayoría se encuentra indistintamente en arroyos agrícolas o ganaderos. Gomphonena truncatum, Navicula veneta y Pinularia sp3 fueron exclusivas de sitios agrícolas mientras que Scenedesmus armatus v. bicauda, Gomphosphaeria y Microcystis aeruginosa fueron exclusivas de sitios ganaderos. Algunas especies se encontraron en sólo uno de los sitios pero éstas se hallaron en una muy baja abundancia relativa (Las abundancias relativas se encuentran en el anexo). Sin embargo se debe mencionar a Raphidiopsis mediterranea que se encontró exclusivamente en el arroyo Arias representando la mayoría de las veces un $50 \%$ de la abundancia relativa dentro del sitio. 
Se examinaron con el análisis ANOSIM las diferencias entre los dos usos agropecuarios predominantes. El coeficiente $\mathrm{R}$ global fue significativo (R: 0,172) con un nivel de significación de $0,1 \%$.

Las abundancias relativas de las especies encontradas se utilizaron para discriminar especies que fueran características de uno u otro tipo de uso. Ello se llevó a cabo a través del análisis no paramétrico SIMPER basado en los porcentajes de la similitud o disimilitud promedio calculados por el coeficiente de Bray-Curtis y el aporte de cada especie a la segregación o no de un grupo en particular.

El valor promedio de similitud obtenido con este análisis de clasificación para el primer grupo, asociado a uso de la tierra agrícola fue de un 23,6 \%. Para el segundo grupo, asociado al uso ganadero, resultó un 23,9\%, siendo la disimilitud media entre ambos grupos de un $79,9 \%$.

Las especies que explican el primer 50\% de disimilitud entre ambos grupos son Lyngbya sp1, Synedra ulna, Melosira varians, Oedogonium, Rhaphidiopsis mediterranea, Stigeoclonium, Planktothrix, Navicula veneta, Gomphonema parvulum, Eunotia pectinalis y Lyngbya sp2.

En la tabla 3.6 se muestran las especies con mayor representatividad numérica, superior al 50\%, en cada uno de los grupos definidos según el uso de la tierra predominante. En el primer grupo, cinco especies fueron mayoritariamente responsables de la similaridad dentro del mismo, mientras que en el segundo grupo aparecen seis especies.

Especies como Lyngbya sp1, Oedogonium y Stigeoclonium que aparecen en los dos tipos de agrupamiento, indican poca especificidad por el uso de la tierra adyacente aunque sus abundancias relativas difieren en cada caso. 
Tabla 3.6 Especies que explican en mayor porcentaje la similitud dentro de cada grupo agropecuario. En negrita se destacan las especies que pertenecen únicamente a uno de los grupos.

\section{Grupo agrícola}

Lyngbya sp1

Synedra ulna

Oedogonium sp

Stigeoclonium sp

Gomphonema parvulum

\section{Grupo ganadero}

Lyngbya sp1

Oedogonium sp

Trachelomonas sp3

Stigeoclonium sp

Raphidiopsis mediterranea

Nitzschia palea

El Indice de Diatomeas Pampeano (IDP) es un índice integrador de los efectos del enriquecimiento por contaminación orgánica y eutroficación y puede ser aplicado en monitoreos de calidad biológica de arroyos de la región pampeana. Si bien este índice fue diseñado para utilizarse con diatomeas bentónicas, en este capítulo se consideró la posibilidad de su uso con los resultados del perifiton. Aplicando este índice en las diatomeas encontradas en los diferentes sitios se observa (tabla 3.7) que todos los sitios son de tipo II (>1,5-2 aceptable: altas concentraciones de nutrientes y materia orgánica) o III (>2-3 malo: presencia de de materia orgánica parcialmente degradada, nitrito, amonio y aminoácidos). Esta clasificación es asociada por las autoras a moderada/intensiva actividad agrícola y ganadería intensiva (sitios tipo II) así como a moderada actividad industrial (sitios tipo III). No se observan diferencias entre los usos agrícola o ganadero aunque en el arroyo Arias durante los tres primeros muestreos la clasificación fue de tipo IV (>3-4 Muy malo: altas concentraciones de materia orgánica, predominancia de procesos reductivos y presencia de productos industriales). Esta puntuación está asociada a actividades industriales intensivas aunque no es el caso del arroyo Arias que en cambio presentó una alta densidad de ganado que es lo que produciría un efecto tan marcado.

Tabla 3.7 Valores de IDP por estación del año y sitio.

Agrícola

Ganadero

\begin{tabular}{l|cccccc|}
\hline & Ch II & Ch III & DII & Ar & Nu & D I \\
Diciembre & 1,91 & 2,43 & & 3,59 & 2,42 & 1,77 \\
Febrero & 2,26 & 1,98 & 2,82 & 3,55 & 2,66 & 1,50 \\
Mayo & 2,05 & 1,97 & 2,46 & 3,06 & 2,14 & 2,21 \\
Agosto & 1,94 & 2,00 & 2,62 & 1,94 & 1,85 & 2,29 \\
Noviembre & 1,53 & 1,94 & 2,43 & 2,47 & 2,30 & 2,21 \\
Marzo & 1,86 & 2,22 & 2,67 & 1,88 & 2,08 & 2,94 \\
Promedio & $\mathbf{1 , 9 2}$ & $\mathbf{2 , 0 9}$ & $\mathbf{2 , 6 0}$ & $\mathbf{2 , 7 5}$ & $\mathbf{2 , 2 4}$ & $\mathbf{2 , 1 5}$
\end{tabular}


Se analizó la abundancia relativa (anexo) de las especies más representativas (10 $\%$ o más de abundancia en, por lo menos, una fecha de muestreo) y la clorofila $a$ en cada sitio de muestreo (fig. 3.11) de manera de poder relacionar la abundancia de estas especies con la biomasa algal del arroyo. Los arroyos agrícolas tienen valores relativos de clorofila a mayores a los ganaderos (fig. 3.7). En todos los casos sus concentraciones más altas aparecen en agosto sin importar el tipo de arroyos al que pertenezca la comunidad.

No aparecen claramente especies indicadoras de unos u otros sitios pero si es claro que en los agrícolas hay mayor predominio de Bacillariophyta mientras que en los ganaderos hay mayores proporciones de otros grupos: Cyanophyta, Chlorophyta y Euglenophyta. Los valores más elevados de clorofila $a$ en agosto no responden a una especie particular ya que se presenta un conjunto de especies, excepto en el Durazno II donde predomina Navicula veneta. También puede observarse que suele haber una proporción importante de especies minoritarias (del 10 al $60 \%$ ) esto significa que estas especies no alcanzan al $10 \%$ de la abundancia en ninguno de los muestreos.

De las 25 especies que aparecen con mayor representación en alguna de las fechas, 12 corresponden a Bacillariophyta, 7 a Cyanophyta, 3 a Chlorophyta y 3 a Euglenophyta. En los arroyos ganaderos las algas que se encontraron con mayor proporción fueron Raphidiopsis mediterranea y Planktotrix sp en el arroyo Arias; en el Nutrias Melosira varians, Oedogonium sp y Stigeoclonium sp; en el Durazno I Lyngbia sp; Gomphonema parvulum y Stigeoclonium sp y en los arroyos agrícolas la mencionada Navicula veneta en el Durazno II junto con Gomphonema affine y Characium sp. En el sitio La Choza II predominaron Synedra ulna y Oedogonium sp y en el sitio La Choza III Synedra ulna, Oedogonium sp y Stigeoclonium sp (fig. 3.11). 

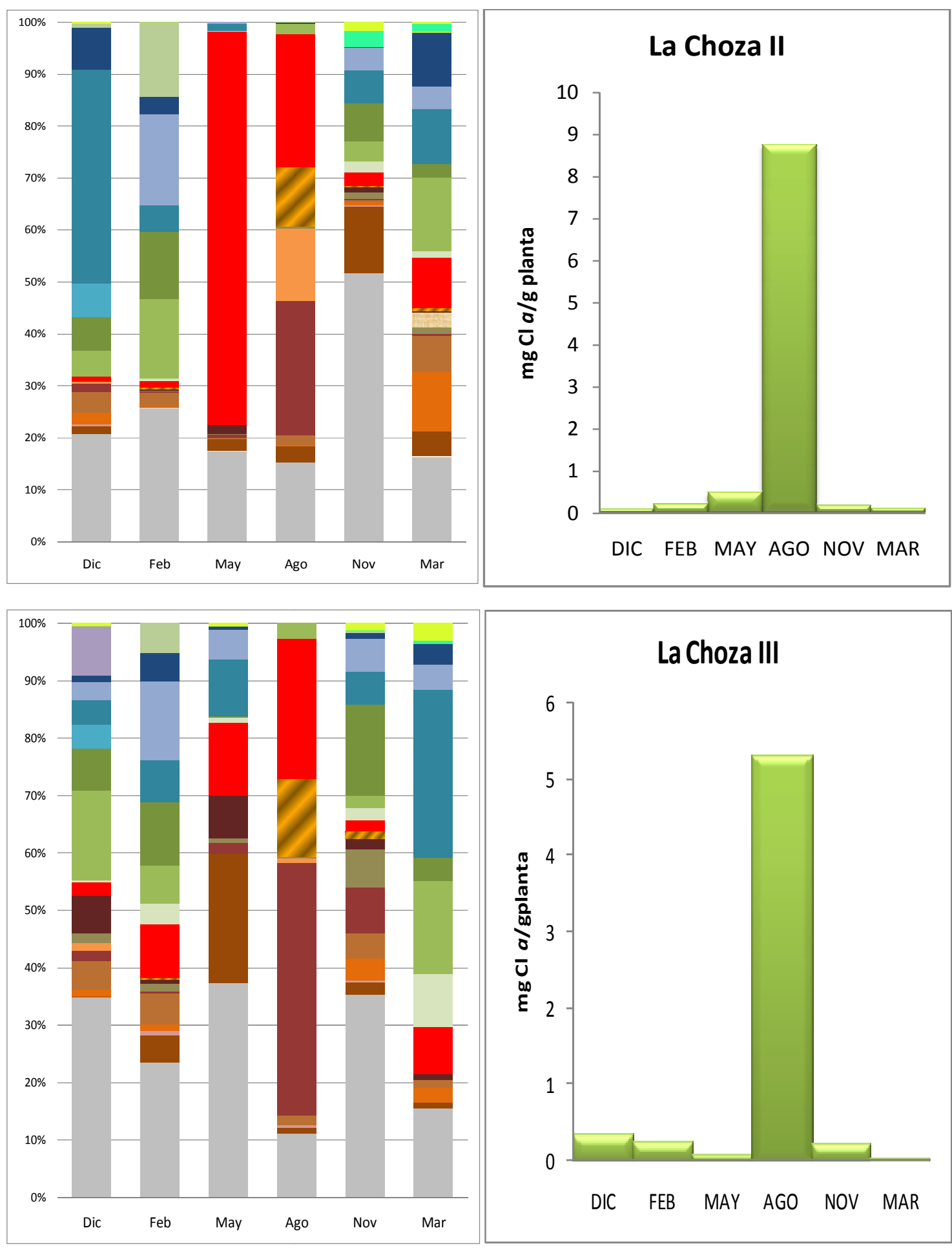

\begin{tabular}{|c|c|c|c|}
\hline especies minoritarias & Cyindiotheca closterium & - Eunotia pectinalis & Gomphonemaaffine \\
\hline - Gomphonema aff clavatum & - Gomphonemaparvilum & - Melosira varians & Navicula peregrina \\
\hline Novicula radiosa & Novicula veneta & - Nitschia palea & - Survella ovalis \\
\hline - Synedrauina & Characiumsp & Oedogoniumsp & Stigeoclonium sp \\
\hline Leptobingbyasp & Lyngbyaspl & Lyngbyasp2 & - Oscillatoria limnetica \\
\hline Phomidium sp & - Planktothrix $s p$ & Raphidiopsis mediterranea & Eugienasp2 \\
\hline Lepocincis salina & Trachelomonas sp3 & & \\
\hline
\end{tabular}



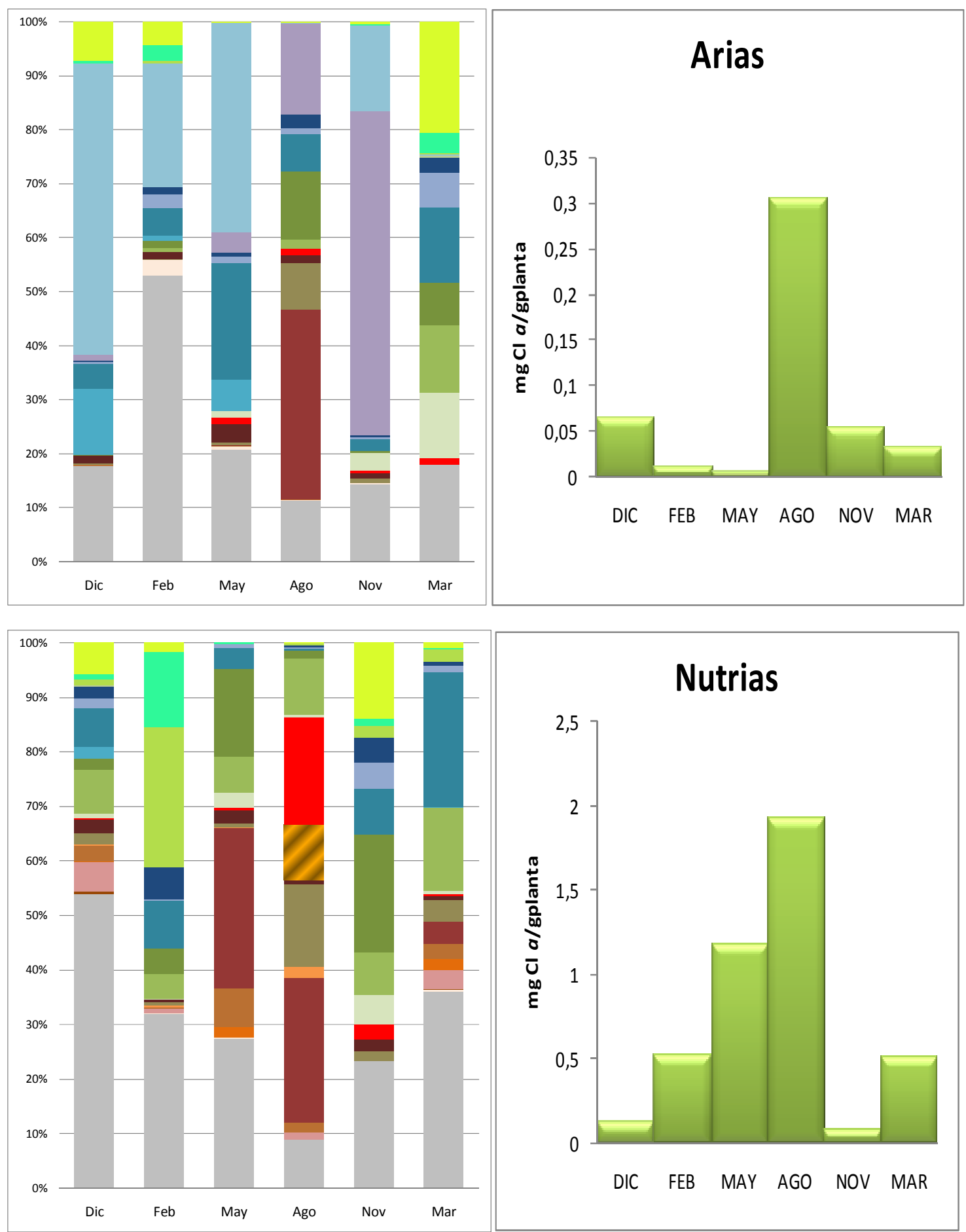

" especies minoritarias
- Gomphonema aff. clavatum
- Navicula radiosa
- Synedra uina
- Leptohngbya sp
- Phormidium sp
- Lepocinciis salina

Cylindiotheca closterium

- Gomphonemaparvium

- Navicula veneta

- Characiumsp

- Lyngbyaspl

- Planktothrix sp

- Trachelomonas sp3
- Gomphonemaafine

= Navicula peregrina

- Survella ovalis

- Stigeocionium sp

- Oscillatoria limnetica

= Euglenasp2 

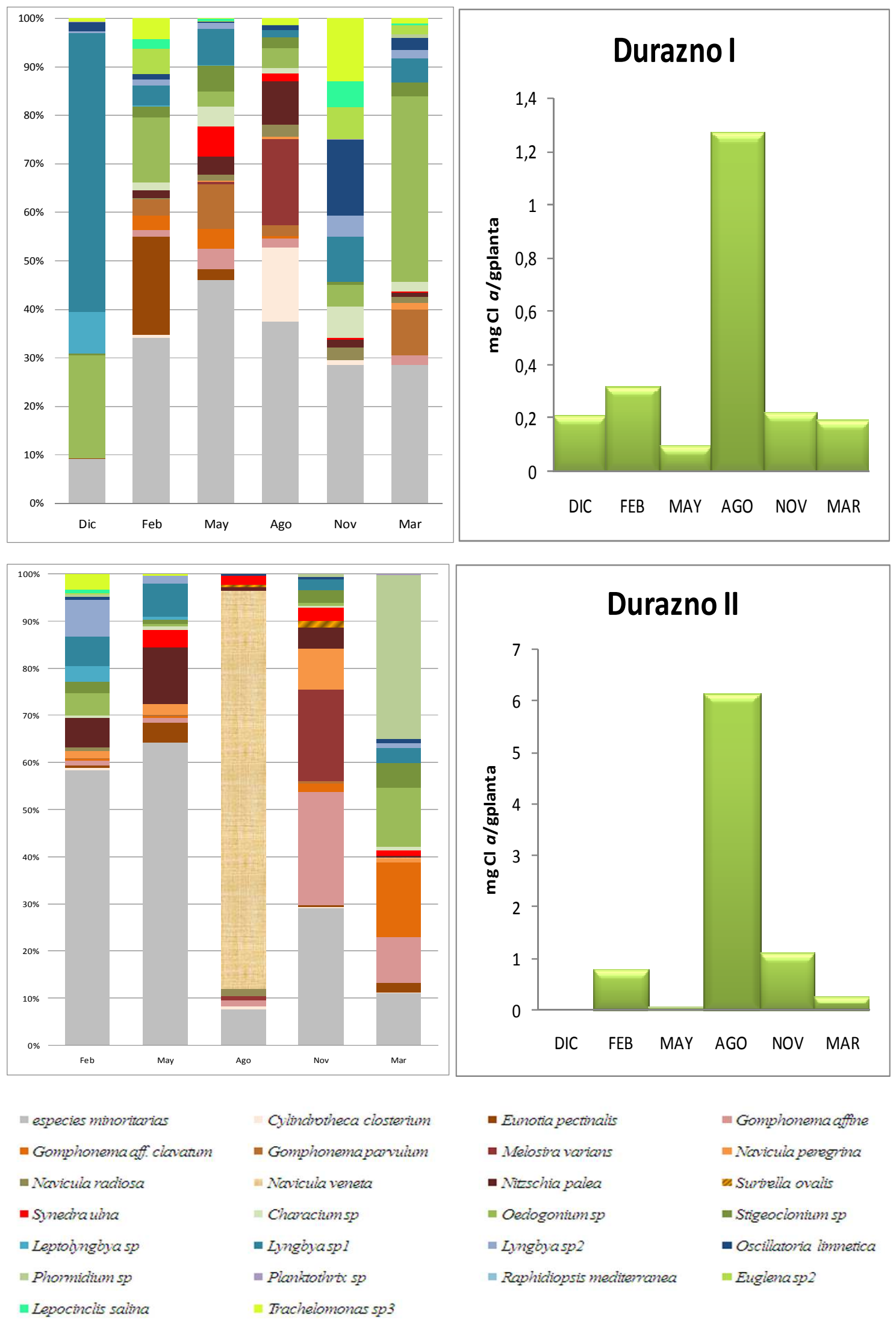

Figura 3.11. Abundancia relativa de las especies del perifiton para cada arroyo en cada fecha de muestreo y concentración de clorofila $a$. El color gris corresponde a especies de representación minoritaria, los tonos de verde a Chlorophyta y Euglenophyta, los azules a Cyanophyta y los naranjas a las Bacillariophyta. 


\section{Discusión}

Una de las principales características que diferencia a los arroyos agrícolas de los ganaderos es la concentración de clorofila $a$. Como se observa en la figura 3.7 las comunidades de arroyos que pasan cerca de campos agrícolas tienen valores de clorofila $a$ promedio mayores que aquellos donde se realiza ganadería. Resultados de este tipo fueron destacados también por otros autores (Heinonen 1984, Urrea y Sabater 2009).

Más allá de las diferencias de clorofila registradas en los arroyos con distintos tipo de uso es evidente una marcada estacionalidad en este parámetro que se incrementa en agosto junto con el desarrollo de clorofitas filamentosas. La estacionalidad también se refleja en el índice de autotrofia (IA) ya que en agosto se observa el paso de una comunidad predominantemente heterotrófica (generada por gran cantidad de material particulado en suspensión) a una comunidad autotrófica. Lo mismo muestra el sistema de Lakatos. Según este, el perifiton analizado en el período de este estudio puede considerarse de tipo inorgánico o inorgánico-orgánico. Giorgi y Feijoó (2010) muestran que los cambios más importantes en el grado de autotrofia del perifiton de un arroyo pampeano estarían asociados a la pluviosidad, aumentando la heterotrofia por incremento de materia orgánica detrítica depositada por arrastre. En nuestro caso, sin embargo, la variación del grado de autotrofia fue estacional ya que se incrementó en agosto por el excesivo desarrollo de filamentosas que ocurre previamente a las estaciones más lluviosas.

La agricultura intensiva está considerada como de alto riesgo de pérdidas de fósforo y nitrógeno hacia los cuerpos de agua. La eutroficación resultante del enriquecimiento en estos nutrientes reduce la biodiversidad acuática y estos efectos se ven exacerbados cuando las prácticas agrícolas se ejecutan en las cercanías de los cuerpos de agua y los suelos son poco permeables (Jarvie et al. 2010).

Varios autores sostienen que el uso agrícola puede impactar en la estructura de la comunidad del perifiton (McCormick y Stevenson 1998, Pan et al. 2000, McCormick et al. 2001). Las variables peso seco orgánico del perifiton y concentración de clorofila $a$ han sido usadas frecuentemente para caracterizar a la comunidad perifitica en respuesta a cambios en el ambiente (Biggs 1990, Sabater y Sabater 1992) aunque no siempre responden bien a los contenidos de nutrientes. 
En promedio el ganado vacuno podría defecar más de 12 veces al día con un peso de $2 \mathrm{~kg}$ por defecación. Cuando tienen acceso a cuerpos de agua superficiales para beber, estos animales defecan el $11 \%$ del tiempo en el agua, lo cual es equivalente a aproximadamente $3 \mathrm{~kg}$ de adición de fecas por animal por día. Las fecas del ganado contienen altos niveles de nitrógeno y fósforo: 0,34 y 0,092 kg/1000 kg de animal vivo por día, respectivamente. Además, la contaminación por nitrógeno y fósforo es comúnmente citada como impacto negativo del acceso del ganado sobre la flora y fauna residente en arroyos y humedales (Middleton 2010).

A pesar de ello, en este estudio las concentraciones de $\mathrm{N}$ y $\mathrm{P}$ no fueron variables importantes para definir sistemas agrícolas o ganaderos ni diferenciar sus intensidades, probablemente porque el grado de fertilización no fue tan elevado como en los casos de agricultura intensiva y porque el ganado también introduce $\mathrm{P}$ y $\mathrm{N}$ en los cuerpos de agua (Withers et al. 2007, Barsotti 2011).

Middleton (2010) comparó la comunidad perifítica entre arroyos con ganadería en los lotes aledaños con exclusión del ganado mediante alambrados y con libre acceso de los animales al cuerpo de agua. Este autor encontró que el acceso del ganado afecta significativamente la composición de la comunidad perifítica y que la riqueza en los sitios donde no hay acceso de ganado es $15 \%$ mayor a los sitios con acceso. En este estudio se encontró que la riqueza de los sitios ganaderos (con y sin acceso) fue $10 \%$ menor que los sitios agrícolas.

El mismo autor encontró que en los campos sin exclusión aumentan las algas verdes filamentosas pero disminuye la biomasa algal general. El alga verde cenobial Scenedesmus es un género muy común en estos arroyos sobre todo en los meses cálidos, es tolerante a la contaminación orgánica y se encuentra en abundancia en lugares ricos en nutrientes. En esta tesis el género se encontró en todos los sitios ya que son ricos en nutrientes. Una especie en particular Scenedesmus armatus v. bicauda fue exclusiva de sitios ganaderos pero presentándose con baja abundancia relativa por lo que no sería un buen indicador de uso de la tierra.

Middlenton (2010) también atribuye a mala calidad del agua la presencia de las diatomeas Navicula cryptocephala y $N$. radiosa, la cianobacteria filamentosa Oscillatoria y el euglenoideo Trachelomonas. Estos organismos, a pesar de estar presentes en los sitios estudiados no se asociaron a ningún uso de la tierra específico, 
excepto Trachelomonas sp3 que participa en la similitud de los sitios ganaderos. En concordancia con este hallazgo, Garduño Solórzano et al. (2011) manifiestan que el género Trachelomonas es un típico indicador de medianas a altas concentraciones de materia orgánica en el agua y especialmente asociado con altas concentraciones de amonio.

Debe destacarse además que en todos los sitios se encontraron siete de los ocho géneros que según Palmer (1969) son significativos en casos de alta contaminación orgánica (Euglena, Oscillatoria, Chlamydomonas, Scenedesmus, Nitzschia, Navicula y Stigeoclonium). Nitzschia palea es considerada por Lange-Bertalot y Watanabe (Round 1993) como heterotrófica y una de las especies más tolerantes a contaminación severa por nutrientes. $N$. palea además es la segunda especie en orden decreciente de tolerancia a la contaminación orgánica según Palmer (1969). Esta especie aparece como importante en la similitud de los sitios ganaderos en este estudio. Por otro lado, Raphidiopsis mediterranea, exclusiva del sitio ganadero Arias (con altos contenidos de material particulado en suspensión y ácidos húmicos que reducen la intensidad lumínica por dispersión de la luz entre 300 y $500 \mathrm{~nm}$ (Conzzono 2010)), es considerada por Reynolds et al. (2002) como tolerante a condiciones de baja intensidad lumínica.

Tell y Conforti (1986) también destacan que muchos euglenoideos son particularmente abundantes en aguas estancadas ricas en materia orgánica y de alto contenido trófico como los sitios cercanos a tierras agrícolas o los expuestos a fecas animales. En este estudio, si bien se encontraron euglenoideos en todos los sitios fueron muy abundantes en el arroyo Nutrias, uno de los sitios con ganado.

Las variaciones halladas en la comunidad perifítica son mayores que las de las hidrófitas. La gran plasticidad y capacidad de adaptación de estas últimas les permitirían prosperar aún en ambientes poco favorables como por ejemplo Ludwidgia peploides que en este estudio se encontró en todos los sitios de muestreo. Feijoó y Lombardo (2007) hallaron que las hidrófitas no presentaban diferencias en distintas regiones de la provincia de Buenos Aires donde sí se registraban diferencias a nivel de características fisicoquímicas y de uso de la tierra. Esto sugiere que su potencial como indicadores del estado de cuerpos de agua de una misma región probablemente sea muy reducido. Pese a ello, en este estudio se observó menor variedad de especies de hidrófitas en tramos donde se realiza ganadería en los lotes marginales que donde se realiza agricultura 
quizás debido al sobrepastoreo y pisoteo por parte del ganado que produciría destrucción del hábitat para las hidrófitas.

Los arroyos estudiados tienen como características comunes ser alcalinos y con altas conductividades. Excepto en el período de crecida las velocidades no superaron los $0,1 \mathrm{~m} / \mathrm{s}$ y las profundidades fueron menores a $0,5 \mathrm{~m}$. La DQO y la $\mathrm{DBO}_{5}$ son indicativos de una baja concentración de sustancias orgánicas disueltas. La primera, se asocia principalmente a la presencia de ácidos húmicos. Las distintas formas del nitrógeno presentan concentraciones menores que otros arroyos de la región. En cambio, los fosfatos se encuentran en el mismo rango (Feijoó y Lombardo 2007). El rango de variación de los parámetros medidos se relaciona con la variación estacional, las precipitaciones y las características morfométricas de cada sitio, más que con el uso predominante de la tierra. Aunque el ganado aportaría materia orgánica y nutrientes al cuerpo de agua no se encontraron diferencias entre los sitios quizás debido al aporte de nutrientes por parte de la fertilización agrícola y la degradación de la cobertura vegetal por el uso de herbicidas. Por lo tanto, las variables físico-químicas no serían buenos indicadores para diferenciar el ingreso de nutrientes debido al uso ganadero o agrícola.

Los arroyos pampeanos tienen normalmente altos contenidos de nutrientes (Feijoó y Lombardo 2007) y no serían limitantes, lo que determina que no haya períodos especiales de mayor demanda de nutrientes por parte de las algas. Sin embargo la variación de las concentraciones y relaciones de nutrientes predominantes en el curso de agua influye en la abundancia relativa de los distintos grupos de algas y otros integrantes del perifiton como se desprende de los resultados de este estudio.

Los resultados sintetizados en la figura 3.6 muestran que los eventos de alto caudal modifican las características físico-químicas de los arroyos de cabecera del Río Reconquista. Por otro lado, en la figura 3.4 se muestra la respuesta diferencial de estos parámetros en arroyos con distintas áreas de drenaje lo que produce grandes cambios en el material transportado por las microcuencas. En el contexto de la conservación y gestión de la cuenca de este río, la información proporcionada aquí debiera considerarse para evitar los efectos negativos de la eutrofización y sedimentación resultantes de eventos de alto caudal en el área de estudio así como para evitar posibles efectos de proliferaciones de algas que pueden tener características nocivas aún para el propio ganado que las utiliza. 
Cuando las lluvias suceden durante varios días, los suelos se colmatan perdiendo su capacidad de infiltración y comportándose como suelos impermeables, por lo que los parámetros fisicoquímicos muestran una homogeneidad de sitios (fig.3.6) donde no se pueden distinguir los tipos de usos agropecuarios. Esta homogeneidad se debe probablemente al drenaje y escorrentía de los solutos desde los suelos a los cuerpos de agua cercanos. De hecho, el escurrimiento aparece por las precipitaciones y la conectividad hidrológica de la superficie cercana entre tierras agrícolas y el arroyo (Houser et al. 2006).

Las crecidas son conocidas por aumentar las concentraciones de nutrientes en los arroyos agrícolas (Arreghini et al. 2005; Mugni et al. 2005). Los suelos en el área de estudio tienen una estructura frágil debido a la abundancia de iones de sodio. Esta característica, junto con las zonas ribereñas sin cobertura vegetal por la acción de biocidas o el pisoteo del ganado puede haber favorecido la eutrofización de la cuenca superior del río Reconquista. Además, el aumento en las cargas de ácidos húmicos observada en condiciones de alto caudal sugiere la pérdida de nutrientes por la erosión del suelo asociadas con el drenaje de las zonas ribereñas adyacentes. Esto coincide con Chagas et al. (2004) quienes demostraron experimentalmente que los suelos desnudos aumentan la escorrentía superficial y el movimiento de las partículas de forma vertical y horizontal. Los resultados del ANOVA realizado con las variables fisicoquímicas no mostraron diferencias significativas entre sitios. Sin embargo, los sitios ganaderos tendieron a presentar una mayor concentración de ácidos húmicos que quizás no fue significativa debido a la dispersión producto de las diferencias de precipitaciones y caudal de las fechas de muestreo.

Acuña y Dahm (2007) muestran que durante los períodos de baja precipitación, la composición química de las aguas que llevan los arroyos depende de la geología de las cuencas, mientras que durante la temporada de lluvias el predominio de la escorrentía superficial puede cambiar la composición química del agua del arroyo. En nuestro estudio, durante la inundación se registraron menores valores de cloruros, valores altos de material particulado en menor proporción al valor del caudal, probablemente debido a la dilución y mayores concentraciones de fósforo en agua producidas indudablemente por el arrastre desde campos aledaños tal como sugieren Arreghini et al. (2005) y Mugni et al. (2005). 
Ellison y Brett (2006) realizaron un estudio en un área con suelos saturados de fósforo con drenaje insuficiente. Estos autores observaron un incremento del fósforo particulado en aguas de arroyos al comienzo de una inundación, el cual atribuyeron a la erosión del suelo. Por otra parte, Arreghini et al. (2005) observaron un aumento del PRS cuando el caudal disminuye. A pesar de las altas concentraciones de fósforo durante las crecidas, su disponibilidad para las algas y macrófitas es limitada. Además la captación del fósforo bajo el estrés generado por las crecidas disminuye (Roberts et al. 2007).

La cantidad de $\mathrm{N}$ en la escorrentía superficial está fuertemente influenciada por una combinación del uso de la tierra y las prácticas de manejo, el tipo de suelo y las condiciones climáticas (Hooda et al. 2000). Un aumento en las concentraciones de nitratos al comienzo de las escorrentías producidas por tormenta fue reportado por Jarvie et al. (2008). Pionke et al. (1999) informaron que las concentraciones de nitratos más bajas fueron para el caudal base (5,36 mg 1-1) y las más altas para un caudal base elevado (7,12 mg. 1-1) y no para un caudal alto producto de las crecidas.

El volumen de poros y la permeabilidad del cauce disminuyen durante las crecidas máximas. Los iones nitrato procedentes de la lixiviación de abonos llegan a las aguas subterráneas debido a su alta movilidad, lo que aumenta la concentración de nitratos en el canal (Bernal et al 2002, Brunke y Gonser 1997). La sincronicidad entre la llegada de $\mathrm{N}$ y $\mathrm{P}$ desde los campos y los períodos de mayor demanda biológica de nutrientes junto con las variaciones de caudal son una clave importante para el impacto por eutroficación (Jarvie et al. 2006).

Biggs (1995) observó que la variación estacional en la clorofila a está más definida en lugares sin perturbaciones por crecidas. Asegura que el desarrollo del perifiton está establecido primariamente por la frecuencia de crecidas y que la interacción del perifiton con el estado de nutrientes de los arroyos está determinada por la geología de la cuenca y el uso de la tierra. En nuestro caso la variación estacional de la clorofila a y la diferencia de este parámetro entre sitios se observó claramente, salvo en el mes de diciembre donde las lluvias repetidas dan una respuesta homogénea entre sitios (fig. 3.11).

De todas formas, el hecho de que la concentración de fósforo aumentó en mayor proporción que el caudal bajo condiciones de inundación sugiere que su presencia en los arroyos estaría relacionada con la fertilización de los campos adyacentes. Jarvie et al. 
(2008) afirman que las concentraciones más altas de PRS (y las altas cargas de fósforo) indican fuentes difusas de PRS, movilizada por el alto caudal. Los mismos autores especifican que las mayores cargas de nutrientes durante el caudal alto indican que a largo plazo las cargas de $\mathrm{P}$ y $\mathrm{N}$ estaban dominadas por una fuente difusa de estos nutrientes.

En síntesis, tanto la ganadería como la agricultura serían fuentes de producción de $\mathrm{P}$ y $\mathrm{N}$ aunque no podrían diferenciarse estas actividades con los parámetros físicoquímicos. El ganado puede incorporar dichos nutrientes directamente al agua o pueden ingresar posteriormente por escorrentía del mismo modo que sucede en los campos agrícolas. Probablemente las mayores diferencias entre tramos que atraviesan campos agrícolas o ganaderos se den en aquellos casos donde se permite el ingreso de animales (Arias, Nutrias, Durazno I) que aportarían además materia orgánica y realizarían otra serie de perturbaciones directamente dentro del cuerpo de agua afectando claramente la biomasa y riqueza del perifiton. 


\section{Capítulo 4}

Efectos de la contaminación difusa en arroyos sobre el perifiton en sustratos artificiales 


\section{Introducción}

El monitoreo del estado ecológico de los sistemas fluviales se ha basado tradicionalmente en el uso de la calidad del agua y medidas estructurales como la composición o la abundancia de las comunidades biológicas (algas, macrófitas, invertebrados acuáticos y peces) (Boulton 1999). Los indicadores funcionales se enfocan en medir las tasas de diferentes procesos ecológicos, tales como la producción primaria o secundaria de una población o una comunidad. Si bien estos procesos han sido rara vez usados en biomonitoreo en el pasado, los nuevos avances tecnológicos facilitan la medición de algunos indicadores funcionales permitiendo incorporarlos en los protocolos de evaluación ambiental (APHA 2005). Esto representa un paso trascendente en la ecología aplicada proveyendo indicadores ecológicos que miden directamente las funciones que tiene un ecosistema y cómo estas son alteradas por actividades antrópicas (Gessner y Chauvet 2002, Young et al. 2008).

Existe un debate vigente en la literatura científica sobre si el número y tipo de especies presentes reflejan el funcionamiento de un ecosistema o si esa estructura particular controla su funcionamiento (Duffy 2002, Cebrian et al. 2009). En cualquier caso, está claro que los atributos estructurales y funcionales de los ecosistemas están fuertemente relacionados y ambos describen diferentes aspectos de la misma entidad. La adecuada caracterización de los ecosistemas y su condición ecológica requiere tanto de información en su estructura como en su funcionamiento (Gessner y Chauvet 2002) debido a que factores de estrés ambiental pueden causar cambios en la estructura pero no en la función, en la función pero no en la estructura, o bien en ambas (Matthews et al. 1982, Bunn y Davies 2000, Riipinen et al. 2008).

Las determinaciones de los parámetros estructurales y funcionales de este capítulo se llevaron a cabo enteramente en comunidades desarrolladas sobre sustratos artificiales debido a que éstos permiten, entre otras ventajas, homogeneizar los tiempos de colonización y estandarizar de manera fácil a una superficie similar y conocida las variables de medición. Por otro lado, el sustrato artificial, al ser inerte nos asegura que los parámetros funcionales estimados correspondan únicamente al perifiton permitiendo además aislar la comunidad del medio circundante para las estimaciones. Finalmente, y dado que se corroboró bajo microscopio que la composición algal en los sustratos naturales fue similar a aquella desarrollada sobre los sustratos artificiales, consideramos 
que nuestros resultados son extrapolables a la comunidad natural.

La comunidad adherida está generalmente distribuida de manera muy heterogénea y es más difícil de cuantificar en términos absolutos cuando se trabaja con sustratos naturales (Sand-Jensen y Borum 1991). El desarrollo de estudios acerca de la comunidad perifítica adherida a sustratos artificiales estratégicamente colocados por el investigador es un intento de minimizar los inconvenientes en la toma de muestras y cuantificación de los atributos de la comunidad (Cattaneo y Kalff 1979). Por otro lado, tanto el tipo de sustrato como sus propiedades físicas y químicas afectan las propiedades del perifiton (Ver cap.3). La utilización de sustratos artificiales inertes facilita el diseño experimental ya que permite conocer con exactitud el tiempo de colonización de la comunidad. Además facilita su cuantificación con el consiguiente beneficio en los análisis numéricos y estadísticos posteriores. Por otro lado, posibilita el análisis de la interacción de los organismos adheridos exclusivamente con la columna de agua y no con el sustrato, sacrificando a veces el realismo por la simplicidad y reproducibilidad (Kalff 2003).

La contaminación por actividades agropecuarias es difusa. Como tal, puede ingresar a lo largo de las márgenes del cuerpo de agua pero no presentar una concentración especialmente alta en alguna parte del segmento estudiado. La contaminación agrícola adquiere mayor importancia en los meses de laboreo de la tierra, siembra y cosecha mientras que la provocada por la acción del ganado es más constante durante el año ya que se trata de áreas marginales donde no se realiza rotación. Sin embargo, cada una de las actividades puede tener distinto grado de intensidad y por ende afectar de modo diferencial a la comunidad perifítica. La hipótesis que se intentó poner a prueba en este capítulo fue: los cambios producidos por actividades agropecuarias repercutirán en las características estructurales y/o funcionales de la comunidad perifítica de acuerdo con la intensidad y tipo de contaminación difusa producida.

Se esperaba que la contaminación difusa afectara primariamente a los parámetros funcionales y sólo cuando su intensidad fuera mayor, a los parámetros estructurales de la comunidad.

Por ello el objetivo de este capítulo fue evaluar la respuesta de la comunidad perifítica desarrollada sobre sustratos artificiales en arroyos sometidos a distinta 
intensidad de explotación agrícola y ganadera.

\section{Materiales y Métodos}

De los tramos descriptos en el capítulo 3 se seleccionaron cinco de ellos. Dos ubicados sobre predios con actividad agrícola intensiva (La Choza III y Durazno II), dos en predios con ganadería intensiva sin exclusión del ganado (Nutrias y Durazno I) y uno en un predio con actividad agrícola de baja intensidad (La Choza II) (Ver fig 2.2). Además se seleccionó un predio que es atravesado por el arroyo Las Flores con uso ganadero en baja intensidad (Ver cap. 2).

Se realizaron experimentos para seleccionar un sustrato artificial adecuado para la colonización por parte de las algas epífitas teniendo en cuenta su similitud con el sustrato natural (hidrófitas), la posibilidad de tener muchas repeticiones y que queden disimulados para evitar actos de vandalismo. Finalmente, para el desarrollo de los estudios que se describen en el presente capítulo se utilizaron como sustrato artificial numerosas cuerdas de nylon negro de $0,1 \mathrm{~cm}$ de diámetro atados por ambos lados a estacas fijas al lecho (fig. 4.1)

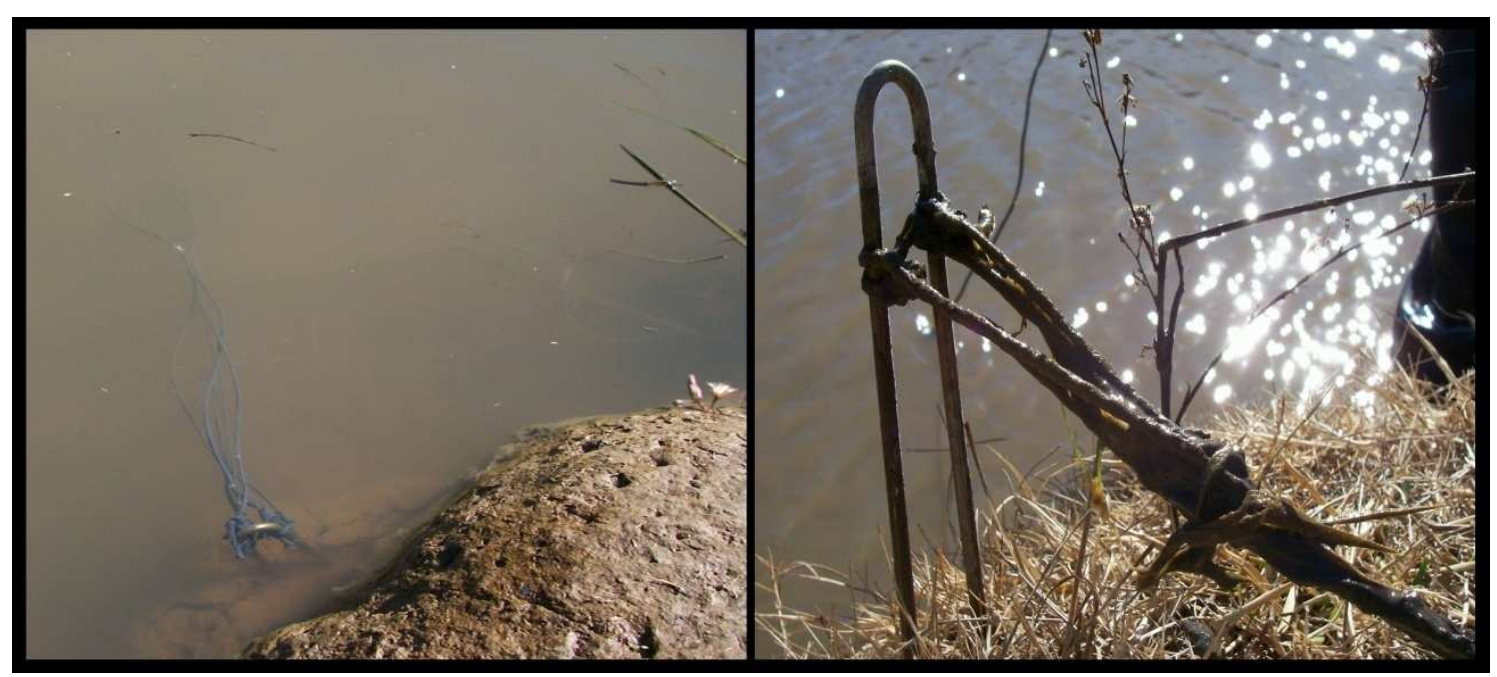

Figura 4.1. Foto de sustrato artificial colocado en el arroyo (izquierda) y ya colonizado (derecha)

Se colocaron tres set de sustratos artificiales en un tramo medio (100 m de longitud) de cada predio seleccionado. Se permitió la colonización durante un lapso de 45 días y luego se tomaron muestras (10 cm de cuerda) del perifiton desarrollado sobre los sustratos (tres réplicas por sitio para cada determinación). 
Se llevaron a cabo tres ensayos utilizando el sustrato artificial seleccionado en otoño (Junio 2008), primavera (Octubre 2008) y verano (Febrero 2009). Cada fecha se asoció a una actividad agrícola determinada: rastrojo, fertilización y cosecha respectivamente.

En cada muestreo se registraron las concentraciones de material particulado y conductividad así como nutrientes (fósforo reactivo soluble, amonio, nitrito y nitrato), temperatura, $\mathrm{pH}$, cloruros y se realizaron estimaciones de ácidos húmicos, oxígeno disuelto, DQO y $\mathrm{DBO}_{5}$ (Ver cap. 2).

Los parámetros estructurales que se utilizaron para evaluar la respuesta del perifiton fueron: Biomasa total estimada como peso seco (orgánico e inorgánico), Clorofila $a$ y Feopigmentos, Polisacáridos, Nitrógeno y Fósforo Total, además se calcularon índices descriptores de la comunidad como el índice autotrófico y el índice de Lakatos (Ver cap. 2).

Los parámetros funcionales del perifiton se centraron en dos estimaciones.

a. Metabolismo: producción y respiración del perifiton midiendo las variaciones de oxígeno disuelto mediante porciones de la comunidad $(10 \mathrm{~cm}$ cuerda) colocadas en botellas de $\mathrm{DBO}_{5}(300 \mathrm{ml})$ oscurecidas (respiración) o expuestas a la luz (producción) (Fig. 4.2). Se obtiene así la Producción Neta (PN), Respiración (R) y Producción Bruta (PB) expresadas como $\mathrm{mgO}_{2}$ (producido o consumido)/hora.m².

b. Actividad de exoenzimas: $\beta$-glucosidasa, fosfatasa alcalina y celobiohidrolasa en un extracto de la comunidad obtenido luego de la sonicación de trozos de $10 \mathrm{~cm}$ de cuerda. 


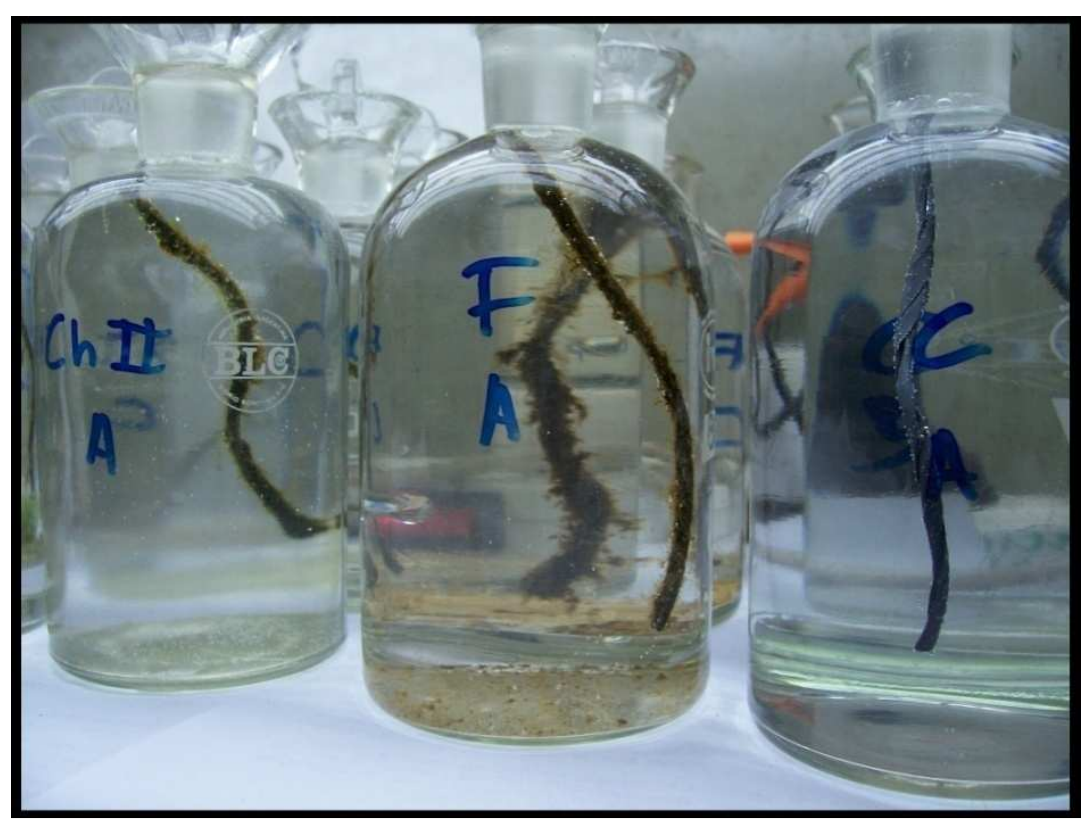

Figura 4.2. Foto de botellas de $\mathrm{DBO}_{5}$ con sustrato artificial. Estimación de Producción Neta

El número de réplicas, la forma de separar el perifiton de su sustrato y demás especificaciones se encuentran detalladas en el Cap. 2. Todos los parámetros del perifiton se refirieron a la superficie colonizada por el mismo. Esta superficie se calculó asimilando el trozo de cuerda de $10 \mathrm{~cm}$ de longitud y $0,1 \mathrm{~cm}$ de diámetro a la superficie de un cilindro.

Se realizó un análisis discriminante con las variables fisicoquímicas y otro con las variables del perifiton para explorar la existencia de diferencias entre los sitios seleccionados.

Se realizó la toma de muestras en tres estaciones del año, otoño (11/06/08, caudal aprox. 7-14 1/seg.), primavera (08/10/08, caudal aprox. <1 1/seg.) y verano (25/02/09, caudal aprox. 11-20 l/seg). La reducción promedio de luz registrada en el arroyo La Choza fue del $50 \%$ aproximadamente en todas las ocasiones de muestreo. Esta reducción se debe a la captación de la luz producto de las sustancias disueltas en el agua. En todos los casos los sustratos artificiales se colocaron 45 días antes para permitir el desarrollo de la comunidad perifítica. Sólo en el muestreo de verano hubo precipitaciones durante los días de colonización de los sustratos (fig.4.3). 


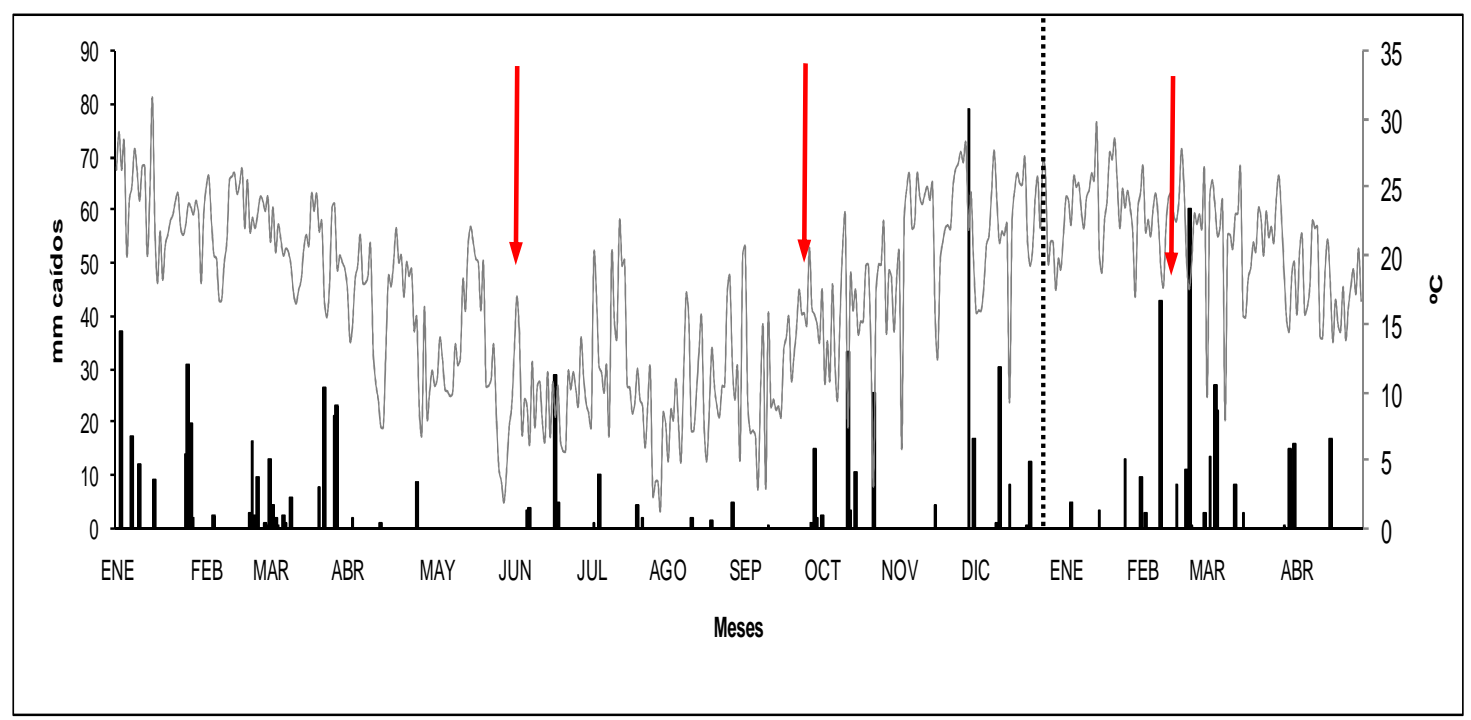

Figura 4.3. Precipitaciones (Eje primario) y temperatura media (Eje secundario) durante el período de muestreos. Las flechas rojas indican las fechas de cada muestreo y la línea de puntos delimita el año 2008

\section{Resultados}

\section{Parámetros fisicoquímicos}

En la tabla 4.1 se muestran los valores medios junto a su rango de variación de los parámetros fisicoquímicos registrados en cada fecha de muestreo. $\mathrm{El} \mathrm{pH}$ en otoño y primavera fue alto mostrando agua medianamente alcalina con un rango de 8,14-9,09. Sin embargo, en el muestreo de verano descendieron hacia valores circumneutrales $(6,31-7,73)$. Lo mismo sucedió con la conductividad eléctrica debido a la estacionalidad asociada al régimen de lluvias, aunque el sitio con menor conductividad fue el Durazno I. La temperatura del agua varió entre 8 y 31 grados de acuerdo a la estación del año. El oxígeno disuelto presentó valores desde deficitarios $(3,3 \mathrm{mg} / 1,30,6 \%$ saturación) hasta valores de sobresaturación (16,4 mg/l, 179,5 \% saturación). En el muestreo de verano se registraron los menores valores de oxígeno disuelto en todos los sitios con un promedio de 4,9 $\pm 0,5 \mathrm{mg} / \mathrm{l}$. Por otro lado, los valores máximos hallados para $\mathrm{DBO}_{5}$ y DQO fueron de 7,1 mg/l y 98,3 mg/l respectivamente, ambos corresponden al sitio Durazno I. Los valores de $\mathrm{DBO}_{5}$ se encuentran la mayoría de la veces por encima de los niveles guía para la calidad del agua en función de cualquiera de los usos del recurso según la Secretaría de Recursos Naturales y Desarrollo Sustentable $(<3 \mathrm{mg} / \mathrm{l})$. En los sólidos en suspensión se observó además de la variación estacional diferencia entre sitios siendo 
Tabla 4.1. Valores medios y desvíos estándar $(\mathrm{N}=9)$ de las variables estimadas en los distintos sitios de muestreo período 2008-2009

\begin{tabular}{|c|c|c|c|c|c|c|}
\hline Sitio & La Choza II & La Choza III & Nutrias & Durazno I & Durazno II & Las Flores \\
\hline $\mathrm{PRS} \mathrm{mgP}-\mathrm{PO}_{4}^{-3} / 1$ & $0,08 \pm 0,08$ & $0,14 \pm 0,09$ & $0,12 \pm 0,13$ & $0,12 \pm 0,13$ & $0,08 \pm 0,09$ & $0,36 \pm 0,12$ \\
\hline Amonio $\mu \mathrm{gN}-\mathrm{NH}_{4}{ }^{+} / 1$ & $4,57 \pm 7,12$ & $26,36 \pm 21,96$ & $7,74 \pm 14,93$ & $98,98 \pm 147,44$ & $11,28 \pm 9,41$ & $33,03 \pm 16,99$ \\
\hline Nitratos $\mathrm{mgN}-\mathrm{NO}_{3}{ }^{-} / 1$ & $1,05 \pm 0,70$ & $0,74 \pm 0,36$ & $0,56 \pm 0,41$ & $1,06 \pm 0,98$ & $0,16 \pm 0,16$ & $3,34 \pm 1,91$ \\
\hline Cloruros $\mathrm{mgCl}^{-} / 1$ & $26,17 \pm 13,28$ & $62,67 \pm 17,72$ & $15,49 \pm 12,83$ & $8,25 \pm 7,28$ & $24,45 \pm 17,78$ & $9,75 \pm 4,38$ \\
\hline Ácidos Húmicos absorbancia & $0,13 \pm 0,11$ & $0,09 \pm 0,07$ & $0,25 \pm 0,17$ & $0,30 \pm 0,07$ & $0,11 \pm 0,08$ & $0,05 \pm 0,04$ \\
\hline $\mathrm{pH}$ & $8,18 \pm 0,76$ & $8,34 \pm 0,49$ & $8,19 \pm 1,17$ & $7,69 \pm 1,04$ & $7,98 \pm 1,09$ & $8,07 \pm 0,27$ \\
\hline Temperatura ${ }^{\circ} \mathrm{C}$ & $17,97 \pm 6,03$ & $14,52 \pm 5,46$ & $16,40 \pm 6,33$ & $19,07 \pm 6,45$ & $21,53 \pm 8,24$ & $18,73 \pm 6,85$ \\
\hline Conductividad $\mu \mathrm{S} / \mathrm{cm}$ & $1246,67 \pm 435,52$ & $1578,67 \pm 470,22$ & $1077,33 \pm 735,12$ & $439,33 \pm 226,36$ & $1090,33 \pm 621,78$ & $980,33 \pm 91,12$ \\
\hline $\mathrm{OD} \mathrm{mgO}_{2} / 1$ & $11,05 \pm 4,37$ & $10,33 \pm 4,92$ & $8,43 \pm 2,98$ & $6,08 \pm 3,02$ & $12,20 \pm 5,72$ & $9,41 \pm 2,98$ \\
\hline Peso Seco g/l & $38,54 \pm 23,89$ & $14,28 \pm 7,56$ & $192,13 \pm 168,46$ & $366,96 \pm 304,37$ & $48,15 \pm 45,28$ & $11,54 \pm 11,28$ \\
\hline
\end{tabular}


Durazno I el sitio que presentó los mayores valores y Las Flores los menores. El fósforo reactivo soluble alcanzó los valores más altos en el verano aunque en el sitio Las Flores la concentración de fósforo fue superior a los otros en todas las estaciones. Los nitratos, nitritos y amonio presentaron promedios de 0,$9 ; 0,02$ y $16,8 \mathrm{mgN} / 1$ respectivamente. El elevado promedio de amonio se debe a que el sitio Durazno I presentó valores muy por encima de los demás sitios en otoño. El caudal durante este período de muestreo fue menor respecto al período anterior (Cap. 3) y por lo tanto también la velocidad del agua. Esto fue así para todos los sitios por igual aunque el sitio Durazno I al ser de bajo caudal se vio más afectado.

Se realizó un análisis discriminante con las variables fisicoquímicas para explorar la existencia de diferencias entre los sitios seleccionados (fig.4.4).

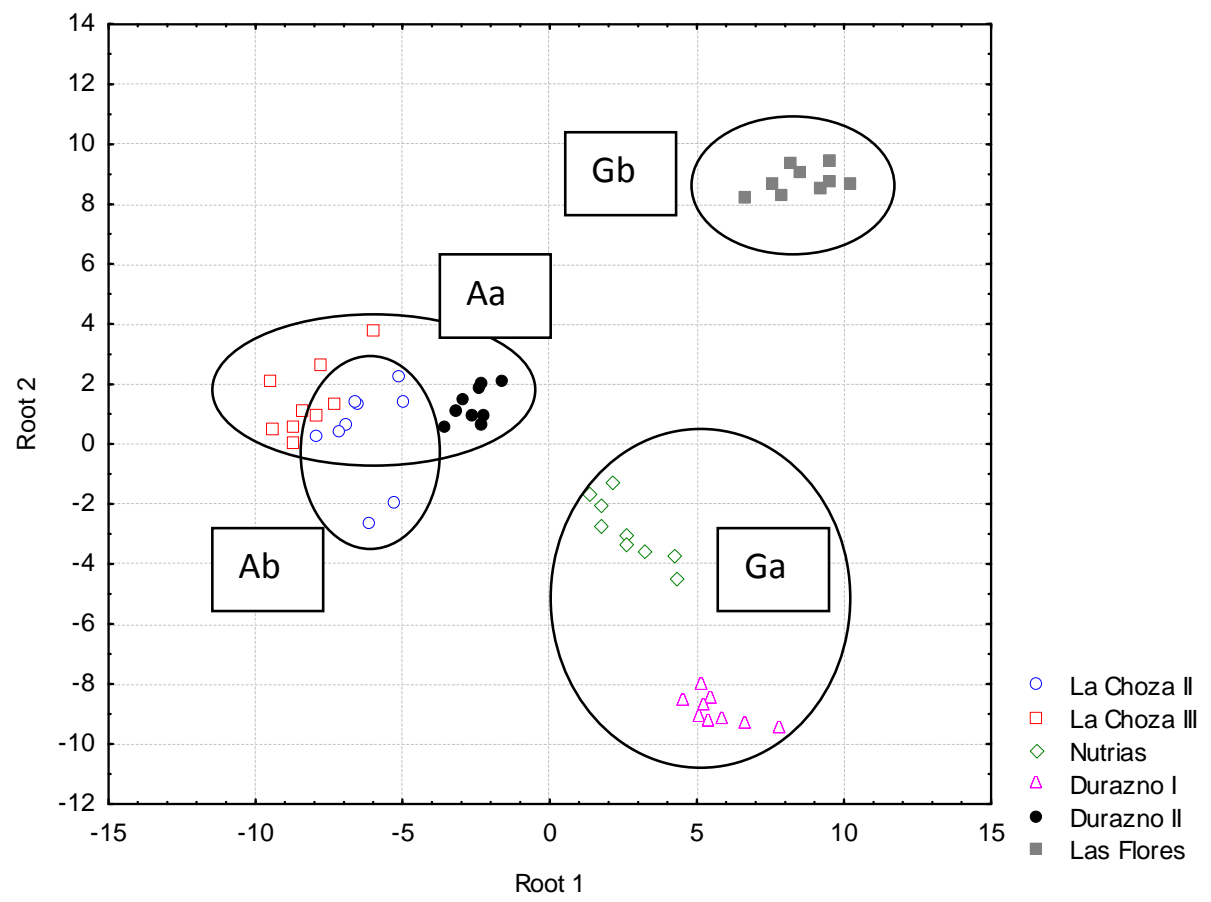

Figura 4.4 Ordenamiento de los sitios obtenido con análisis discriminante a partir del empleo de las variables fisicoquímicas. Período 2008-2009. Se destacan con elipses los diferentes usos (Aa, Agrícola alta intensidad; Ab, Agrícola baja intensidad; Ga, Ganadero alta intensidad; Gb, Ganadero baja intensidad)

La matriz de clasificación muestra una gran distancia entre los sitios y destaca al arroyo Las Flores como el más distante de los otros sitios. La mayor distancia estimada por el método del cuadrado de Mahalanobis $(321,15)$ es entre los sitios Las Flores y Durazno I. Las variables más importantes para la diferenciación fueron el $\mathrm{pH}$ y la 
conductividad eléctrica y en segundo lugar el Fósforo Reactivo Soluble ( $\mathrm{p}<0,0001)$. Los sitios con ganadería se encuentran distantes de los agrícolas. Además se encuentran más dispersos que los cultivados. Los primeros se localizan a la derecha del gráfico y los segundos a la izquierda.

Considerando la importancia de los ácidos húmicos se realizó un ANOVA entre sitios teniendo en cuanta esta variable (tabla 4.2)

Tabla 4.2. Diferencias considerando la variable ácidos húmicos entre sitios. n.s., no significativo, * $\mathrm{p}<0,05, * *, \mathrm{p}<0,01$

Sitios La Choza II La Choza III Nutrias Durazno I Durazno II

\begin{tabular}{l|ccccc|}
\hline La Choza III & n.s. & & & & \\
Nutrias & n.s. & $* *$ & & & \\
Durazno I & $* *$ & $* *$ & n.s. & & \\
Durazno II & n.s & n.s. & $*$ & $* *$ & \\
Las Flores & n.s. & n.s. & $* *$ & $* *$ & n.s. \\
\hline
\end{tabular}

El análisis a posteriori Tukey para esta variable indica diferencias altamente significativas en la concentración de ácidos húmicos entre los sitios ganaderos de alta intensidad y los otros sitios con otros usos e intensidades. Sin embargo, no se encontraron diferencias significativas entre el sitio Nutrias (Ga) y La Choza II ( $\mathrm{Ab}$ ).

\section{Parámetros del perifiton}

En la tabla 4.3 se muestran los rangos de variación de los parámetros estructurales y funcionales del perifiton registrados durante todo el período de muestreo.

La concentración de clorofila $a$ fue diferente en cada sitio aunque los valores más bajos para todos ellos se encontraron en verano. Los arroyos Nutrias y Durazno I sin embargo, fueron los sitios con los menores valores de clorofila $a$ para cualquiera de los muestreos. El arroyo Durazno I nunca superó los $17 \mathrm{mg} / \mathrm{m}^{2}$.

El Índice autotrófico (IA) mostró valores heterotróficos para los sitios ganaderos de alta intensidad mientras que el sitio Las Flores (ganadero de baja intensidad) mantuvo valores autotróficos en todos los muestreos. Los sitios agrícolas presentaron valores de IA autotróficos o cercanos a 200. El sitio Durazno II fue el único agrícola 
Tabla 4.3. Rango de variación de los parámetros estructurales y funcionales del perifiton sobre sustratos artificiales período $2008-2009$.

\begin{tabular}{|c|c|c|c|c|c|c|}
\hline & Agrícola baja & Agrícola alta & Ganadero alta & Ganadero alta & Agrícola alta & Ganadero baja \\
\hline & La Choza II & La Choza III & Nutrias & Durazno I & Durazno II & Las Flores \\
\hline Clorofila $a \mathrm{mg} / \mathrm{m}^{2}$ & $19,77-402,36$ & $73,70-484,58$ & $2,60-153,32$ & $0,71-16,94$ & $0,94-267,68$ & $72,00-795,41$ \\
\hline Feopigmentos $\mathrm{mg} / \mathrm{m}^{2}$ & $0,00-0,00$ & $0,00-4,09$ & $0,00-6,33$ & $0,00-0,00$ & $0,00-135,71$ & $0,00-9,25$ \\
\hline Peso Seco $\mathrm{g} / \mathrm{m}^{2}$ & $8,99-198,48$ & $41,56-146,87$ & $20,92-109,50$ & $6,85-24,75$ & $11,90-139,44$ & $17,96-122,83$ \\
\hline PS Orgánico g/m² & $6,08-52,28$ & $14,66-63,45$ & $5,84-22,62$ & $3,74-10,05$ & $5,02-51,18$ & $5,71-37,75$ \\
\hline Índice Autotrófico & $76,05-312,11$ & $78,22-202,33$ & $101,39-2996,25$ & $280,90-5617,98$ & $46,22-5337,08$ & $29,91-126,29$ \\
\hline Lakatos \%Cenizas & $32,35-80,26$ & $41,86-86,98$ & $70,54-90,60$ & $29,63-82,95$ & $50,88-87,50$ & $62,18-76,33$ \\
\hline Lakatos \%Clorofila & $0,32-1,31$ & $0,49-1,28$ & $0,03-0,99$ & $0,02-0,36$ & $0,02-2,16$ & $0,79-3,34$ \\
\hline Polisacararidos $\mathrm{mg} / \mathrm{ml}$ & $11,22-62,63$ & $16,14-313,7$ & $5,19-54,79$ & $3,77-45,52$ & $19,17-28,39$ & $4,72-111,12$ \\
\hline Fósforo Total mg/m² & $16,17-110,03$ & $16,16-160,87$ & $2,12-129,78$ & $7,64-112,83$ & $2,38-100,29$ & $20,51-151,93$ \\
\hline Nitrógeno Total mg/m² & $0,75-108,03$ & $1,10-119,34$ & $0,08-138,82$ & $0,00-739,84$ & $0,00-63,28$ & $1,03-104,62$ \\
\hline Producción Neta $\mathrm{mgO}_{2} / \mathrm{h} \cdot \mathrm{m}^{2}$ & $-153,38-991,18$ & $30,99-2839,58$ & $-715,41-557,83$ & $-701,75-226,91$ & $-461,71-765,84$ & $-126,06-2259,69$ \\
\hline Respiración $\mathrm{mgO} / \mathrm{h} \cdot \mathrm{m}^{2}$ & $0,00-553,63$ & $0,00-682,84$ & $0,00-448,58$ & $0,00-273,14$ & $0,00-947,58$ & $60,93-600,90$ \\
\hline Producción Bruta $\mathrm{mgO}_{2} / \mathrm{h} \mathrm{m}^{2}$ & $-26,79-1188,67$ & $209,58-3192,04$ & $-399,73-952,83$ & $-554,15-196,45$ & $-24,69-967,01$ & $138,67-2517,60$ \\
\hline Celobiohidrolasa nmolMUF/h.cm ${ }^{2}$ & $0,00-69,65$ & $6,98-51,74$ & $0,00-33,84$ & $0,00-208,41$ & $0,00-78,60$ & $0,00-132,31$ \\
\hline Glucosidasa nmolMUF/h.cm² & $94,27-855,20$ & $0,00-908,92$ & $15,93-741,06$ & $67,41-2553,89$ & $42,79-1600,48$ & $85,31-1965,28$ \\
\hline Fosfatasa nmolMUF/h.cm² & $436,69-3057,45$ & $280,02-1822,05$ & $38,31-1739,24$ & $78,60-2168,94$ & $78,60-1640,76$ & $172,60-1734,76$ \\
\hline
\end{tabular}


que mostró valores elevados de heterotrofia. De acuerdo con el sistema de Lakatos el perifiton podría clasificarse, en relación al \% de cenizas, como inorgánico-orgánico en todos los casos. En relación al \% de clorofila $a$ en el PS puede clasificarse como un perifiton de tipo III (Hetero-autotrófico) o IV (Heterotrófico) en los sitios ganaderos de alta intensidad mientras que Las Flores, también en este caso se clasificó como de tipo I (Autotrófico). Los sitios agrícolas se clasificaron como tipo I o II (Auto-heterotrófico). Aunque el sitio Durazno II pasó de tipo I en otoño a tipo III en primavera para terminar en tipo IV en verano.

Los polisacáridos totales estimados en este estudio no se relacionaron con la estacionalidad ni con el uso de la tierra adyacente aunque los menores valores se observaron en los sitios ganaderos de alta intensidad y en el sitio Durazno II.

El fósforo total no mostró una relación con el uso de la tierra pero sí una variación estacional presentando los mayores valores en primavera (siembra) y los menores en verano (cosecha) para todos los sitios, excepto Las Flores (fig. 4.5 a). En el mismo sentido, el nitrógeno total no mostró un patrón asociado al uso de la tierra pero si estacional. Este nutriente presenta una dinámica similar al fósforo total aunque los menores valores se observan en otoño (rastrojo) (fig. 4.5b).

a-

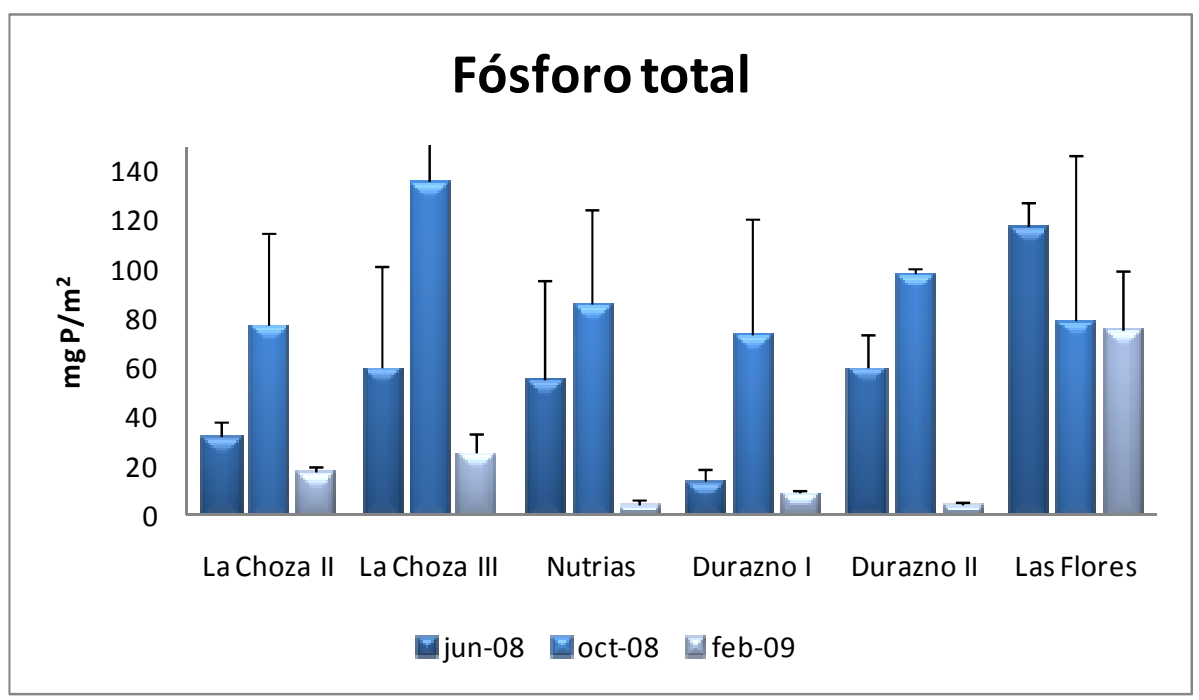


b-

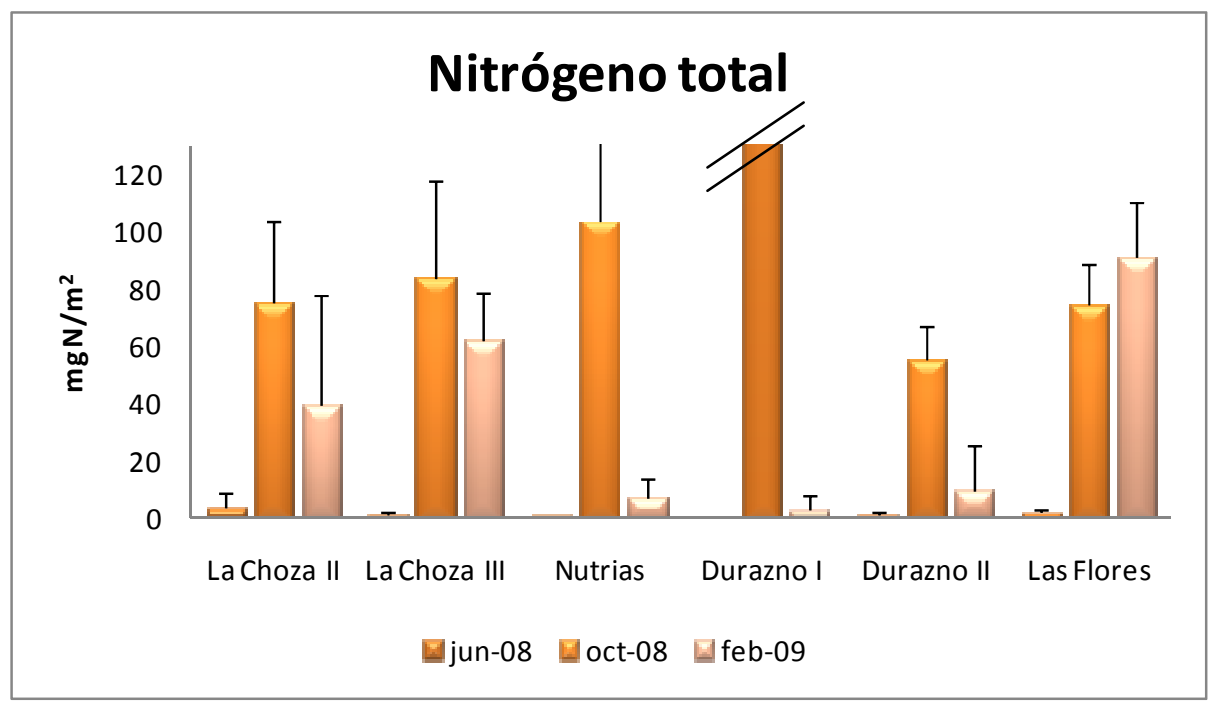

Figura 4.5. Variabilidad de los nutrientes contenidos en el perifiton. a- Fósforo total; bNitrógeno total. El valor en Durazno I, octubre 2008 es de $560 \mathrm{mgN} / \mathrm{m}^{2}$

Los parámetros funcionales no presentaron un patrón diferente a los estructurales aunque se relacionaron mejor con el uso de la tierra (ganaderíaagricultura). La Producción Neta y la Respiración tuvieron los menores valores en el muestreo de verano para la mayoría de los sitios. Sin embargo, para el sitio Nutrias y Durazno II los menores valores se encontraron en primavera. Las actividades de las exoenzimas fueron muy variables. No se encontró un patrón estacional ni con el uso de la tierra para la celobiohidrolasa ni para la $\beta$-glucosidasa. La fosfatasa alcalina en cambio, en el sitio Choza II mostró valores superiores a los demás sitios.

La composición porcentual de la comunidad perifítica en grupos algales (Divisiones) presentó los valores mayores en Bacillariophyta para los sitios agrícolas Choza II, Choza III, Durazno II y el ganadero de baja intensidad Las Flores. Los sitios Nutrias y Durazno I (Ganaderos de alta intensidad) estuvieron representados por valores semejantes de Chlorophyta y Cyanophyta. De las cuatro divisiones representadas la de menor proporción en general fue Euglenophyta, aunque fue muy abundante en el sitio Nutrias en algunas fechas (fig. 4.6).

Para facilitar la observación de la variación temporal de estas proporciones se graficaron las abundancias relativas por división separadas por el uso predominante de la tierra adyacente (fig. 4.6). Las Bacillariophyta tienen un gran predominio durante el 
otoño y la primavera pero en el verano predominan las Cyanophyta más allá del tipo de uso predominante.

a-

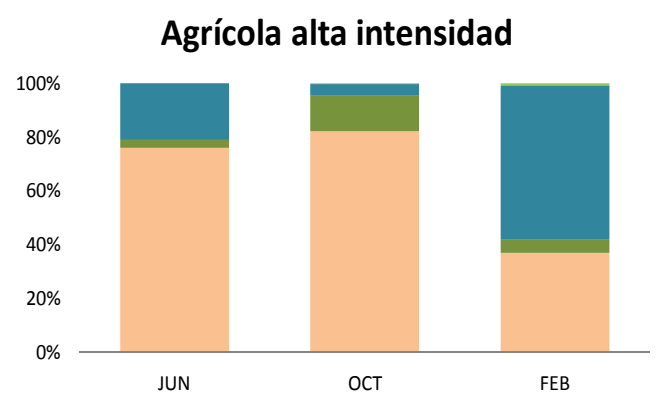

b-

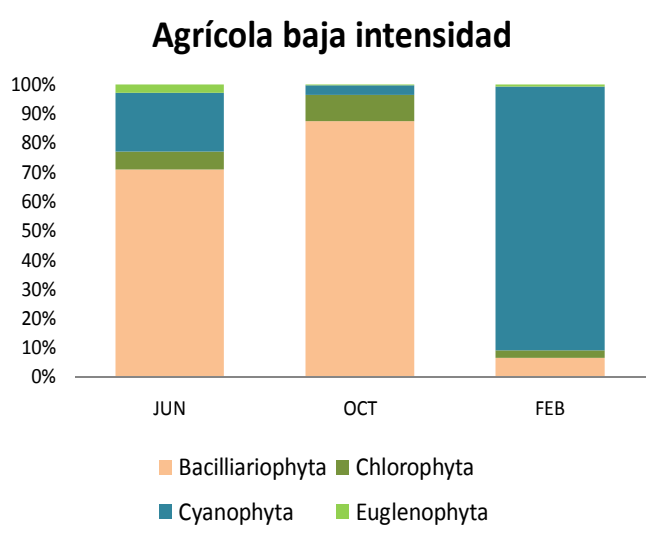

c -

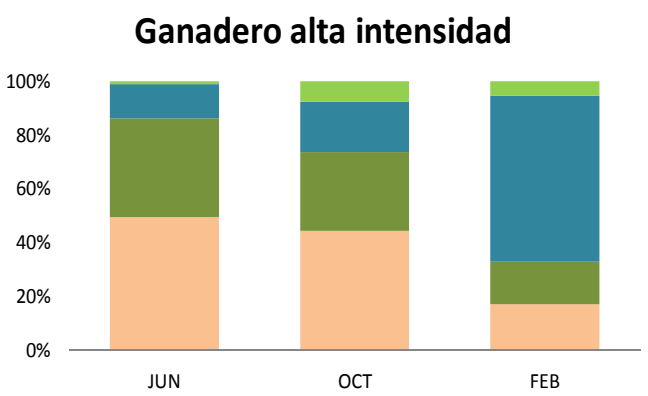

dGanadero baja intensidad

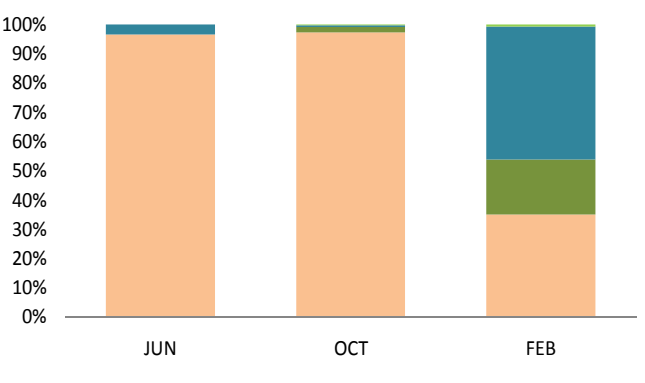

Bacilliariophyta $\square$ Chlorophyta

- Cyanophyta Euglenophyta

Figura 4.6. Composición de grupos algales a lo largo del tiempo para los sitios agrícolas de alta intensidad (a), de baja (b) y para los sitios ganaderos de alta intensidad (c) y de baja (d). Período 2008-2009

Se realizó un análisis de discriminantes con las variables del perifiton para explorar las diferencias entre los usos seleccionados (fig.4.7). 


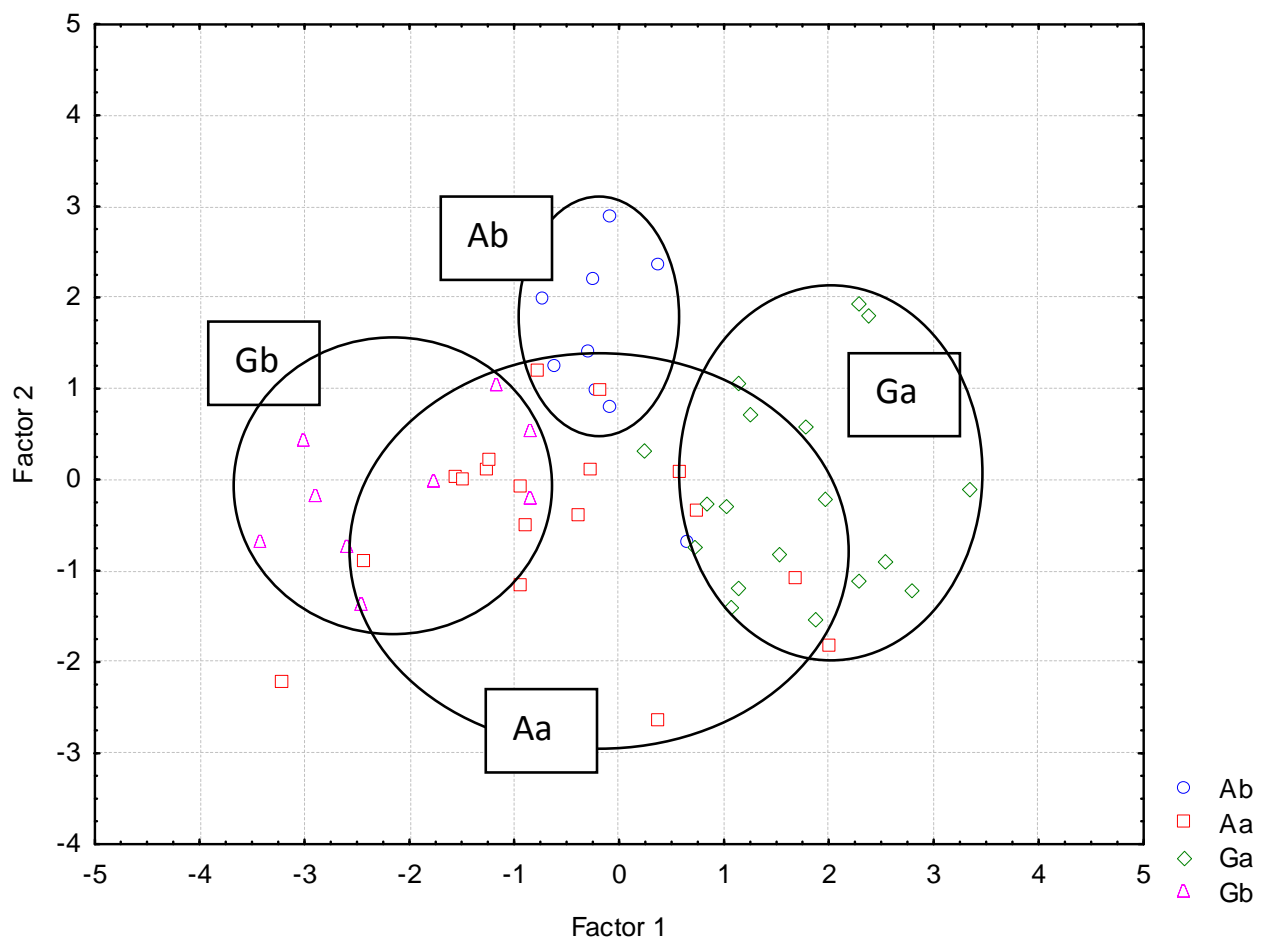

Figura 4.7. Análisis discriminante realizado con las variables del perifiton período 2008-2009. Aa, Agrícola alta intensidad; Ab, Agrícola baja intensidad; Ga, Ganadero alta intensidad; Gb, Ganadero baja intensidad.

La matriz de clasificación no muestra una gran distancia entre los sitios. La mayor distancia utilizando el cuadrado de Mahalanobis es de 14,65 y se da entre el uso Ganadero de baja intensidad y el de alta intensidad. Las variables más importantes y significativas para la diferenciación fueron la clorofila $a(\mathrm{p}<0,001)$, la producción neta $(\mathrm{p}<0,05)$ y la actividad de la fosfatasa alcalina $(\mathrm{p}<0,01)$.

La diferencia entre los usos también fue evaluada a través de un ANOVA de una vía para las variables que se destacaron en el discriminante: clorofila $a$, producción neta y actividad de la fosfatasa alcalina. Este análisis se realizó para contrastar estadísticamente la hipótesis emanada del discriminante de que estas variables diferenciaban las comunidades perifíticas desarrolladas en tramos con distintos tipos de uso. Los análisis resultaron significativos $(\mathrm{p}<0,001)$ para las tres variables. El análisis post-hoc Tukey HSD (Honestly Significant Difference) para la variable clorofila $a$ indicó que el uso ganadero de alta intensidad $(\mathrm{Ga})$ era estadísticamente diferente y menor a los otros usos (fig.4.8). En cambio para la variable producción neta muestra que el uso Ga es significativamente diferente sólo al uso Ganadero de baja intensidad 
(Gb) y al Agrícola de alta intensidad (Aa) (fig. 4.9).

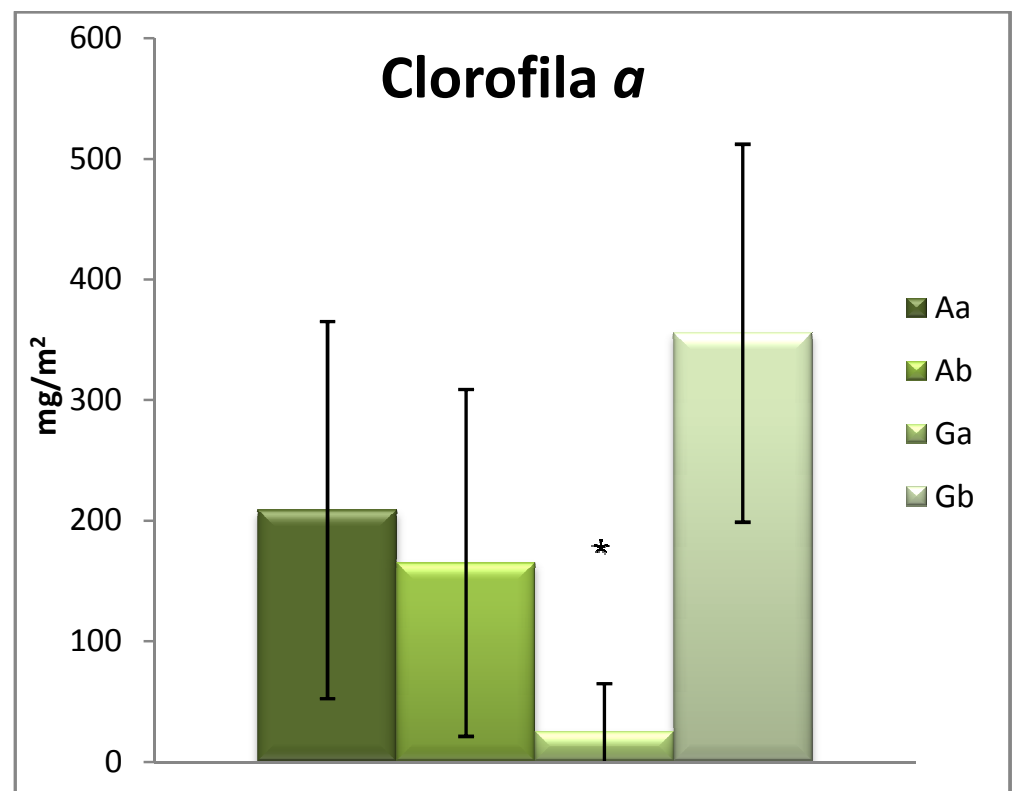

Figura 4.8. Valores promedio y desvíos de clorofila $a$. Aa, Agrícola alta intensidad; Ab, Agrícola baja intensidad; Ga, Ganadero alta intensidad; Gb, Ganadero baja intensidad.

*, Diferencia significativa

No se observan diferencias significativas entre $\mathrm{Ga}$ y el Agrícola de baja intensidad (Ab) (fig.4.9).

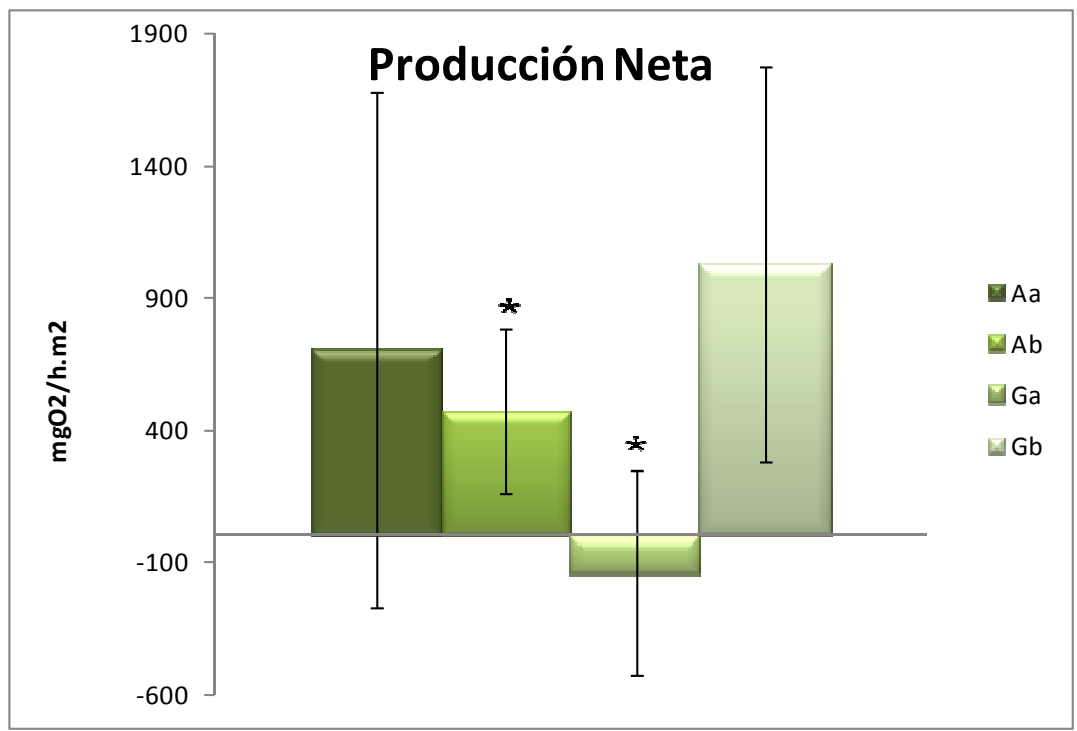

Figura 4.9 Valores promedio y desvíos de la producción neta. Aa, Agrícola alta intensidad; Ab, Agrícola baja intensidad; Ga, Ganadero alta intensidad; Gb, Ganadero baja intensidad. *, Diferencia significativa 
El análisis de Tukey HSD para la tercera variable (Actividad de la fosfatasa alcalina) mostró diferencias significativas para el uso agrícola de baja intensidad con respecto a los otros usos (fig. 4.10).

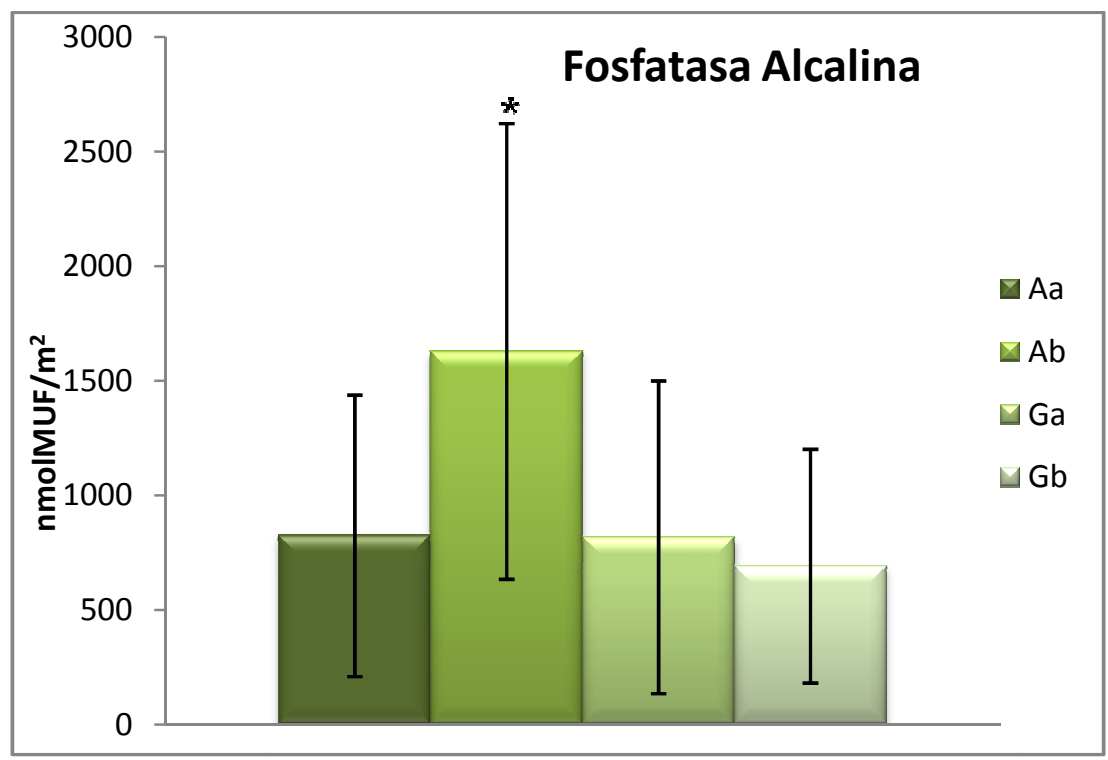

Figura 4.10. Valores promedio y desvíos de la actividad de fosfatasa alcalina. Aa, Agrícola alta intensidad; Ab, Agrícola baja intensidad; Ga, Ganadero alta intensidad; Gb, Ganadero baja intensidad. *, Diferencia significativa

Se realizó un análisis de correspondencia canónica para hallar la máxima correlación entre dos grupos de variables diferentes y se representó la combinación de las variables fisicoquímicas y las variables del perifiton (Fig. 4.11). Se utilizó la transformación log para todas las variables. El test de significancia de Monte Carlo del primer eje canónico arrojó un valor de $\mathrm{p}=0,002$. Los autovalores de los ejes canónicos resultaron 0,044 y 0,022 para el primero y segundo eje, mientras que el porcentaje de varianza explicada de la relación variables fisicoquímicas-variables del perifiton fue $50,3 \%$ para el primer eje y $75,8 \%$ para el segundo.

Este análisis permite correlacionar los dos tipos de variables pero las diferencias estacionales enmascaran la relación de estas variables con los sitios estudiados. El ordenamiento de las variables en el plano muestra que a mayor concentración de ácidos húmicos menor será la concentración de clorofila $a$ y la producción neta. La variable ácidos húmicos sigue un comportamiento similar a la DQO como se observó en el 
análisis de PCA del capítulo 3. La fracción orgánica del material particulado en suspensión se correlaciona en forma inversa a la producción neta. La fosfatasa alcalina tiende a una relación inversa al fósforo total del perifiton aunque esta relación no es significativa.

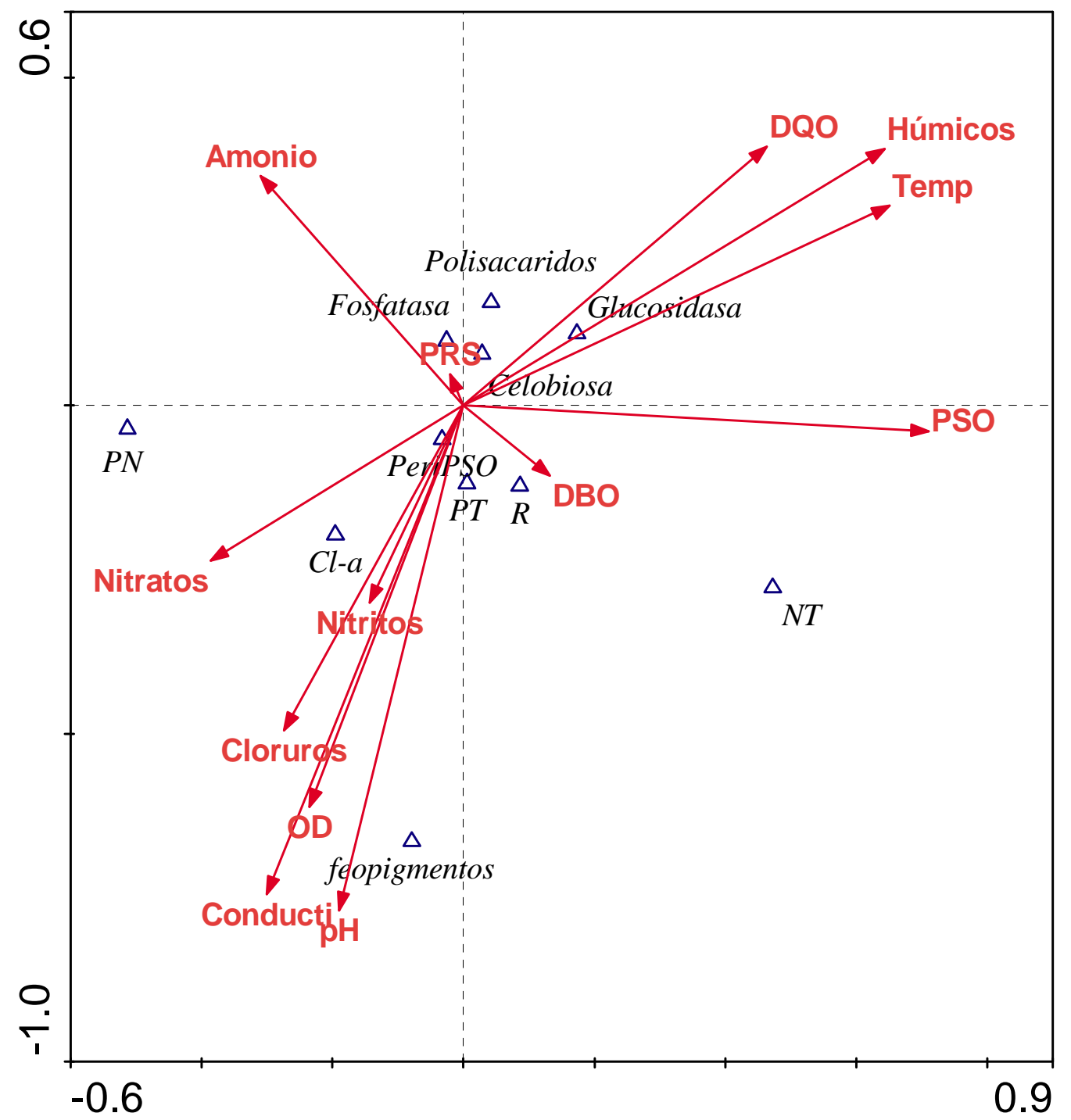

Figura 4.11 Ordenamiento de las variables fisicoquímicas (rojo) y del perifiton (negro) en el período 2008-2009 de acuerdo al análisis de correspondencia canónica. PN, producción neta, Conducti, conductividad, NT, nitrógeno total, R, respiración, PT, fósforo total, $\mathrm{Cl}$-a, clorofila, PeriPSO, biomasa del perifiton, $\mathrm{PSO}$, material particulado orgánico en suspensión, PRS, fósforo reactivo soluble, temp, temperatura 


\section{Discusión}

Las diferencias fisicoquímicas entre los tramos pueden atribuirse no solo a las características del arroyo sino también al efecto de la actividad agropecuaria que se realiza en los campos aledaños. El análisis de discriminantes (fig. 4.4) muestra la distancia que separa a los sitios por el uso predominante. Las características similares de los tramos con diferente intensidad agrícola (ej. Ch II y Ch III) se explicaría porque en todos ellos se realiza un laboreo del suelo similar (siembra directa, fertilización y herbicidas recomendados para el cultivo de soja). Además, muchos arroyos estaban cerca de los valores que indican eutroficación (Smith et al. 1999) por lo que se considera que utilizan una fertilización similar. Esto ha sido confirmado en una serie de encuestas realizadas a los productores del lugar referidas al tipo de labores y adición de fertilizantes realizado durante 2008 donde se manifiesta que se adicionaron $20 \mathrm{Tn}$ de fósforo y 63 Tn de nitrógeno para los cultivos en el área previa al sitio La Choza II y 23 Tn de fósforo y 80 de nitrógeno en el área previa al sito La Choza III aunque la cantidad de campos sembrados fuera mucho mayor en Ch III que en Ch II (Barsotti 2011). Así también, el herbicida Glifosato, aplicado en las zonas de cultivo de soja aumenta el fósforo total en el agua (Perez et al. 2007). A pesar del aumento de fósforo se ha demostrado que el glifosato reduce la biomasa perifítica entonces, hay efectos opuestos en los flujos de la agricultura, donde el aumento de fósforo contribuiría a aumentar la biomasa perifítica y los herbicidas a reducir el desarrollo de perifiton o a modificar los grupos dominantes (Vera et al 2010). Esto coincide con nuestros resultados donde el incremento del contenido de fósforo en el perifiton estimado aparece en la época de siembra. Sin embargo, no se registran diferencias entre las intensidades del uso agrícola.

En cambio, los tramos con diferente intensidad ganadera presentan mayor distancia en el conjunto de variables representadas en análisis de discriminantes (fig.4.4). En tanto que las variables del perifiton, se diferenciaron significativamente entre ambas intensidades por la concentración de clorofila $a$ y la producción neta. Además, los sitios ganaderos de alta intensidad difieren en de los de baja intensidad por el tipo de ganado presente. En el caso de los arroyos Nutrias y Durazno I (Ga) el ganado fue vacuno mientras que en Las Flores $(\mathrm{Gb})$ hubo ganado equino. Este último no suele ingresar tanto en el cuerpo de agua por lo que produce menor pisoteo, erosión e ingreso de desechos. 
El predominio de la división Bacillariophyta durante el otoño (junio) y primavera (octubre) coincide con lo encontrado en los muestreos a campo durante el año 2007-2008 (fig.4.5). A su vez, también se pudo ver que durante el verano hubo predominio de Cyanophyta. Estas características se atribuyen a la variación temporal del perifiton y no al uso de la tierra adyacente. Las Bacillariophyta se ven favorecidas por poseer un bajo umbral de saturación de la luz por lo que son exitosas en un ambiente con una importante carga de sólidos en suspensión (Gómez et al. 2003) como lo son estos arroyos. Mientras que las Cyanophyta se vuelven más abundantes en condiciones de eutrofia, bajos caudales y altas temperaturas (Giorgi 1998, Vilalta 2004).

Los mayores valores de actividad de fosfatasa alcalina (APA) se encontraron para el uso agrícola de baja intensidad. Altos niveles de APA son indicadores de deficiencia de fósforo en algas (Bothwel 1985, Labry et al. 2005). Sin embargo, existe una controversia con el uso de APA como indicador ya que sólo resultaría útil en el caso de que el fósforo fuera el único parámetro de cambio (Newman et al. 2003). En este estudio el sustrato no interfiere en la respuesta de APA por ser artificial pero debido a que se trata de un estudio en campo hay otros factores que varían con el uso de la tierra, no sólo la disponibilidad de fósforo para las algas (concentración de nitrógeno, pesticidas, ácidos húmicos). Los resultados muestran que no hay una relación significativa de APA con las concentraciones de PRS o fósforo total (fig. 4.11) quizás debido al mecanismo de "inducción-represión". Cao et al. (2010) explican este mecanismo sugiriendo que en cuerpos de agua con alto nivel trófico, las bacterias o los microorganismos heterótrofos de la comunidad podrían contribuir sustancialmente a la fosfatasa extracelular sintetizándola para la hidrólisis de compuestos organofosforados pero probablemente utilizando la fracción orgánica como fuente de carbono orgánico. Este proceso produce simultáneamente $\mathrm{P}$ inorgánico, lo que lleva a la co-ocurrencia de altas concentraciones de fosfatos y APA. Por ello, estos autores, aseguran que no es adecuada la utilización de APA como indicador general para la descripción de la deficiencia de $\mathrm{P}$ de algas, especialmente en cuerpos de agua eutróficos. Además, las microalgas de agua dulce producen enzimas extracelulares, especialmente APA por lo que esta actividad está relacionada con el régimen lumínico: será mayor a más luz ya que habrá más algas fotosintéticamente activas (Chappell y Goulder 1994). Wetzel (1992) encontró que existe una inhibición de la APA por las sustancias húmicas ya que estas forman un complejo húmico-enzima que reduce la actividad de la enzima. De esta 
manera el complejo puede ser transportado aguas abajo y reactivarse la actividad de la enzima por degradación bacteriana selectiva del complejo o por fotólisis física mediante radiación $U V$.

La concentración de ácidos húmicos aumenta en los cuerpos de agua luego de las lluvias por el arrastre desde los campos aledaños (Serrano 1992) y baja su concentración en períodos secos por la fotoxidación de la materia orgánica (Serrano 1994). Nuestros resultados coinciden con estas afirmaciones en los sitios agrícolas o ganaderos de baja intensidad. En cambio en los sitios ganaderos de alta intensidad el acceso del ganado a los arroyos disminuye la disponibilidad de luz por la resuspensión constante de material particulado y sustancias húmicas (Middlenton 2010) sin depender exclusivamente de las lluvias. Esta menor disponibilidad de luz tiene importantes consecuencias en la producción secundaria y la composición de la comunidad, modificando entonces procesos fotoquímicos, la captación de nutrientes y condicionando el crecimiento del perifiton (Julian et al. 2008). Como se ve en los resultados de este estudio, la comunidad desarrollada en los sustratos artificiales es heterotrófica en los sitios ganaderos de alta intensidad (IA, Lakatos) que son a su vez los sitios donde se encuentra más del doble de la concentración de ácidos húmicos (tabla 4.2). Teniendo en cuenta que en las mediciones realizadas en el arroyo La Choza se encontró una reducción del $50 \%$ de la luz en ausencia de material particulado, es posible que la comunidad autotrófica estuviera restringida en su desarrollo debido a la limitación lumínica causada por las altas concentraciones de húmicos y el componente heterotrófico del propio perifiton. Steinberg 2003, afirma que las sustancias húmicas modifican el clima lumínico bajo el agua y consecuentemente cambian las condiciones de vida para los organismos autotróficos. En resumen, tanto los ácidos húmicos, el material particulado en suspensión y la concentración de materia orgánica favorecerían la comunidad heterotrófica.

Los menores valores de Producción Neta y Respiración en el muestreo de verano para la mayoría de los sitios estarían relacionados con una menor biomasa por unidad de superficie posiblemente resultado del arrastre de las comunidades por las lluvias. La producción neta se vería desfavorecida por una limitación lumínica en el campo por la concentración de húmicos o favorecida por ingreso de nutrientes. Sin embargo, en este estudio se estimó el metabolismo en el laboratorio en iguales condiciones de luz y nutrientes para todas las muestras. De esta manera se midió el metabolismo de la 
comunidad desarrollada con las limitaciones propias del sitio en estudio y por consiguiente las diferencias encontradas se deben a la comunidad de origen y no a las condiciones experimentales. Los resultados mostraron una PN significativamente menor en los sitios ganaderos de alta intensidad donde la comunidad colonizada en los sustratos fue mayormente heterotrófica. También se muestra en la figura 4.11una relación inversa de la concentración de ácidos húmicos y la PN lo que indicaría que la mayor o menor concentración de húmicos condicionaría la capacidad de producción de la comunidad. La relación inversa encontrada para la clorofila $a$ (fig. 4.11) refuerza la idea de que habría una comunidad mayormente heterotrófica en los sitios con altos contenidos de ácidos húmicos.

Dos variables funcionales (APA y PN) de las cinco estimadas en este capítulo resultaron importantes para diferenciar el tipo de uso agropecuario en los sitios de estudio. Sólo una variable estructural (clorofila $a$ ) fue significativa diferenciando los sitios ganaderos de alta intensidad respecto de los otros sitios. La concentración de ácidos húmicos (tabla 4.2) en estos sitios sería uno de los factores más importantes para explicar esta respuesta del perifiton. 


\section{Capítulo 5}

Efecto de la contaminación difusa sobre el perifiton en arroyos artificiales 


\section{Introducción}

Los estudios de campo donde se han detectado más modificaciones en la comunidad perfítica son aquellos que se asocian a fuentes puntuales de contaminación (Giorgi y Malacalza 2002, Sierra y Gómez 2007 y 2010), mientras que el análisis de fuentes difusas ha sido escasamente realizado y los resultados obtenidos son menos específicos (Delong y Bruswen 1992, Urrea y Sabater 2009, Vera et al. 2010).

Frente a la necesidad de valorar de manera aislada el efecto de los compuestos que llegan a los arroyos se han desarrollado métodos de trabajo en laboratorio que permiten conocer el efecto de éstos sobre los organismos acuáticos. La mayoría de estas metodologías se basan en estudios de dosis-respuesta monoespecíficos (por ejemplo Olguin y Salibian 1994) pero esta tendencia perdió fuerza frente a la visión que propone que la protección de los niveles superiores del ecosistema no podía basarse en resultados obtenidos a partir de estos estudios, dada la complejidad de interacciones presentes en los ecosistemas (Cairns 1988). Por otro lado, el uso de arroyos artificiales ha permitido no sólo aislar el efecto de distintos factores sino también estudiar el efecto sinérgico de varios de ellos (Horner y Welch 1981, Horner et al. 1990). De esta manera, los canales y arroyos artificiales son un puente entre los ensayos de laboratorio y los sistemas naturales ya que permiten exponer comunidades complejas a concentraciones realistas de tóxicos (Navarro, 1998).

Los arroyos artificiales se definen como cualquier tipo de canal, con flujo de agua controlable, usado para estudiar las propiedades físicas, químicas, o biológicas de los sistemas naturales (Warren y Davis, 1971). Estos mesocosmos han contribuido enormemente al conocimiento del impacto de diferentes disturbios como presencia de metales pesados y pulsos tóxicos (Brooks et al. 1996, Guasch et al. 2010), pesticidas (Mitchell et al. 1993), herbivorismo (Navarro et al. 2000), acidez (Maurice et al. 1987), velocidad de corriente (Horner y Welch 1981) y luz incidente (Steinman y McIntire 1986).

Las respuestas obtenidas tanto en los sustratos naturales como en los artificiales citadas en los dos capítulos anteriores, se asocian principalmente a los nutrientes, particularmente el fósforo y a la demanda química de oxígeno producto de las sustancias húmicas. Los ácidos húmicos, como se vio en el capitulo precedente, serían 
la variable más importante que afectaría la respuesta del perifiton a la contaminación difusa. Suelen producir un incremento en la DQO porque están constituidos por materia orgánica refractaria a la descomposición (Conzzono 2010).

Las sustancias húmicas pueden constituir hasta el $60 \%$ de la materia orgánica disuelta en el agua. Pueden provenir por escorrentía desde los suelos aledaños a los cuerpos de agua y se caracterizan por no ser biodegradables. El Argialbol y especialmente el Natracualf propios de estos ambientes se caracterizan por poseer materia orgánica poco polimerizada lo que ocasiona una importante pérdida de sustancias húmicas a través del agua de inundación y/o escurrimiento (Taboada et al. 1987).

También existen antecedentes de otros autores que indican a estos factores (los nutrientes, particularmente el fósforo y las sustancias húmicas) como relevantes, Serrano (1992) encuentra un rápido enriquecimiento de polifenoles durante períodos de lluvias fuertes mientras que Jarvie et al. (2008) demuestran la importante contribución de fósforo que llega difusamente desde campos agrícolas. Tanto en esos casos como en la primera parte de esta tesis no se estudió experimentalmente la acción de los factores sino que se dedujo su importancia de los resultados de los análisis exploratorios realizados a partir de datos obtenidos en los estudios de campo. Sin embargo, debe considerarse que las respuestas de las comunidades acuáticas a estos factores sólo pueden analizarse adecuadamente aislando experimentalmente las variables cuyo efecto quiere estudiarse. Estos experimentos complementan y completan los análisis realizados a partir del trabajo de campo.

El concepto de tolerancia de la comunidad inducida por contaminación (PICT, pollution-induced community tolerance) predice que una comunidad que ha sido desarrollada sobre un estrés químico crónico puede llegar a ser más tolerante a los químicos (Blank 2002). En base a este concepto los ácidos húmicos producirían cambios estructurales anticipados para incrementar la tolerancia de la comunidad perifítica su aumento. En este modelo conceptual, Vinebrooke et al. (2004) sugiere que este cambio hacia una comunidad con especies más resistentes debida a la inducción por estrés también puede inducir cotolerancia (o ecotelarancia o tolerancia cruzada) a otros agentes estresores, o sea que existe una resistencia al estresor adicional dada por la inducción del primero. 
Es por ello que se propuso utilizar arroyos artificiales en ensayos de laboratorio para exponer al perifiton a la acción de estas sustancias y poner a prueba las siguientes hipótesis:

- Una mayor concentración de sustancias húmicas disminuye la biomasa del perifiton y modifica su metabolismo.

- La captación de nutrientes y agroquímicos (fertilizante, herbicida) por parte del perifiton es afectado por la concentración de sustancias húmicas en el agua.

- El grado de cotolerancia del perifiton a las sustancias generadas por las actividades agrícolas-ganaderas está influido por las interacciones entre esas variables.

\section{Objetivos}

Indagar si existen respuestas diferenciales al utilizar distintos parámetros estructurales o funcionales del perifiton cuando es afectado por:

* un incremento de sustancias húmicas

* un incremento de fósforo.

* un incremento de nutrientes al utilizar un fertilizante comercial

* un herbicida de amplia utilización

* la interacción entre sustancias húmicas con un agroquímico o con los nutrientes disponibles.

\section{Materiales y Métodos}

Para exponer al perifiton a la acción de estas sustancias habitualmente generadas por la actividad agrícola-ganadera y que pueden llegar por escorrentía al cuerpo de agua se utilizaron arroyos artificiales en ensayos de laboratorio.

Las unidades experimentales (arroyos artificiales) se diseñaron de acuerdo con la bibliografía específica (Lamberti y Steinman 1993) y las características (baja velocidad 
de corriente y alto tiempo de residencia del agua, predominio de flujo laminar) propias de los arroyos pampeanos (Feijoó et al. 1999).

De acuerdo a la bibliografía, el tamaño del arroyo debe ser suficiente para el desarrollo y supervivencia de la biota que se estudia y a su vez permitir la expresión de los factores que se pretenden controlar. Canales pequeños (menos de $5 \mathrm{~m}$ ) pueden poseer una comunidad lo suficientemente compleja como para obtener resultados extrapolables a las comunidades naturales (Belanger, 1997). Las condiciones impuestas artificialmente en los canales, podrán provocar cambios en las características del agua, por lo que deben ser controlados.

El sistema de arroyos artificiales usados en este estudio constaba de 12 canales de acrílico de $4 \mathrm{~mm}$ de espesor. Los canales tuvieron una longitud de 0,9 $\mathrm{m}$ y un ancho y altura de 0,1 m. La alimentación de los arroyos se realizó mediante recirculación de agua proveniente del sitio La Choza III (ver Cap.2) filtrada previamente con filtro de tela para evitar el ingreso de herbívoros y material vegetal, de manera independiente para cada uno de ellos. La recirculación se logró mediante el uso de una bomba Atman ${ }^{\circledR}$ AT-301 individual e independiente a un flujo constante de 0,1 ml/seg. Esta velocidad fue seleccionada considerando el tiempo de residencia estimado para los arroyos de la zona de acuerdo a los datos recabados en el Cap. 3. Para evitar un flujo turbulento en la entrada de agua al canal se colocaron porciones de acrílico para así lograr un flujo constante (fig. 5.1 y 5.2).

El sistema de arroyos se instaló en una habitación climatizada para mayor control de las variables físicas externas. Los tratamientos se distribuyeron de forma aleatoria sobre una mesada con iluminación propia. Este sistema se iluminó con tubos fluorescentes Philips® (30 Watt) que emiten luz día para representar el espectro de la luz visible que proporcionan una irradiancia aproximada de $80 \mu \mathrm{E} / \mathrm{m}^{2} \mathrm{seg}$, de radiación fotosintéticamente activa. Esta irradiancia, similar a un día nublado, fue la mayor que se consiguió en condiciones de laboratorio sin provocar un exceso térmico. El fotoperiodo se estableció en 12 horas luz y 12 horas oscuridad para todos los experimentos. El sistema se aisló del resto del área de trabajo mediante una tela de nylon negra para evitar interferencias de la iluminación ambiental y planchas de telgopor blanco en los dos laterales del sistema para evitar la reducción de iluminación en los canales allí ubicados. Con el fin de evitar el calentamiento excesivo se controló la temperatura 
mediante un acondicionador de aire, y la instalación de los canales disponía de un ventilador y un extractor (fig. 5.1 y 5.2).

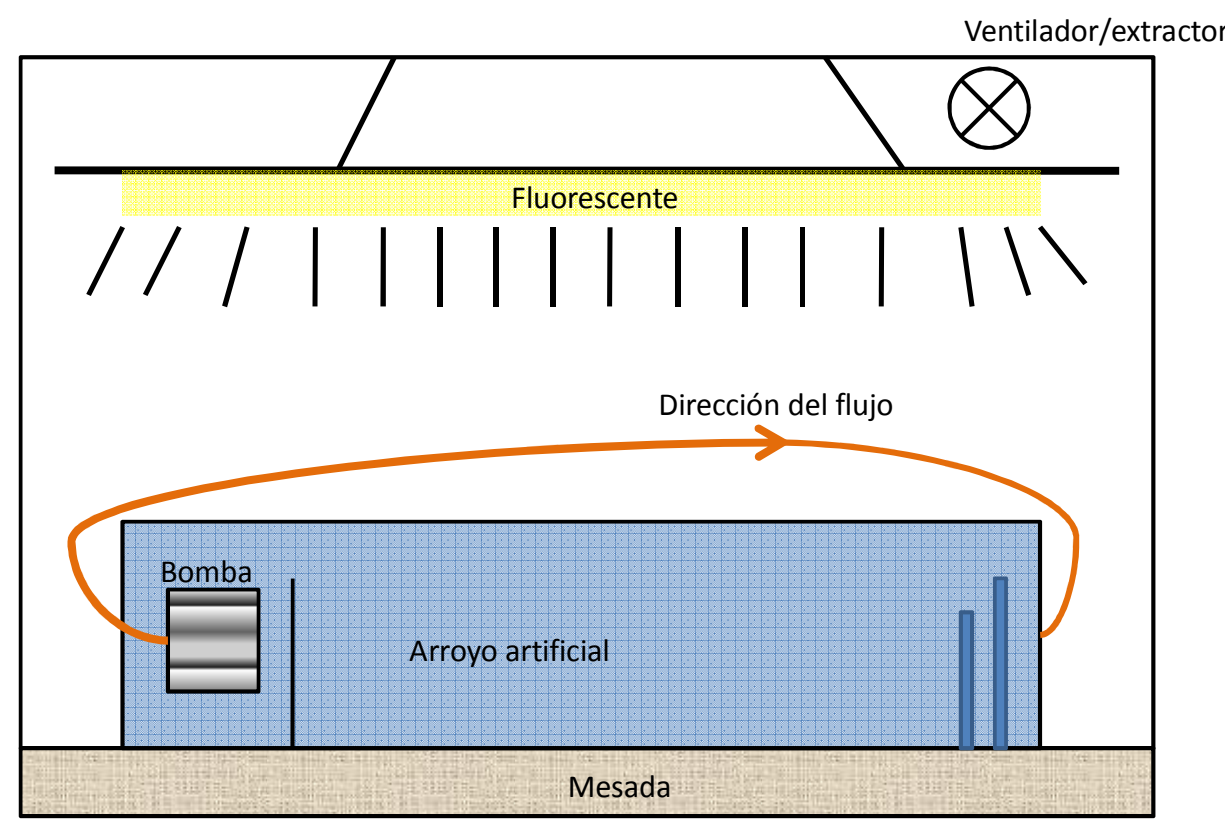

Figura 5.1. Diagrama del sistema de arroyos artificiales utilizado

Como sustrato artificial se seleccionó el vidrio esmerilado ya que es especialmente indicado en estudios ecotoxicológicos, pues es inerte y permite la colonización de las algas, facilita el mantenimiento de cierta biomasa algal, que permite una buena recuperación de la comunidad (Sladeckova 1962, Aloi 1990, Navarro, 1998).

Los sustratos de vidrios esmerilados de $40 \mathrm{~cm}^{2}$ se colocaron de manera verticaloblicua para simular la posición de las hojas de las hidrófitas que son el sustrato natural de la comunidad en estudio. 


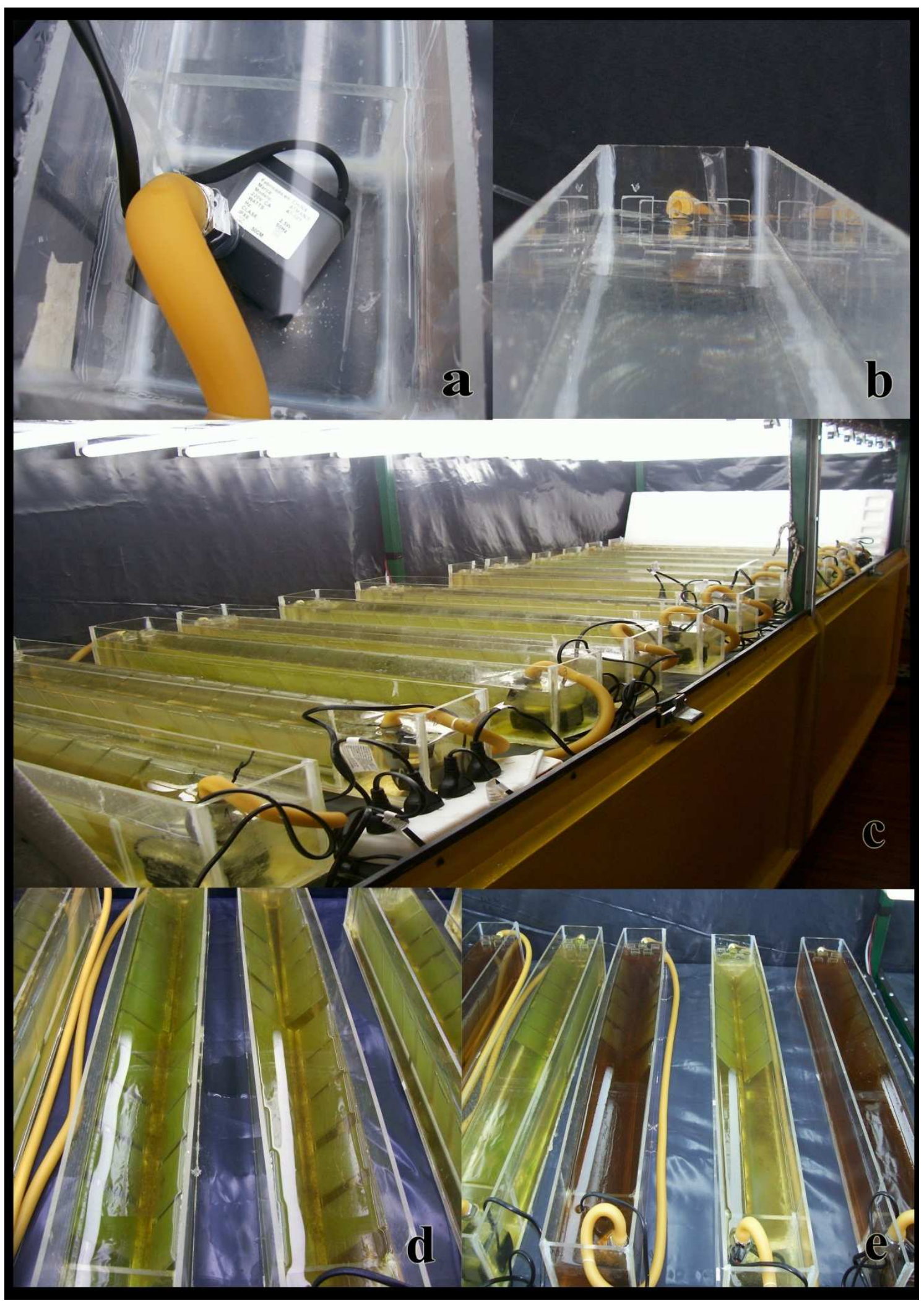

Figura 5.2. Sistema de arroyos artificiales. a- bomba de recirculación. b- Dispositivo para evitar flujo turbulento. c- Sistema completo en período de colonización. d- Detalle de posición de los sustratos artificiales. e- Tiempo inicial del experimento. Se observa la diferencia de color debido a los tratamientos con ácido húmico. 
Los experimentos se llevaron a cabo utilizando como origen la comunidad del arroyo La Choza. Durante un lapso mínimo de 40 días previos al inicio cada uno de los experimentos se inoculó periódicamente algas perifíticas traídas del sitio La Choza III en los canales artificiales, con el objeto de lograr la colonización de los sustratos de vidrio esmerilado. El inoculo consistió en $50 \mathrm{ml}$ de resuspensión de algas perifíticas obtenidas del lavado de porciones de vástago de Ludwidgia peploides traídas del arroyo.

Al comienzo y al final de cada experimento se tomaron muestras para registrar algunos parámetros de la calidad del agua (oxígeno disuelto, $\mathrm{pH}$, conductividad y temperatura) según la descripción metodológica del capítulo 2. Además, se registraron las concentraciones de material particulado, materia orgánica, así como nutrientes (fósforo reactivo soluble, amonio, nitrito y nitrato), cloruros, y se realizaron estimaciones de ácidos húmicos, DQO y $\mathrm{DBO}_{5}$ (Ver cap. 2).

Para los experimentos se optó por un diseño factorial que permite distinguir el efecto de los factores aislados y combinados. Se buscó la interacción de los parámetros seleccionados (fósforo, fertilizante, herbicida) con uno de los factores naturales (ácidos húmicos), de modo que la potenciación o inhibición del efecto se pueda atribuir a este factor.

Los experimentos tuvieron el mismo diseño base: a) arroyos control, b) arroyos con una concentración mayor a la inicial de sustancias húmicas c) arroyos con una concentración mayor a la inicial de la variable a estudiar (fósforo, fertilizante, herbicida) y d) arroyos con la combinación de b) y c). El diseño temporal se realizó como se muestra en la figura 5.3. 


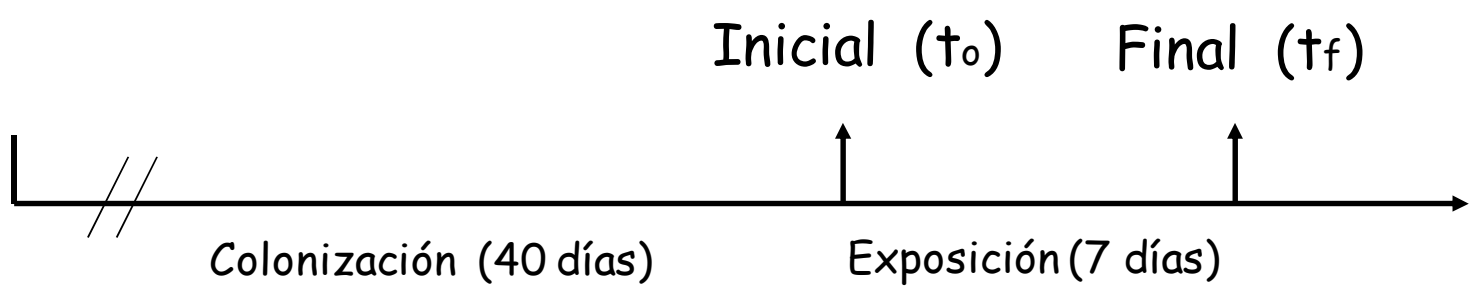

Figura 5.3. Arreglo temporal. Colonización del perifiton en los arroyos artificiales durante un lapso mínimo de 40 días mediante la adición de inóculo periódico de algas perifíticas extraídas del sitio La Choza III. Tiempo Inicial: comienzo de las condiciones experimentales. Exposición: período de exposición a las condiciones experimentales.

Tiempo final: fin del experimento. Flecha horizontal: Tiempo. Flechas verticales: Extracción de muestras.

Los parámetros estructurales que se utilizaron para evaluar la respuesta del perifiton fueron: Biomasa total estimada como peso seco (orgánico e inorgánico), Clorofila-a y Feopigmentos, Polisacáridos, Nitrógeno y Fósforo Total, además se calcularon índices descriptores de la comunidad como el índice autotrófico y el índice de Lakatos siguiendo el número de réplicas y la metodología detallada en el capítulo 2. La unidad muestreal es vidrio esmerilado de $40 \mathrm{~cm}^{2}$ de superficie (descripto más arriba).

Los parámetros funcionales del perifiton se centraron en dos estimaciones siguiendo la metodología detallada en el capítulo 2. Metabolismo: producción y respiración del perifiton midiendo las variaciones de oxígeno disuelto mediante porciones de la comunidad (un cristal esmerilado de $40 \mathrm{~cm}^{2}$ ) colocadas en recipientes plásticos trasparentes y herméticos $(200 \mathrm{ml})$ oscurecidas (respiración) y sin oscurecer (producción) (fig. 5.4). Se obtiene así la Producción Neta (PN), Respiración (R) y Producción Bruta (PB) expresadas como $\mathrm{mg} \mathrm{O}_{2}$ (producido o consumido)/hora.m².

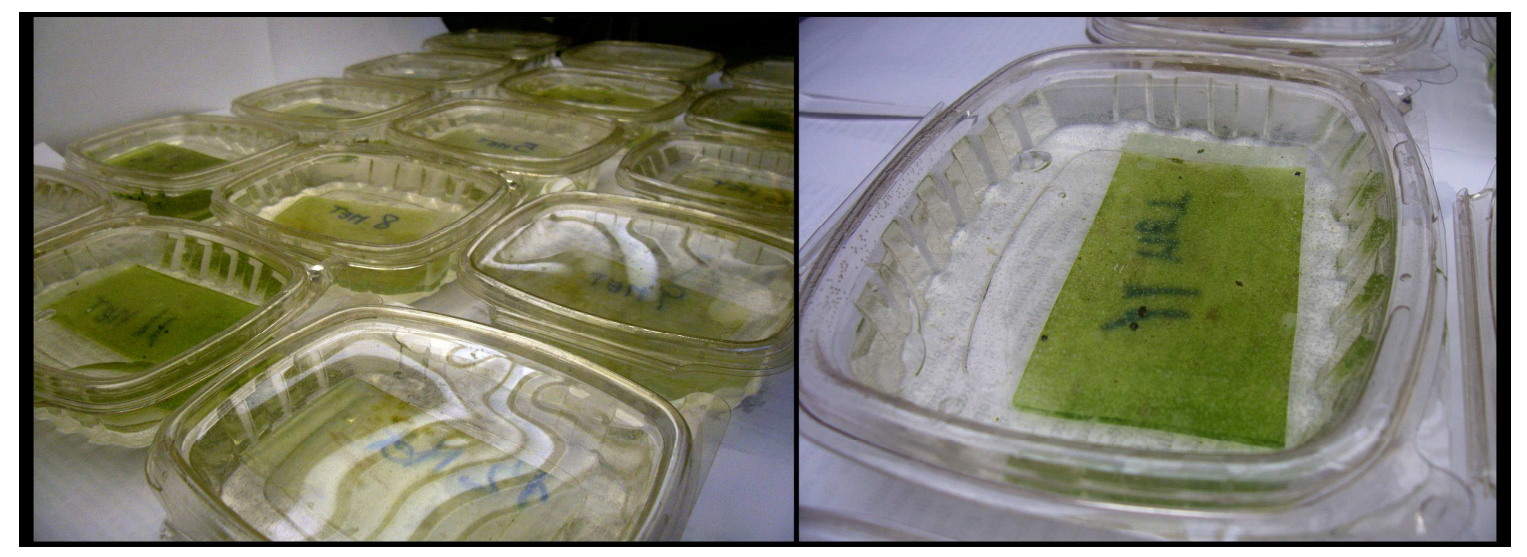

Figura 5.4. Foto de recipientes herméticos con sustrato artificial. Estimación de producción neta 
Además se midieron las variaciones de oxígeno disuelto en el agua de los arroyos artificiales en el período de exposición a los tratamientos. Las medidas de oxígeno se registran durante todo un día a intervalos de cinco minutos. En el experimento 1 se realizó en los primeros días de exposición y en los últimos. En el experimento 2 durante los primeros, medios y últimos días de exposición. Esta técnica derivada de la de metabolismo abierto (Ver Cap. 2) permite graficar la variación de oxígeno en el tiempo. Esta información permitiría estimar las diferencias de producción y respiración entre los tratamientos durante el experimento sin necesidad de remover muestras de la comunidad. Actividad de exoenzimas: se estimó la actividad de las enzimas $\beta$-glucosidasa, fosfatasa alcalina y celobiohidrolasa en un extracto de la comunidad obtenido luego de la sonicación del sustrato artificial (Ver Cap. 2).

Para cumplir con los objetivos propuestos se realizaron 3 experimentos independientes. En todos ellos se trabajó con sustancias húmicas como factor, más el componente a analizar. La concentración de ácidos húmicos fue la misma en todos los experimentos. Para ello se preparó una solución $50 \mathrm{ppm}$ con la sal sódica de ácidos húmicos (Aldrich®). Las concentraciones de ácidos húmicos y de fósforo utilizadas se seleccionaron de acuerdo con los resultados obtenidos en el Capítulo 3 en la fecha de alto caudal tomando como criterio la proporción de incremento de estos. En todos los casos se trató de simular pulsos de ingresos que resultarían de una mayor escorrentía provocada por lluvia por lo que no se realizaron cambios ni renovación del agua de los tratamientos durante la semana de exposición. Por otro lado, se agregaron iguales cantidades de la solución correspondiente a cada arroyo para minimizar la pérdida de agua por evaporación.

Experimento 1) Se estudió la respuesta del perifiton cuando es afectado por un incremento en la concentración de fósforo y su relación con las sustancias húmicas. Para ello se utilizó el diseño base con tres arroyos artificiales por cada tratamiento. La concentración de fósforo seleccionada para este experimento fue: $0,5 \mathrm{mgP}_{-} \mathrm{PO}_{4}{ }^{-3} / 1$

Experimento 2) Se estudió la respuesta del perifiton cuando es afectado por un incremento de nutrientes (fósforo y nitrógeno) y su relación con las sustancias húmicas. Para ello se utilizó el diseño base con tres réplicas al igual que el experimento 1. Como nutrientes se utilizó un fertilizante líquido de uso comercial (Nitrofoska® SL) que contiene un $10 \%$ de nitrógeno total, $2 \%$ de fósforo asimilable, $6 \%$ de potasio soluble en 
agua y 0,31\% de magnesio como compuestos mayoritarios. La concentración seleccionada fue: $5 \mathrm{ml}$ Fertilizante/l que se asemeja a la concentración de fósforo y nitrógeno de la cuenca en estudio luego de las precipitaciones (Ver cap. 3).

Experimento 3) Se estudió la respuesta del perifiton cuando es afectado por un herbicida de amplia utilización y su relación con las sustancias húmicas. Se utilizó el mismo diseño que en los otros dos experimentos. Como herbicida se utilizó glifosato comercial (Glifosato 48 SEM®). La concentración seleccionada fue: 0,17ml herbicida/l con la que se obtiene una concentración final similar a la aplicada de principio activo (sal isopropilamina del $\mathrm{N}$-fosfonometilglicina).

Para realizar el tratamiento estadístico de los datos se utilizó una matriz única para cada experimento. Esta matriz se obtiene por la diferencia dato a dato del valor final menos el inicial. De esta manera quedan fuera del análisis las posibles variaciones internas de cada arroyo artificial y las posibles variaciones de los controles entre cada uno de los experimentos. Esto significa que la matriz con la que se trabajó estuvo compuesta por la variación de cada arroyo sometido a cada tratamiento, lo que permitió comparar las variaciones de los tratamientos con la variación del control. Se verificó la distribución normal a través de la prueba de Kolmogorov-Smirnov y la homogeneidad de varianza con la prueba de Levene con el paquete estadístico Statistica ${ }^{\circledR}$ 7.0. Sólo fue necesaria una transformación en la variable Índice autotrófico (IA) para el segundo experimento. La transformación fue $\log \left(\mathrm{IA}^{2}\right)$. Se realizó un ANOVA de una vía con la variable categórica "Tratamiento" y se aplicó a posteriori el test de Dunnett que contrasta cada uno de los tratamientos con los controles.

\section{Resultados}

Los resultados obtenidos en los experimentos que se describen a continuación se han detallado en forma de tablas en la sección de Anexo. De modo que las variables que se presentan gráficamente en esta sección corresponden a aquellas en las que se obtuvieron respuestas estadísticamente significativas en los tratamientos. La metodología utilizada en la extracción de muestras y parámetros físicoquímicos implicó una diferencia de horario en la estimación de la temperatura del agua. La habitación climatizada donde se encontraban los arroyos artificiales evitaba el gradiente de 
temperatura externa pero no la debida a la iluminación, por lo que se observa una diferencia de temperatura entre el inicio y el final del experimento (anexo) debido al tiempo transcurrido desde el encendido de las luces y la estimación de la temperatura. También se grafican las variaciones de oxígeno diarias registradas en los arroyos artificiales. Se tomaron estas variaciones sólo en algunos arroyos ya que el tiempo de exposición y el instrumental disponible permitían el registro únicamente en ocho de los doce arroyos artificiales.

\section{Experimento 1:}

Se expuso al perifiton colonizado en los arroyos artificiales a los distintos tratamientos: tres arroyos con una alta concentración de fósforo $\left(0,5 \mathrm{mgP}^{-} \mathrm{PO}_{4}^{-3} / 1\right)$ para el tratamiento Fósforo (P), otros tres con alta concentración de ácidos húmicos (50ppm) para el tratamiento húmicos $(\mathrm{H})$ y otros tres arroyos con altas concentraciones de los dos factores para el tratamiento fósforo más húmicos $(\mathrm{P}+\mathrm{H})$. Además tres arroyos fueron utilizados únicamente con agua del arroyo sin modificaciones constituyendo los controles (C). Luego de una semana de exposición se observó que el fósforo reactivo soluble (PRS) disminuyó en todos los tratamientos. Sin embargo, en aquellos con agregado de fósforo $(\mathrm{P}$ y $\mathrm{P}+\mathrm{H})$ esta disminución fue mayor. Estadísticamente, esta diferencia es significativa respecto del control según la prueba de Dunnett en el tratamiento con fósforo $(\mathrm{p}<0,001)$ y en el de húmicos más fósforo $(\mathrm{p}<0,001)$. De manera análoga la concentración de ácidos húmicos disminuyó en forma significativa respecto a la disminución observada en el control en los tratamientos con agregado de húmicos $(\mathrm{H}, \mathrm{p}=0,018$ y $\mathrm{P}+\mathrm{H}, \mathrm{p}=0,002)$. Los parámetros químicos estimados en el agua no mostraron diferencias significativas respecto al control luego de la exposición.

El fósforo total contenido en el perifiton aumentó significativamente luego de una semana de exposición en los arroyos artificiales correspondientes a los tratamientos de alta concentración de fósforo $(\mathrm{P})(\mathrm{p}=0,003)$ y de alta concentración de fósforo junto con alto contenido de ácidos húmicos $(\mathrm{H}+\mathrm{P})(\mathrm{p}=0,028)$ (fig. 5.5). La actividad de la fosfatasa alcalina (APA) fue mayor en los tratamientos sin fósforo añadido y significativamente menor respecto al control en el tratamiento de fósforo $(p<0,001)$ y en el de húmicos más fósforo (p<0,001) (fig. 5.6). 


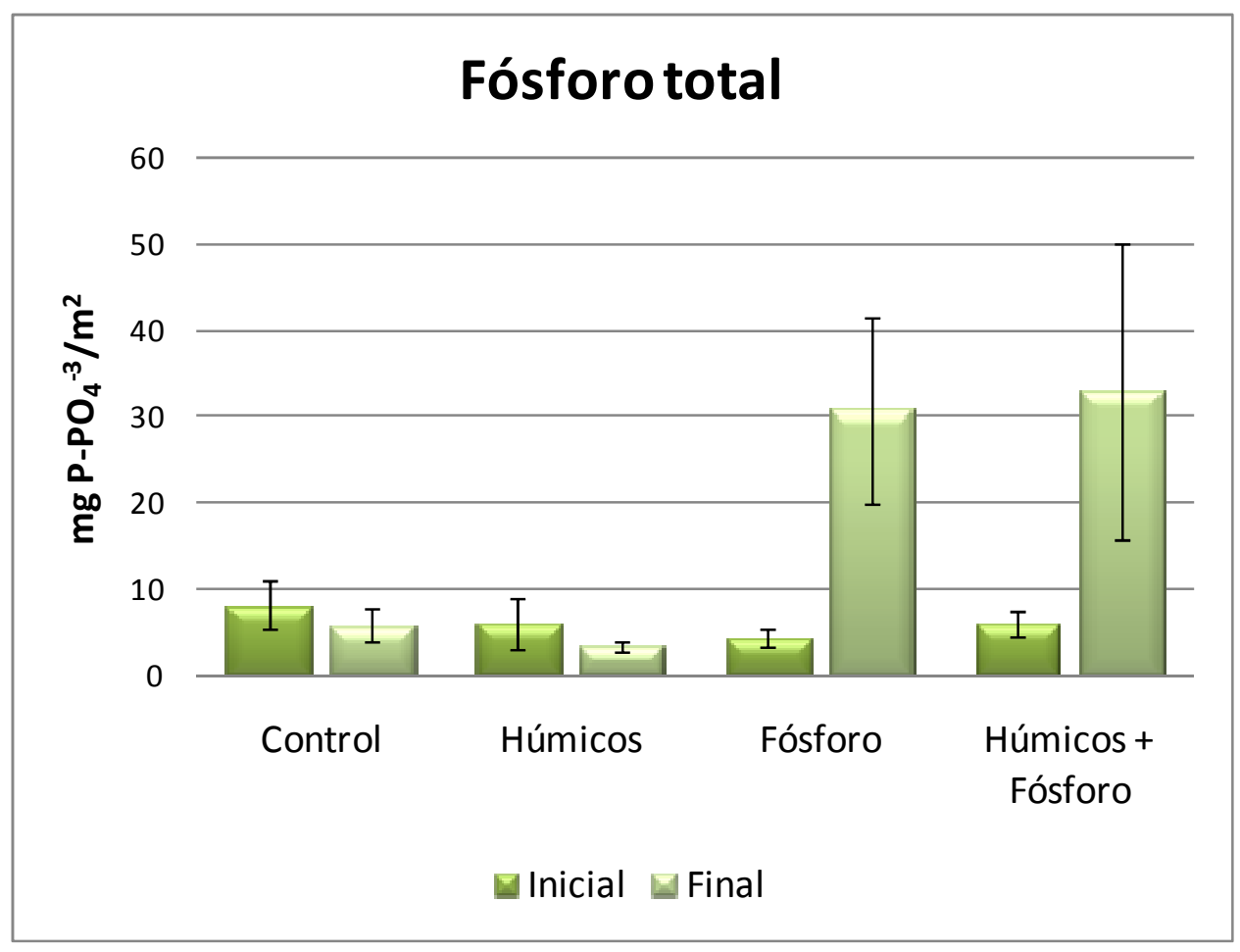

Figura 5.5. Valores medios y desvíos estándar de fósforo total contenido en el perifiton a tiempo inicial y final del experimento 1

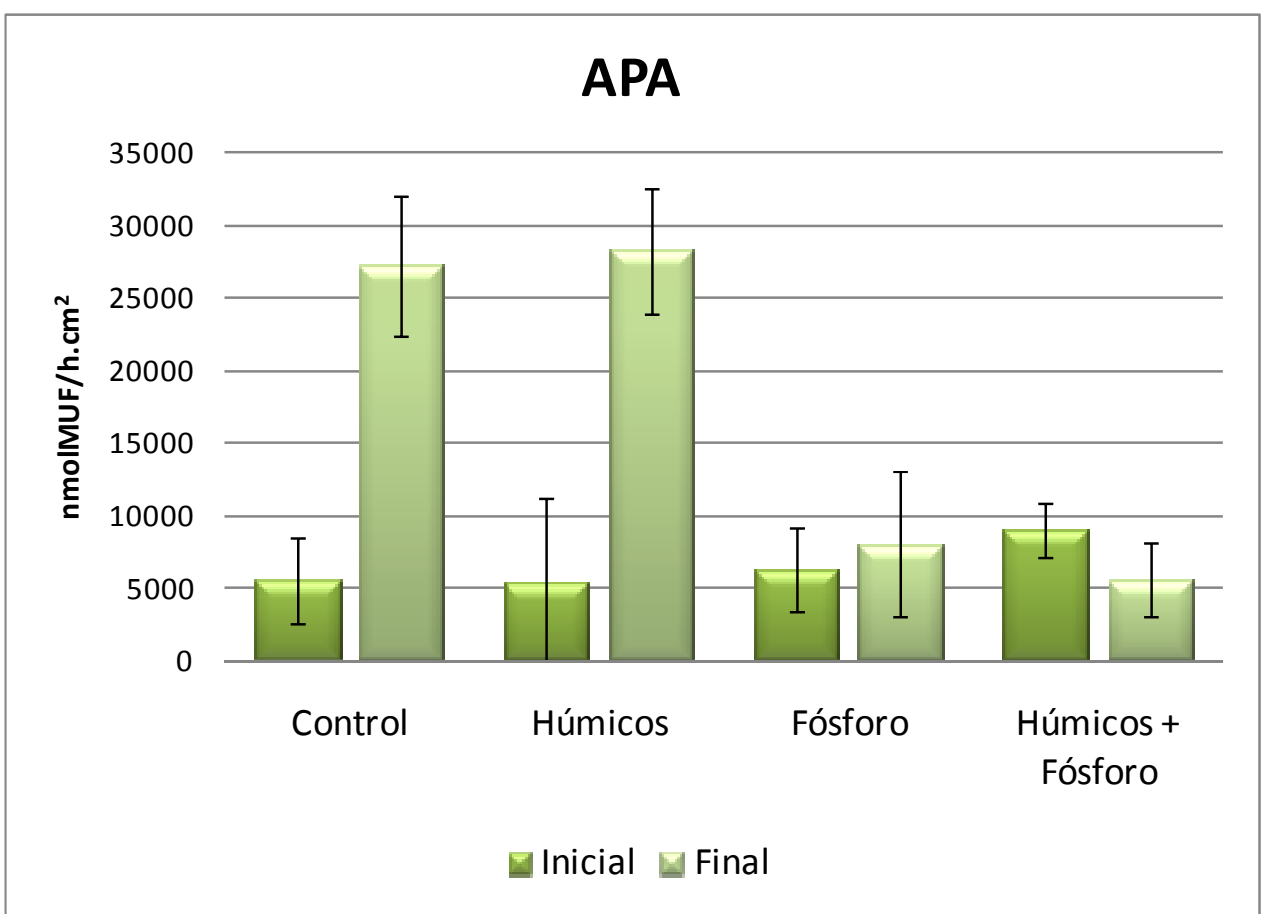

Figura 5.6 Valores medios y desvíos estándar de la actividad de la fosfatasa alcalina a tiempo inicial y final del experimento 1

A modo de síntesis, se detallan en la tabla 5.1 las significancias y variaciones de los parámetros estudiados respecto al control. 
Tabla 5.1. Significancias y variación de cada tratamiento respecto al control (Dunnet) para el experimento 1. En naranja los parámetros manipulados, en celeste los estimados en el agua y en verde los estimados en el perifiton.

\section{Húmicos Fósforo Húmicos + Fósforo Variación}

\begin{tabular}{l|cccc} 
PRS & n.s. & $* *$ & $* *$ & menor \\
Ácidos Húmicos & $*$ & n.s. & $* *$ & menor \\
Químicos & n.s. & n.s. & n.s. & \\
Fósforo Total & n.s. & $* *$ & $* *$ & mayor \\
Fosfatasa alcalina & n.s. & $* *$ & $* *$ & menor \\
\hline
\end{tabular}

Las estimaciones del metabolismo con el método de cámaras no mostraron diferencias significativas. Sin embargo, con el método de metabolismo abierto se observan algunas diferencias (fig. 5.7). En la primera parte de la exposición (fig. 5.7a) se observa una mayor concentración de oxígeno del tratamiento P durante las horas de luz respecto al control y menor durante las horas de oscuridad. La concentración de oxígeno del tratamiento $\mathrm{H}$ se mantuvo por debajo de la concentración del control durante todo el fotoperíodo. El comportamiento del tratamiento $\mathrm{H}+\mathrm{P}$ durante las horas de luz es similar al control aunque durante las horas de oscuridad la concentración de oxígeno se mantiene muy por debajo.

En los últimos días de exposición (fig. 5.7b) no fue posible estimar la variación de oxígeno para el tratamiento $\mathrm{H}+\mathrm{P}$. Los otros dos tratamientos $(\mathrm{P}$ y $\mathrm{H})$ mantuvieron sus concentraciones por debajo de las del control durante todo el fotoperíodo.

a)

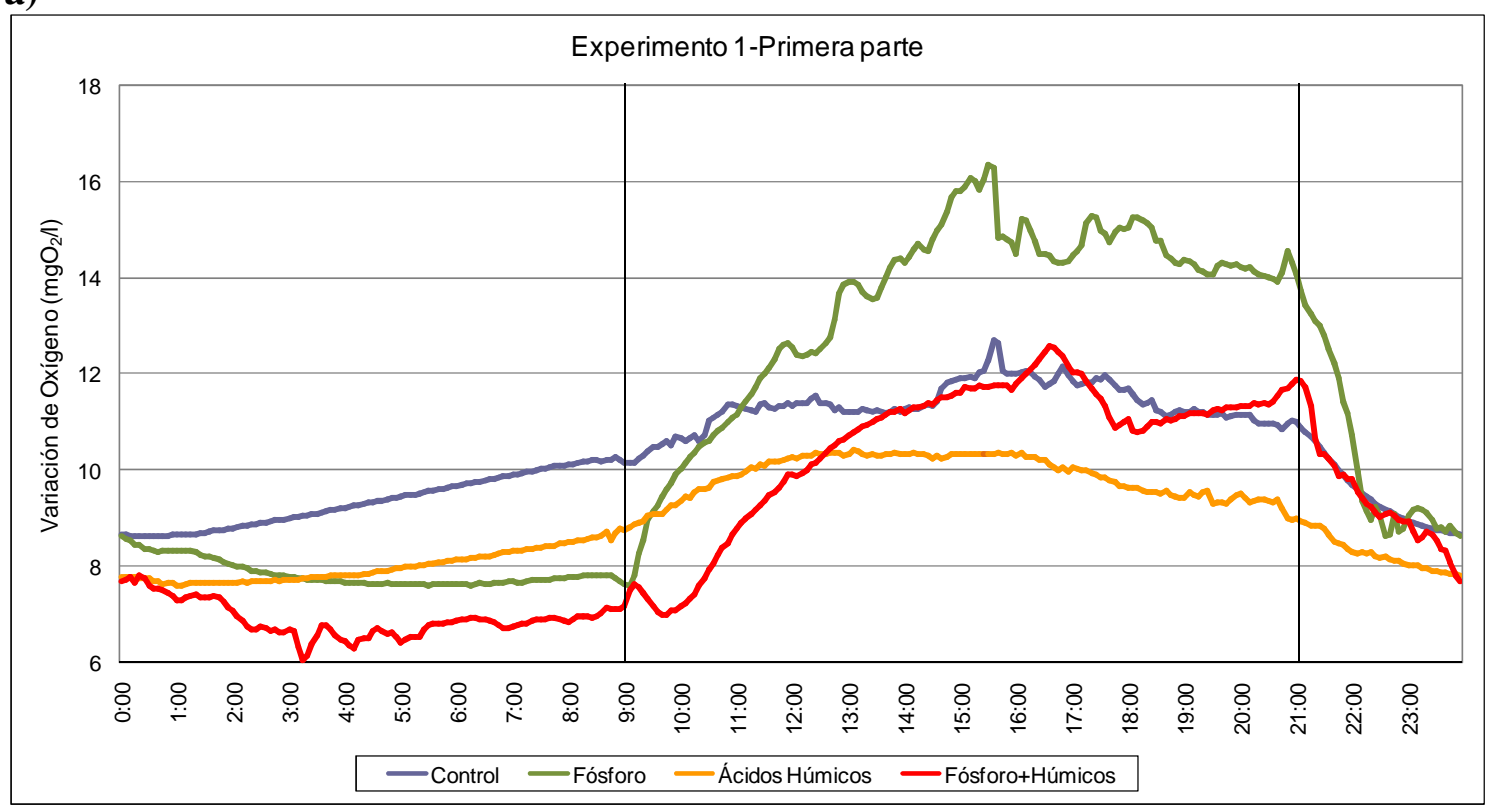


b)

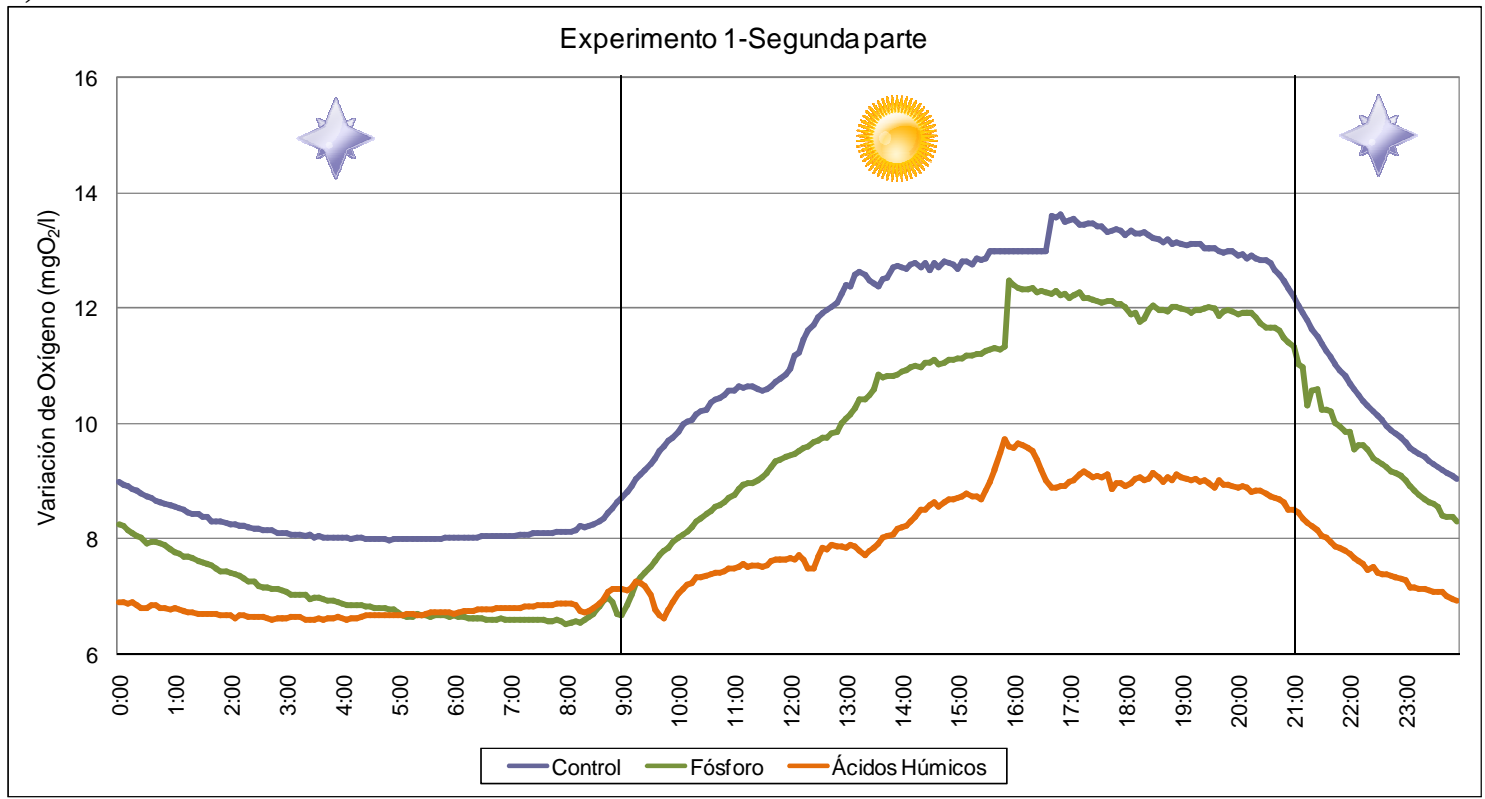

Figura 5.7. Variación de oxígeno diaria para cada uno de los tratamientos. Las líneas verticales delimitan el fotoperíodo. a) Primeros días de exposición (Día 1-4). b) Últimos días de exposición (Día 5-8)

Experimento 2:

En este experimento también se utilizaron tres arroyos control (C) conteniendo únicamente agua del arroyo, y tres con agregado de sustancias húmicas $(\mathrm{H})$. Además, tres arroyos con agregado de fertilizante $(\mathrm{F})$ y otros tres con el agregado conjunto de fertilizante y sustancias húmicas $(\mathrm{H}+\mathrm{F})$ como nuevos tratamientos.

Las placas colonizadas se expusieron en los tratamientos con fertilizante ( $\mathrm{F}$ y $\mathrm{H}+\mathrm{F})$ a un fertilizante comercial obteniéndose a tiempo inicial en el agua concentraciones mayores a las del control en PRS (3,0 mgP-PO $\left.{ }_{4}^{-3} / 1\right)$, amonio $(0,5 \mathrm{mgN}-$ $\left.\mathrm{NH}_{4}{ }^{-} / 1\right)$, Nitrato $\left(4,3 \mathrm{mgN}^{-N^{2}}{ }_{3}{ }^{-} / 1\right)$, Nitrito $\left(0,1 \mathrm{mgN}-\mathrm{NO}_{2}{ }^{-} / 1\right)$ y cloruros $\left(245 \mathrm{mgCl}^{-} / 1\right)$ y en los tratamientos con húmicos $(\mathrm{H}$ y $\mathrm{H}+\mathrm{F})$ a una concentración mayor de ácidos húmicos (50 ppm). Luego de una semana de exposición se observó en el agua que la concentración del PRS fue mayor significativamente respecto al control en el tratamiento de $\mathrm{H}+\mathrm{F}(\mathrm{p}<0,001)$. La concentración del nitritos fue mayor respecto al control luego de la exposición en los tratamientos $\mathrm{F}$ y $\mathrm{H}+\mathrm{F}(\mathrm{p}<0,001)$, la concentración de nitratos también fue mayor pero sólo significativamente en el tratamiento $\mathrm{H}+\mathrm{F}$ $(\mathrm{p}=0,029)$, en cambio el amonio no mostró diferencias significativas. Los valores de cloruros también aumentaron luego de la exposición en los tratamientos con fertilizante 
(tratamiento $\mathrm{F}, \mathrm{p}<0,001$, tratamiento $\mathrm{H}+\mathrm{F}, \mathrm{p}=0,005)$. Los valores de ácidos húmicos no mostraron diferencias significativas.

La mayoría de los parámetros químicos que se estimaron no mostraron diferencias significativas. El valor de la demanda química de oxígeno (DQO) es mayor en los tratamientos con agregado de ácidos húmicos en tiempo inicial. A tiempo final en los arroyos tratados con húmicos (tratamientos $\mathrm{H}$ y $\mathrm{H}+\mathrm{F}$ ) disminuyó el valor de este parámetro y en el tratamiento F (fertilizante) aumentó. Sin embargo esta variación con respecto al control sólo fue significativa en el tratamiento $\mathrm{H}$ (ácidos húmicos) con un nivel de significancia de $\mathrm{p}=0,003$ (fig. 5.8).

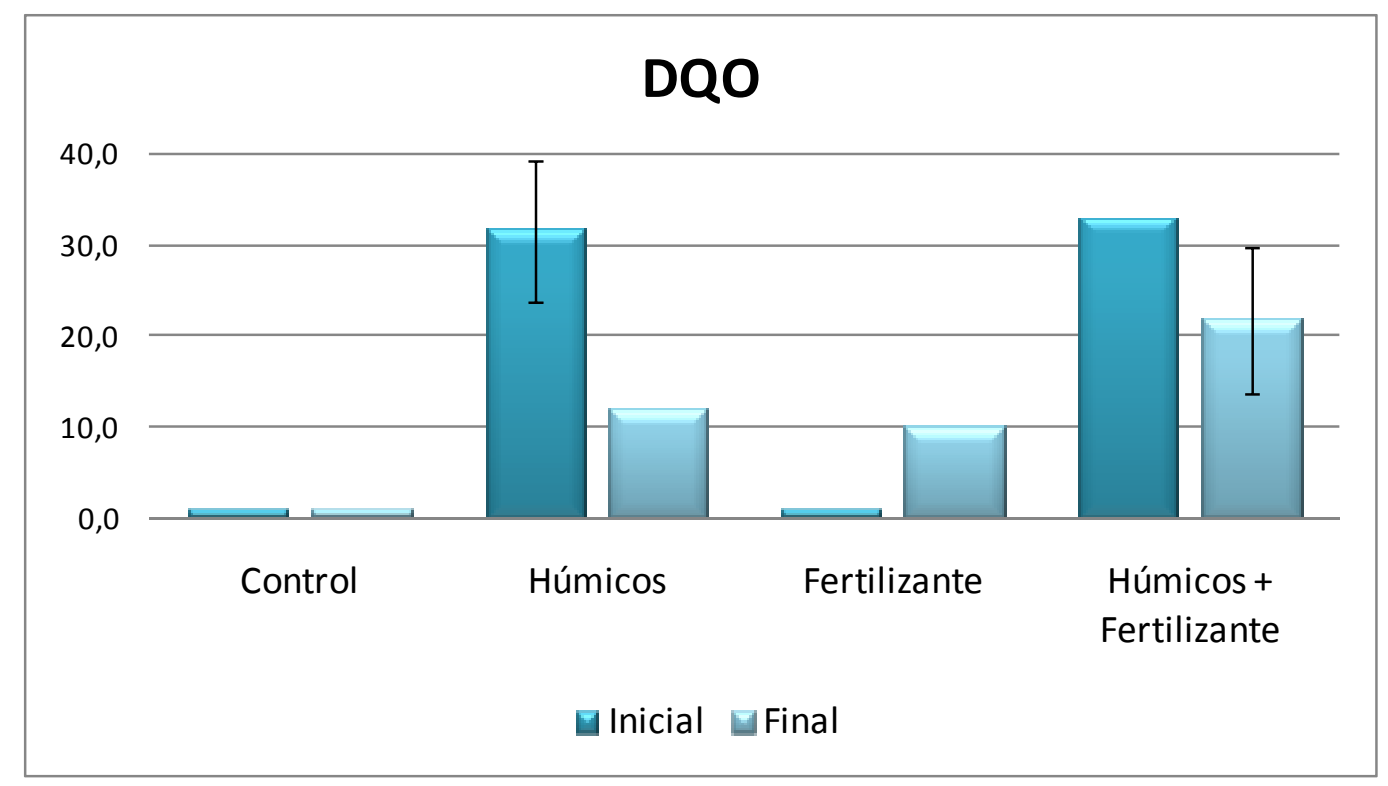

Figura 5.8. Valores medios y desvíos estándar de la demanda química de oxígeno a tiempo inicial y final en el experimento 2 . Unidades: $\mathrm{mg} \mathrm{O}_{2} / 1$ consumidos

El fósforo total contenido en el perifiton aumentó significativamente $(\mathrm{p}=0,044)$ respecto al control en el tratamiento con fertilizante $(\mathrm{F})$ mientras que en el tratamiento de fertilizante + ácidos húmicos (H+F) este incremento no fue significativo (fig. 5.9). La concentración de clorofila $a$ aumentó en todos los tratamientos a tiempo final, sin embargo este aumento sólo fue significativo con respecto al control en el tratamiento con fertilizante ( $\mathrm{p}=0,039)$ (fig. 5.10). Algo similar sucede con la producción neta (fig. 5.11) ya que el valor de oxígeno producido por metro cuadrado fue mayor luego de la exposición al fertilizante sólo en el tratamiento sin agregado de húmicos ( $\mathrm{p}=0,048)$. 


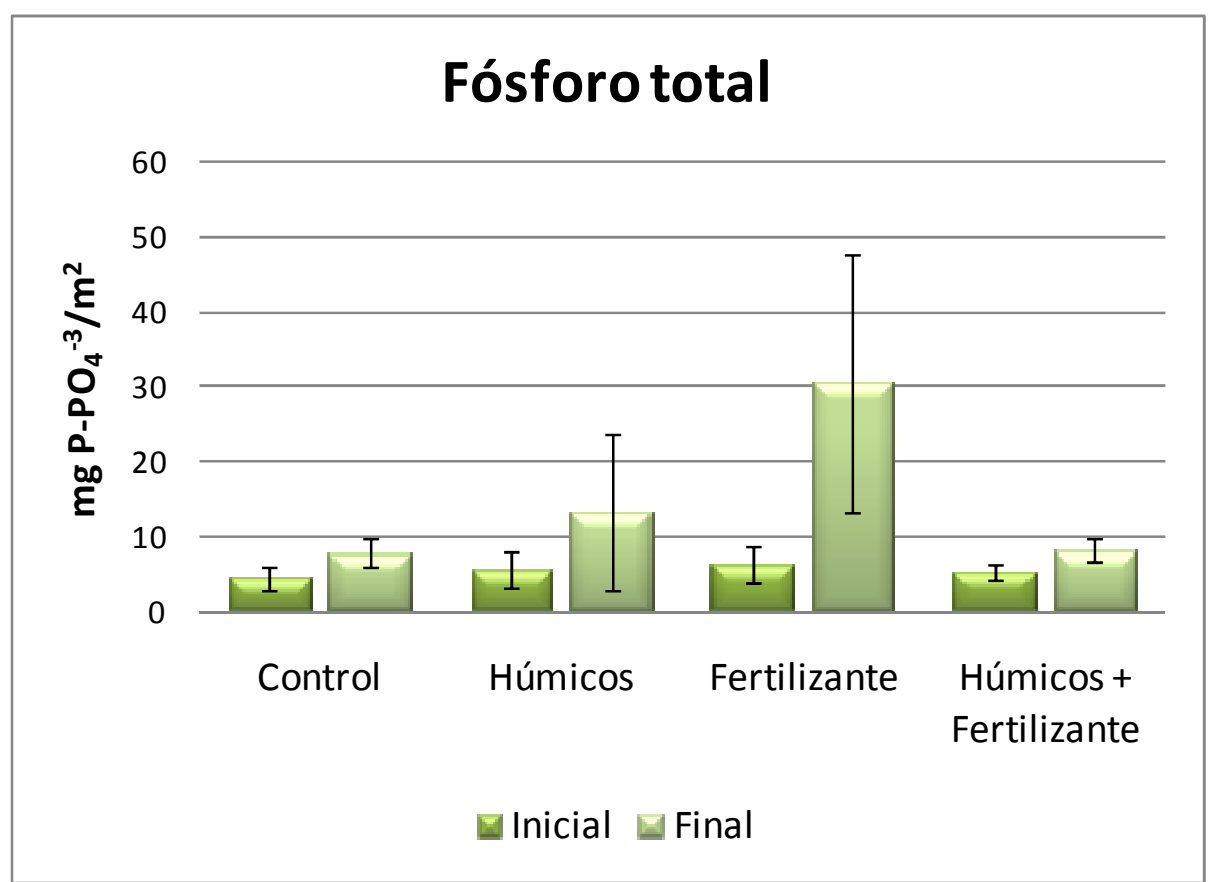

Figura 5.9. Valores medios y desvíos estándar de fósforo total contenido en el perifiton a tiempo inicial y final del experimento 2

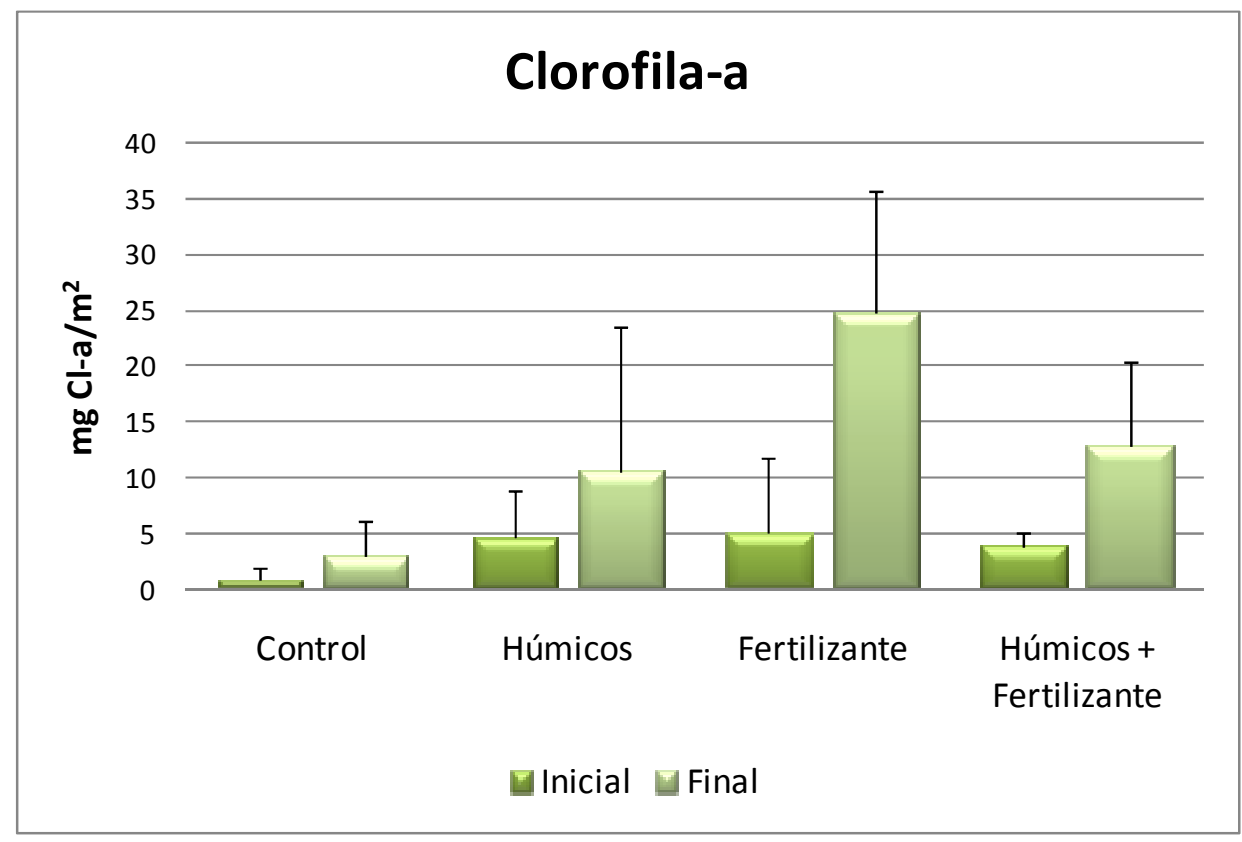

Figura 5.10. Valores medios y desvíos estándar de clorofila-a a tiempo inicial y final del experimento 2 


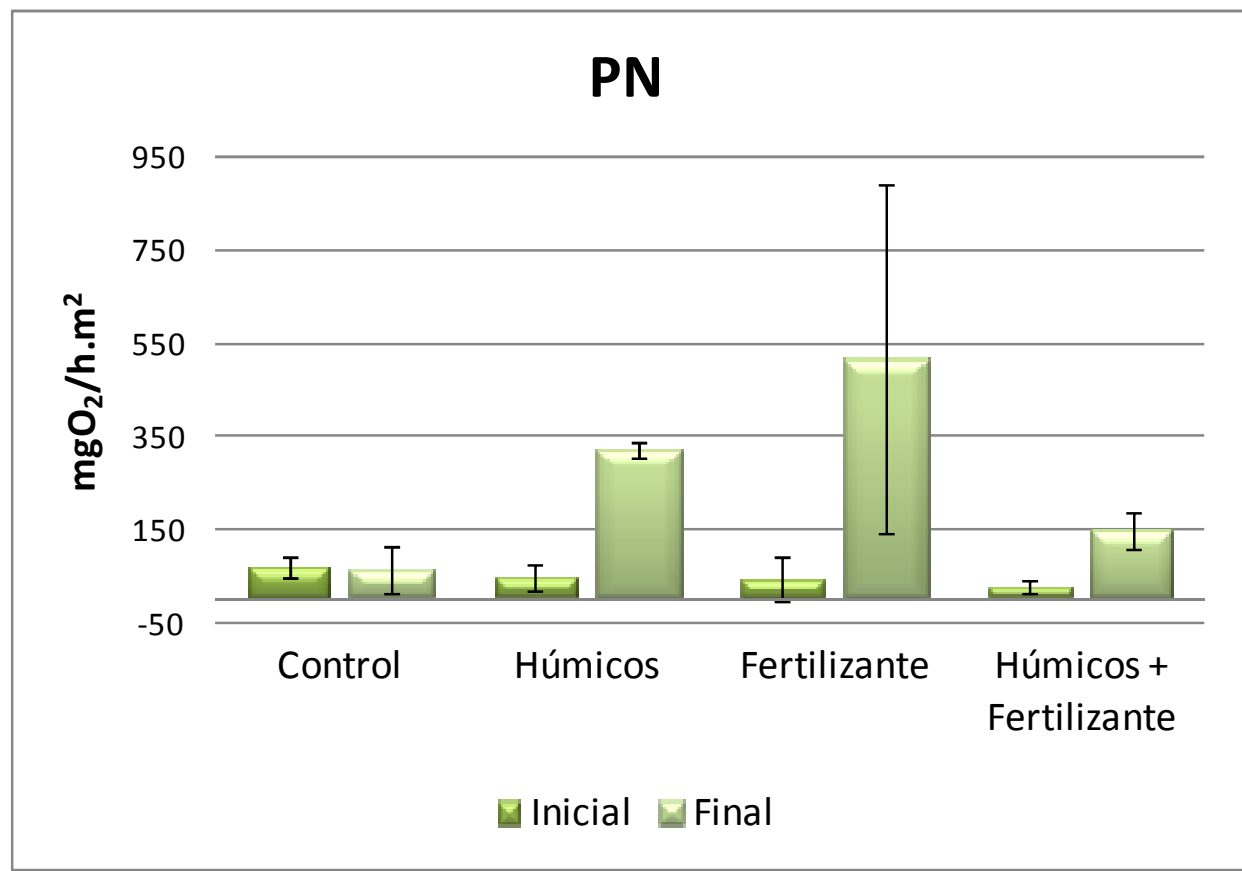

Figura 5.11. Valores medios y desvíos estándar de producción neta a tiempo inicial y final del experimento 2

A modo de síntesis, se detallan en la tabla 5.2 las significancias y variaciones de los parámetros estudiados respecto al control.

Tabla 5.2. Significancias y variación de cada tratamiento respecto al control (Dunnet) para el experimento 2. En naranja los parámetros manipulados, en celeste los estimados en el agua y en verde los estimados en el perifiton.

\section{Húmicos Fertilizante Húmicos + Fertilizante Variación}

\begin{tabular}{l|cccc|} 
PRS & n.s. & n.s. & $* *$ & mayor \\
Nitritos & n.s. & $* *$ & $* *$ & mayor \\
Nitratos & n.s & n.s. & $*$ & mayor \\
Amonio & n.s. & n.s. & n.s. & \\
Cloruros & n.s. & $* *$ & $* *$ & mayor \\
Ácidos Húmicos & n.s & n.s. & n.s. & \\
DQO & $* *$ & n.s. & n.s. & menor \\
Fósforo Total & n.s. & $*$ & n.s. & mayor \\
Clorofila $\boldsymbol{a}$ & n.s. & $*$ & n.s. & mayor \\
Producción neta & n.s. & $*$ & n.s. & mayor \\
\hline
\end{tabular}

Como se observa en la figura 5.11 las estimaciones del metabolismo con el método de cámaras mostraron diferencias significativas respecto al control en la producción neta para el tratamiento con fertilizante. El registro de oxígeno al modo del método de metabolismo abierto se realizó esta vez en tres etapas durante la exposición y 
como en el caso del experimento 1 se observan algunas diferencias entre los tratamientos (fig. 5.12). En los primeros días de exposición (fig. 5.12a) se observa que no hay mucha variación en la concentración de oxígeno entre las horas de luz y las de oscuridad en los tratamientos control, húmicos y húmicos + fertilizante. Cabe destacar que el tratamiento $\mathrm{H}$ mantiene una concentración superior a la del control en todo el fotoperíodo mientras que el tratamiento $\mathrm{H}+\mathrm{F}$ se mantiene por debajo. El tratamiento $\mathrm{F}$ muestra una disminución de la concentración de oxígeno durante las horas de oscuridad más acentuada que el control. Por otro lado, la pendiente de incremento al comenzar las horas de luz es mucho más abrupta hasta alcanzar valores muy superiores al control.

En los días medios de la exposición (fig. 5.12b) el tratamiento F mantiene la concentración de oxígeno por encima de la del control pero la caída en las horas de oscuridad no es tan abrupta. El tratamiento $\mathrm{H}$ muestra un comportamiento similar al del control mientras que el $\mathrm{H}+\mathrm{F}$ mantiene concentraciones menores.

En la última etapa de la exposición (fig. 12c) las curvas de variación de oxígeno registradas son similares a las observadas en la segunda etapa (fig. 12b).

a)

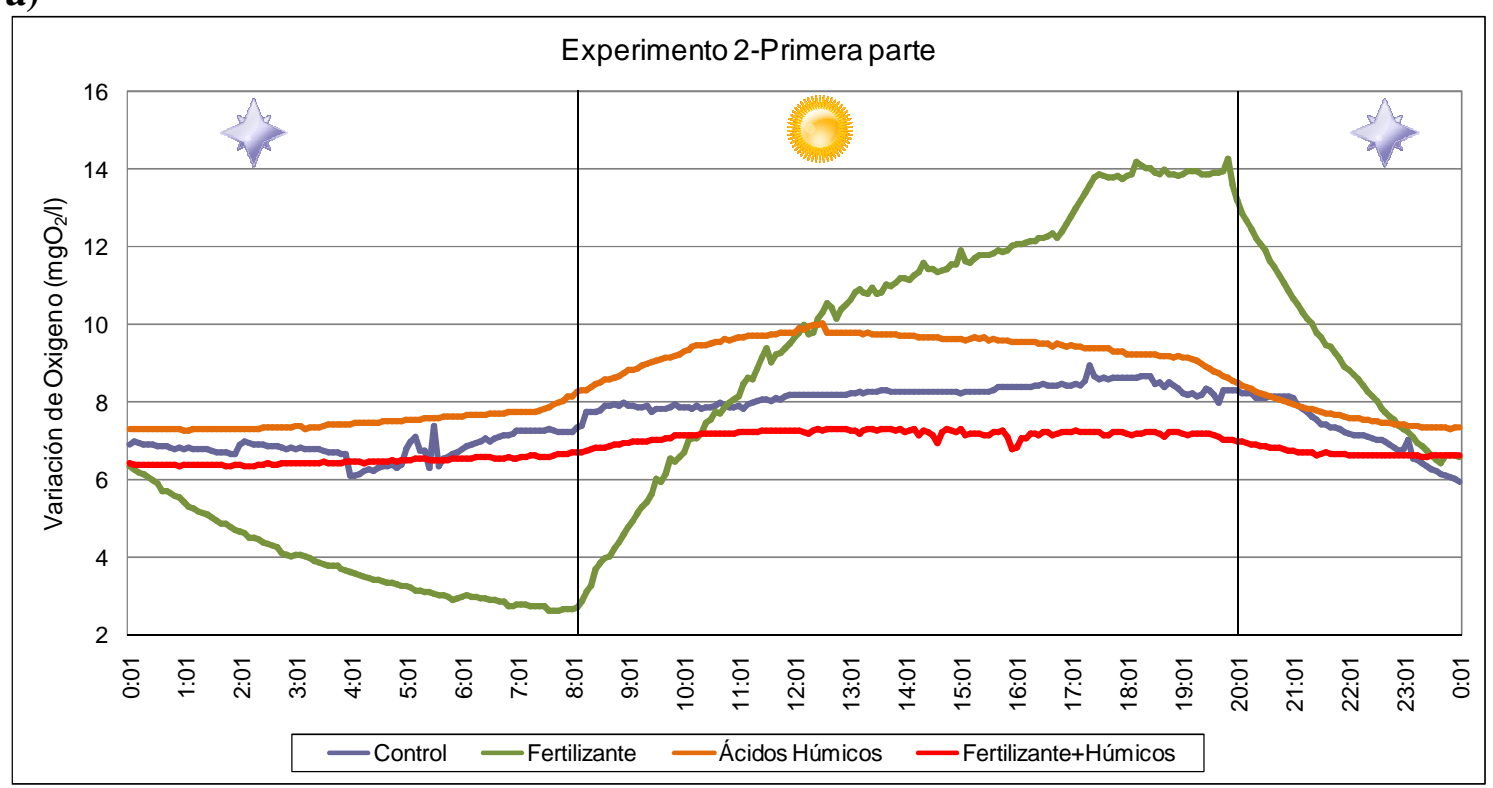


b)

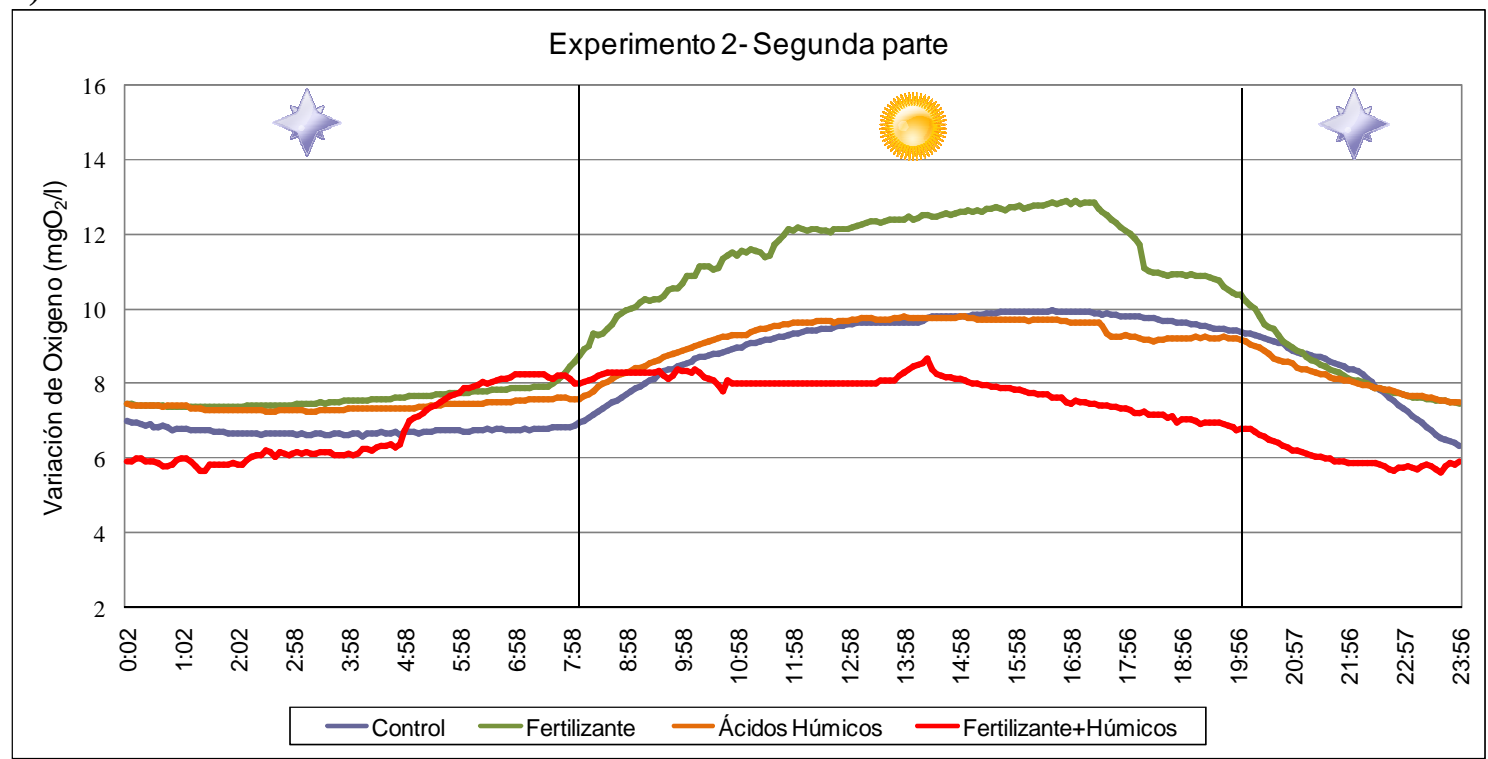

c)

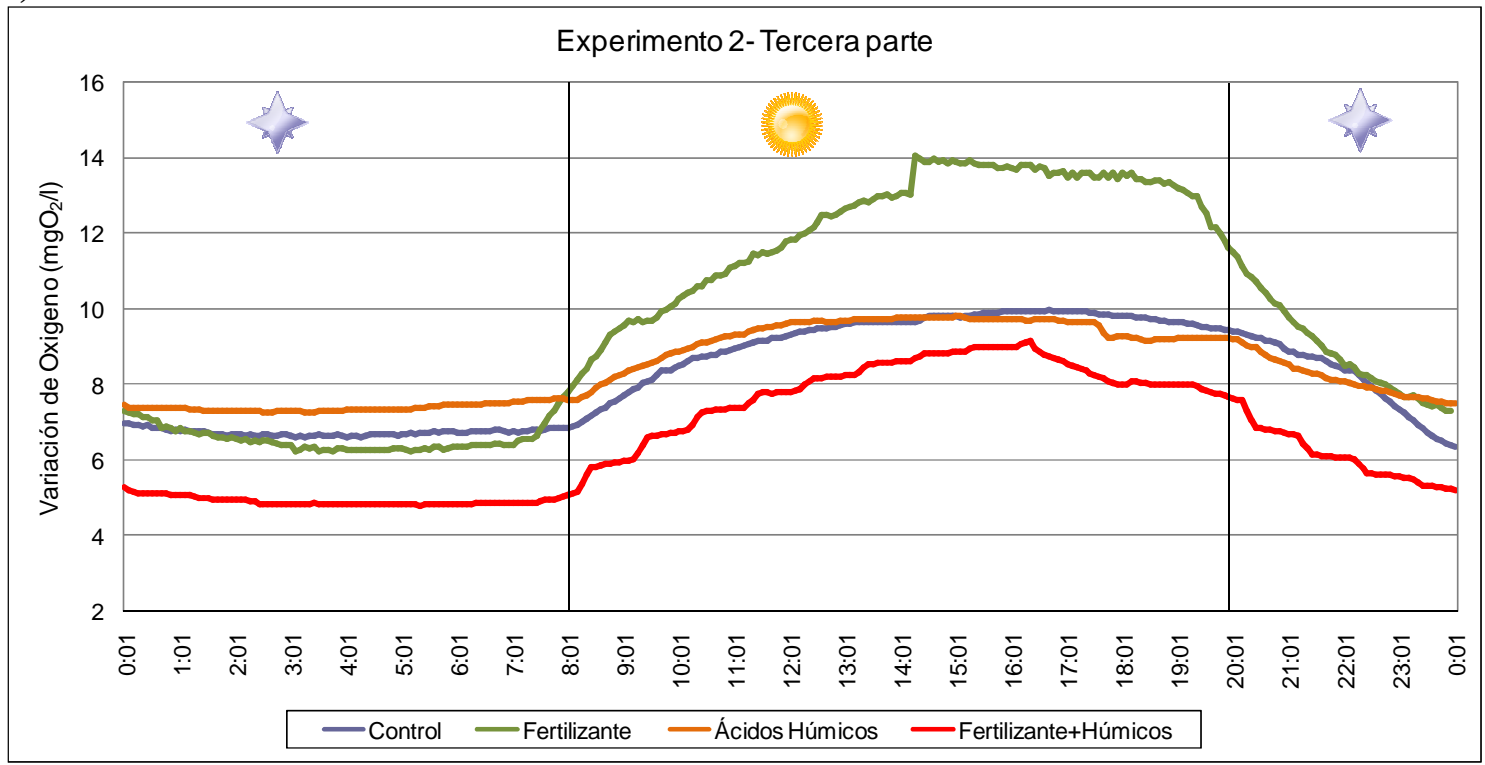

Figura 5.12. Variación de oxígeno diaria para cada uno de los tratamientos. Las líneas verticales delimitan el fotoperíodo. a) Primeros días de exposición (Día 1-3). b) Días en medio de la exposición (Día 4-6). c) últimos días de exposición (Día 6-8)

\section{Experimento 3:}

En este experimento también se utilizaron los tratamientos control (C) y con adición de ácidos húmicos $(\mathrm{H})$. Además, se agregó un tratamiento con adición de glifosato $(\mathrm{G})$ y otro con la adición conjunta de glifosato y ácidos húmicos $(\mathrm{H}+\mathrm{F})$.

Se expuso al perifiton colonizado en los arroyos artificiales a una concentración de herbicida $(0,17 \mathrm{ml}$ herbicida/l) en los tratamientos $\mathrm{G}$ y $\mathrm{H}+\mathrm{G}$ y de ácidos húmicos (50 
ppm) a los tratamientos H y H+G. Luego de una semana de exposición se observó que los ácidos húmicos disminuyeron significativamente $(\mathrm{p}=0,031)$ sólo en el tratamiento conjunto de húmicos y herbicida $(\mathrm{H}+\mathrm{G})$.

Se encontraron diferencias significativas respecto al control en algunos parámetros químicos. El fósforo reactivo soluble disminuyó su concentración en todos los tratamientos salvo en el tratamiento $\mathrm{H}+\mathrm{G}$ que aumentó su concentración en forma significativa ( $p<0,001)$ (fig. 5.13). La demanda química de oxígeno (DQO) no sólo fue mayor a tiempo inicial en los tratamientos con ácidos húmicos $(\mathrm{H}$ y $\mathrm{H}+\mathrm{G})$ sino también el tratamiento con herbicida (G). Luego de una semana de exposición la DQO disminuyó en todos los tratamientos pero esta disminución fue significativa con respecto al control en el tratamiento de $\mathrm{H}+\mathrm{G}(\mathrm{p}=0,048)$ (fig. 5.14). La demanda biológica de oxígeno fue mayor en los tratamientos con herbicida a tiempo final y luego de la exposición se observó una disminución en todos los tratamientos (fig. 5.15). Esta disminución fue significativa en el tratamiento de $\mathrm{H}+\mathrm{G}(\mathrm{p}=0,003)$.

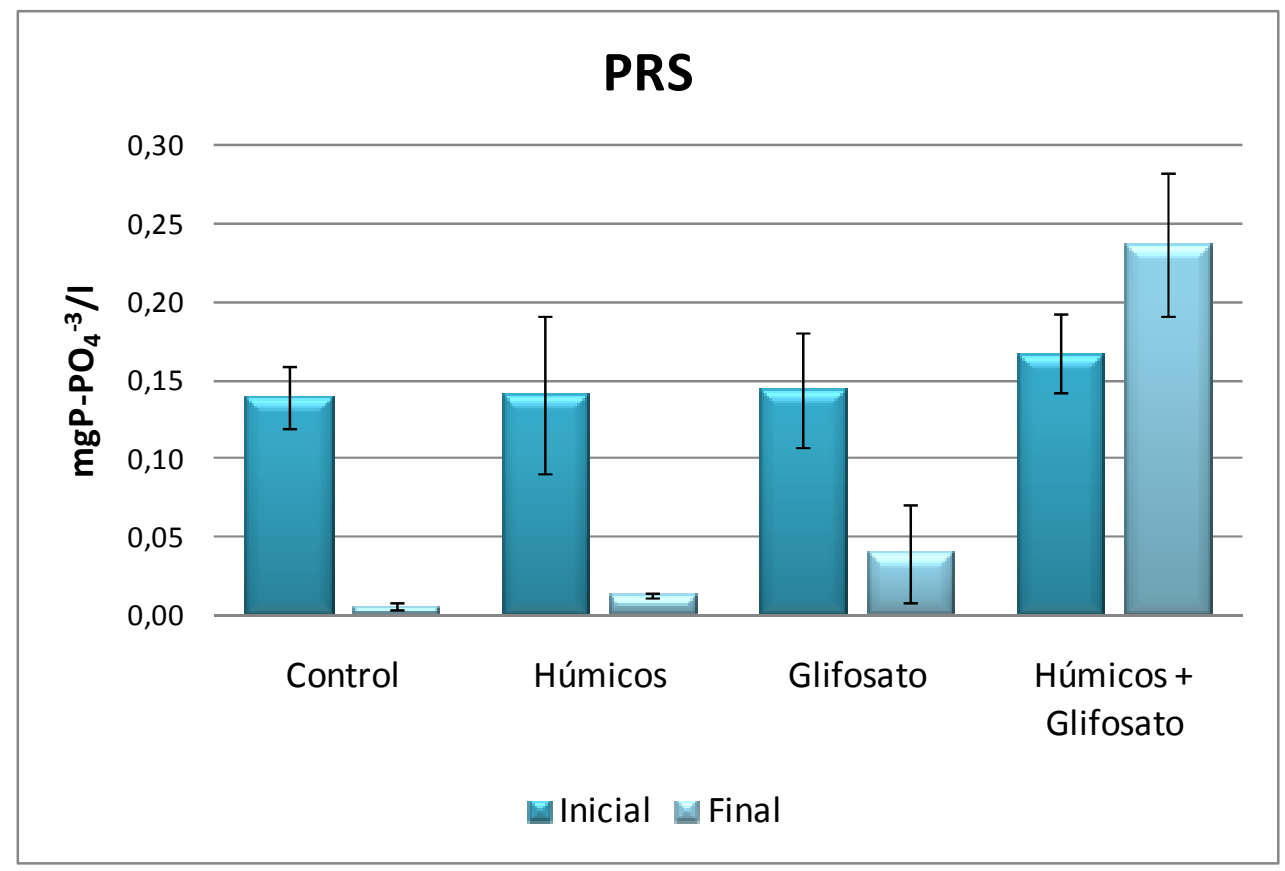

Figura 5.13. Valores medios y desvíos estándar de fósforo reactivo soluble a tiempo inicial y final en el experimento 3 


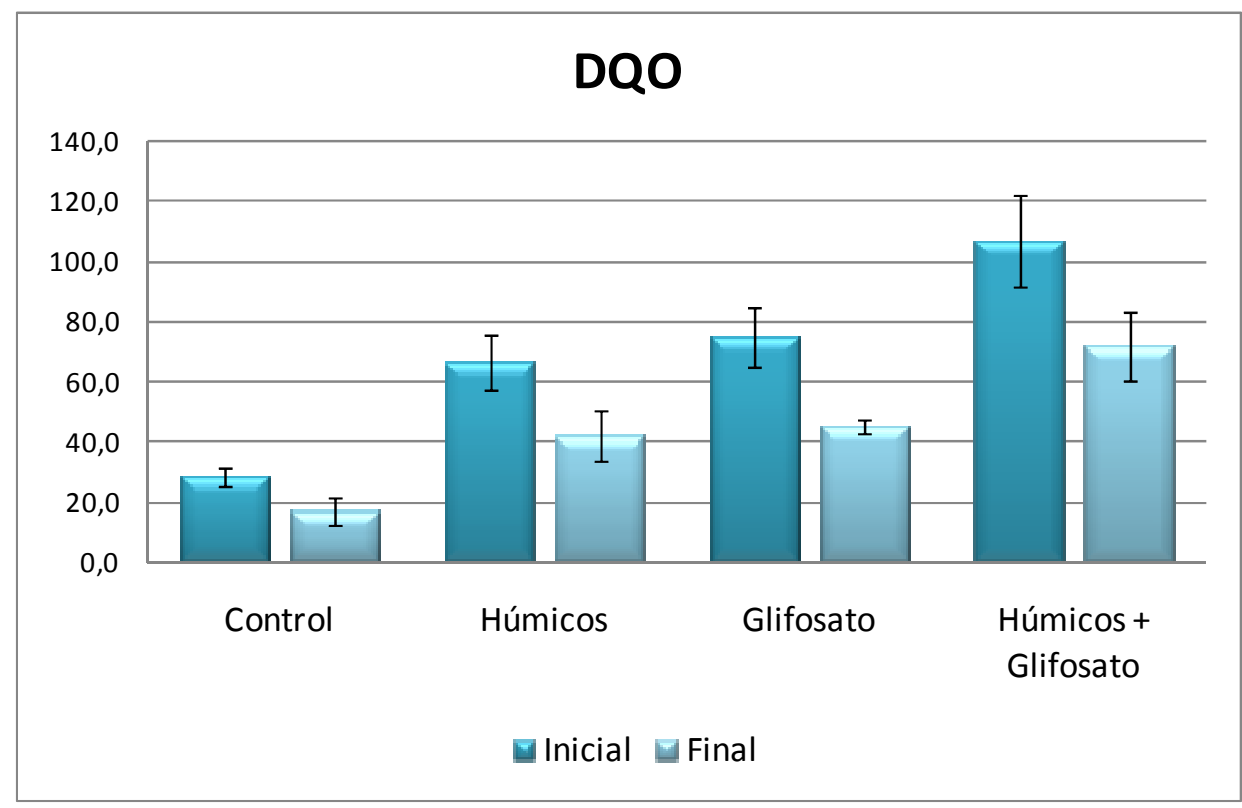

Figura 5.14. Valores medios y desvíos estándar de la demanda química de oxígeno a tiempo inicial y final en el experimento 3. Unidades: $\mathrm{mgO}_{2} / 1$ consumidos

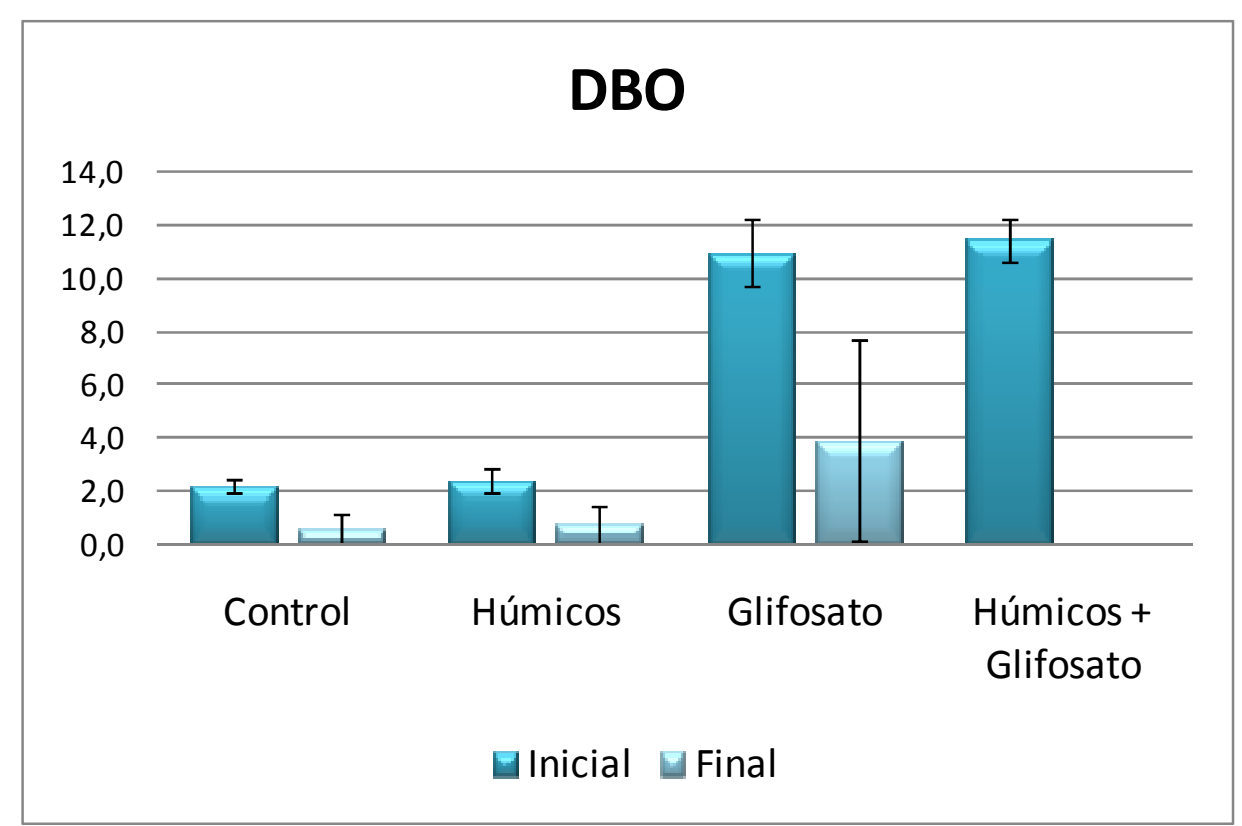

Figura 5.15. Valores medios y desvíos estándar de la demanda biológica de oxígeno realizada en 5 días a tiempo inicial y final en el experimento 3. Unidades: $\mathrm{mgO}_{2} / 1$ consumidos. $\mathrm{La} \mathrm{DBO}_{5}$ final del tratamiento $\mathrm{H}+\mathrm{G}$ es cero.

De acuerdo con el sistema de Lakatos en relación al \% de cenizas, el perifiton en el tiempo inicial podría clasificarse como orgánico en todos los tratamientos. Y a tiempo final como inorgánico-orgánico salvo en el tratamiento de húmicos más glifosato $(\mathrm{H}+\mathrm{G})$ que continuó clasificándose como orgánico. El análisis a posteriori de 
Dunnett muestra que este tratamiento es significativamente diferente al control $(p=0,04)$ (figura 5.16).

La actividad de la enzima fosfatasa alcalina (APA) aumenta a tiempo final en todos los arroyos artificiales. Este incremento fue significativamente menor $(p=0,017)$ que el control en el tratamiento de húmicos + glifosato (fig. 5.17).

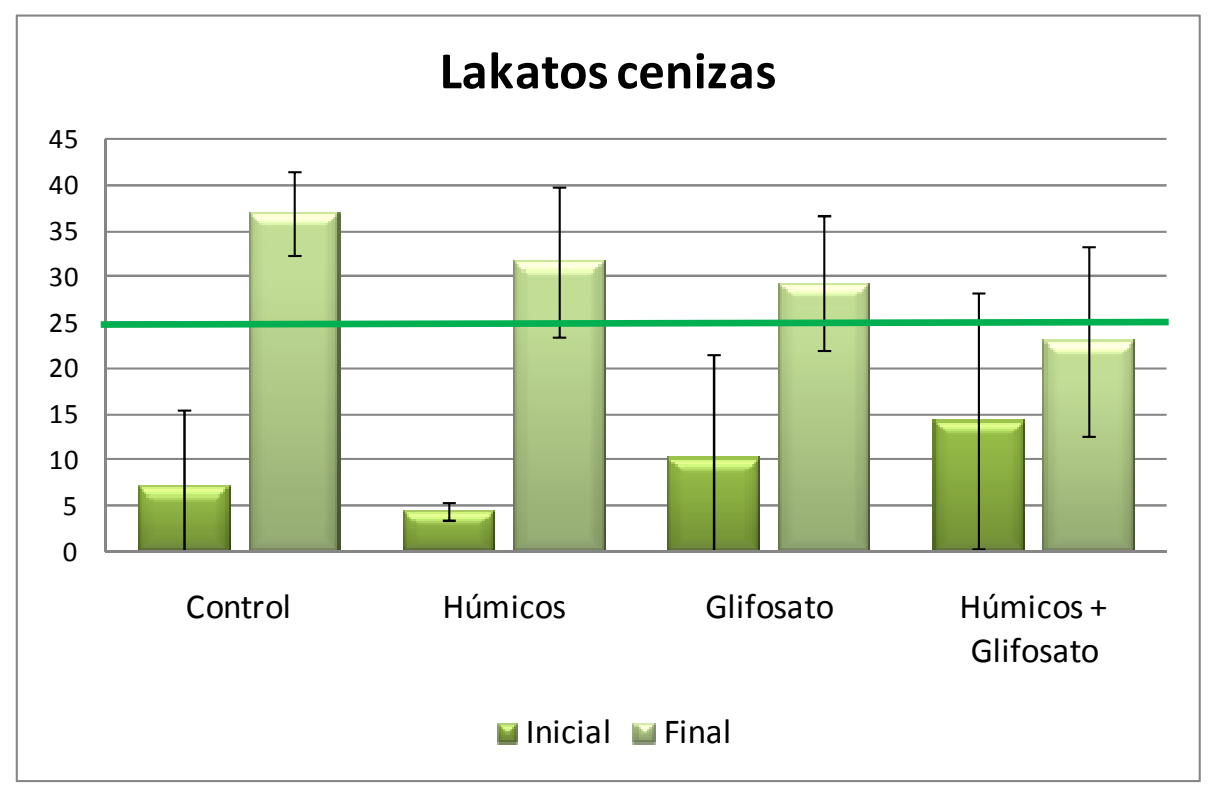

Figura 5.16. Valores medios y desvíos estándar del índice de Lakatos (\% de cenizas) a tiempo inicial y final en el experimento 3. La línea verde marca el límite de $25 \%$. < $25 \%$, perifiton orgánico, $>25 \%$ perifiton orgánico-inorgánico

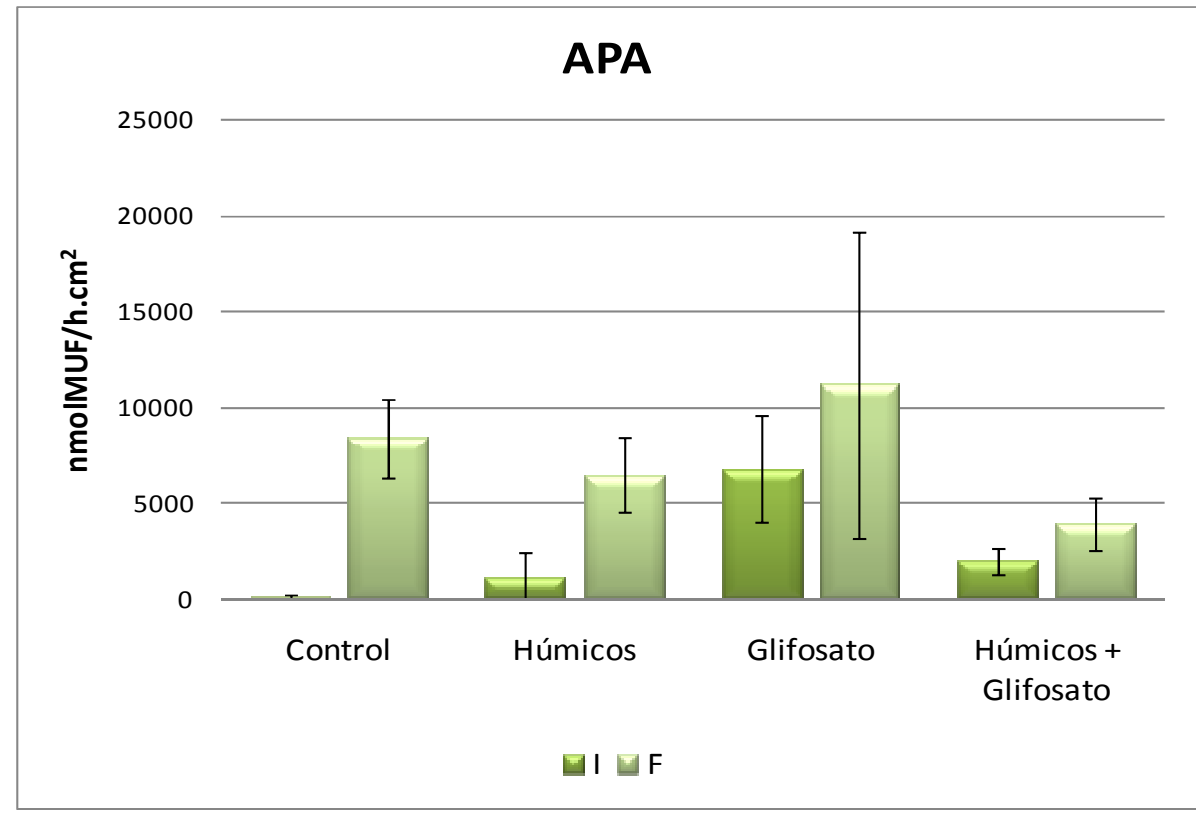

Figura 5.17. Valores medios y desvíos estándar de la actividad de fosfatasa alcalina (APA) a tiempo inicial y final en el experimento 3 
A modo de síntesis, se detallan en la tabla 5.3 las significancias y variaciones de los parámetros estudiados respecto al control.

Tabla 5.3. Significancias y variación de cada tratamiento respecto al control (Dunnet) para el experimento 3. En naranja los parámetros manipulados, en celeste los estimados en el agua y en verde los estimados en el perifiton.

\section{Húmicos Glifosato Húmicos + Glifosato Variación}

\begin{tabular}{|l|cccc|}
\hline Ácidos Húmicos & n.s & n.s. & $*$ & menor \\
PRS & n.s. & n.s. & $* *$ & mayor \\
DQO & n.s. & n.s. & $*$ & menor \\
DBO & n.s. & n.s. & $* *$ & menor \\
Lak. cenizas & n.s. & n.s. & $*$ & mayor \\
Fosfatasa alcalina & n.s. & n.s. & $*$ & mayor \\
\hline
\end{tabular}

\section{Discusión}

Los arroyos artificiales, si bien son sistemas simplificados que no incluyen todos los factores que interactúan en condiciones naturales, han demostrado ser una metodología útil en el estudio del efecto del incremento de la concentración en el agua de nutrientes y glifosato, productos de la contaminación difusa, sobre las comunidades algales del perifiton puesto que han permitido el control de los factores estudiados y su nivel de realismo ha sido suficiente para aproximarse a la respuesta de estas comunidades en condiciones naturales.

El exceso de fósforo tiene un efecto sobre el perifiton que se observa tanto en parámetros estructurales como en funcionales y podría afectar muchos otros aspectos considerados en los estudios ecológicos de los arroyos (McCormick et al. 2001). Sin embargo este efecto puede variar si el fósforo es el único parámetro de cambio (Newman et al. 2003). El experimento 1 contó con un tratamiento donde la única variable manipulada fue la concentración de fósforo y otro con los dos parámetros manipulados (fósforo y sustancias húmicas) para probar la posible respuesta de cotolerancia o respuesta de sinergia de ambos. Este experimento mostró una menor APA en los dos tratamientos con adición de fósforo mientras que la actividad enzimática se incrementó significativamente en los otros dos tratamientos (fig.5.6). En el experimento 2 el parámetro de cambio no fue sólo el fósforo sino que al utilizar un fertilizante comercial se incrementaron también las concentraciones de los nutrientes 
nitrogenados. En este experimento no se encontraron diferencias significativas en la APA tal como sugieren Newman et al. (2003). Wetzel (1992) en un trabajo de revisión sugiere que existe una inhibición de la APA por las sustancias húmicas ya que estas forman un complejo húmico-enzima que reduce la actividad de la enzima. De esta manera el complejo puede ser transportado aguas abajo y reactivarse la actividad de la enzima por degradación bacteriana selectiva del complejo o por fotólisis física mediante radiación UV. Sin embargo en el experimento 1 se encontró una alta actividad tanto en el control como en el tratamiento con ácidos húmicos (tabla 5.1). Por lo tanto los ácidos húmicos en las condiciones de este experimento (luz, temperatura) no modificó la respuesta del APA. En el experimento 3 la APA se incrementó en todos los tratamientos (fig. 5.17) y este aumento de actividad sólo fue significativamente menor en el tratamiento conjunto con el agregado de glifosato probablemente debido a una sinergia entre ambas sustancias que podría producir un aumento de la concentración de fosfatos y/o una inhibición metabólica (Vera et al. 2010). Los húmicos en este caso sí estarían inhibiendo la respuesta del APA quizás al permitir una mayor liberación de fósforo al sistema (Hessen y Tranvik 1998, Steinberg 2003).

McCormick et al. 2001 realizaron una serie de experimentos de adición de fósforo y encontraron que el fósforo añadido fue rápidamente acumulado por el perifiton a una tasa proporcional a la carga. De la misma forma se incrementa el metabolismo proporcionalmente. En nuestros experimentos (1 y 2) se manipuló la concentración de fósforo a tiempo inicial pero se encontraron respuestas diferentes. En el experimento 1 se encontró una mayor reducción de $\mathrm{P}$ en los dos tratamientos con fósforo (tabla 5.1) pero en el experimento 2 no hubo disminución en los tratamientos con fertilizante, incluso la concentración de PRS fue mayor a tiempo final en el tratamiento de fertilizante más húmicos (tabla 5.2). En el experimento 3 no se manipuló la concentración de fósforo aunque el herbicida que se utilizó libera fósforo al medio (Vera et al. 2010). A tiempo final el tratamiento de glifosato más húmicos aumentó significativamente la concentración de PRS (tabla 5.3). Estos resultados sugieren que hay una mayor absorción de PRS cuando existe un exceso del mismo en el medio pero si no es el único nutriente en exceso. Esto probablemente se relacione con la capacidad de homeostasis en la composición estequiométrica del perifiton (Sterner y Elser 2008). En el caso de la fertilización con varios nutrientes los ácidos húmicos impedirían esta 
absorción o estimularían la eliminación del fósforo al medio. De la misma manera actuarían en conjunción con el herbicida.

El fósforo total contenido en el perifiton se incrementó significativamente en los tratamientos con fósforo del experimento 1 (fig. 5.5) pero sólo en el tratamiento fertilizado pero sin húmicos del 2 (fig. 5.9). Esto sugiere que cuando el fósforo no es el único nutriente manipulado los ácidos húmicos impedirían la absorción de fósforo por formación de complejos húmicos-hierro-fosfatos (Hessen y Tranvik 1998, Steinberg 2003) o por coagulación asociada a coprecipitación de metales complejados (Conzonno 2010). Por otro lado, en el experimento 1 no se encontró un incremento significativo de la clorofila $a$ ni del peso seco del perifiton lo que sugiere que existe un consumo de lujo de fósforo por parte de las algas pero no crecimiento (Feijoó et al. 2011). En cuanto a los nutrientes nitrogenados no se observaron diferencias significativas en el contenido de nitrógeno en el perifiton. Sin embargo, tampoco se encontraron diferencias significativas respecto al control en la concentración de amonio en el agua por lo que el amonio inicial podría haber sido captado por las algas en la misma proporción al control y el exceso pasado a una forma oxidada. Tanto la concentración de nitritos como la de nitratos fue significativamente mayor a los controles en el experimento 2 (tabla 5.2), lo que confirmaría el paso del amonio a formas oxidadas por la concentración de oxígeno disuelto en esta agua (Conzonno 2010).

La concentración de húmicos en el agua disminuye en los tratamientos con húmicos en el experimento 1 (tabla 5.1), no muestra diferencias significativas en el 2 (tabla 5.2) y sólo disminuye significativamente en el tratamiento conjunto del experimento 3 (tabla 5.3). Esto podría deberse a un proceso de degradación oxidativa pasando los ácidos húmicos a ácidos fúlvicos de menor peso molecular y ya no se podrían estimar con la técnica utilizada (Steinberg 2003).

En el segundo experimento la concentración de clorofila $a$ y la producción neta fueron significativamente mayores al control en el tratamiento con fertilizante (fig. 5.10 y 5.11) así como encuentran McCormick et al. (2001) en sus resultados. Estas diferencias son inhibidas por la presencia de ácidos húmicos que retendrían y aún precipitarían parte de los nutrientes que podrían hallarse en solución. 
Tanto en el primer experimento como en el segundo se encontraron diferencias en las respuestas metabólicas si comparamos ambos métodos (abierto y cámaras). Estas diferencias se deberían a que las variaciones de oxígeno fueron registradas en diferentes momentos de la exposición. En el primer experimento, utilizando el registro directo en los arroyos artificiales se observa un rápido incremento de la concentración de oxígeno durante las horas de luz en el tratamiento con adición de fósforo. Esta respuesta es menor en los días siguientes. Suponemos que esta es la razón por la que las diferencias de producción neta no ser registraron con el método de cámaras realizado luego de siete días de exposición. En el segundo experimento el incremento en la concentración de oxígeno del tratamiento con adición de fertilizante también fue muy notorio en los primeros días de exposición y se mantuvieron por encima de los valores control en toda la exposición. No ocurrió lo mismo con la respiración ya que el oxígeno disminuye abruptamente durante la noche sólo en los primeros días de exposición y luego se estabiliza. Por ello, en este caso si se observaron diferencias significativas en la Producción Neta del tratamiento con fertilizante luego de una semana pero no hubo diferencia en la respiración en los distintos tratamientos. De modo que puede afirmarse que la información registrada en una escala de tiempo menor concuerda con lo obtenido por Blanck (1985) y apoyaría nuestros supuestos de que los parámetros funcionales se ven afectados primariamente.

El tercer experimento muestra que el glifosato aunque no afecte directamente a los organismos del perifiton, reduciendo su biomasa, por ejemplo, lo afectaría indirectamente cambiar las condiciones del cuerpo de agua. Los arroyos que tuvieron glifosato presentaron una menor absorción de fosfato que se hace nula cuando hay sustancias húmicas (fig 5.13). Tanto las sustancias húmicas como el glifosato incrementan la DQO (fig. 5.14). Por otro lado el glifosato pareciera ser el responsable de un incremento inicial de la $\mathrm{DBO}_{5}$ y una reducción de la misma en el transcurso de una semana (fig. 5.15). Esto puede haber sido producido por daño de la flora bacteriana que pudo provocar su muerte o reducción de su tasa respiratoria.

Teniendo en cuenta las hipótesis iniciales se puede concluir:

- La hipótesis de que una mayor concentración de sustancias húmicas disminuye la biomasa del perifiton y modifica su metabolismo debe rechazarse. 
Esta hipótesis se basó en la posible disminución de biomasa debido a limitación de luz disponible, entre otros factores, que ejercen los ácidos húmicos. Sin embargo, no se encontraron diferencias significativas con respecto al control en cuanto a la biomasa del perifiton ni a su producción neta o respiración en los tratamientos de agregado de ácidos húmicos en los tres experimentos. Si bien podría haber modificaciones en su metabolismo de modo inmediato como muestran las curvas de oxígeno, esto no se sostendría en el tiempo probablemente por la capacidad de adaptación de los organismos.

- La captación de nutrientes y agroquímicos por parte del perifiton se alteran por la concentración de sustancias húmicas en el agua.

La captación de nutrientes fue variable primero dependiendo del nutriente (fósforo o fertilizante) pero además por el efecto producido por las sustancias húmicas. En el experimento con agregado de fósforo los ácidos húmicos no modificarían la incorporación de éste a las algas. Sin embargo, en el experimento con fertilizante la captación de fósforo en el tratamiento conjunto con húmicos no fue significativa respecto al control pero sí en el de fertilizante solo por lo que las sustancias húmicas alterarían esta captación. En cuanto al glifosato, las sustancias húmicas permitirían una liberación más eficiente del fósforo contenido en el herbicida posiblemente por disociación del mismo (por formación de complejos húmicos-hierro-fosfatos o por coagulación asociada a coprecipitación de metales complejados), por lo que se observó una menor actividad de la fosfatasa alcalina.

- El grado de cotolerancia del perifiton a las sustancias generadas por las actividades agrícolas-ganaderas está influido por las interacciones entre esas variables.

Las sustancias húmicas naturales de los arroyos pampeanos llegan a los mismos a través de la escorrentía superficial al igual que los nutrientes y pesticidas generados por las actividades agropecuarias. La interacción de estas sustancias muestra una cotolerancia del perifiton, por ejemplo en el experimento 2 se observó un incremento significativo de la clorofila- a y de la producción neta (sinónimos de eutroficación por incorporación de nutrientes) sólo en los tratamientos con agregado de fertilizante pero no en el tratamiento conjunto $(\mathrm{H}+\mathrm{F})$. Esto podría significar que el ingreso a los cuerpos de agua de las distintas sustancias provenientes de actividades agropecuarias produjeran 
efectos que duraran escaso tiempo pero que a largo plazo provocarían cambios en las comunidades. Por otro lado, la mezcla de diferentes sustancias podrían generar situaciones en las que algunas, como las sustancias húmicas, inhibieran total o parcialmente a otras como los nutrientes o biocidas (por formación de complejos húmicos-hierro-fosfatos o por coagulación asociada a coprecipitación de metales complejados). 


\section{Capítulo 6}

Discusión y Conclusiones 
El perifiton tiene muchas ventajas potenciales como indicador biológico en monitoreos de calidad de agua ya que ofrece información complementaria a la suministrada por las variables físicas y químicas (Cairns et al. 1993). Quizás la ventaja más importante es que juega un rol clave en la transducción de energía y en la incorporación o retención de nutrientes (Sabater et al. 2000). En la zona en la que se desarrolló este estudio el perifiton y en particular el epifiton, es un componente irremplazable del sistema ya que tiene un papel fundamental en el metabolismo de los ríos porque es el mayor responsable de la producción primaria neta superando a las macrófitas (Vilches y Giorgi 2010). También se afirma que responde predictiva y rápidamente a los cambios en las condiciones ambientales en un gran rango de escalas espaciales (Gaiser 2009). Sin embargo, el uso directo del perifiton como indicador tiene sus limitaciones ya que a veces las causas ambientales de la respuesta de la comunidad son difíciles de identificar (Cattaneo et al. 1993) o cuantificar en términos absolutos (Sand-Jensen y Borum 1991). Para interpretar estas limitaciones en este estudio se trabajó tanto con perifiton desarrollado sobre sustratos naturales como con el que colonizó sustratos artificiales colocados en los arroyos considerados y también se estudió la respuesta del perifiton en un sistema experimental completamente artificial. Este tipo de abordaje permitió aislar los factores que se destacan por su nivel explicativo en el trabajo de campo, de manera de estudiar su efecto aislado y contrastarlo con la respuesta hallada en los arroyos (Salt 1971). Por otro lado, el uso de sustratos artificiales permitió la incorporación de parámetros funcionales con medidas sensibles y eficientes para detectar el impacto sobre el funcionamiento del perifiton aislado de su interacción con el sustrato natural tal como ha sido recomendado por Kalff (2003).

Todas las variables que intervienen en el desarrollo de las comunidades algales son susceptibles de alterar de algún modo su sensibilidad de las comunidades frente a contaminantes (Navarro 1998). Estas variables que modifican la tolerancia pueden ser factores propios de la dinámica del perifiton como la sucesión de especies y la edad de la comunidad (Guasch et al. 1997). También pueden ser variables ambientales como la irradiancia (Wetzel 1992) o la velocidad del agua (Navarro et al. 2000) entre otras. Por la importancia detectada durante los muestreos en los arroyos, los ácidos húmicos se consideran una variable destacada en estos ambientes. Si bien su presencia no ha sido considerada relevante en estudios anteriores o simplemente se han estimado para ser utilizados como descriptores de los sitios de muestreo nuestros resultados demuestran 
que los ácidos húmicos, en arroyos pampeanos, deben ser tenidos en cuenta como una variable clave más, por las repercusiones que tienen en el desarrollo de las comunidades, tanto por la interferencia lumínica como por los cambios que producen en la biodisponibilidad de los nutrientes (Steinberg 2003). Las implicaciones ecológicas del mecanismo de atenuación en la captación de nutrientes debido a una alta concentración de ácidos húmicos (encontradas en los experimentos del capítulo 5) son remarcables. Nuestros resultados muestran que el perifiton expuesto a altos contenidos de ácidos húmicos se vería poco afectado por el incremento de nutrientes. Las sustancias húmicas inhiben la captación de fósforo (por formación de complejos o coprecipitación) por parte de las algas cuando hay un incremento de varios nutrientes (fertilizante) como se observó en el experimento 2 del capítulo 5. De acuerdo con estos resultados sería posible predecir que el efecto de incremento de nutrientes sobre el perifiton debido a las lluvias será menor en ambientes con altos contenidos de ácidos húmicos.

Idealmente en los estudios sobre el efecto de contaminantes en la comunidad perifítica deberían considerarse tanto los parámetros estructurales como los funcionales de la comunidad (Sabater et al. 2002, Crossey y La Point 1988). Sin embargo, la mayoría de los estudios se enfocan solamente en los atributos estructurales ya que muchos son de bajo costo y rápidos de muestrear (Boulton 1999). También debe destacarse que el uso de atributos estructurales en este tipo de estudios ha estado generalmente limitado a la evaluación de la composición taxonómica que aunque no es costosa requiere de especialistas y necesita mucho tiempo para ser realizada (Burns y Ryder 2001). La medición de atributos funcionales da una idea de procesos del ecosistema que son fundamentales para la salud de los ríos y que no son fácilmente asequibles a través de los atributos estructurales. Por otro lado, comparativamente con algunos parámetros estructurales como la composición específica de la comunidad, los parámetros funcionales pueden estimarse con mucho menos esfuerzo para evaluar la salud ecológica de los ambientes acuáticos (Gessner y Chauvet 2002).

En esta tesis se trabajó tanto con parámetros estructurales como funcionales. Nuestros resultados mostraron que los parámetros estructurales que mejor indicaron el efecto de la contaminación difusa sobre el perifiton fueron la estimación de biomasa como concentración de clorofila $a$, el contenido de fósforo total en el perifiton, la composición taxonómica, y entre los funcionales el metabolismo de la comunidad 
expresado como producción neta y la actividad de la exoenzima fosfatasa alcalina. Sin embargo, ninguno de estos parámetros por sí solos sería "el mejor indicador" sino que se necesitaría una combinación de ellos para interpretar los cambios acerca de los que nos informan. Podría decirse que los parámetros funcionales serían sistemas de alerta temprana de contaminación debida al uso agropecuario de la tierra u otros tipos de contaminación difusa, mientras que los estructurales informarían acerca de situaciones sostenidas de buena o mala calidad del agua tal como se observó en la respuesta metabólica inmediata en los registros diarios de oxígeno de los experimentos 1 y 2 del capítulo 5. Estos resultados concuerdan con Boisson y Perrodin (2006) que en una serie de experimentos con agua de escorrentía urbana encontraron que la actividad fotosintética del perifiton ( $\mathrm{PN}$ y R) constituye un indicador más sensible al disturbio porque se vio modificada ante cualquier concentración de tóxico o dilución de agua de escorrentía. En cambio, la biomasa (peso seco orgánico y Clorofila $a$ ) se modificó pero sólo en respuesta a una concentración de tóxico determinada, a un mayor tiempo de exposición o a una baja dilución del agua de escorrentía. De cualquier modo, en algunos casos la respuesta conjunta de un parámetro estructural como el peso seco orgánico y una funcional, la producción neta, fueron significativamente afectados por concentraciones bajas de amonio (Niederlehner y Cairns 1990).

La biomasa (peso orgánico, clorofila $a$ ) es un indicador estructural utilizado a nivel mundial. Sin embargo, no parece ser un indicador muy fiable de la calidad química del agua ya que este parámetro tiene una fuerte dependencia de las condiciones hidráulicas y la disponibilidad de luz (Montuelle et al. 2010). Por otro lado, el estudio de la estructura de la comunidad en su composición taxonómica es un factor muy útil ya que permite la comparación histórica basada en fuentes bibliográficas (Burns y Ryder 2001). En nuestra zona de estudio esta bibliografía de base es deficitaria ya que pocos investigadores han trabajado en algas de cuerpos lóticos de la zona. Por ejemplo, Loez y Topalian (1999) estudiaron el fitoplancton del río Reconquista, Giorgi (1998) trabajó sobre el fitobentos y perifiton de arroyos de la cuenca del río Luján, Gómez y Licursi (2001) estudiaron el epipelon en ríos y arroyos de la región, Claps (1996) estudió el epipelon del Río Samborombón, Pizzarro y Alemanni (2005) estudiaron el perifiton del río Lujan.

La actividad de la fosfatasa alcalina pese a que es un indicador sensible a los cambios de las concentraciones de fósforo presentó en los experimentos de este estudio 
interacciones con otros factores como la luz, las sustancias húmicas y la componente bacteriana de la comunidad. Por ello debe usarse en conjunción con otros indicadores complementarios para tenerla en cuenta como sistema de alarma temprana tal como sugieren Newman et al. (2003).

Los experimentos de este estudio se llevaron a cabo en una comunidad con características de $\beta$-mesosaprobios formada por organismos con diferentes sensibilidades a los contaminantes. El estrés podría modificar la composición taxonómica de las poblaciones de algas, causando una reducción en el número de especies sensibles y un aumento en el número de especies tolerantes. Nuestros resultados muestran que siete de los ocho géneros señalados por Palmer (1969) como más tolerantes a la contaminación orgánica pertenecen a las especies más abundantes del sitio de estudio. Sin embargo, una situación de estrés podría no inducir de forma automática las modificaciones estructurales y/o funcionales, debido a la producción de numerosos procesos fisiológicos de regulación. Por ejemplo, la captación de lujo de fósforo no lleva asociada un incremento en la biomasa (Havens et al. 1999). Del mismo modo, en el experimento 1 del capítulo 5 no se encontró un incremento significativo de la clorofila $a$ ni del peso seco del perifiton sugiriendo un consumo de lujo por parte de las algas no asociado a crecimiento.

La contaminación difusa está relacionada con los eventos climáticos (cantidad, calidad y periodicidad de precipitaciones), así como con las condiciones geográficas (geomorfología, pendiente) y geológicas (tipo de suelo), por lo que el grado e impacto puede diferir significativamente desde un lugar a otro y de un año a otro. La dificultad para evaluar y predecir los impactos se debe a las características intermitentes de contaminación, su variabilidad espacio-temporal, y una multitud de procesos físicos, químicos y biológicos que condicionan la respuesta (Novotny 2003).

Según Cambell et al. (2004) la erosión del suelo es la mayor causa de contaminación difusa y los sedimentos son el contaminante más visible. El material particulado en suspensión estimado en los arroyos en el capítulo 3 fue una variable importante en el Análisis de Componentes Pricipales (fig. 3.4) y muestra una variación estacional asociada al régimen de lluvias (anexo). Esta variación puede enmascarar las posibles diferencias entre sitios ganaderos y agrícolas. La erosión puede producir deterioro o destrucción del hábitat acuático por la excesiva deposición de sedimentos en 
los tramos de poca corriente que "pavimenta" el bentos de los arroyos con materia inerte y también causa una rápida pérdida de la capacidad de almacenamiento en estos sitios. Además, los nutrientes transportados con el sedimento pueden estimular el crecimiento algal (experimento 1 y 2 capítulo 5) y consecuentemente, acelerar los procesos de eutrofización, así también pueden ingresar los componentes persistentes de pesticidas con bajas solubilidades en agua que son adsorbidos por los sedimentos en suspensión. Finalmente, la turbidez producida por los sedimentos reduce la fotosíntesis en los arroyos (por ejemplo arroyo Nutrias y Durazno I, ganaderos de alta intensidad, capítulo 4), los tipos de hábitat disponibles por reducción de macrófitas y la cantidad y calidad del alimento disponible para los herbívoros por reducción del perifiton que se desarrolla sobre las macrófitas (Cambell et al. 2004).

Según los autores mencionados previamente el sobrepastoreo también puede considerarse contaminación difusa ya que produce pisoteo con la consecuente compactación del suelo y pérdida de la cobertura vegetal en las márgenes. De esta manera, reduce los servicios ecosistémicos de las áreas de ribera como la amortiguación de los impactos de la agricultura y la ganadería. En este estudio los sitios ganaderos de alta intensidad ( $>5$ cabezas/Ha y sin alambrado) están asociados al sobrepastoreo de las márgenes y compactación del suelo por pisoteo además de los ingresos puntuales de materia orgánica y nutrientes por animal. Nuestros resultados muestran para estos sitios un perifiton heterotrófico e inorgánico (capítulo 3 y 4), la composición de especies representada por Chlorophyta y Cyanophyta (fig. 4.6) y una mayor distancia de estos sitios respecto a los otros usos en el análisis de discriminante (fig. 4.4)

Los ingresos de nutrientes a los arroyos pueden ser de manera natural a través de la atmósfera, la vegetación ribereña, los peces migratorios o la erosión de sus cauces. Los ingresos antropogénicos convencionalmente se dividen en dos tipos: "fuentes puntuales" con altas concentraciones de formas solubles, descarga continua desde pocos puntos discretos asociados a efluentes industriales o de plantas de tratamiento, y "fuentes difusas" con una gran proporción de formas particuladas en la escorrentía superficial o subsuperficial que llegan únicamente durante eventos de tormentas desde un número disperso de puntos de entrada a la cuenca asociados a la agricultura. Sin embargo, existen fuentes con características intermedias entre puntual y difuso, en ellas se incluyen los campos ganaderos (Withers y Jarvie 2008). Los campos ganaderos sin exclusión del ganado al cuerpo de agua producen un ingreso continuo de nutrientes y 
material particulado además de los episodios de ingresos de materia (orgánicainorgánica) asociados a las lluvias.

Las relaciones entre los ingresos de fósforo a los arroyos, la concentración de fósforo en la columna de agua y en el sedimento y la respuesta de las comunidades son complejas. Los tiempos de residencia del agua pueden fluctuar extensamente y la capacidad de los sistemas acuáticos para asimilar fósforo es muy variable tanto espacial como temporalmente (Withers y Jarvie 2008).

La contaminación difusa, además de estar asociada a los eventos de lluvia, también depende del tipo de suelo y de la estacionalidad. Suelos más estructurados como los argiudoles típicos de la región pueden retener gran cantidad de nutrientes y pesticidas en su matriz mientras que suelos más desagregados como los Natracuales o Alfisoles típicos de áreas ribereñas tendrán menos capacidad de retención por su escasa capacidad de intercambio catiónico (Lavado et al. 1982). Por esa razón las zonas de ribera cumplen una función muy importante en el área de estudio (Troitiño et al. 2010). Respecto a la incidencia de la estacionalidad, en períodos secos hay mayor evapotranspiración y absorción en el suelo de los campos por lo que habrá menos escorrentía. Por otro lado, los campos agrícolas quizás no se vean afectados tanto por la estacionalidad sino más por el manejo ya que sus "estaciones" pueden clasificarse en siembra-cosecha-rastrojo y los períodos de aplicación de fertilizantes/pesticidas asociados. Así también la carga de contaminantes desde campos ganaderos como fuente difusa depende del manejo pecuario que se realice, es decir con o sin exclusión al cuerpo de agua, con pastura natural o implantada o fertilizada, así como número de cabezas de ganado, su densidad y rotación (Tabla 6.1).

Tabla 6.1. Factores que intervienen en cada tipo de uso agropecuario de la tierra

\begin{tabular}{|c|c|c|c|c|}
\hline Tipo & $\begin{array}{c}\text { Tipo de } \\
\text { Descarga }\end{array}$ & $\begin{array}{c}\text { Incidencia de } \\
\text { la lluvia }\end{array}$ & $\begin{array}{c}\text { Incidencia } \\
\text { estacional }\end{array}$ & $\begin{array}{c}\text { Incidencia del } \\
\text { manejo }\end{array}$ \\
\hline Agrícola & Episódico & Alta & Media & Alta \\
\hline \multirow{2}{*}{ Ganadero } & Episódico & Alta & Alta & Media \\
\cline { 2 - 5 } & Continuo & Baja & Baja & Alta \\
\hline
\end{tabular}


Sin embargo, como se vio en el capítulo 3, cuando las lluvias suceden durante varios días, los suelos se colmatan perdiendo su capacidad de infiltración y comportándose como suelos impermeables, por lo que las variables fisicoquímicas muestran una homogeneidad de sitios donde no se pueden distinguir el efecto sobre los cuerpos de agua de distintos tipos de usos agropecuarios.

Como se dijo antes, las zonas de ribera preservadas son más importantes en controlar los efectos de la eutroficación que lo que pueda deberse al manejo del ingreso de nutrientes. En zonas donde las riberas han sido preservadas (Las Flores, ganadero baja intensidad) no se observa un incremento significativo de biomasa algal debido al filtrado de los nutrientes que realizan estas zonas de amortiguamiento (Lee et al. 2003). El efecto estimulador del metabolismo y el crecimiento por parte de los nutrientes sobre el perifiton puede ser mucho mayor que el efecto negativo de los pesticidas como se desprende de los resultados de los experimentos del capítulo 5. Esto también ha sido observado por Ma et al. (2011). Ferreiro et al. (2011) encuentran que en los arroyos pampeanos, naturalmente ricos en nutrientes, los organismos descomponedores pueden ser más propensos a almacenar o utilizar los nutrientes adicionales para procesos como la reproducción en vez de usarlos para el crecimiento. De la misma manera, en el presente estudio encontramos una mayor concentración de fósforo total contenido en el perifiton pero no un incremento de la concentración de clorofila $a$ o de la producción neta.

La mayoría de los estudios sobre contaminación difusa se han realizado en ambientes que eran originalmente oligotróficos y pasaron a ser eutróficos en respuesta al uso agropecuario. Al ser ambientes con escasos recursos para los autótrofos por mínimo que sea el ingreso de nutrientes el perifiton responde aumentando la biomasa (Heinonen 1984, Stevenson et al. 1996) hasta llegar a valores considerados floraciones peligrosas (Dodds 2007, Havens et al. 2003). También puede cambiar la composición taxonómica desde una mayor proporción de Bacillariophyta a una comunidad estructurada mayoritariamente por Chlorophyta filamentosas (McCormick et al. 2001). Sin embargo, en las zonas ganaderas donde se permite el ingreso del ganado a los cuerpos de agua el aumento de turbidez generado por los animales modifica los procesos fotoquímicos impidiendo en muchos casos la captación de los nutrientes ingresados (Middleton 2010). 
Los ambientes eutróficos responden de manera diferente a los oligotróficos frente a la contaminación difusa. Por ejemplo, las algas del perifiton incrementan su biomasa y metabolismo pero sólo en condiciones favorables de luz y temperatura, por lo que la estacionalidad es un factor importante aunque puede variar su intensidad con un aumento de caudal (Uehlinger y Brock 2005, Sabater et al. 2005). Los ambientes en los que se trabajó en este estudio pueden considerarse eutróficos por su concentración de nutrientes (Feijoó y Lombardo 2007). Se encontró que para los sitios afectados por ganadería en los campos aledaños al arroyo, el perifiton es mayormente heterotrófico, y las especies de algas que aportan a la similitud entre estos sitios (tabla 3.6) son Trachelomonas sp3 (indicador de medianas a altas concentraciones de materia orgánica y amonio) (Garduño Solórzano et al. 2011), Raphidiopsis mediterranea (tolerante a condiciones de baja intensidad lumínica (Reynolds et al. 2002) y Nitzschia palea (una de las especies más tolerantes a la contaminación severa por nutrientes y materia orgánica) (Palmer 1969, Round 1993). En cambio, en los sitios agrícolas se encontró un perifiton auto-heterotrófico con mayor variación estacional y mayor riqueza específica donde las algas que más aportan a la similitud son Synedra ulna y Gomphonema parvulum (ambas especies son señaladas entre las más tolerantes a la contaminación severa por nutrientes (Round 1993)).

El perifiton es una comunidad que según Cattaneo et al. (1993) se "resiste" a ser modelada debido a la complejidad de su estructura y su heterogeneidad espacial. Aunque no es posible predecir cuáles serían los cambios en el perifiton más esperados en las distintas situaciones se pretendió mediante la realización de este estudio, tener herramientas para detectar este tipo de contaminación. Como un paso en ese sentido, se elaboró un esquema general predictivo para arroyos pampeanos en base a las respuestas posibles en la comunidad perifítica desarrollada en arroyos con ganadería o agricultura en función de los resultados obtenidos en esta tesis. Se tuvo en cuenta el tipo e intensidad de uso de la tierra para diferenciar los posibles impactos (fig. 6.1). 


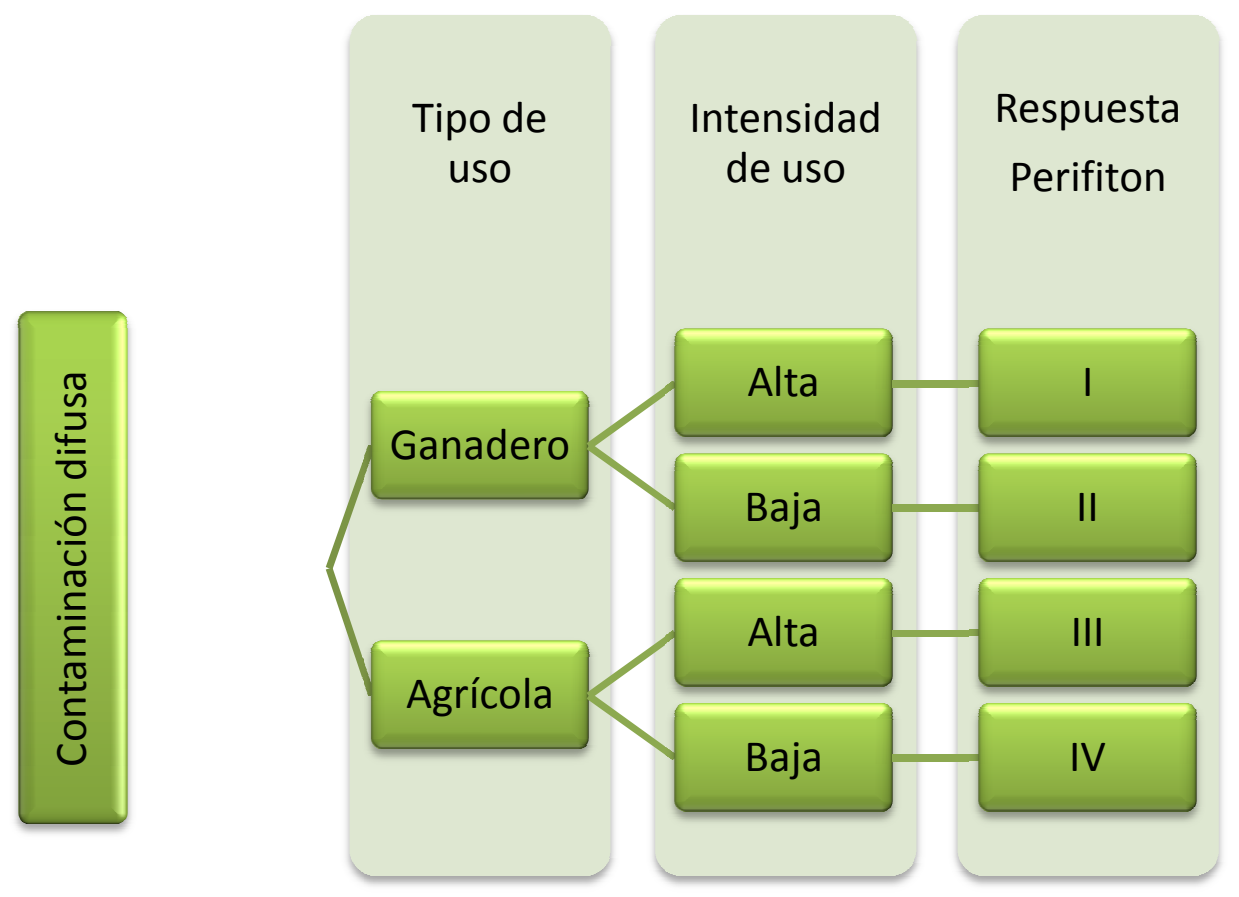

Figura 6.1. Esquema general predictivo del tipo de respuesta esperable de acuerdo al tipo e intensidad de uso.

Respuesta Tipo I: Se manifestó en situaciones de uso ganadero, alta intensidad (>5 cabezas/Ha. Ingreso de ganado irrestricto). Se caracterizó por una mayor proporción de Chlorophyta y Euglenophyta con poca influencia de la componente estacional (fig. $3.7 \mathrm{y}$ 4.6). Presentó tanto bajas concentraciones de clorofila $a$ como baja producción neta, ya que el perifiton sería mayoritariamente heterotrófico (fig. 4.8 y 4.9).

Respuesta Tipo II: Fue 1 registrada con uso ganadero, baja intensidad ( $<1$ cabeza/Ha. Alambrado). Caracterizada por una composición mayoritaria de Bacillariophyta con fluctuación estacional mostrando un incremento de Cyanophyta durante los meses cálidos (fig. 3.7 y 4.6).

Respuesta Tipo III: Se encontró con uso agrícola, alta intensidad (siembra directa, uso de fertilizantes y herbicidas). Estuvo caracterizada por una fuerte componente estacional en la riqueza y diversidad del perifiton (capítulo 3). Presentó una flora estable de Bacillariophyta compuesta por especies generalistas y tolerantes a pesar de los cambios estacionales de los factores fisicoquímicos del agua (Miretzky et al. 2002).

Respuesta Tipo IV: Regitrada con uso agrícola, baja intensidad (siembra con menor frecuencia, rotación de cultivos). Presentó una composición mayoritariamente de 
Bacillariophyta, altos contenidos de clorofila $a$ y alta producción neta (fig. 3.7, 4.6, 4.8 y 4.9). Sería esperable una alta actividad de la fosfatasa alcalina (fig. 4.10) no debida a falta de fósforo disponible (fig. 4.11 y experimento 2 capítulo 5) sino a su posibe síntesis por parte de bacterias o microorganismos heterótrofos de la comunidad para hidrolizar compuestos organofosforados.

Puede decirse entonces que las respuestas del perifiton en el ambiente estudiado fueron de menor amplitud que las que presenta el perifiton de ambientes oligotróficos y esto puede deberse a que estas comunidades están adaptadas a sobrevivir y prosperar en un ambiente naturalmente rico en nutrientes y con presencia de ácidos húmicos que amortiguarían notablemente la intensidad de las respuestas (experimento 1 y 2 , capítulo $5)$.

\section{Conclusiones}

- El modo de abordar la tesis permitió aislar los factores que se identificaron como importantes influencias sobre el perifiton de los arroyos estudiados. De esa manera pudo estudiarse cada efecto particular y contrastarlo con el hallado en el ambiente natural (capítulo 5).

- El uso de sustratos artificiales resultó una técnica adecuada para la incorporación de parámetros funcionales del perifiton con medidas sensibles y eficientes para detectar el impacto de los factores ambientales sobre esta comunidad sin la interacción con el sustrato natural (capítulos 4 y 5).

- Los ácidos húmicos deben ser tenidos en cuenta como una variable clave por las repercusiones que tienen tanto en el desarrollo de las comunidades como en la atenuación en la captación de nutrientes (capítulos 4 y 5).

- Se puede esperar que el efecto del incremento de nutrientes sobre el perifiton disminuya en ambientes con altos contenidos de ácidos húmicos (experimento 2, capítulo 5).

- Los parámetros que mejor mostraron el efecto de la contaminación difusa sobre el perifiton fueron la biomasa estimada como concentración de clorofila $a$ (capítulos 3, 4 y 5), el contenido de fósforo total en el perifiton (figs. $5.5 \mathrm{y}$ 
5.9), la composición taxonómica (tabla 3.6), el metabolismo de la comunidad expresado como producción neta (figs. 4.9 y 5.11) y la actividad de la exoenzima fosfatasa alcalina (fig. 4.10, 5.6 y 5.17).

- Los parámetros funcionales podrían ser utilizados como sistemas de alerta temprana de contaminación debida al uso agropecuario de la tierra (figs. 5.7 y $5.12)$.

- Ninguno de los parámetros mencionados sería por sí solo "el mejor indicador" ya que debería evaluarse una combinación de ellos.

- Este estudio demuestra que la inundación homogeniza las características físico-químicas de los sitios con diferentes usos de la tierra (fig. 3.5).

- La concentración de fósforo aumentó en mayor proporción que el caudal bajo condiciones de inundación, lo que sugiere que su presencia en los arroyos estaría relacionada con la fertilización de los campos adyacentes (fig. 3.3).

\section{Epílogo}

Este trabajo de tesis intenta analizar las distintas respuestas posibles de la comunidad perifítica a la contaminación difusa producto de actividades agropecuarias y a partir de ello tener mayor capacidad predictiva.

El perifiton es una comunidad acuática por lo que su respuesta se registra luego de la llegada de los contaminantes antes al cuerpo de agua. Los arroyos estudiados son sistemas abiertos de modo que puede ingresar materia en todo su recorrido. ¿Cómo lograr que la materia que ingrese sea sólo la necesaria para sostener el sistema? ¿Cómo evitar el exceso de nutrientes o el ingreso de tóxicos?

Como se discutió antes, el uso de fertilizantes y pesticidas en las labores agropecuarias son las principales fuentes de nutrientes y tóxicos que llegan al arroyo por escorrentía. Modificando algunos aspectos de su manejo se puede disminuir la proporción que llega al arroyo. Por otro lado, la conservación de las áreas de ribera que sirven de amortiguación de estos contaminantes disminuiría en gran medida el impacto. 
Para ello se proponen una serie de medidas de manejo (1) y conservación (2) que debieran difundirse entre los productores que explotan los campos de la región pampeana:

1. Analizar regularmente los nutrientes del suelo y fertilizar de acuerdo con los requerimientos propios de cada cultivo y los resultados del análisis del suelo, para evitar un exceso de fertilización que sería arrastrado en la escorrentía hacia los cuerpos de agua (Clapcott et al. 2010).

Aplicar los fertilizantes en las zonas de raíces controlando el tiempo de aplicación para maximizar la captación por parte del cultivo (Falco, com. Pers., Hooda et al. 2000).

No aplicar fertilizantes o pesticidas en días con pronósticos de lluvias y tampoco cuando el suelo se encuentre cercano a la capacidad de campo ya que sería menor el aprovechamiento por parte del cultivo y mayor la pérdida por escorrentía (Clapcott et al. 2010, Hooda et al. 2000).

Evitar que la densidad de cabezas de ganado produzca sobrepastoreo y compactación del suelo ya que la falta de cobertura vegetal y la impermeabilidad del suelo favorecen el arrastre por escorrentía de fertilizantes, orines y heces.

2. Conservar la vegetación natural del lugar, conservando así la biodiversidad de la zona de ribera e incorporando estos agroecosistemas como corredores biológicos (Szpeiner et al. 2007).

Excluír el ganado mediante boyeros o alambrados, no permitiendo el acceso o dando acceso restringido para evitar el pisoteo, compactación del suelo, falta de cobertura vegetal, desestabilización de sedimentos, desestructuración del cauce, etc. (Troitiño et al. 2010).

En lotes agrícolas, mantener la zona ribereña libre de labranzas y de aplicación de agroquímicos.

Con estas propuestas sería posible obtener la estabilización de los agroecosistemas reduciendo los sedimentos, nutrientes y agroquímicos que llegan al 
agua, conservar la biodiversidad y aumentar la calidad del agua Es allí donde el perifiton adquiere mayor utilidad como herramienta de monitoreo de la contaminación difusa. 
Capítulo 7

Bibliografía 
Acuña, V. y C. Dahm. 2007. Impact of monsoonal rains on spatial scaling patterns in water chemistry of a semiarid river network. Journal of Geophysical Research. 112, G04009, doi: 10.1029/2007JG000493

Aizaki, M. 1985. Removal and excretion of disolved Organic matter by periphyton community grown in eutrophic river water. The Japanese Journal of Limnology 46 (3): 159-168.

Allan, J. D. 1995. Stream ecology, structure and function of running waters. Chapman \& Hall, London 388pp

Aloi, J.E. 1990. A critical review of recent freshwater periphyton field methods. Canadian Journal Fisheries Aquatic Science. 47: 656-670

Aminot, A. 1983. Dosage de la chlorophylle et des phéopigment par spectrophotométric. En: Aminot,A. y M. Chansspied (eds.). Manual des analyses chimiques en Milien marin Centre National pour L'Explotation des Océans, Brest, Francia, 177-189

Anthoni, U., C. Christophersen, J. Madsen, S. Wium-Andersen y N. Jacobsen. 1980. Biologically active sulphur compounds from the green alga Chara globularis. Phytochemistry. 19:1228-1229

APHA-WWA-WPCF. 2005. Standard methods for the examination of water and wastewater. Washington DC. $1550 \mathrm{pp}$

Arreghini, S., L. de Cabo, R. Seoane, N. Tomazin, R. Serafini y AF. de Iorio. 2005. Influence of rainfall on the discharge, nutrient concentrations and loads of a stream of the "Pampa Ondulada" (Buenos Aires, Argentina). Limnetica 24(3-4): 225-236.

Arreghini, S., L. de Cabo, R. Seoane, N. Tomazin, R. Serafini y AF. de Iorio 2007. A methodological approach to water quality assessment in a ungauged basin, Buenos Aires, Argentina. GeoJournal 70(4): 281-288

Barsotti, C. 2011. Estimación del uso de fósforo, nitrógeno y agroquímicos en una microcuenca de la provincia de Buenos Aires. Tesis de licenciatura en Información ambiental. Universidad Nacional de Luján. 122 pp

Basilico, G. 2008. Calidad de aguas en la cuenca superior del río Reconquista.

Proyecto final de la carrera Ingeniería en Ecología. Facultad de Ingeniería. Universidad de Flores. Buenos Aires.114 pp

Bauer, D. 2009. Ecología del fitoplancton de arroyos pampeanos y su valor como indicador de la calidad del agua. Tesis doctoral. UNLP-FCNyM 
Belanger, S. 1997. Literature review and analysis of biological complexity in model stream ecosystems: Influence of size and experimental design. Ecotoxicology and Environmental Safety. 36(1): 1-16

Bernal, S., A. Butturini y F. Sabater. 2002. Variability of DOC and nitrate responses to storms in a small Mediterranean forested catchment. Hydrology and Earth System Sciences 6:1031-1041

Biggs, B. 1990. Periphyton communities and their environments in New Zealand rivers. New Zealand Journal of Marina and Freshwater Research. 24:367-386

Biggs, B. 1995. The contribution of flood disturbance, catchment geology and land use to the habitat template of periphyton in stream ecosystems. Freshwater Biology 33:419-438.

Blanck, H. 1985. A simple, community level, ecotoxicological test system using samples of periphyton. Hydrobiologia 124: 251-261.

Blanck, H. 2002. A critical review of procedures and approaches used for assessing pollution-induced community tolerance (PICT) in biotic communities. Human and Ecological Risk Assessment. 8: 1003-1034

Boisson, J. y Y. Perrodin. 2006. Effects of road runoff on biomass and metabolic activity of periphyton in experimental streams. Journal of Hazardous Materials. 132: $148-154$

Bothwell, M. 1985. Phosphorus limitation of lotic periphyton growth rates: An intersite comparison using continuous-flow troughs (Thompson River system, British Columbia). Limnology and Oceanography. 30(3): 521-542

Bott T.L., J.T.Brock, C.S. Dunn, R.J. Naiman, R.W. Ovink y R.C. Petersen. 1985. Benthic community metabolism in four temperate stream systems: an inter-biome comparison and evaluation of the river continuum concept. Hydrobiologia 123: 3-45

Boulton, A. 1999. An overview of river health assessment: philosophies, practice, problems and prognosis. Freshwater Biology 41:469-479.

Brandt, L. y E. Koch. 2003. Periphyton as UV-B filter on seagrass leaves: a result of different transmittance in the UV-B and PAR. Aquatic Botany. 76:317-327

Brooks, A., L. Maltby, A. Saul y P. Calow. 1996. A simple indoor artificial stream system designed to study the effects of toxicant pulses on aquatic organisms. Water Research. 3 (2): 285-290

Brunke M. y T. Gonser. 1997. The ecological significance of exchange processes etween rivers and groundwater. Freshwater Biology 37:1-33 
Bunn, S. y P. Davies. 2000. Biological processes in running waters and their implications for the assessment of ecological integrity. Hydrobiologia. 422:61-70.

Burgueño, G. 2003. Elementos para el plan de manejo del Área Natural Protegida Dique Ing. Roggero. Trabajo final de investigación. FADU - UBA. 82pp

Burns, A. y D. Ryder. 2001. Potencial for biofilms as biological indicators in Australian riverine systems. Ecological Management and Restoration. 2(1): 53-63

Cabrera, AL. 1978. Manual de la flora de los alrededores de Buenos Aires. $2^{\circ}$ edición. Ed. ACME. Buenos Aires.

Cairns, J. Jr. 1988. Should regulatory criteria and standards be based on multispecies evidence? The environmental Professional. 10:157-165

Cairns J., P.V. McCormick y B.R. Niederlehner. 1993. A proposed framework for developing indicators of ecosystem health. Hydrobiologia. 263: 1-44

Cambell, N. B. D’Arcy, A. Frost, V. Novotny y A. Sansom. 2004. Diffuse Pollution: An introduction to the problems and solutions. IWA Publishing. Londres. $315 \mathrm{pp}$

Cao, X., C. Song y Y. Zhou. 2010. Limitations of using extracellular alkaline phosphatase activities as a general indicator for describing $\mathrm{P}$ deficiency of phytoplankton in Chinese shallow lakes. Journal of Applied Phycology. 22:33-41

Cattaneo, A. y J. Kalff. 1979. Primary production of algae growing on natural and artificial aquatic plants: A study of interactions between epiphytes and their substrate. Limnology and Oceanography. 14: 1031-1037

Cattaneo, A, P. Legendre y T. Niyonsenga. 1993. Exploring periphyton unpredictability. Journal of North American Benthological Society. 12(4):418-430

Cebrian, J., J. Shurin, E. Borer, B. Cardinale, J. Ngai, M. Smith y W. Fagan. 2009. Producer Nutritional Quality Controls Ecosystem Trophic Structure. PLUS ONE 4 (3): e4929. doi:10.1371/journal.pone.0004929.

Chagas, C., C. Irurtia, J. Thisted, O. Santanatoglia, M. Massobrio, M. Castiglioni y A. Bujan. 2004. Movimiento horizontal y vertical de agua y partículas en un argiudol bajo siembra directa. Ciencia del Suelo 22 (2):117-122

Chappell K. y R. Goulder. 1994. Seasonal variation of epiphytic extracellular enzyme activity on two freshwater plants, Phragmites australis and Elodea canadensis. Archiv für Hydrobiologie. 132(2): 237-253

Chase J. 2003. Strong and weak trophic cascades along a productivity gradient. Oikos 101(1): 187-195 
Clapcott, J., R. Young, E. Goodwin y J. Leathwick. 2010. Exploring the response of functional indicators of stream health to land-use gradients. Freshwater Biology. 55: 2181-2199

Claps, MC. 1996.Structure and dynamics of epipelic algae from a plaine river (Samborombón River, Buenos Aires, Argentina). Archiv Hydrobiologie. 137 (2): 251-263

Conzonno, V. 2010. Limnología Química. Editorial de la Universidad de La Plata, La Plata, $222 \mathrm{pp}$

Cortelezzi, A. 2010. Hábitats funcionales y macroinvertebrados en cauces modificados de arroyos de llanura. Impacto sobre la calidad ecológica. Tesis doctoral. UNLPFCNyM

Cox, E. 1996. Identification of freshwater diatoms from live material. Chapman \& Hall. London. $158 \mathrm{pp}$

Crossey, M. J. y T.W. La Point. 1998. A comparison of periphyton community structural and functional responses to heavy metals. Hydrobiologia 162: 109-121.

Danilov, R. y N. Ekelund. 2000. The use of epiphyton and epilithon data as a base for calculating ecological indices in monitoring of eutrophication in lakes in central Sweden. The Science of the Total Environment. 248: 63-70

Delong M.D. y M.A. Bruswen. 1992. Patterns of periphyton chlorophyll a in an agricultural nonpoint source impacted stream. Water Resources Bulletin. 28 (4): 731741

Desrosiers, M., D. Planas y A. Mucci. 2006. Total mercury and methylmercury accumulation in periphyton of boreal shield lakes: Influence of watershed physiographic characteristics. Science of the Total Environment. 355(1-3): 247-258

Dodds, W. 2007. Trophic state, eutrophication and nutrient criteria in streams. Trends in Ecology and Evolution. 22(1): 669-676

DuBois, M., KA. Gilles, JK Hamilton, PA Rebers y F. Smith. 1956. Colorimetric method for determination of sugar and related substances. Anaytical Chemistry 28: 350-356

Duffy, J. 2002. Biodiversity and ecosystem function: the consumer connection. Oikos. 99: $201-219$

Economou-Amilli, A. 1980. Periphyton analysis for the evaluation of water quality in running waters of Greece. Hydrobiologia 74:39-48 
Ellison, M.E. y M.T. Brett. 2006. Particulate phosphorus bioavailability as a function of stream flow and land cover. Water Research. 40: 1258-1268

Eminson, D. y B. Moss. 1980. The composition and ecology of periphyton communities in freshwaters. 1 . The influence of host type and external environment on community composition. British Phycological Journal. 15:429-446

Ereño, C. 2002. Climatología de la cuenca. En: Borthagaray, JM (Comp). El Río de la Plata como territorio. FADU-UBA Ed. Infinito-Furban. Buenos Aires. 51-75

Faggi, AM., M. Arriaga y S. Aliscioni. 1999. Composición florística de las riberas del río Reconquista y sus alteraciones antrópicas. Revista del Museo Argentino de Ciencias Naturales. 1(1): 1-6.

Feijoó. C., A. Giorgi, M.E. García y F. Momo. 1999. Temporal and spatial variability in streams of pampean basin. Hydrobiologia 394 (1): 41-52.

Feijoó, C. y R. Lombardo. 2007. Baseline water quality and macrophyte assemblages in Pampean streams: A regional approach. Water Research. 41(7), 1399-1410

Feijoó, C., A. Giorgi y N. Ferreiro. 2011. Phosphorus uptake in a macrophyte-rich pampean stream Limnologica. (en prensa). (doi:10.1016/j.limno.2010.11.002)

Ferreiro, N., A. Giorgi, L. Leggieri, C. Feijoó y C. Vilches. 2011. Phosphorus Enrichment Affects Immobilization but not Litter Decomposition or Exoenzymatic Activities in a Pampean Stream. International Review of Hydrobiology. 96(3): 209220

Fidalgo, F. 1983. Algunas características de los sedimentos superficiales en la cuenca del Río Salado y en la Pampa Ondulada. Coloquio internacional sobre hidrobiología de grandes llanuras. 1045-1066

Gaiser, E. 2009. Periphyton as an indicator of restoration in the Florida Everglades. Ecological indicators 9:37-45

Garduño Solórzano, G., MG. Oliva Martínez, A. Lugo Vázquez, MB. Mendoza Garfias, R. Quintanar Zuñiga y V. Conforti. 2011. Trachelomonas (Euglenophyta) from a eutrophic reservoir in Central Mexico. Journal of Environmental Biology. 32: 46-471

Gessner, M. y E. Chauvet. 2002. A case for using litter breakdown to assess functional stream integrity. Ecological Applications. 12: 498-510.

Giorgi, A. 1998. Factores reguladores del fitobentos en arroyos de llanura. Tesis doctoral, Facultad de Ciencias Naturales y Museo. UNLP. 173 pp

Giorgi, A. y C. Feijoó. 2010. Variación temporal de la biomasa del perifiton de Egeria densa Planch. en un arroyo pampeano. Limnetica. 29(2): 269-278 
Giorgi, A. y L. Malacalza. 2002. Effect of an industrial discharge on water quality and periphyton structure in pampean stream. Environmental Monitoring and Assessment 75: 107-119.

Gómez, N. y M. Licursi. 2001. The pampean diatom index (IDP) for assessment of rivers and streams in Argentina. Aquatic Ecology: 35: 173-181.

Gómez, N. y M. Licursi. 2003. Abnormal forms in Pinnularia gibba (Bacillariophyceae) in a polluted lowland stream from Argentina. Nova Hedwigia. 77 (3): 389-398.

Gómez, N., M. Licursi, D. Bauer, P. Hualde y MV Sierra. 2003. Reseña sobre modalidades de estudio mediante la utilización de microalgas en la evaluación y monitoreo de algunos sistemas lóticos pampeanos bonaerenses. Boletín de la Sociedad Argentina de Botánica. 38 (1-2): 93-103

Gómez, N., MV. Sierra, A. Cortelezzi y A. Rodrigues Capítulo. 2008. Effects of discharges from the textile industry on the biotic integrity of benthic assemblages. Ecotoxicology and Environmental Safety. 69: 472-479

Gómez, N., MV. Sierra, J. Cochero, M. Licursi y D. Bauer. 2009. Epipelic biofilms as indicators of environmental changes in lowland fluvial systems. En: W. Baley (Ed.) Biofilms: formation, development and properties. Nova Science Publisher. 259-290

Gómez, N. y N. Toresani. 1999. Región 3. Pampas. En Los humedales de la Argentina: Clasificación, situación actual, conservación y legislación. Eds. Canevari, P., D. Blanco, E. Bucher, G. Castro y I. Davison. Wetlands International, Buenos Aires. 46: 97-113

Gordon, B., T. McMahon y B. Finlayson. 1994. Stream hydrology. An introduction for ecologists. J. Wiley \& Sons, Toronto.

Graham, L. y L. Wilcox. 2000. Algae. Prentice-Hall. Upper Saddle River. 700 pp

Guasch, H., I. Muñoz, N. Rosés y S. Sabater. 1997. Changes in atrazine toxicity throughout succession of stream periphyton communities. Journal Applied Phycology. 9(2): 137-146

Guasch, H., G. Atli, B. Bonet, N. Corcoll, M. Leira y A. Serra. 2010. Discharge and the response of biofilms to metal exposure in Mediterranean rivers. Hydrobiologia. 657(1):143-147

Gustavson, K., F. Møhlenberg y L. Schlüter. 2003. Effects of exposure duration of herbicides on natural stream periphyton communities and recovery. Archives of Environmental Contamination and Toxicology. 45: 48-58 
Havens, K., T. East, A. Rodusky and B. Sharfstein. 1999. Littoral periphyton responses to nitrogen and phosphorus: an experimental study in a subtropical lake. Aquatic Botany. 63: 267-290

Havens, K., R. James, T. East y V. Smith. 2003. N:P ratios, light limitation, and cyanobacterial dominance in a subtropical lake impacted by non-point source nutrient pollution. Environmental Pollution 122: 379-390

Heinonen, P. 1984. Early warning of eutrophication in rivers by analysis of periphyton chlorophyll a. En: Pascoe D. y R. Edwards (Eds.). Freshwater biological monitoring. Pergamon Press. New York. 45-52

Hessen D. y L. Tranvik. 1998. Aquatic humic substances: ecology and biogeochemistry. Springer. New York. 334pp

Hooda, P., A. Edwards, H. Anderson y A. Miller. 2000. A review of water quality concerns in livestock farming areas. The Science of the total Environment 250:143167

Horner, R. y E. Welch. 1981. Stream periphyton development in relation to current velocity and nutrients. Canadian Journal of Fisheries and Aquatic Sciences. 38:449457

Horner, R., E. Welch, M. Sceley y J. Jacoby. 1990. Responses of periphyton to changes in current velocity, suspended sediment and phosphorus concentration. Freshwater Biology. 24: 215-232

Houser, J., P. Mulholland y K. Maloney. 2006. Upland Disturbance Affects Headwater Stream Nutrients and Suspended Sediments during Baseflow and Stormflow. Journal of Environmental Quality. 35:352-36

INDEC. 2010 http://www.indec.mecon.ar

Jarvie, H., C. Neal y P. Whithers. 2006. Sewage-effluent phosphorus: a greater risk to river eutrophication than agricultural phosphorus? Science of the Total Environment. 360:246-253

Jarvie, H., P. Withers, R. Hodgkinson, A. Bates, M. Neal, H. Wickham, S. Harman y L. Armstrong. 2008. Influence of rural land use on stream water nutrients and their ecological significance. Journal of Hydrology 350:166-186

Jarvie, H., P. Withers, M. Bowes, E. Palmer-Felgate, D. Horper, K. Wasiak, P. Wasiak, R. Hodgkinson, A. Bates, C. Stoate, M. Neal, H. Wickham, S. Horman y H. Armstrong. 2010. Streamwater phosphorus and nitrogen across a gradient in rural- 
agricultural land use intensity. Agriculture, Ecosystems and Environment. 135: 238252

Jergentz, S., H. Mugni, C. Bonetto y R. Schulz. 2005. Assessment of insecticide contamination in runoff and stream water of small agricultural stream in the main soybean area of Argentina. Chemophere 61(6):817-826

Julian, J., E. Stanley y M. Doyle. 2008. Basin-Scale Consequences of Agricultural Land use on Benthic Light Availability and Primary Production along a Sixth-Order Temperate River. Ecosystems. 11: 1091-1105

Kalff, J. 2003. Limnology, Inland Water Ecosystems. Pretice Hall. New Jersey. 592 pp

Komárek, J. y K. Anagnostidis. 1999. Süßwasserflora von Mitteleuropa. Cyanoprokaryota: Chroococcales. Editorial Elsevier. München. 548 pp

Komárek, J. y K. Anagnostidis. 2005. Süßwasserflora von Mitteleuropa. Cyanoprokaryota: Oscillatoriales. Editorial Elsevier. München. 759 pp.

Labry C., D. Delmas y A. Herbland. 2005. Phytoplankton and bacterial alkaline phosphatase activities in relation to phosphate and DOP availability within the Gironde plume waters (Bay of Biscay). Journal of Experimental Marine Biology and Ecology. 318: 213-225

Lakatos, G. 1989. Composition of reed periphyton (biotecton) in the Hungarian part of lake Fertö. Biol. Forschung für Burg. 71: 125-134

Lamberti, G y A. Steinman. 1993. Research in artificial streams: applications, uses and abuses. Journal of North American Benthology Society. 2(4) 313-384

Lanson, D., L. Schein y M. Miglioranza. 2009. Aportes para la comprensión de la incidencia de los factores climáticos y tecnológicos sobre la deriva de agroquímicos aplicados a cultivos de soja y sus respectivos efectos sobre la población potencialmente expuesta. En: Dámaso Ponvert-Delisles Batista-Compiladora: Julieta Straschnoy. Seminario Internacional "La tecnología satelital de observación de la tierra en la evaluación, monitoreo y manejo de desastres naturales en la agricultura. Retos y perspectivas", 1a ed., Buenos Aires: Ediciones INTA p. 69-79.

Lastra, G. 2007. Problemática del Río de la Reconquista y sus consecuencias socioambientales. Proyecto final de la carrera Ingeniería en Ecología. Facultad de Ingeniería - Universidad de Flores. Buenos Aires. 123 pp

Lavado, R., O. Duymovich, J. Jiménez y L. Alvarez. 1982. Pérdidas de sustancias húmicas de suelos nítricos a través del Río Samborombón. Revista del Museo de la Plata IX, Geología. 76:97-103. 
Lee, K., T. Isenhart y R. Schultz. 2003. Sediment and nutrient removal in an established multi-species riparian buffer. Journal of Soil and Water Conservation. 58(1): 1-8

Licursi, M. 2005. Efectos de las perturbaciones antropogénicas sobre la taxocenosis de diatomeas bentónicas en sistemas lóticos pampeanos. Tesis doctoral. UNLP-FCNyM

Licursi, M. y N. Gómez. 2004. Aplicación de Indices bióticos en la evaluación de la calidad del agua en sistemas lóticos de la llanura pampeana a partir del empleo de diatomeas. Biología Acuática. 21: 31-49.

Loez, C. 1995. Estudios limnológicos en el río Reconquista (Provincia de Buenos Aires): relación entre parámetros biológicos y químicos, especialmente el impacto del zinc sobre la estructura del fitoplancton. Tesis doctoral. Facultad de Ciencias Exactas y Naturales, Universidad de Buenos Aires. 222 p.

Loez, C. y M. L. Topalián. 1999. Use of algae for monitoring rivers in Argentina with special emphasis for the Reconquista river (region of Buenos Aires). En: J.Prygiel, B. A. Whitton \& J. Bukowska (eds.). Use of algae for monitoring rivers III. pp 7283.

Ma, M., J. Liu y X. Wang. 2011. Biofilms as potential indicators of macrophytedominated lake health. Ecotoxicology. 20:982-992

Magurran, A. E. 1994. Diversidad Ecológica y su Medición. Editorial Vedra. Barcelona. $193 \mathrm{pp}$

Margalef, R. y N. Prat. 1979. La limnologia. Quaderns d'Ecologia Aplicada. 4:9-23

Margalef, R. 1991. Teoría de los sistemas ecológicos. Publicacions Universitat de Barcelona. 289pp

Margalef, R. 1994. El río planetario. Tankay 1: 3-12

Matthews, R., A. Buikema, J. Cairns y J. Rodgers. 1982. Biological monitoring, Part IIA - receiving system functional methods, relationships and indices. Water Research. 16: 129-139.

Maurice, C., R. Lowe, T. Burton y R. Standford. 1987. Biomass and compositional changes in the periphytic community of on artificial stream in response to lowered pH. Water, Air and Soil Pollution. 33: 165-177

McCormick, P. y R. Stevenson. 1998. Periphyton as a tool for ecological assessment and management in the Florida Everglades. Journal of Phycology 34:726-733.

McCormick, P. M. O’Dell, R. Shuford III, J. Backus y W. Kennedy. 2001. Periphyton responses to experimental phosphorus enrichment in a subtropical wetland. Aquatic Botany 71:110-139. 
Meybeck, M. y R. Helmer. 1989. The quality of rivers: From pristine stage to global pollution. Global and Planetary Change. 1 (4): 283-309.

Middleton, R. 2010 Cattle access affects periphyton community structure in Tennessee farm ponds. Master's Thesis, University of Tennessee. 103pp

Miretzky, P., N. Maidana y A. Fernández Cirelli. 2002. Stability of diatom composition in a variable lake environment: Lake Chascomús, Argentina. Limnology. 3:77-85

Mitchell, G.C., D. Bennett y N. Pearson. 1993. Effects of lindane on macroinvertebrates and periphyton in outdoor artificial streams. Ecotoxicology and environmental safety. 25:90-102

Mondino, E. 2007. Informe especial Cuenca del Río Reconquista - $1^{\circ}$ parte. Defensor del Pueblo de la Nación. 294pp

Montuelle, B. U. Dorigo, A. Bérard, B. Volat, A. Bouchez, A. Tlili, V. Gouy y S. Pesce. 2010. The periphyton as a multimetric bioindicator for assessing the impact of land use on rivers: an overview of the Ardières-Morcille experimental watershed (France). Hydrobiologia. 657:123-141

Morin, A. y A. Cattaneo. 1992. Factors affecting sampling variability of freshwater periphyton and the power of periphyton studies. Canadian Journal of Fisheries and Aquatic Sciences. 49(8): 1695-1703

Mugni, H., S. Jergentz, R. Schulz, A. Maine y C. Bonetto. 2005. Phosphate and nitrogen compounds in streams of Pampean Plain areas under intensive cultivation (Buenos Aires, Argentine). En: Proceeding of 4th International Symposium of Phosphates in Sediments. Serrano L. y HL Golterman (Ed.). The Netherlands, pp $163-170$

Navarro, E. 1998. Respuesta ecotoxicológica de comunidades microbentónicas de ríos mediterráneos. Tesis doctoral de la carrera doctorado en Biología. Facultad de biología. Universidad de Barcelona. 115 pp.

Navarro, E, H. Guash, I. Muñoz, M. Real y S. Sabater. 2000. Aplicación de un sistema de canales artificiales en el estudio ecotoxicológico de comunidades microbentónicas. Limnetica 18:1-14

Newman, S., P. McCormick y J. Backus. 2003. Phosphatase activity as an early warning indicator of wetland eutrophication: problems and prospects. Journal of Applied Phycology. 15: 45-59

Niederlehner, B. y J. Cairns. 1990. Effects of ammonia on periphytic communities. Environmental Pollution. 66:207-221 
Novotny, V. 2003. Water quality: Diffuse pollution and watershed management. J. Wiley y sons. Nueva York. 888 pp

O’Farrell, I., R. J. Lombardo, P. de Tezanos Pinto y C. Loez. 2002. The assessment of water quality in the lower Luján River (Buenos Aires, Argentina): phytoplankton and algal bioassays. Environmental Pollution 120: 207-218.

Olguin, H. y A. Salibian. 1994. Bioensayos algales uniespecíficos para evaluar la calidad del agua del río Reconquista: experiencia preliminar. Tankay I: 325-328

Palmer, C. 1969. A composite rating of algae tolerating organic pollution. Journal of Phycology 5:78-82.

Pan, Y., B. Hill, P. Vaithiyanathan, J. Slate y C. Richardson. 2000. Changes in algal assemblages along observed and experimental phosphorus gradients in a subtropical wetland, U.S.A. Freshwater Biology 44:339-353.

Patrick, R. y C. Reimer. 1966. The diatoms of the United States. (vol 1). Academy of Natural Sciences of Philadelphia, Philadelphia. 688pp

Patrick, R. y C. Reimer. 1975. The diatoms of the United States. (vol 2. part 1). Academy of Natural Sciences of Philadelphia, Philadelphia. 192pp

Pereyra, F. 2002. Evolución geológica de la región. En: Borthagaray, JM (Comp). El Río de la Plata como territorio. FADU-UBA Ed. Infinito-Furban. Buenos Aires. 1549

Perez, G., A. Torremorell, H. Mugni, P. Rodriguez, M. Vera, M. Do Nascimento, L. Allende, J. Bustingorry, R. Escaray, M. Ferraro, I. Izaguirre, H. Pizarro, C. Bonetto, D. Morris y H. Zagarese. 2007. Effects of the herbicide Roundup on freshwater microbial communities: a mesocosm study. Ecological Applications 17 (8): 23002322.

Pionke, H., W. Gburek, R. Schnabel, A. Sharpley y G. Elwinger. 1999. Seasonal flow, nutrient concentrations and loading patterns in stream flow draining an agricultural hill-land watershed. Journal of Hydrology 220:62-73

Pizarro, H. y M.E. Alemanni. 2005. Variables fîsico-químicas del agua y su influencia en la biomasa del perifiton en un tramo inferior del Río Luján (Provincia de Buenos Aires). Ecología Austral. 15: 73-78.

Quirós, R. 2000. La eutrofización de las aguas continentales de Argentina. En: El agua en Iberoamérica: acuíferos, lagos y embalses. Eds. Fernandez A. CYTED XVII Subprograma VII. Aprovechamiento y Gestión de recursos hídricos, Buenos Aires $43-47$ 
Reynolds, C., V. Huszar, C. Kruk, L. Naselli-Flores y S. Melo. 2002. Towards a functional classification of the freshwater phytoplankton. Journal of Plankton Research. 24:417-428

Riipinen, M., J. Davy-Bowker y M. Dobson. 2009. Comparison of structural and functional stream assessment methods to detect changes in riparian vegetation and water pH. Freshwater Biology. 54: 2127-2138.

Ringuelet, R. 1962. Ecología acuática continental. EUDEBA. Buenos Aires. 138 pp

Roberts, B.J., P.J. Mulholland y W.R. Hill. 2007. Multiple scales of temporal variability in ecosystem metabolism rates: results from 2 years of continuous monitoring in a forested headwater stream. Ecosystems 10: 588-606.

Rodrigues Capítulo, A. N. Gómez, A, Giorgi y C. Feijoó. 2010. Global changes in pampean lowland streams (Argentina): implications for biodiversity and functioning. Hydrobiologia. 657: 53-70

Romaní, A. M. y S. Sabater. 1999. Effect of primary producers on the heterotrophic metabolism of a stream biofilm. Freshwater Biology. 41: 729-736.

Romaní, A. M. 2001. Biofilms fluvials. Metabolisme heterotrofic I autotrofic en rius mediterranis (Arxius de les seccions de ciences: 129). Biología. Premi Institu de Estudis Catalans d’ Ecologia. 254pp

Round, F. 1993. A review and methods for the use of epilithic diatoms for detecting and monitoring changes in river water quality. Methods for the examination of waters and associated materials. Her Majesty's Stationery Office. Londres, Reino Unido. $65 \mathrm{pp}$

Sabater, S. y F. Sabater. 1992. Longitudinal changes of benthic algal biomass in a Mediterranean river during two high production periods. Archive Für Hidrobiologie. 124(4):475-487

Sabater F., A. Butturini, E. Martí, I. Muñoz, A. Romaní, J. Wray, S. Sabater. 2000 Effects of riparian vegetation removal on nutrient retention in a Mediterranean stream. Journal of North American Benthological Society. 19:609-620

Sabater, S., H. Guasch, A. Romaní e I. Muñoz. 2002. The effect of biological factors on the efficiency of river bioilms in improving water quality. Hydrobiologia. 469: 149156

Sabater, S., V. Acuña, A. Giorgi, H. Guasch, E. Guerra, I. Muñoz y A. Romaní. 2005. Assessing the ecological integrity after nutrient inputs in streams: The relevance of the observation scale. Aquatic Ecosystem Health and Management. 8(4):397-403 
Sadañiowsky, I. 2003. El problema de las inundaciones en la cuenca del río Reconquista: la represa Ingeniero Carlos F. Roggero y las funciones ecológicas. Tesis de grado. Universidad Nacional de General Sarmiento. Buenos Aires. 102pp

Sala, J y M. Auge. 1970. Algunas características geohidrológicas del noreste de la provincia de Buenos Aires. Cuartas Jornadas Geológicas Argentinas. Tomo III: 321-336

Salibian, A. 2006. Ecotoxicological assessment of the highly polluted Reconquista river of Argentina. Reviews of Environmental Contamination and Toxicology. 185: 35-65

Salt, G. 1971. The role of Laboratory Experimentation in Ecological Research. En: Cairns, J (Ed.) The structure and function of freshwater microbial communities. Virginia polytechnic institute and state university. Virginia. 87-100

Sand-Jensen K., D. Borg y E. Jeppesen. 1989. Biomass and oxygen dynamics of the epiphyte community in a Danish lowland stream. Freshwater Biology. 22:431-443

Sand-Jensen, K. y J. Borum. 1991. Interactions among phytoplankton, periphyton and macrophytes in températe freshwaters and estuaries. Aquatic Botany. 41:137-175

Serrano, L. 1992. Leaching from vegetation of soluble poliphenolic compounds, and their abundance in temporary ponds in the Doñana National Park (SW Spain). Hydrobiologia. 229:43-50

Serrano, L. 1994. Sources, abundance and disappearance of poliphenolic compound in temporary ponds on Doñana National Park (South-western Spain). Australian Journal of Marine \& Freshwater Research. 45(8):1555-1564.

Sierra, MV. 2009. Microbentos de sistemas lóticos pampeanos y su relación con la calidad del agua. Respuestas funcionales y estructurales. Tesis doctoral. UNLPFCNyM

Sierra, M.V. y N. Gómez. 2007. Structural characteristics and oxygen consumption of the epipelic biofilms in three lowland streams exposed to different land uses. Water Air and Soil Pollution. 186: 115-127.

Sierra, MV. y Gómez, N. 2010. Assessing the disturbance caused by an industrial discharge using field transfer of epipelic biofilm. Science of the Total Environment. 408: 2696-2705

Sladeckova, A. 1962. Limnological investigation methods for the periphyton community. The Botanical Review. 28: 286-350 
Smith, V., G. Tilman y J. Nekola. 1999. Eutrophication: Impact of excess nutrient inputs on freshwater, marine and terrestrial ecosystems. Enviromental pollution 100: 170-196.

Steinberg, C. 2003. Ecology of humic substances in freshwaters. Springer. New York. $346 \mathrm{pp}$

Steinman, A. y D. McIntire. 1986. Effects of current velocity and light energy on the structure of periphyton assemblages in laboratory streams. Journal of Phycology. 22: $352-361$

Steinman A. y D. Mc Intire. 1990. Recovery of lotic periphyton communities after disturbance. Enviromental Management. 14 (5): 589-604

Sterner, R. y J. Elser. 2008. Ecological Stoichiometry: Overview. En: S. Jorgensen y B. Fath (ed) Encyclopedia of Ecology. Academic press. Amsterdam. 1101-1116

Stevenson R. J., M.L. Bothwell y R.L. Lowe. 1996. Algal Ecology, Freshwater benthic ecosystems. Academic Press Inc, San Diego, California 753 pp.

Stewart, P.1995. Use of algae in aquatic pollution assessment. Natural Areas Journal. 15 (3): 234-239.

Strickland, L. D. y F. R. Parsons 1972. A practical handbook of seawater analysis. Journal of the Fisheries Research Board of Canada. 167, 310 pp.

Szpeiner, A., MA. Martínez-Ghersa y C. Ghersa. 2007. Agricultura pampeana, corredores biológicos y biodiversidad. Ciencia hoy. 17(101): 38-46

Taboada, M., E. Panuska, R. Lavado, J. Gimenez y O. Duymovich. 1987. Pérdidas de sustancias húmicas de suelos nátricos a través del río Samborombon. Notas del museo de La Plata, Geología. 21(74): 67-76

Tell, G. y V. Conforti. 1986. Euglenophyta pigmentadas de la Argentina. J. Cramer. Berlin. 300pp

Trimble, S. y A. Mendel. 1995. The cow as a geomorphic agent: A critical review. Geomorphology 13, 233-253.

Troitiño, E. 2008. Evaluación de la conservación de las zonas ribereñas de arroyos pampeanos. Trabajo Final de aplicación. Ingeniería agronómica. Universidad Nacional de Luján. 71 pp.

Troitiño, E., MC Costa, L. Ferrari y A. Giorgi. 2010. La conservación de las zonas ribereñas de arroyos pampeanos. Actas I Congreso Internacional de Hidrología de Llanuras. Azul, 1256-1263 
Uehlinger, U. y J. Brock. 2005. Periphyton metabolism along a nutrient gradient in a desert river (Truckee river, Nevada, USA). Aquatic Science. 67: 507-516

Underwood G.J.C. y D.M. Paterson. 1993. Recovery of intertidal benthic diatoms after biocide treatment and associated sediment dynamics. Journal of Marine Biological Assessment United Kingdom. 73: 25-45

Urrea, G. y S. Sabater. 2009. Epilithic diatom assemblages and their relationship to environmental characteristic in an agricultural watershed (Guadiana River, SW Spain). Ecological indicators. 9: 693-703

Van Den Hoek, Mann y Jahns (Eds.) 1995. Algae. An introduction to phycology. Cambridge University Press. Cambridge 623pp

Vera, M., L. Lagomarsino, M. Sylvester, G. Pérez, P. Rodriguez, H. Mugni, R. Sinistro, M. Ferraro, C. Bonetto, H. Zagarese y H. Pizarro. 2010. New evidences of Roundoup (glyphosate formulation) impact in the periphyton community and the water quality of freshwater ecosystems. Ecotoxicology. 19(4):710-721

Vermaat, J. 2005. Periphyton dynamics and influencing factors. En: Periphyton: Ecology, Exploitation and Management. M. Azim, M. Verdegem, A. Van Dam \& M. Beveridge (eds.) CABI Publishing, Estados Unidos. Pp 35-49

Viglizzo, E., F. Frank, L. Carreño, E. Jobbagy, H. Pereyra, J. Clatt, D. Pincén y MF. Ricard. 2011. Ecological and environmental footprint of 50 years of agricultural expansion in Argentina. Global Change Biology. 17: 959-973

Vilalta Baliellas, E. 2004. Structure and function in fluvial biofilm. Implication in river DOC. Dynamics and nuisance metabolic production. Tesis doctoral. Departament d’Ecologia. Universitat de Barcelona. 150 pp

Vilches, C. y A. Giorgi. 2010. Metabolism in macrophyte-rich stream exposed to flooding. Hydrobiologia, 654: 57-65

Vinebrooke, R., K. Cottingham, J. Norberg, M. Scheffer, S. Dodson, S. Maberly y U. Sommer. 2004. Impacts of multiple stressors on biodiversity and ecosystem functioning: The role of species co-tolerance. Oikos. 104: 451-457

Von Schiller, D. E. Martí, J. Riera y F. Sabater. 2007. Effects of nutrients and light on periphyton biomass and nitrogen uptake in Mediterranean streams with contrasting land uses. Freshwater Biology. 52(5):891-906

Warren, C. y G. Davis. 1971. Laboratory stream research: Objectives, possibilities and constraints. Annual Review of Ecology, Evolution, and Systematics. 2:111-142 
Washington, H.G. 1984. Diversity, biotic and similarity indices: a review with special relevance to aquatic ecosystems. Water Research. 18 (6): 653-694

Wetzel, R. 1981. Limnologia. Omega. Barcelona. 679 p

Wetzel, R. 1983. Opening remarks. En: Wetzel (Ed) Periphyton of freshwater ecosystems. W. Junk. The Hague. 346 pp

Wetzel, R. 1992. Gradient-dominated ecosystems: sources and regulatory functions of dissolved organic matter in freshwater ecosystems. Hydrobiologia. 229: 181-198

Wiley M.J., L.L. Osborne y R.W. Larimore. 1990. Longitudinal structure of an agricultural prairie system and its relationship to current stream ecosystem theory. Canadian Journal of Fisheries and Aquatic Sciences 47: 373-384

Withers, P., R. Hodgkinson, H. Adamson y G. Green. 2007. The impact of pasture improvement on phosphorus concentrations in soils and streams in an upland catchment in Northern England. Agriculture, Ecosystems and Environment $122(2): 220-232$

Withers, P y H. Jarvie 2008. Delivery and cycling of phosphorus in rivers: A review. Science of the total environment. 400: 379-395

Young, R., C. Mathaei y C. Towsend. 2008. Organic matter breakdown and ecosystem metabolism: functional indicators for assessing river ecosystem health. Journal of North American Benthology Society. 27(3):605-625

Žižec, S., R. Milačič, N. Kovak, R. Jaćimović, M. Toman y M. Horvat. 2011. Periphyton as a bioindicator of mercury pollution in a temperate torrential river ecosystem. Chemosphere. 85(5): 883-891 
Anexo 
Anexo cap.3. Valores medios y desvíos por fecha de muestreo para cada uno de los sitios de las variables fisicoquímicas estimadas en el período 2006-2008.

\begin{tabular}{|c|c|c|c|c|c|c|c|c|c|c|}
\hline Sitio & Fecha & $\begin{array}{l}\text { PRS mgP- } \\
\mathrm{PO}_{4}^{-3} / 1\end{array}$ & $\begin{array}{l}\text { Amonio } \\
\mu \mathrm{gN}-\mathrm{NH}_{4}{ }^{+} / \mathbf{l}\end{array}$ & $\begin{array}{l}\text { Nitritos } \\
\mu \mathrm{NN}^{-} \\
\mathrm{NO}_{2}{ }^{-} / \mathbf{l}\end{array}$ & $\begin{array}{l}\text { Nitratos } \\
\text { mgN-NO}_{3}^{-} \\
\text {/ }\end{array}$ & $\begin{array}{l}\text { Cloruros } \\
\text { mgCl-/l }\end{array}$ & $\begin{array}{l}\text { Alc. Fen } \\
\mathrm{mgCaCO}_{3} / \mathrm{l}\end{array}$ & $\begin{array}{l}\text { Alcalinidad } \\
\mathrm{mgCaCO}_{3} / \mathrm{l}\end{array}$ & $\begin{array}{l}\mathrm{DQO} \\
\mathrm{mgO}_{2} / \mathrm{l}\end{array}$ & $\begin{array}{l}\mathrm{DBO} \\
\mathrm{mgO}_{2} / \mathrm{l}\end{array}$ \\
\hline \multirow{6}{*}{$\begin{array}{c}\text { La } \\
\text { Choza I }\end{array}$} & Diciembre & $0,32 \pm 0,06$ & $0,0 \pm 0,0$ & $0,7 \pm 1,2$ & $0,47 \pm 0,4$ & $12,4 \pm 0,8$ & $0,0 \pm 0,0$ & $28,0 \pm 0,0$ & 113 & 6,2 \\
\hline & Febrero & $0,22 \pm 0,09$ & $8,5 \pm 7,5$ & $4,9 \pm 3,9$ & $1,48 \pm 1,4$ & $14,1 \pm 3,6$ & $0,0 \pm 0,0$ & $44,6 \pm 3,3$ & 105 & 11,8 \\
\hline & Mayo & $0,06 \pm 0,02$ & $11,36 \pm 1,86$ & $3,7 \pm 0,7$ & $0,007 \pm 0,01$ & $22,1 \pm 0,37$ & $0,0 \pm 0,0$ & $33,0 \pm 1,7$ & 71 & 2,5 \\
\hline & Agosto & $0,21 \pm 0,01$ & $38,38 \pm 10,97$ & $4,7 \pm 0,7$ & $0,06 \pm 0,0$ & $96,5 \pm 12,2$ & $5,8 \pm 0,0$ & $68,9 \pm 14,6$ & 60 & 2,5 \\
\hline & Noviembre & $0,19 \pm 0,09$ & $12,17 \pm 17,5$ & $2,8 \pm 4,9$ & $0,06 \pm 0,06$ & $40,9 \pm 3,2$ & $6,8 \pm 4,4$ & $48,5 \pm 4,4$ & 118 & 3,4 \\
\hline & Marzo & $0,02 \pm 0,00$ & $3,04 \pm 5,25$ & $25,5 \pm 4,6$ & $0,0 \pm 0,0$ & $9,3 \pm 0,6$ & $0,0 \pm 0,0$ & $35,9 \pm 1,7$ & 118 & 8,9 \\
\hline \multirow{6}{*}{$\begin{array}{c}\text { La } \\
\text { Choza } \\
\text { II }\end{array}$} & Diciembre & $0,32 \pm 0,04$ & $0,0 \pm 0,0$ & $13,3 \pm 1,6$ & $0,75 \pm 0,93$ & $12,0 \pm 3,5$ & $0,0 \pm 0,0$ & $33,3 \pm 8,3$ & 101 & 6,2 \\
\hline & Febrero & $0,02 \pm 0,01$ & $0,06 \pm 0,05$ & $8,9 \pm 6,3$ & $1,94 \pm 1,1$ & $49,1 \pm 4,3$ & $23,3 \pm 0,0$ & $194,1 \pm 6,7$ & 45 & 18,3 \\
\hline & Mayo & $0,07 \pm 0,01$ & $11,71 \pm 4,05$ & $4,5 \pm 0,6$ & $0,23 \pm 0,04$ & $24,1 \pm 0,75$ & $4,8 \pm 1,7$ & $45,6 \pm 4,4$ & 61 & 2,2 \\
\hline & Agosto & $0,13 \pm 0,01$ & $34,4 \pm 59,5$ & $4,9 \pm 3,0$ & $0,77 \pm 0,05$ & $56,8 \pm 3,9$ & $9,7 \pm 1,7$ & $79,6 \pm 18,9$ & 36 & 0,5 \\
\hline & Noviembre & $0,43 \pm 0,04$ & $36,4 \pm 21,2$ & $78,4 \pm 35,4$ & $1,53 \pm 0,3$ & $45,1 \pm 0,6$ & $6,8 \pm 3,4$ & $80,5 \pm 16,8$ & 15 & 1,8 \\
\hline & Marzo & $0,09 \pm 0,02$ & $18,05 \pm 5,5$ & $105,6 \pm 3,0$ & $1,66 \pm 0,2$ & $34,8 \pm 0,6$ & $5,8 \pm 0,0$ & $76,7 \pm 1,7$ & 25 & 2,4 \\
\hline \multirow{6}{*}{$\begin{array}{c}\text { La } \\
\text { Choza } \\
\text { III }\end{array}$} & Diciembre & $0,34 \pm 0,04$ & $0,0 \pm 0,0$ & $19,6 \pm 7,2$ & $1,2 \pm 0,3$ & $10,4 \pm 0,4$ & $4,8 \pm 1,7$ & $26,7 \pm 4,6$ & 96 & 9,7 \\
\hline & Febrero & $0,04 \pm 0,01$ & $53,5 \pm 22,5$ & $20,0 \pm 5,7$ & $3,47 \pm 0,45$ & $101,6 \pm 11,1$ & $15,6 \pm 3,4$ & $180,5 \pm 0,0$ & 25 & 11,4 \\
\hline & Mayo & $0,09 \pm 0,01$ & $39,5 \pm 7,04$ & $14,2 \pm 0,7$ & $0,74 \pm 0,24$ & $55,1 \pm 0,4$ & $3,9 \pm 1,7$ & $61,2 \pm 2,9$ & 55 & 2,7 \\
\hline & Agosto & $0,05 \pm 0,00$ & $8,6 \pm 7,9$ & $22,0 \pm 0,9$ & $1,28 \pm 0,12$ & $87,3 \pm 4,9$ & $7,8 \pm 1,7$ & $81,5 \pm 5,8$ & 21 & 2,7 \\
\hline & Noviembre & $0,22 \pm 0,01$ & $35,3 \pm 5,7$ & $71,0 \pm 7,9$ & $1,59 \pm 0,07$ & $110,3 \pm 5,0$ & $4,8 \pm 1,7$ & $60,2 \pm 1,7$ & 65 & 4,3 \\
\hline & Marzo & $0,08 \pm 0,01$ & $12,8 \pm 7,4$ & $60,6 \pm 1,9$ & $1,72 \pm 0,15$ & $92,0 \pm 0,4$ & $10,7 \pm 1,7$ & $78,6 \pm 2,9$ & 11 & 2,0 \\
\hline \multirow[t]{3}{*}{ Arias } & Diciembre & $0,55 \pm 0,04$ & $2,25 \pm 2,0$ & $23,1 \pm 10,5$ & $1,25 \pm 1,2$ & $11,8 \pm 1,1$ & $0,0 \pm 0,0$ & $22,7 \pm 2,3$ & 91 & 14,6 \\
\hline & Febrero & $0,11 \pm 0,07$ & $0,0 \pm 0,0$ & $7,9 \pm 13,7$ & $2,94 \pm 1,08$ & $4,9 \pm 0,8$ & $0,0 \pm 0,0$ & $60,2 \pm 3,4$ & 126 & 11,9 \\
\hline & Мayo & $0,08 \pm 0,01$ & $55,9 \pm 9,8$ & $7,6 \pm 11,5$ & $0,2 \pm 0,12$ & $12,9 \pm 0,6$ & $3,9 \pm 3,4$ & $27,2 \pm 7,3$ & 87 & 3,4 \\
\hline
\end{tabular}




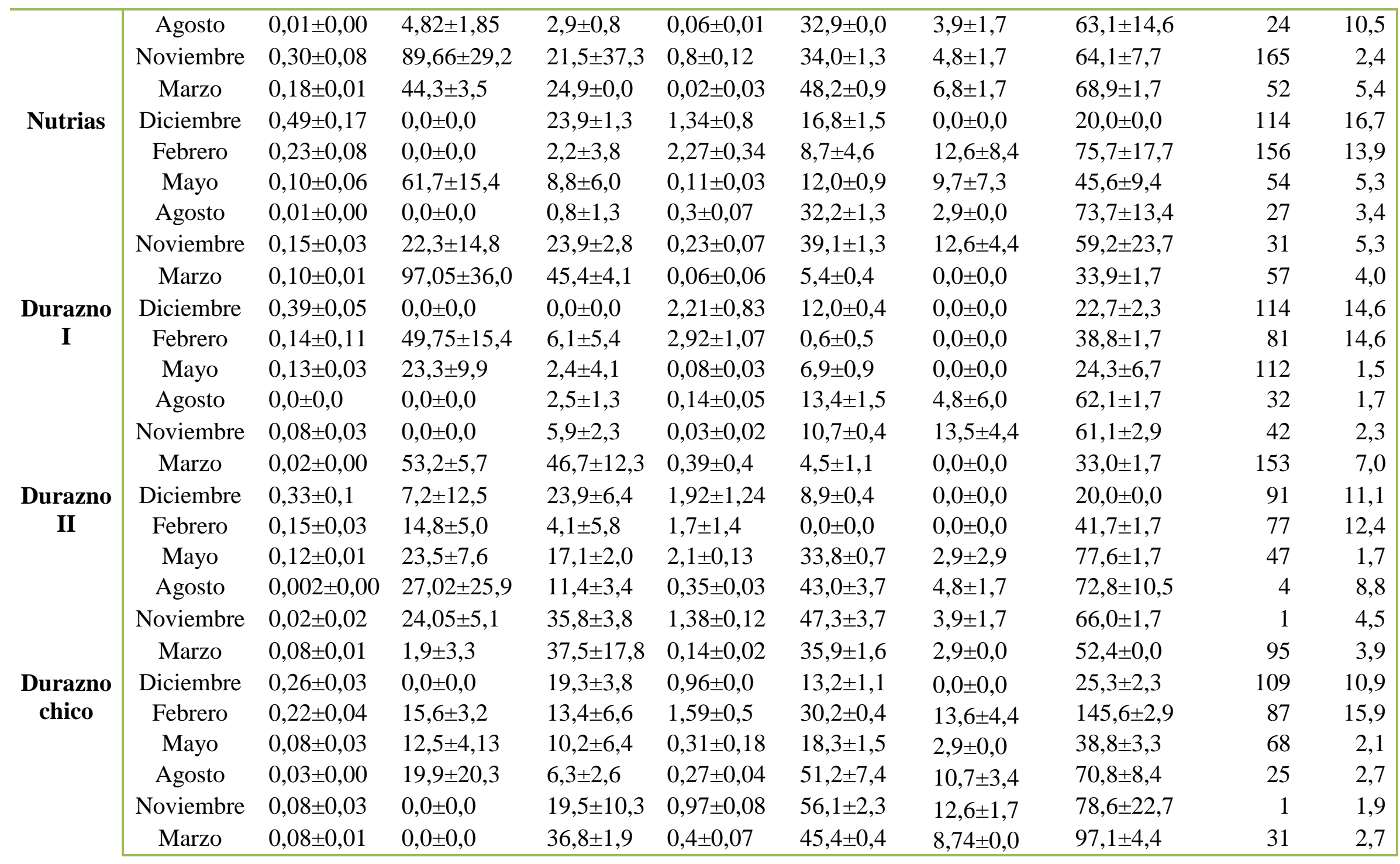




\section{Continuación}

\begin{tabular}{|c|c|c|c|c|c|c|c|c|c|c|c|c|}
\hline Sitio & Fecha & $\begin{array}{l}\text { Ácidos } \\
\text { Húmicos } \\
\text { Abs }\end{array}$ & $\begin{array}{l}\mathrm{OD} \\
\mathrm{mgO}_{2} / \mathbf{l}\end{array}$ & $\begin{array}{l}\text { Temp. } \\
{ }^{\circ} \mathrm{C}\end{array}$ & $\mathbf{p H}$ & $\begin{array}{l}\text { Conduct. } \\
\mu \mathrm{S} / \mathrm{cm}\end{array}$ & $\begin{array}{l}\text { Vel. } \\
\text { media } \\
\text { cm/seg }\end{array}$ & $\begin{array}{l}\text { Prof. } \\
\text { media } \\
\text { m }\end{array}$ & $\begin{array}{l}\text { Ancho } \\
\text { medio } \\
\text { m }\end{array}$ & $\begin{array}{l}\text { Caudal } \\
\text { l/seg }\end{array}$ & $\begin{array}{l}\text { Peso Seco } \\
\text { g/l }\end{array}$ & $\begin{array}{l}\text { PS } \\
\text { Orgánico } \\
\text { g/l }\end{array}$ \\
\hline \multirow{6}{*}{$\begin{array}{c}\text { La } \\
\text { Choza I }\end{array}$} & Diciembre & $0,4 \pm 0,01$ & 3,2 & 32 & 6,7 & 232 & 0,0027 & 0,54 & 13,23 & 19,08 & $7,35 \pm 2,2$ & $1,3 \pm 0,19$ \\
\hline & Febrero & $0,3 \pm 0,03$ & 8,3 & 31,9 & 8,33 & 257 & 0,0037 & 0,29 & 10,52 & 11,41 & $87,7 \pm 27,5$ & $14,9 \pm 4,2$ \\
\hline & Mayo & $0,2 \pm 0,0$ & 9,5 & 12 & 7,83 & 405 & 0,0032 & 0,47 & 12,43 & 18,64 & $2,4 \pm 1,2$ & $0,68 \pm 0,92$ \\
\hline & Agosto & $0,2 \pm 0,02$ & 12,2 & 12 & 8,41 & 1382 & 0,0011 & 0,40 & 11,45 & 4,97 & $30,8 \pm 2,3$ & $6,7 \pm 3,6$ \\
\hline & Noviembre & $0,5 \pm 0,07$ & 5 & 19 & 7,06 & 816 & 0,0024 & 0,37 & 10,63 & 9,29 & $80,3 \pm 2,1$ & $14,3 \pm 1,2$ \\
\hline & Marzo & $0,4 \pm 0,04$ & 0,9 & 17,8 & 8,11 & 454 & 0,0005 & 0,23 & 9,78 & 1,10 & $196,6 \pm 2,3$ & $30,6 \pm 3,4$ \\
\hline \multirow{6}{*}{$\begin{array}{c}\text { La } \\
\text { Choza } \\
\text { II }\end{array}$} & Diciembre & $0,4 \pm 0,01$ & 1,4 & 28 & 6,58 & 178 & 0,1016 & 0,40 & 4,82 & 197,77 & $2,67 \pm 0,4$ & $0,57 \pm 0,33$ \\
\hline & Febrero & $0,1 \pm 0,03$ & 8,1 & 26,2 & 8,03 & 1369 & 0,0037 & 0,06 & 3,75 & 0,78 & $47,6 \pm 14,5$ & $6,4 \pm 1,9$ \\
\hline & Mayo & $0,18 \pm 0,0$ & 9,7 & 12 & 8,09 & 555 & 0,0841 & 0,21 & 4,54 & 78,41 & $7,02 \pm 1,4$ & $0,56 \pm 0,3$ \\
\hline & Agosto & $0,1 \pm 0,0$ & 17,8 & 11 & 8,64 & 1282 & 0,0268 & 0,16 & 3,75 & 15,55 & $13,6 \pm 0,95$ & $1,77 \pm 0,14$ \\
\hline & Noviembre & $0,18 \pm 0,02$ & 5,8 & 20 & 7,72 & 1596 & 0,0086 & 0,10 & 3,97 & 3,24 & $114,7 \pm 40,0$ & $17,7 \pm 6,8$ \\
\hline & Marzo & $0,1 \pm 0,01$ & 4,9 & 18,6 & 7,1 & 1078 & 0,0009 & 0,08 & 3,49 & 0,24 & $29,9 \pm 1,04$ & $2,4 \pm 0,68$ \\
\hline \multirow{6}{*}{$\begin{array}{c}\text { La } \\
\text { Choza } \\
\text { III }\end{array}$} & Diciembre & $0,36 \pm 0,02$ & 1,5 & 28 & 7,18 & 244 & 0,0820 & 0,71 & 4,87 & 281,76 & $8,56 \pm 0,77$ & $1,5 \pm 0,1$ \\
\hline & Febrero & $0,02 \pm 0,01$ & 10,9 & 22,4 & 8 & 198 & 0,0025 & 0,19 & 4,44 & 2,16 & $44,7 \pm 9,1$ & $5,4 \pm 0,79$ \\
\hline & Mayo & $0,14 \pm 0,01$ & 7,5 & 12 & 8,02 & 808 & 0,0437 & 0,37 & 5,02 & 80,45 & $7,6 \pm 5,04$ & $0,98 \pm 0,1$ \\
\hline & Agosto & $0,04 \pm 0,0$ & 18,7 & 10 & 8,69 & 1752 & 0,0314 & 0,23 & 4,37 & 31,74 & $7,3 \pm 0,4$ & $1,01 \pm 0,15$ \\
\hline & Noviembre & $0,07 \pm 0,01$ & 3,8 & 19 & 7,49 & 949 & 0,0309 & 0,19 & 4,87 & 29,07 & $33,6 \pm 7,8$ & $5,06 \pm 0,9$ \\
\hline & Marzo & $0,07 \pm 0,01$ & 2,7 & 23,7 & 7,4 & 1414 & 0,0095 & 0,18 & 3,85 & 6,67 & $44,2 \pm 1,5$ & $3,8 \pm 0,68$ \\
\hline \multirow[t]{3}{*}{ Arias } & Diciembre & $0,29 \pm 0,0$ & 1,3 & 25 & 6,66 & 159,2 & 0,0609 & 0,55 & 9,62 & 319,47 & & \\
\hline & Febrero & $0,57 \pm 0,01$ & 4,2 & 21,1 & 7,2 & 506 & 0,0004 & 0,05 & 4,10 & 0,07 & $788,2 \pm 199,6$ & $100,1 \pm 21,0$ \\
\hline & Mayo & $0,25 \pm 0,01$ & 8 & 11,6 & 7,62 & 272 & 0,0191 & 0,26 & 8,01 & 39,74 & $67,6 \pm 13,1$ & $9,3 \pm 1,4$ \\
\hline
\end{tabular}




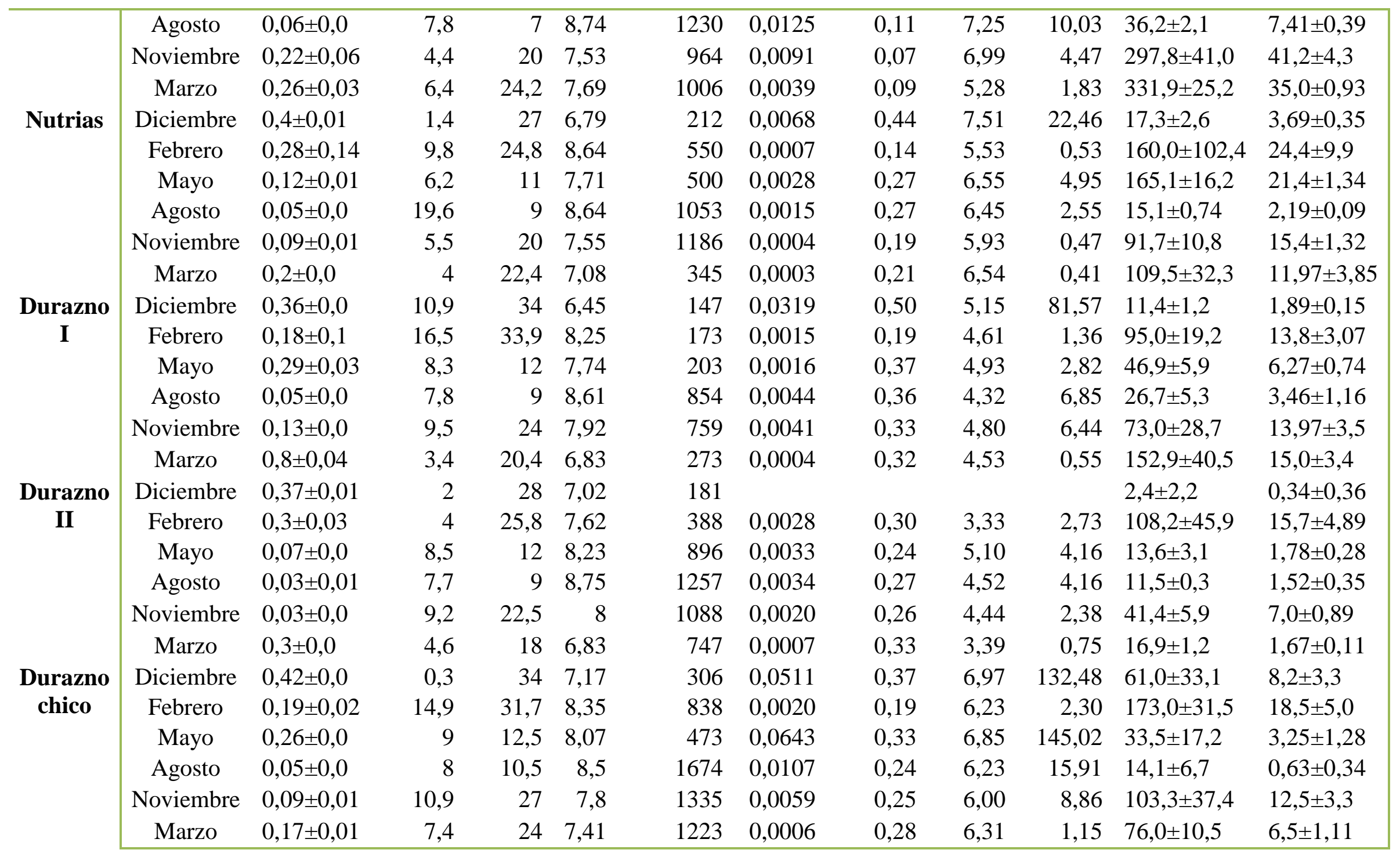


Anexo Cap. 3. Abundancias relativas de las algas del perifiton para cada sitio y fecha de muestreo

\begin{tabular}{|c|c|c|c|c|c|c|c|c|c|c|c|c|c|c|c|c|c|c|c|c|c|c|c|c|c|c|c|c|c|c|c|c|c|c|c|}
\hline \multirow[b]{3}{*}{ División Bacillariophyta } & \multicolumn{5}{|c|}{ DIC-06 } & \multicolumn{6}{|c|}{ FEB-07 } & \multicolumn{6}{|c|}{ MAY-07 } & \multicolumn{6}{|c|}{ AGO-07 } & \multicolumn{6}{|c|}{ NOV-07 } & \multicolumn{6}{|c|}{ MAR-08 } \\
\hline & C II & C & $\mathrm{Ar}$ & $\mathbf{t}$ & D I & II & C III & $\mathrm{Ar}$ & $\mathbf{t}$ & D I & D II & C II & C III & $\mathrm{Ar}$ & & D I & D II & CII & C III & $\mathrm{Ar}$ & it & D I & D II & CII & C III & $\mathrm{Ar}$ & ut & D I & D II & CII & C III & II $\mathrm{Ar}$ & Jut & t D I & D II \\
\hline & & & & & & & & & & & & & & & & & & & & & & & & & & & & & & & & & & & \\
\hline Achnanthe & 0,1 & 0 & 0 & 0 & 0 & 0 & 0 & 0 & 0 & 0 & 0 & 0 & 0 & 0 & 0 & 0 & 0 & 0 & 0 & 0 & 0 & 0 & 0 & 0 & 0 & 0 & 0 & 0 & 0 & 0 & 0 & 0 & 0 & 0 & 0 \\
\hline Amphora ovalis & 1,4 & 1,0 & 0,1 & 0,1 & 0 & 0,2 & 0,2 & 0 & 0 & 0 & 0 & 0,5 & 3,1 & 0,2 & 0,3 & 0,2 & 0,8 & 0,5 & 0 & 0,4 & 0 & 0,3 & 0,3 & 1,4 & 0,8 & 0 & 0 & 0 & 0,5 & 0 & 0 & 0 & 0 & 0 & 0,1 \\
\hline $\begin{array}{l}\text { Anor } \\
\text { Aula }\end{array}$ & 0 & 0 & 0 & 0,1 & 0 & 0,3 & 0 & 0 & 0,4 & 0 & 0 & 0 & 0 & 0 & 0 & 0 & 0 & 0,2 & 0,1 & 0 & 0 & 0 & 0,5 & 0,1 & 0 & 0,1 & 0 & 0 & 0 & 0 & 0 & 0 & 0 & 0 & 0 \\
\hline angu & 0 & 0 & 0,1 & 0 & 0 & 0 & 0 & 0 & 0 & 0 & 0 & 0 & 0 & 0 & 0 & 0 & 0 & 0 & 0 & 0 & 0 & 0 & 0 & 0 & 0 & 0 & 0 & 0 & 0 & 0 & 0 & 0 & 0 & 0 & 0 \\
\hline Bacillaria pa & 0 & 0 & 0 & 0 & 0 & 0 & 0 & 0 & 0 & 0 & 0,2 & 0 & 0 & 0 & 0 & 0 & 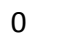 & 0 & 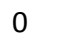 & 0 & 0 & 0 & 0 & 0 & 0,1 & 0 & 0 & 0 & 0,3 & 0 & 0 & 0 & 0 & 0 & 0 \\
\hline Cocc & 0,1 & 0 & 0,1 & 0,3 & 0 & 0 & 0 & 0 & 0 & 0 & 0 & 0 & o & 0 & - & - & - & 0,2 & 0 & . & 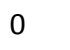 & 0 & 0 & 0 & 1,5 & 0 & 0 & 0 & 0,2 & 0 & 0 & 0 & 0 & 0,1 & 0 \\
\hline Cocc & 0 & 0 & 0 & 0,1 & 0 & 0 & 0,1 & 0,3 & 0,1 & 0 & 0 & 0,1 & 0 & 0 & 0 & 0,1 & 0 & 0,3 & 0,3 & 0,2 & 0 & 0 & 0 & 0,1 & 6,9 & 0 & 0 & 0,1 & 0,6 & 0,6 & 0 & 0,6 & 0,1 & 0 & 0 \\
\hline Craticula & 0 & 0 & 0 & 0 & 0 & 2 & 0,1 & 0 & 0 & 0 & 0 & 0 & 0 & 0 & 0 & 0 & 0 & 0 & 0 & 0 & 0 & 0 & 0 & 0 & 0 & 0 & 0 & 0,5 & 0 & 0 & 0 & 0 & 0 & 12 & 0 \\
\hline Cycl & 0,3 & 1,4 & 0,8 & 0,4 & 0 & 0,1 & 0 & 0,4 & 0,4 & 0 & 0,3 & 0,1 & 0 & 0,1 & 0,4 & 0,8 & 3,4 & 0 & 0,1 & 0,5 & 0 & 0 & 0 & 1,2 & 0,5 & 0,1 & 0 & 0 & 0 & 0 & 0 & 0 & 0 & 0 & 0 \\
\hline Cyli & 0 & 0 & 0 & 0 & 0 & 0,1 & 0 & 3 & 0,2 & 0,7 & 0,6 & 0,1 & 0 & 0,5 & 0,1 & 0 & - & 0 & - & 0,2 & 0 & J & 0,5 & o & 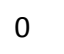 & 0,3 & 0 & 0,9 & 0,2 & 0,3 & 0 & 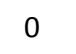 & 0,2 & 0 & 0,1 \\
\hline la minuta & 2,1 & 0,4 & 0 & 0,2 & 0 & 0 & 0 & 0 & 0 & 0 & 0,2 & 0 & 0 & 0 & 1,6 & 2,6 & 4,1 & 0,5 & 0 & 0 & 0,4 & 0,2 & 0 & 0,1 & 0 & 0 & 0 & 0,1 & 0,7 & 0 & 0 & 0 & 0,5 & 0,5 & 0,1 \\
\hline Cymk & 0 & 0 & 0 & 0 & 0 & 0 & 0 & 0 & 0 & 0 & 0 & 0 & 0 & 0 & 0 & 0 & 0 & 0 & 0 & 0 & 0 & 0 & 0 & 0 & 0 & 0 & 0 & 0 & 0 & 0 & 0 & 0 & 0 & 0,3 & 0 \\
\hline Dent & 0,1 & 0 & 0 & 0 & 0 & 0 & 0 & 0 & 0 & 0 & 0 & 0 & 1,7 & 0 & 0,1 & 0 & 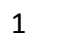 & 0,2 & 0 & 0 & 0 & 0 & 0 & 0 & 0 & 0,2 & 0 & 0 & 0,3 & 1,7 & 0 & 0,6 & 0 & 0 & 0 \\
\hline Diplc & 0 & 0 & 0 & 0 & 0 & 0 & 0 & 0 & 0 & 0 & 0 & 0 & 0 & 0 & 0 & 0 & 0 & 0 & 0 & 0 & 0,2 & 0 & 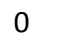 & 0 & 0 & 0 & 0 & 0 & 0,1 & 0 & 0 & 0 & 0 & 0 & 0 \\
\hline Epithemia sorex & 0 & 0 & 0 & 0 & 0 & 0 & 0 & 0 & 0 & 0 & 0,2 & 0 & 0 & 0 & 0 & 0,1 & 0,3 & 0 & 0 & 0 & 0 & 0 & 0 & 0,1 & 0 & 0 & 0 & 0 & 0 & 0 & 0 & 0 & 0 & 0 & 0 \\
\hline Eunotia pectinalis & 1,5 & 0,2 & 0 & 0,7 & 0,2 & 0,2 & 4,7 & 0 & 0 & 20 & 0,5 & 2,1 & 22,9 & 90,2 & 0 & 2,2 & 4,4 & 3,2 & 1,1 & 0 & 0 & 0 & 0 & 13,1 & 12,3 & 0 & 0 & 0 & 0,3 & 4,8 & 1 & 0 & 0,2 & 0 & 2 \\
\hline Euno & 0 & 0 & 0 & 0 & 0 & 0 & 0 & 0 & 0 & 0 & 3,3 & 0,7 & 1,2 & 0 & 0 & 0,3 & 0,8 & 3,3 & 0 & 政 & 0 & 0 & 0 & 6,0 & 0,3 & 0 & 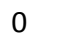 & 0 & 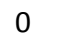 & 0 & 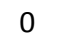 & 0 & 6,7 & 0 & 2,2 \\
\hline Fragi & 0 & 0 & 0 & 0 & 0 & 0 & 0 & 0 & 0 & 0 & 0 & 0 & 0 & 0 & 0 & 0 & 0 & 0 & 0 & 0 & 0 & 5,6 & 0 & 0 & 0 & 0 & 0 & 0 & $\sigma$ & 0 & 0,7 & 0 & 0 & 0 & 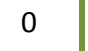 \\
\hline Gomphonema affine & 0,4 & 0 & 0 & 5,6 & 0 & 0,1 & 0,9 & 0 & 0,6 & 1,3 & 0,4 & 0 & 0 & 0 & 0 & 4,3 & 0,5 & 0 & 0,3 & 0 & 1,3 & 1,7 & 0 & 0,4 & 0,3 & 0 & 0 & 0 & 1,7 & 0 & 0 & 0 & 3,5 & 1,8 & $15, \varepsilon$ \\
\hline Gomphonema angustatum & 1,2 & 3,0 & 0 & 5,2 & 0,3 & 1,7 & 3,6 & 0 & 0 & 5,6 & 0 & 0,2 & 0,2 & 0 & 6,1 & 6,9 & 0 & 0 & 0 & 0 & 0 & 0 & 0 & 0 & 1,5 & 0 & 0 & 0 & 0 & 0 & 0 & 0 & 0 & 0 & 0 \\
\hline Gomphonema brasiliense & 0,3 & 0,3 & 0 & 0,4 & 0 & 1,5 & 1 & 0 & 0 & 1,2 & 0,6 & 0,3 & 3,3 & 0,2 & 0,7 & 1 & 0,5 & 0 & 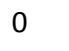 & 政 & 0 & 0 & $\sigma$ & 0,3 & 0,9 & 0 & 0 & 0 & 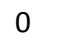 & 0 & 0 & 0 & 0 & 0 & 0 \\
\hline Gomphonema aff. clavatum & 2,1 & 1,1 & 0 & 0,2 & 0 & 0,1 & 1 & 0 & 0 & 3,1 & 0,2 & 0 & 0 & 0 & 1,9 & 4,1 & 0,3 & 0,3 & 0 & 0 & 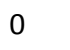 & 0,7 & 0 & 0,5 & 3,8 & 0 & 0 & 0 & 0,5 & 11, & 52,7 & 0 & 2,1 & 0 & 0 \\
\hline
\end{tabular}




\begin{tabular}{|c|c|c|c|c|c|c|c|c|c|c|c|c|c|c|c|c|c|c|c|c|c|c|c|c|c|c|c|c|c|c|c|c|c|c|c|}
\hline Gomphonema parvulum & 4 & 5,0 & 0,2 & 2,9 & 0 & 2,6 & 5,4 & 0 & 0,3 & 3,5 & 1 & 0,4 & 0 & 0 & 7,1 & 9,3 & 1 & 1,6 & 1,7 & 0,2 & 1,8 & 2,1 & 1,2 & 0,4 & 4,5 & 0,1 & 0 & 0 & 24,2 & 7 & 1,3 & 0 & 2,8 & 9,6 & ( \\
\hline omphonema truncatum & 1,6 & 0 & 0 & 0 & 0 & 0 & 0 & 0 & 0 & 0 & 0 & 0 & 0 & 0 & 0 & 0 & 0 & 0,8 & 0 & 0 & 0 & 0 & 0 & 0 & 0 & 0 & 0 & 0 & 0,1 & 0 & 0 & 0 & 0 & 0 & 0 \\
\hline lalamphora veneta & 0 & 0 & 0 & 0,8 & 0 & 0 & 0 & 0 & 0 & 0,2 & 0,8 & 0 & 0 & 0 & 0 & 0 & 0 & 0,3 & 0 & 0 & 0 & 0,1 & 0 & 0 & 0,1 & 0 & 0 & 0 & 0,3 & 0 & 0 & 0 & 0 & 0 & 0 \\
\hline lanzschia amphioxys & 0 & 0 & 0 & 0,2 & 0 & 0 & 0 & 0 & 0 & 0,1 & 0 & 0 & 0 & 0,2 & 0 & 0,1 & 0,3 & 0,4 & 0,1 & 0 & 0 & 0,2 & 0 & 0 & 0 & 0 & 0 & 0 & 0 & 0 & 0 & 0 & 0 & 0 & 0 \\
\hline anzschia elon & 0 & 0 & 0 & 0 & 0 & 0 & 0 & 0 & 0 & 0 & 0 & 0 & 0 & 0 & 0 & 0 & 0 & 0 & 0 & 0 & 0 & 0,4 & 0 & ( & 0 & 0 & 0 & 0 & 0 & 0 & 0 & 0 & 0 & 0 & 0 \\
\hline Hippodonta capitata & 0 & 0,1 & 0 & 0,5 & 0 & 0,1 & 0,1 & 0 & 0 & 0,3 & 0,3 & 0 & 0 & 0 & 0 & 0 & 0 & 0 & 0 & 0 & 0 & 1,7 & 0,7 & 0 & 0 & 0 & 0 & 0 & 1,3 & 0 & 0 & 0 & 0 & 0 & 0 \\
\hline Melosira varians & 1,5 & 1,8 & 0 & 0 & 0 & 0,1 & 0,4 & 0 & 0 & 0 & 0 & 0,6 & 1,9 & 0,1 & 29,5 & 50,7 & 0 & 26 & 43,9 & 935,1 & 26,5 & 18 & 0,9 & 0,3 & 8,3 & 0 & 0 & 0 & 19,4 & 0,3 & 0 & 0 & 4 & 0 & 0 \\
\hline$a v$ & 0,7 & 0 & 0 & 0 & 0 & 0 & 0 & 0 & 0 & 0 & 1 & 0 & 0 & 0 & 0 & 0 & 3,1 & 0 & 0 & 0 & 0 & 0 & 0 & 0,5 & 0,8 & 0 & 0 & 0 & 0 & 1,4 & 0 & 0 & 0 & 0 & 0 \\
\hline Navicula sp2 & 0 & 0,3 & 0 & 0 & 0,2 & 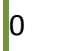 & 0 & 0 & 0 & 0 & 0,2 & 0 & 0 & 0 & 0 & 0 & 0 & 0 & O & 0 & 0 & 0,2 & c & J & 0 & 0 & 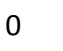 & 0 & 0 & 0 & 3 & 0 & 0,8 & 0,3 & 0,1 \\
\hline Vavicula sp3 & 0 & 0 & 0 & 0 & 0 & 0 & 0 & 0 & 0 & 0 & 0,2 & 0,2 & 0,9 & 0,1 & 0 & 0,1 & 0 & 0 & 0 & 0 & 0 & 0 & 0 & ( & 0 & 0 & 0 & 0 & 0 & 0 & 0 & 0 & 0 & 0,3 & 0 \\
\hline avicula sp4 & 0 & 0 & 0 & 0 & 0 & 0 & 0 & 0 & 0 & 0 & 0 & 0 & 0 & 0 & 0 & 0 & 2,6 & 0 & 0 & 0 & 0 & 0 & 0 & 0 & 0 & 0 & 0 & 0 & 0 & 0 & 0 & 0 & 0 & 0 & 0 \\
\hline Navicula sp5 & 0 & 0 & 0 & 0 & 0 & 0 & 0 & 0 & 0 & 0 & 0 & 0 & 0 & 0 & 0 & 0 & 0 & 0 & 0 & 0 & 0 & 0 & 0 & c & 0,9 & 0 & 0 & 0 & 0,4 & 0 & 0 & 0 & 0 & 0 & 0 \\
\hline$s p 6$ & 0 & 0 & 0 & 0 & 0 & 0 & 0 & 0 & 0 & 0 & 0 & 0 & 0 & 0 & $c$ & 0 & 0 & 0 & 0 & 0 & o & 0 & 0 & 1 & 0 & 0 & 0 & 2,7 & 0,6 & 0 & 0 & 0 & 0 & 0 & 0 \\
\hline Navicula cryptc & 0 & 0 & 0,2 & 0 & 0 & 0,3 & 2,2 & 0 & 0,3 & 0 & 0,8 & 1,3 & 1,2 & 0 & 0,2 & 0 & 2,1 & 0 & 0 & 0,9 & 0 & 0,7 & 0 & 0,1 & 0,3 & 0 & 0 & 0 & 0 & 0 & 0 & 0 & 0,1 & 0 & 0 \\
\hline Navicula & 0,4 & 1,4 & 0,2 & 0,2 & 0 & 0 & 0 & 0 & 0,5 & 0 & 0,8 & 0 & 0 & 0 & 0,1 & 0,1 & 0 & 13,8 & 30,8 & 0 & 2,1 & 0,4 & 1,6 & 0 & 0 & 0 & 0 & 0 & 0 & 0 & 0 & 0 & 0 & 1,4 & 0 \\
\hline Navi & 0 & 1,7 & 0,1 & 2,0 & 0 & 0,2 & 1,4 & 0,1 & 0,5 & 0,1 & 1,5 & 0,2 & 0,9 & 0,4 & 0,5 & 1,2 & 2,3 & 0,3 & 0,2 & 8,6 & 15,3 & 2,5 & 0 & 1,3 & 6,8 & 0,7 & 1,7 & 2,5 & 8,7 & 1,4 & 0 & 0 & 3,9 & 1,4 & 1 \\
\hline ela & 0 & 0 & 0 & 0 & 0 & 0 & 0 & 0 & 0 & 0 & 0 & 0 & 0 & 0 & 0 & 0 & 0 & 0 & 0 & 0 & 0 & 0 & 4 & ( & 0 & 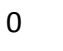 & 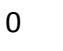 & 0 & 0 & 2,8 & 0 & 0 & 0 & 0 & 0,1 \\
\hline Neidium iridis & 0 & 0,1 & 0 & 0,1 & 0 & 0,3 & 1,8 & 0 & 0,3 & 0 & 0,7 & 0 & 0,2 & 0 & 0 & 0 & 0,5 & 0,2 & 0 & 0 & 1,6 & 0 & 0 & 0,1 & 0,1 & 0,1 & 0 & 0,4 & 1,9 & 0,3 & 0 & 0 & 0 & 0 & 0,1 \\
\hline Nitzsc & 1 & 0 & 0 & 0 & 0 & 0 & 0 & 0 & 0 & 0 & 0 & 0 & 0 & 0 & 0,2 & 0 & 0,5 & 0 & 0,1 & 0 & 1,2 & 1,9 & 0,2 & 0,1 & 1,6 & 0 & 0,4 & 0,2 & 5,2 & 0 & 0 & 0 & 0,1 & 0,1 & 0,4 \\
\hline Nitz & 0 & 0 & 0 & 0 & 0 & 0,8 & 0,4 & 0 & 0 & 0,2 & 1,1 & 0,2 & 0 & 1,6 & 3,4 & 3,4 & 7,5 & 0,3 & 0 & 0 & 1 & 4,7 & $c$ & ,9 & 1,2 & 0,7 & 0 & 0,1 & 4,3 & 0,6 & 1 & 0,6 & 5,2 & 4,6 & 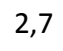 \\
\hline Nitz & 2,2 & 0,1 & 0 & 0,2 & 0 &, 5 & 0,7 & 0 & 0,2 & 0 & 0,6 & 0 & 0,2 & 0 & 0 & 0 & 0 & 0 & 0,8 & 0 & 0 & 1 & 0,4 & 1,9 & 1,2 & 0 & 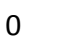 & 0 & 0,2 & 0 & 0 & 0 & 0,4 & 0 & 0,5 \\
\hline Nitzschia commutata & 0 & 0 & 0 & 0 & 0 & 0 & 0 & 0 & 0 & 0 & 0 & 0 & 0 & 2,2 & 1,4 & 0,2 & 1,3 & 0 & 0 & 0 & 0 & 0 & 0 & 0,1 & 0 & 0 & 0 & 0 & 0 & 0 & 0 & 0 & 0 & 0 & 0 \\
\hline Nitzschia gracilis & 0 & 0 & 0 & 0 & 0 & 0 & 0,2 & 0,5 & 0 & 0 & 0,5 & 0 & 0 & 0 & 0 & 0,1 & 0 & 0 & 0 & 0 & 0 & 0,3 & 0 & 0 & 0 & 0 & 0 & 0,1 & 0,1 & 0 & 0 & 0 & 0 & 0 & 0 \\
\hline Nitzsc & 0 & 6,7 & 1,5 & 2,8 & 0 & 0,3 & 0,7 & 1,3 & 0,5 & 1,7 & 6,1 & 7 & 7,4 & 3,4 & 2,5 & 3,6 & 13 &, 2 & 0 & 1,4 & 0,6 & 9 & 0,9 & 1 & 1,9 & 1 & 2,2 & 1,7 & 4,5 & 0,3 & 1 & 0 & 0,8 & 0,8 & 0,3 \\
\hline Nitzschia parvula & 0 & 0,3 & 0 & 0,1 & 0 & 0 & 0 & 0 & 0,1 & 0,2 & 0 & $v$ & 0,5 & 0 & 0 & 0 & 0,3 & 0,1 & 0 & , & 0,4 & 0,6 & 0 & c & 0 & 0 & 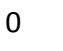 & 0 & 0,2 & 0 & 0 & 0 & 0 & 0 & 0 \\
\hline Nitzschia recta & 0,1 & 4,8 & 0,2 & 0,3 & 0,4 & 0,1 & 0,2 & 0 & 0 & 2,3 & 4,8 & 0,1 & 3,8 & 1,4 & 3,3 & 4,7 & 5,2 & 1,9 & 0,5 & 0,5 & 0,6 & 6,6 & 0 & 0,9 & 1,3 & 0 & 0,9 & 0,6 & 3,4 & 0 & 0 & 0 & 0,4 & 0,7 & 0,3 \\
\hline zschia scalpeliformis & 0 & 0 & 0 & 0 & 0 & 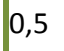 & 0,1 & 0 & 0 & 0 & 1,4 & 0 & 0 & 0 & 0 & 0 & 0,3 & 0 & 0 & 0 & 0 & 0,2 & 0,7 & 0,1 & 0 & 0,1 & 0 & 0,1 & 0,7 & 0,3 & 0 & 0 & 0,6 & 0 & 0 \\
\hline tzschia sigma & 0 & 0 & 0 & 0 & 0 & & 0 & 0 & 0 & 0 & 0 & & 0 & U & & & & & 0 & 0 & 0 & 0 & & & 0 & 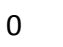 & 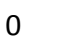 & 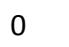 & 0,1 & & 0 & 0 & 0 & 0 & \\
\hline
\end{tabular}




\begin{tabular}{|c|c|c|c|c|c|c|c|c|c|c|c|c|c|c|c|c|c|c|c|c|c|c|c|c|c|c|c|c|c|c|c|c|c|c|c|}
\hline Nitzschia sigmoidea & 0 & 0,8 & 0 & 0,2 & 0 & 0,2 & 0,6 & 0 & 0 & 0 & 0 & 0 & 0,5 & 0,1 & 0,1 & 0 & 0 & 0,2 & 0 & 0 & 0 & 0,4 & 0 & 0,1 & 0 & 0 & 0 & 0 & 0 & 0 & 0 & 0 & 0 & 0 & 0 \\
\hline Nitzschia subacicularis & 0,4 & 1,7 & 3,0 & 3,5 & 0,2 & 0,1 & 0,9 & 7,6 & 0,4 & 1 & 5,6 & 1,1 & 5,7 & 4,2 & 3,4 & 5,6 & 4,9 & 0,3 & 0 & 0 & 0,4 & 4,7 & 0,2 & 0,3 & 0,1 & 0 & 0 & 0,7 & 1,3 & 0,6 & 2,7 & 0 & 0,7 & 0,9 & 0,3 \\
\hline Pinnularia sp1 & 0 & 0,2 & 0 & 0 & 0 & 0 & 0 & 0 & 0,4 & 0,2 & 0,5 & 0,2 & 0 & 0 & 0 & 0 & 0,3 & 0 & 0 & 0 & 0,2 & 0 & 0,8 & 0,3 & 0 & 0 & 0 & 0 & 0,1 & 0,3 & 0 & 0 & 0,2 & 0 & 0 \\
\hline Pinnularia sp2 & 0 & 0 & 0 & 0,8 & 0 & 0 & 0 & 0 & 0,2 & 0,9 & 1,1 & 0 & 1,9 & 0 & 0,2 & 0,1 & 1,3 & 0,1 & 0 & 0,5 & 0 & 0 & 0 & 0 & . & 0 & 0 & 0 & 0,3 & 0 & 0 & 0 & 0 & 0 & 0 \\
\hline Pinnularia sp3 & 5 & 0 & 0 & 0 & 0 & 0 & 0 & 0 & 0 & 0 & 0 & 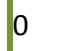 & 0 & 0 & 0 & 0 & 2,6 & 0,2 & 0 & 0 & 0 & 0 & 0 & & 0 & 0 & 0 & 0 & 0,1 & 0 & 0 & 0 & 0 & 0 & 0 \\
\hline Pinnularia braunii & 0 & 0 & 0 & 0 & 0 & 0 & 0 & 0 & 0,1 & 0,5 & 0,4 & 0,2 & 1,4 & 0 & 0 & 0 & 0 & 0,1 & 0 & 0 & 0,1 & 0 & 0,2 & 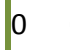 & 0 & 0 & 0 & 0 & 0,1 & U & 0 & 0 & 0 & 0 & 0 \\
\hline Pinnularia gibba & 0 & 0,3 & 0 & 0,2 & 0,2 & 0 & 0 & 0 & 0,1 & 1 & 0,4 & 0,5 & 0,5 & 0,3 & 0,6 & 0,3 & 0,3 & 0 & 0 & 0 & 0 & 1,1 & 0 & 0 & 0 & 0 & 0 & 0 & 0 & 0 & 0 & 0 & 0 & 0 & 0 \\
\hline Pinnularia viridis & 0 & 0 & 0 & 0 & 0 & 0,1 & 0 & 0 & 0,2 & 0 & 0 & 0 & 0,2 & 0 & 0 & 0 & 0,3 & 0,2 & 0,4 & 0,2 & 0 & 0,1 & 2,2 & 0 & 0,1 & 0 & 0 & 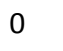 & 0,3 & 0 & 0 & 0,3 & 0,7 & 0 & 0 \\
\hline Placoneis & 0,2 & 0 & 0 & 0 & 0 & 0,1 & 0,1 & 0 & 0 & 0 & 0 & 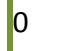 & 0 & 0,2 & 0 & 0,1 & 0,3 & 0,1 & 0 & 0 & 0 & 0 & 0,1 & 1 & 0 & 0 & 0 & 0 & 0,2 & 0 & 0 & 0 & 0 & 0 & 0 \\
\hline Planothidium & 0,1 & 0 & 0 & 0,2 & 0,3 & 0,6 & 0,5 & 0 & 0 & 0,2 & 0,2 & 0,4 & 0 & 0 & 0 & 0,4 & 0,3 & 0 & 0 & 0 & 0,1 & 0 & 0 & 0,1 & 0,7 & 0 & 0 & 0 & 1,3 & 0 & 0 & 0 & 0,2 & 0 & 0 \\
\hline Pleurosira laevis & 0,4 & 1,5 & 0 & 0 & 0 & 0 & 0,1 & 0 & 0 & 0 & 0 & 0 & 0 & 0 & 0,4 & 0 & 0,3 & 0 & 0 & 0 & 0 & 0 & 0 & 0 & 0,7 & 0 & 0 & 0 & 0 & 0 & 0,3 & 0 & 0 & 0 & 0 \\
\hline Rhoicosphenia abbreviata & 0,2 & 0,4 & 0 & 0 & 0 & 0,3 & 0,2 & 0 & 0 & 0,2 & 0 & 0 & 0 & 0 & 0 & 0 & 0 & 0 & 0,1 & 0 & 0 & 0 & 0 & & 0,3 & 0 & 0 & 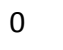 & 0,1 & 0 & 0 & 0 & 0 & 0 & 0 \\
\hline Rhopalodia gibba & 0 & 0 & 0 & 0 & 0 & 0 & 0 & 0 & 0 & 0 & 0 & 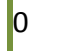 & 0 & 0 & 0 & 0 & 0 & 0,2 & 0 & 0 & 0 & 0 & 0 & 1 & 0 & 0 & 0 & 0 & 0 & 0 & 0 & 0 & 0 & 0 & 0 \\
\hline Rhopalodia gibberula & 0 & 0,3 & 0,1 & 0 & 0 & 0 & 0 & 0 & 0 & 0 & 0,2 & 0 & 0 & 0 & 0 & 0 & 0 & 0 & 0,1 & 0 & 0 & 0 & 0 & 0 & 0 & 0 & 0 & 0 & 0,1 & 0 & 0 & 0 & 0 & 0 & 0,1 \\
\hline Sellaphora pupula & 0 & 0 & 0 & 0 & 0 & 0 & 0 & 0 & 0 & 0 & 0,5 & 0 & 0 & 0 & 0 & 0 & 0,3 & 0 & 0 & 0 & 0 & 0 & 0,2 & 0 & 0,1 & 0 & 0 & 0 & 0,4 & 0 & 0 & 0 & 0,2 & 0 & 0 \\
\hline $\begin{array}{l}\text { Stauroneis phoenicenteron } \\
\text { Stephanocyclus }\end{array}$ & 0 & 0 & 0 & 0 & 0 & 0 & 0 & 0 & 0 & 0 & 0 & 0 & 0 & 0 & 0 & 0 & 0 & 0 & 0 & 0 & 0 & 0,1 & 0 & 0 & 0 & 0,1 & 0 & 0 & 0,1 & c & 0 & 0 & 0 & 0 & 0 \\
\hline iniana & 0,4 & 1,8 & 0,4 & 1,5 & 0,2 & 1,1 & 0,4 & 6 & 0,8 & 0,5 & 2,9 & 1,3 & 0,7 & 0,2 & 0,2 & 1,8 & 8,3 & 0,1 & 0 & 0 & 0 & 0 & 0,2 & 0 & 1,8 & 0 & 0 & 0 & 0 & 0 & 0 & 0 & 0 & 0 & 0 \\
\hline Surirella angustata & 0 & 0 & 0 & 0 & 0 & a & 0 & 0 & 0 & 0 & 0 & U & 0,2 & 0 & 0 & 0,4 & 0,3 & 0 & 0 & $\sigma$ & 0 & 0 & 0 & & 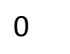 & 0 & 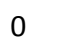 & 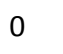 & 0,11 & 0 & 0 & 0 & 0 & 0 & 0 \\
\hline Surirella ovalis & 0 & 0 & 0 & 0 & 0 & 0,3 & 0,3 & 0 & 0 & 0 & 0 & 0 & 0 & 0 & 0 & 0 & 0 & 11,4 & 13,6 & 50 & 10,3 & & 0,4 & 0,3 & 1,3 & 0 & 0 & 0 & 1,4 & 0,6 & 0 & 0 & 0 & 0 & 0 \\
\hline Surirella robusta & 0 & 0 & 0 & 0,1 & 0 & 0,9 & 0,5 & 0 & 0 & 0 & 0,1 & 0 & 0,7 & 0 & 0 & 0 & 0,3 & 0 & 0 & 0 & 0 & 0,1 & 0 & 0,9 & 1,3 & 0 & 0 & 4,6 & 0,2 & 0,3 & 1,7 & 0 & 0 & 0 & 0 \\
\hline Surirella tenera & 0 & 0 & 0 & 0 & 0 & 0,2 & 0,8 & 0 & 0,1 & 0 & 0,2 & 0,2 & 0 & 0 & 0 & 0 & 0 & 3 & 2,9 & 0 & 1,1 & 0 & 0,6 & 3 & 0,4 & 0 & 0 & 0 & 0 & 0 & 0 & 0 & 0 & 0 & 0 \\
\hline Synedra ulna & 1,1 & 2,3 & 0 & 0,2 & 0 & 1,3 & 9,4 & 0 & 0 & 0 & 0 & 76 & 13,1 & 1,3 & 0,5 & 6,3 & 3,9 & 25,6 & 24,4 & 1,2 & 19,8 & 31,5 & 2 & 2,6 & 1,9 & 0,5 & 2,8 & 0,5 & 2,8 & 9,9 & 8,3 & 1,2 & 0,2 & 0,1 & 1,2 \\
\hline \multicolumn{36}{|l|}{ División Chlorophyta } \\
\hline tinastrum hantzschii & 0,1 & 0 & 0,4 & 0 & 0 & 0 & 0 & 0 & 0,2 & 0,2 & 0 & 0 & 0 & 0 & 0 & 0 & 0,3 & 0 & 0 & 0 & 0 & 0 & 0 & 0 & 0 & 0,3 & 0 & 0 & 0 & 0 & 0 & 0 & 0 & 0 & 0 \\
\hline Ankistrodesmus acicularis & 0,3 & 0,1 & 0,6 & 0,5 & 0,4 & 0,1 & 0,3 & 7,6 & 2,0 & 0,2 & 1,1 & 2,4 & 1,9 & 3,3 & 0,9 & 5 & 0,5 & 0,4 & 0,1 & 0,2 & 0,5 & 0,1 & 0 & , & 1,8 & 3,2 & 0,4 & 0,7 & 0,3 & 0 & 0 & 0,6 & 0,3 & 0,2 & 0 \\
\hline kistrodesmus angustus & 0,2 & 0,3 & 1,5 & 0,7 & 0,2 & 1 & 0 & 0,6 & 0,5 & 0,2 & 0,7 & 0 & 0 & 1 & 0 & 0 & 0 & 0 & 0 & 0,9 & 0,1 & 0,2 & 0 & 3 & 0 & 2,3 & 0 & 0,4 & 0 & 0 & 0,7 & 0,3 & 0 & 0,3 & 0 \\
\hline Characium sp & 0 & 0,3 & 0 & 0,8 & 0 & 0,5 & 4,1 & 0 & 0,2 & 1,6 & 0,7 & 0,1 & 0,9 & 1,1 & 2,8 & 4,2 & 0,8 & ( & 0 & 0 & 0,4 & 1 & 0 & 2 & 2,3 & 3,3 & 5,5 & 6,3 & 0,4 & & 9,3 & 12 & 0,7 & 2,1 & 9 \\
\hline
\end{tabular}




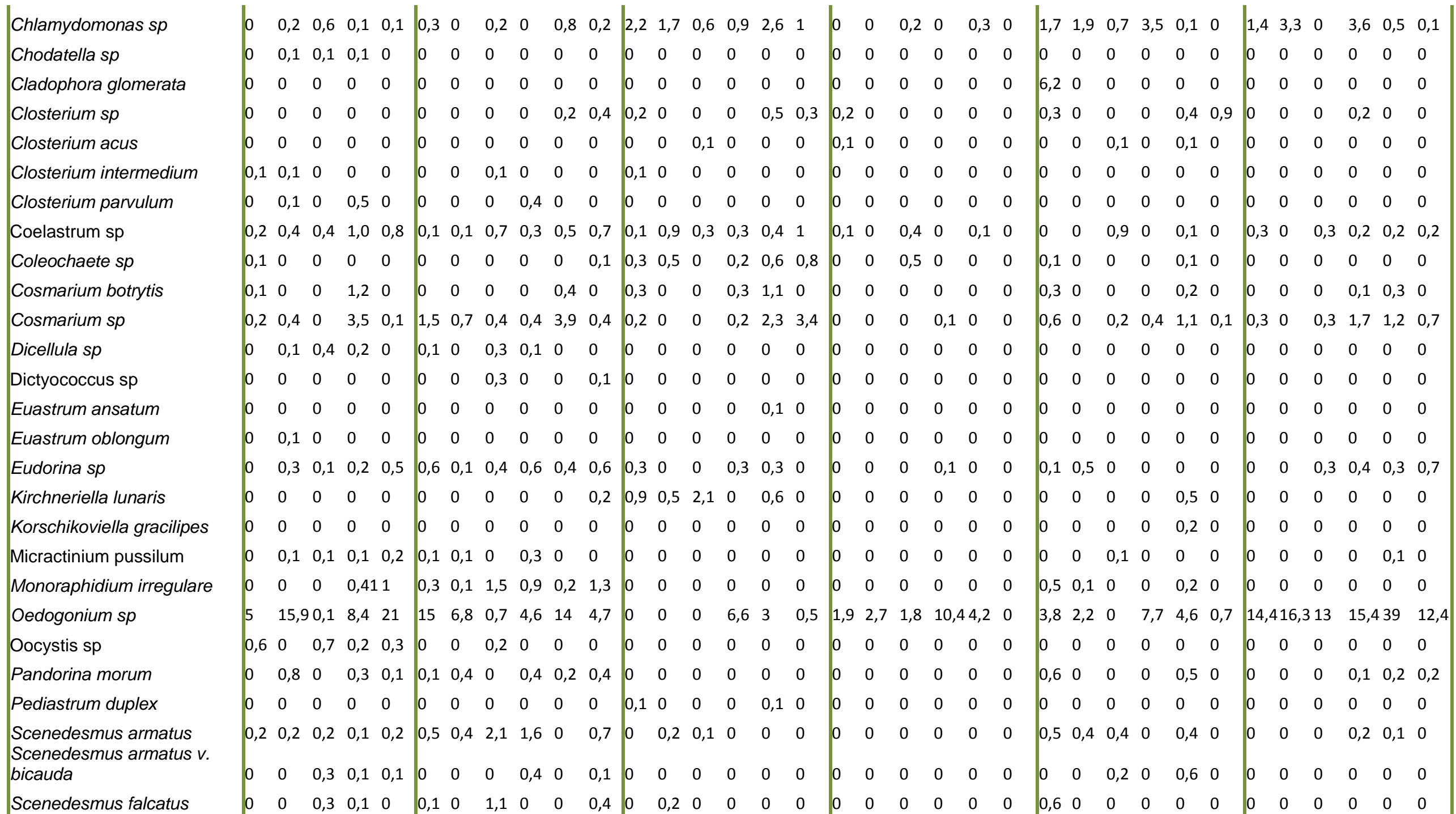




\begin{tabular}{|c|c|c|c|c|c|c|c|c|c|c|c|c|c|c|c|c|c|c|c|c|c|c|c|c|c|c|c|c|c|c|c|c|c|c|c|}
\hline Scenedesmus flexuosus & 0,1 & 0 & 0,1 & 0,1 & 0 & 0,1 & 0 & 1,2 & 0,1 & 0 & 1,8 & 0,9 & 0 & 0,5 & 0,1 & 0,8 & 0,3 & 0,2 & 0 & 0 & 0 & 0 & 0 & 0,8 & 0,5 & 0,3 & 0,4 & 0 & 0 & 0 & 0 & 0 & 0 & 0,1 & 0 \\
\hline Schizomeris sp & 0 & 0,2 & 0 & 0 & 0,2 & 0 & 0 & 0 & 0 & 0 & 0 & 0 & 0 & 0 & 0 & 0 & 0 & 0 & 0 & 0 & 0 & 0 & 0 & 0 & 0 & 0 & 0 & 0 & 0 & 0 & 0 & 0 & 0 & 0 & 0 \\
\hline Schroederia setigera & 0 & 0,2 & 0,4 & 0,2 & 0,4 & 0,1 & 0 & 0,6 & 0,2 & 0,1 & 0,1 & 0 & 0 & 0,4 & 0 & 0 & 0 & 0 & 0 & 0 & 0 & 0 & 0,5 & 0 & 0 & 0 & 0 & 0 & 0 & 0,3 & 0 & 0,3 & 0,1 & 0,2 & 0 \\
\hline Spirogyra $s p$ & 0 & 1,6 & 0 & 0,1 & 0,5 & 0 & 0 & 0 & 0 & 0 & 0 & 0 & 0 & 0 & 0 & 0 & 0 & 0,3 & 5,3 & 0 & 0,1 & 0,7 & 0 & 0 & 0 & 0 & 0 & 0 & 0 & 0 & 0 & 0 & 0 & 0 & 0 \\
\hline Staurastrum $s p$ & 0 & 0,1 & 0 & 0,2 & 0 & 0 & 0 & 0 & 0 & 0,2 & 0,1 & 0,9 & 0,2 & 0,1 & 0,1 & 0,3 & 0 & 0 & 0 & 0 & 0 & 0 & 0 & 0 & 0 & 0 & 0 & 0 & 0 & 0 & 0 & 0 & 0 & 0 & 0 \\
\hline Staurastrum teliferum & 0 & 0 & 0 & 0 & 0 & 0 & 0 & 0 & 0 & 0 & 0 & 0 & 0 & 0 & 0 & 0,3 & 0 & 0 & 0 & 0 & 0 & 0 & 0 & 0 & 0 & 0 & 0 & 0 & 0 & 0 & 0 & 0 & 0 & 0 & 0 \\
\hline Stigeoclonium tenue & 6,4 & 7,4 & 0,1 & 2,0 & 0,4 & 13 & 11 & 1,3 & 4,7 & 2,3 & 2,5 & c & 0,2 & 0 & 16,3 & 35,4 & 1 & 0,1 & 0 & 12,5 & 1,6 & 2,3 & 0 & 7,6 & 16,1 & 0,4 & 21,9 & 0,6 & 2,5 &, 5 & 4 & 8 & 0,1 & 2,8 & 5,3 \\
\hline traedron minimun & 0 & 0 & 0,2 & 0,1 & 0 & 0 & 0 & 0,2 & 0,3 & 0 & 0,2 & c & 0 & 0,1 & 0 & 0 & 0 & 0 & 0 & 0 & 0 & 0 & 0 & 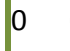 & 0 & 0 & 0 & 8 & 0 & 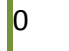 & 0 & 0 & 0 & 0 & 0 \\
\hline Tetrastrum sp & 0 & 0 & 0 & 0 & 0 & 0 & 0 & 0 & 0 & 0 & 0 & 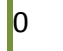 & 0 & 0 & 0 & 0 & 0 & 0 & 0 & 0 & 0 & 0 & 0 & 0 & 0 & 0,4 & 0 & 0 & 0 & 0,6 & 0 & 0 & 0 & 0,1 & 0 \\
\hline Ulothrix sp & 0 & 0,3 & 0 & 0 & 0,2 & 0,2 & 0 & 0 & 0,6 & 1,1 & 0,1 & 0 & 0 & 0 & 0 & 0,2 & 0 & 0 & 0 & 0,5 & 0,1 & 0 & 0 & 0 & 0 & 0 & 1,3 & 0 & 0 & 1,1 & 0 & 1,2 & 0,7 & 0,3 & 0 \\
\hline Xanthidium sp & 0 & 0 & 0 & 0 & 0,1 & 0 & 0 & 0 & 0 & 0 & 0 & 0 & 0 & 0 & 0 & 0,1 & 0 & 0 & 0 & 0 & 0 & 0 & 0 & 0 & 0 & 0 & 0 & 0 & 0 & 0 & 0 & 0 & 0 & 0 & 0 \\
\hline Zignema sp & 0 & 0 & 0 & 0,2 & 0 & 0 & 0 & 0 & 0 & 0 & 0 & 0 & 0 & 0 & 0 & 0 & 0 & 0 & 0 & 0 & 0 & 0 & 0 & 0 & 0 & 0 & 0 & 0 & 0 & 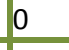 & 0 & 0 & 0 & 0 & 0 \\
\hline \multicolumn{36}{|l|}{ División Cyanophyta } \\
\hline Anabaena sp1 & 2,4 & 1,1 & 0,2 & 3,2 & 0,2 & 0 & 0 & 0,1 & 0,1 & 0,1 & 0 & 0 & 0,2 & 0 & 0 & 0,2 & 0 & 0 & 0 & 0 & 0 & 0 & 0 & 0,3 & 0 & 0 & 0 & 0,5 & 0 & 0 & 0 & 0 & 0,5 & 0,2 & 0,1 \\
\hline Anabaena sp2 & 0 & 0 & 0 & 0 & 0 & 0 & 0,1 & 0 & 0 & 0 & 0,1 & 0 & 0 & 0 & 0 & 0 & 0 & 0 & 0 & 0 & 0 & 0 & 0 & 0 & 0 & 0 & 0 & 0 & 0 & 0 & 0 & 0 & 0,4 & 0 & 0 \\
\hline Aphanocapsa sp & 0 & 0,1 & 0 & 0 & 0 & 0,8 & 0,3 & 0 & 0 & 0,2 & 0 & 0 & 0 & 0 & 0,4 & 0 & 0 & 0 & 0 & 0 & 0 & 0 & 0 & 0 & 0 & 0 & 0 & 0 & 0 & 0 & 0 & 0 & 0 & 0 & 0 \\
\hline Calothrix $s p$ & 0 & 0 & 0 & 0 & 0 & 0 & 0 & 0 & 0 & 0,2 & 3,6 & 0 & 0 & 0 & 0 & 0 & 0 & 0 & 0 & 0 & 0 & 0 & 0 & 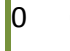 & 0 & 0 & 0 & 0 & 0 & 0 & 0 & 0 & 0 & 0 & 0 \\
\hline Chrooccocus sp & 0 & 0,5 & 0 & 0 & 0 & 0 & 0 & 0,6 & 0,1 & 0 & 0 & 0,2 & 0 & 0 & 0 & 0 & 0 & 0 & 0 & 0,9 & 0 & 0 & 0 & 0 & 0 & 0 & 0 & 0,7 & 0,2 & 0,6 & 0 & 0 & 0,6 & 0 & 0 \\
\hline Chrooccocus minutus & 0 & 0 & 0 & 0 & 0 & 0 & 0 & 0 & 0 & 0 & 0 & 0 & 0 & 0 & 0 & 0 & 0 & 0 & 0 & 0 & 0 & 0 & 0 & 0 & 0 & 0 & 0 & 0 & 0 & 0 & 0 & 0 & 0 & 0 & 1 \\
\hline omphosphaeria sp & 0 & 0 & 0 & 0,2 & 0 & 0 & 0 & 0 & 0 & 0 & 0 & 0 & 0 & 0 & 0 & 0 & 0 & 0 & 0 & 0 & 0 & 0 & 0 & 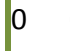 & 0 & 0 & 0 & 0 & 0 & 0 & 0 & 0 & 0 & 0 & 0 \\
\hline Leptolyngbya sp & 6,3 & 4,0 & 12,3 & 32,3 & 8,6 & 0 & 0 & 1,2 & 0 & 0,2 & 3,3 & c & $\sigma$ & 5,9 & 0 & 0,1 & 0,5 & 0 & 0 & 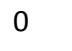 & 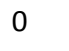 & . & 0 & 0 & 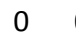 & 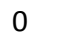 & 0 & 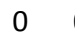 & 0 & 0 & 0 & 0 & 0,1 & 0 & 0 \\
\hline Lyngbya sp1 & 41 & 4,5 & 4,8 & 7,3 & 58 & 5,1 & 7,3 & 5,1 & 8,6 & 4,2 & 6,3 & 1,4 & 10 & 22 & 3,7 & 7,5 & 7,5 & 0 & 0 & 6,9 & 0,2 & 1,4 & 0 & 6,4 & 6,1 & 2,2 & 8,3 & 9,3 & 2,6 & & 729,6 & 614 & & 85 & 3,2 \\
\hline Lyngbya sp2 & 0 & 3,1 & 0,3 & 2,0 & 0,3 & 18 & 14 & 2,5 & 0,4 & 1,2 & 7,8 & 0,2 & 5,2 & 1,3 & 0,8 & 1,2 & 1,8 & 0 & 0 & 1,1 & 0,2 & 0 & 0 & 4,6 & 5,7 & 0,4 & 4,8 & 4,3 & 0 & 4,5 & 4,3 & 6,4 & 1,3 & 1,7 & 1,1 \\
\hline Lyngbya sp3 & 1,3 & 0 & 0 & 0 & 0 & 0 & 0 & 0 & 0 & 0 & 0 & O & 0 & 0 & 0 & 0 & 0 & 0 & 0 & 0 & 0 & 0 & 0 & & 0 & 0 & 0 & 0 & 0 & 0 & 0 & 0 & 0 & 0 & 0 \\
\hline lerismopedia sp1 & o & 0 & 0 & 0 & 0 & 5,8 & 2,6 & 0,3 & 0 & 0,1 & 0,1 & ( & 0 & 0 & 0 & 0 & 0 & 0 & 0 & 0 & 0 & 0 & 0 & 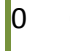 & 0,3 & 0 & 0 & 0 & 0 & 0 & 0 & 0 & 0 & 0 & 0 \\
\hline erismopedia sp2 & 0 & 0,3 & 0,1 & 0 & 0 & 0,4 & 0 & 0,1 & 0 & 0 & 0 & 0,2 & 0 & 0 & 0 & 0 & 0 & 0 & 0 & 0 & 0 & 0,1 & 0 & 0,1 & 0 & 0 & 0 & 0 & 0 & 0 & 0 & 0 & 0,3 & 0 & 0 \\
\hline crocystis aeruginosa & 0 & 0 & 0 & 0 & 0,2 & 0 & 0 & 0 & 0 & 0 & 0 & 0 & 0 & 0 & 0 & 0 & 0 & 0 & 0 & 0 & 0 & 0 & 0 & & 0 & 0 & 0 & 0 & 0 & 0 & 0 & 0 & 0 & 0 & 0 \\
\hline cillatoria sp & 7,9 & 1,1 & 0,4 & 2,3 & 2 & 3,3 & 5 & 1,3 & 5,8 & 1,1 & 0,8 & 0 & 0,7 & 0,6 & 0 & 0,2 & 0 & 0,2 & 0 & 2,7 & 0,4 & 1,1 & 0,3 & 0,1 & 1,1 & 0,3 & 4,6 & 15,6 & 0,4 & 10,4 & 43,6 & 2,8 & 0,7 & 2,6 & 0,9 \\
\hline
\end{tabular}




\begin{tabular}{|c|c|c|c|c|c|c|c|c|c|c|c|c|c|c|c|c|c|c|c|c|c|c|c|c|c|c|c|c|c|c|c|c|c|c|c|}
\hline scillatoria limnetica & 0 & 0 & 0 & 0,3 & 0 & 1 & 0 & 0 & 0,9 & 0,3 & 5,2 & 0 & 0 & 0 & 0 & 0 & 0 & 0 & 0 & 0 & 0 & 0 & 0 & 0,3 & 0 & 0,7 & 0 & 0,7 & 0,3 & 0 & 0 & 3,7 & 0,4 & 0 & 0 \\
\hline Oscillatoria princeps & 0 & 0,1 & 0 & 0,3 & 0 & 0 & 0 & 0 & 0,1 & 0 & 0 & 0 & 0 & 0 & 0 & 0 & 0 & 0 & 0 & 0 & 0 & 0 & 0 & 0 & 0 & 0 & 0 & 0 & 0 & 0 & 0,7 & 0 & 0,4 & 0 & 0 \\
\hline Oscillatoria tenuis & 0 & 2,9 & 0,7 & 0,2 & 0,1 & 0 & 0 & 0 & 0 & 0 & 0,1 & 0 & 0 & 0 & 0,3 & 0 & 0,3 & 0 & 0 & 0 & 0 & 0 & 0 & 0 & 0 & 1,3 & 3,1 & 0,7 & 0,1 & 0 & 0 & 0,3 & 0 & 0,4 & 0 \\
\hline Phormidium sp & 0,7 & 0 & 0 & 0,2 & 0 & 14 & 5,2 & 0 & 0 & 0 & 0,4 & 0 & 0 & 0 & 0 & 0 & 0 & 0 & 0 & 0 & 0 & 0 & 0 & 0 & 0,4 & 0 & 0 & 0 & 0,5 & 0 & 0 & 0,3 & 0 & 0,7 & 34,8 \\
\hline Planktothrix sp & 0 & 8,7 & 1,0 & 0 & 0,1 & 0 & 0 & 0 & 0 & 0 & 0 & 0 & 0 & 3,8 & 0 & 0 & 0 & 0 & 0 & 16,8 & 0 & 0 & 0 & 0 & 0 & 60 & 0 & 0,1 & 0 & 0 & 0 & 0 & 0 & 0 & 0,1 \\
\hline Pseudoanabaena sp & 1,3 & 1,1 & 0 & 3,8 & 0 & 0,4 & 0,3 & 0,2 & 0,6 & 0,7 & 1,5 & 0 & 0,2 & 0,1 & 0,1 & 0 & 0,3 & 0 & 0 & 3,6 & 0,1 & 3,9 & 0,1 & 0,3 & 0,4 & 0 & 0,9 & 1,8 & 0,4 & 2,8 & 0 & 0,6 & 2,8 & 0,4 & 0,4 \\
\hline Raphidiopsis mediterranea & 0 & 0 & 55,1 & & 0 & 0 & 0 & 23 & 0 & 0 & 0 & 0 & 0 & 39 & 0 & 0 & 0 & 0 & 0 & 0,2 & 0 & 0 & 0 & 0 & 0 & 16 & 0 & 0 & 0 & 0 & 0 & 0,3 & 0 & 0 & 0 \\
\hline Spirulina sp & 0,2 & 0,2 & 0,1 & 0 & 0,1 & 0,1 & 1,1 & 0 & 0,5 & 0 & 1,4 & 0 & 0 & 0 & 0 & 0 & 0 & 0 & 0 & 0 & 0 & 0 & 0 & 0 & 0 & 0 & 0 & 0 & 0 & 0 & 0 & 0 & 0,6 & 0 & 0 \\
\hline Synechococcus sp & 0 & 0 & 0 & 0,82 & & 0 & 0 & 0 & 0 & 0 & 0 & 0 & 0 & 0 & 0 & 0 & 0 & 0 & 0 & 0 & 0 & 0 & 0 & 6,2 & 0,4 & 0 & 0 & 0 & 0 & 0 & 0 & 0 & 0 & 0 & 0 \\
\hline \multicolumn{36}{|l|}{ División Euglenophyta } \\
\hline Colacium epiphyticum & 0 & 0 & 0 & 0,2 & 0 & 0 & 0 & 0 & 0 & 0 & 0 & 0 & 0 & 0 & 0 & 0 & 0 & 0 & 0 & 0 & 0 & 0 & 0 & 0 & 0 & 0,2 & 0 & 0 & 0 & 0 & 0 & 0 & 0 & 0 & 0,1 \\
\hline Euglena sp1 & 0,4 & 1,6 & 2,1 & 6,1 & 0,3 & 0,5 & 0,5 & 9,5 & 9,2 & 2,9 & 5,1 & 0,1 & 0,9 & 0,3 & 0,6 & 0,3 & 0 & 0 & 0 & 0,7 & 0 & 0,7 & 0 & 2,6 & 0,3 & 0,2 & 0 & 0,1 & 0 & 0,8 & 0,7 & 2,8 & 2,7 & 0,9 & 0,5 \\
\hline Euglena sp2 & 0,3 & 0,1 & 0 & 1,1 & 0 & 0,1 & 0 & 0,4 & 25,8 & 5,4 & 0,8 & 0 & 0 & 0 & 0 & 0,2 & 0 & 0,1 & 0 & 0 & 0,4 & 0,1 & 0 & 0 & 0 & 0 & 2,2 & 6,6 & 0 & 0,3 & 0 & 0,3 & 2,3 & 1,8 & 0 \\
\hline Euglena acus & 0 & 0 & 0 & 1,6 & 0 & 0 & 0 & 0,5 & 1,2 & 0,3 & 0 & 0 & 0 & 0 & 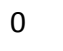 & 0 & 0 & 0 & 0 & 0 & 0 & 0 & 0 & 0 & 0 & 0 & 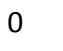 & 0,2 & 0 & o & 0 & 0 & 0 & 0 & 0 \\
\hline Euglena ehrembergii & 0,3 & 0,4 & 0,6 & 1,8 & 0,2 & 0,2 & 0,2 & 0,6 & 1,4 & 0,4 & 0,1 & 0 & 0 & 0,2 & 0,1 & 0 & 0,3 & 0,1 & 0 & 0 & 0 & 0 & 0 & 1,6 & 0,4 & 0,1 & 1,1 & 2,2 & 0,1 & 0,8 & 0 & 0,6 & 0,6 & 0 & 0 \\
\hline Lepocinclis salina & 0 & 0 & 0,4 & 1 & 0 & 0 & 0 & 3 & 13,9 & 2 & 0,4 & 0 & 0 & 0 & 0,2 & 0,4 & 0 & 0 & 0 & 0 & 0 & 0 & 0 & 3,1 & 0,1 & 0,1 & 1,3 & 5,4 & 0 & 1,4 & 0,7 & 3,7 & 0,2 & 0,3 & 0 \\
\hline Lepocinclis caudata & 0 & 0 & 0 & 0,1 & 0 & 0 & 0 & 0 & 2,7 & 0,7 & 0 & 0 & 0 & 0 & 0 & 0 & 0 & 0 & 0 & 0 & 0 & 0 & 0 & 0,4 & 0 & 0 & 0 & 0 & 0 & 0 & 0 & 0 & 0,3 & 0 & 0 \\
\hline Phacus sp1 & 0 & 0,2 & 0 & 3,8 & 0 & 0,1 & 0 & 3,8 & 0,7 & 2 & 0,7 & 0,2 & 0,2 & 0 & 0,2 & 0,2 & 0,3 & 0,1 & 0 & 0,2 & 0,1 & 0 & 0 & 1,8 & 0,1 & 0 & 1,3 & 0,9 & 0 & 0 & 0 & 0,3 & 0,6 & 0,7 & 0 \\
\hline Phacus sp2 & 0 & 0,1 & 0,2 & 1,15 & & 0,1 & 0 & 2,7 & 0,4 & 1 & 0,2 & 0 & 0 & 0 & 0 & 0,1 & 0 & 0 & 0 & 0 & 0 & 0 & 0 & 0,5 & 0 & 0 & 0,4 & 0,5 & 0 & 0 & 0 & 0 & & 30 & 0 \\
\hline Strombomonas sp & 0 & 0 & 0 & 0,16 & & 0,2 & 0 & 0 & 0,5 & 0,2 & 0,3 & 0,2 & 0 & 0,1 & 0 & 0 & 0,3 & 0 & 0 & 0 & 0 & 0 & 0 & 0,3 & 0,4 & 0,1 & 0,9 & 0,9 & 0 & 0,6 & 0,3 & 3,4 & 0,7 & 0 & 0 \\
\hline Trachelomonas sp1 & 0 & 0,1 & 0,2 & 1,7 & 0 & 0 & 0,1 & 0,2 & 0,2 & 0,2 & 1 & 0 & 0 & 0 & O & 0 & 0 & 0 & 0 & 0 & 0 & 0 & 0 & 0 & 0,1 & 0,8 & 6,1 & 0,9 & 0 & 0 & 0 & 0 & 0,1 & 0,4 & 0 \\
\hline Trachelomonas sp2 & 0 & 0,1 & 0,2 & 0,6 & 0 & 0 & 0 & 0 & 0,3 & 0,5 & 0,2 & 0 & 0 & 0,1 & 0 & 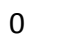 & 0 & 0 & 0 & 0 & 0 & 0 & 0 & 0 & 0 & 0,1 & 0 & 1,9 & 0 & 0 & 0 & 0 & 0,1 & 0,1 & 0 \\
\hline Trachelomonas sp3 & 0,2 & 0,4 & 7,4 & 5,9 & 0,6 & 0 & 0 & 4,3 & 1,6 & 4,3 & 3,3 & 0 & 0,5 & 0,2 & 0 & 0,1 & 0,3 & 0 & 0 & 0,2 & 0,1 & 1,2 & 0 & 1,7 & 1,2 & 0,5 & 14 & 12,9 & 90 & 0,3 & 3 & 21 & 0,9 & 1,2 & 0 \\
\hline Trachelomonas sp4 & 0 & 0 & 0,47 & 0,49 & & 0 & 0 & 1 & 0 & 0 & 0,2 & 0,1 & 0 & 0 & 0 & 0 & 0 & 0 & 0 & 0 & 0 & 0 & 0 & 0,9 & 0 & 0,2 & 1,7 & 0,5 & 0 & 0 & 0 & 0 & 0,1 & 0,6 & 0 \\
\hline
\end{tabular}


Anexo cap. 5 Experimento 1. Valores medios y desvíos a tiempo inicial y final para cada tratamiento. En violeta los parámetros cuya variación se registró, en naranja los forzados en los tratamientos, en celeste los estimados en el agua y en verde los estimados en el perifiton.

\begin{tabular}{|c|c|c|c|c|c|c|c|c|}
\hline & \multicolumn{4}{|c|}{ Inicial } & \multicolumn{4}{|c|}{ Final } \\
\hline $\mathrm{pH}$ & $8,6 \pm 0,1$ & $8,7 \pm 0,05$ & $8,8 \pm 0,06$ & $8,7 \pm 0,05$ & $8,9 \pm 0,3$ & $8,9 \pm 0,07$ & $9,1 \pm 0,03$ & $9,0 \pm 0,03$ \\
\hline Temperatura ${ }^{\circ} \mathrm{C}$ & $17,3 \pm 0,15$ & $17,4 \pm 0,25$ & $17,3 \pm 0,2$ & $17,6 \pm 0,4$ & $24,8 \pm 0,6$ & $25,0 \pm 0,3$ & $25,0 \pm 0,3$ & $24,9 \pm 0,3$ \\
\hline Conductividad $\mu \mathrm{S} / \mathrm{cm}$ & $1837 \pm 2,64$ & $1853 \pm 15,7$ & $1898 \pm 8,9$ & $1916 \pm 35,8$ & $2045 \pm 87,9$ & $2176 \pm 57,7$ & $2156 \pm 80,2$ & $2240 \pm 98,5$ \\
\hline Ácidos Húmicos Abs & $0,04 \pm 0,003$ & $0,38 \pm 0,01$ & $0,04 \pm 0,001$ & $0,4 \pm 0,01$ & $0,04 \pm 0,003$ & $0,32 \pm 0,02$ & $0,04 \pm 0,003$ & $0,3 \pm 0,02$ \\
\hline Amonio $\mu \mathrm{gN}-\mathrm{NH}_{4}{ }^{+} / 1$ & $1,17 \pm 2,03$ & $0,0 \pm 0,0$ & $18,2 \pm 31,5$ & $0,0 \pm 0,0$ & $0,0 \pm 0,0$ & $0,0 \pm 0,0$ & $0,0 \pm 0,0$ & $0,0 \pm 0,0$ \\
\hline Nitritos $\mathrm{mgN}-\mathrm{NO}_{2}{ }^{-} / \mathrm{l}$ & $0,03 \pm 0,03$ & $0,02 \pm 0,02$ & $0,03 \pm 0,01$ & $0,01 \pm 0,005$ & $0,001 \pm 0,0$ & $0,0 \pm 0,0$ & $0,001 \pm 0,001$ & $0,0 \pm 0,0$ \\
\hline Cloruros mgCl-/l & $80,4 \pm 20,4$ & $74,9 \pm 5,9$ & $81,3 \pm 15,6$ & $69,0 \pm 4,6$ & $100,1 \pm 24,9$ & $108,1 \pm 12,7$ & $100,8 \pm 20,9$ & $104 \pm 16,2$ \\
\hline Peso Seco g/l & $19,18 \pm 1,65$ & $30,8 \pm 6,3$ & $19,9 \pm 7,8$ & $31,6 \pm 3,4$ & $16,8 \pm 7,8$ & $16,0 \pm 7,6$ & $13,4 \pm 4,4$ & $11,1 \pm 3,4$ \\
\hline PS Orgánico g/l & $8,8 \pm 1,07$ & $14,7 \pm 0,8$ & $8,0 \pm 2,3$ & $14,3 \pm 0,2$ & $10,3 \pm 2,0$ & $11,4 \pm 6,1$ & $8,6 \pm 4,2$ & $6,9 \pm 2,2$ \\
\hline
\end{tabular}




\begin{tabular}{|c|c|c|c|c|c|c|c|c|}
\hline Peso Seco perifiton $\mathrm{g} / \mathrm{m}^{2}$ & $8,6 \pm 1,39$ & $4,2 \pm 1,1$ & $7,6 \pm 3,8$ & $7,6 \pm 2,1$ & $4,9 \pm 1,1$ & $4,1 \pm 3,1$ & $3,4 \pm 0,9$ & $3,3 \pm 0,3$ \\
\hline PS Orgánico perifiton $\mathrm{g} / \mathrm{m}^{2}$ & $4,87 \pm 0,48$ & $2,7 \pm 0,99$ & $4,5 \pm 1,8$ & $3,75 \pm 1,0$ & $2,8 \pm 1,1$ & $1,9 \pm 1,6$ & $1,5 \pm 0,6$ & $1,5 \pm 0,9$ \\
\hline Polisacararidos mg/ml & $3621,5 \pm 561$ & $2504,3 \pm 2118$ & $2478,8 \pm 1406$ & $1932,9 \pm 707$ & $3764 \pm 388$ & $2024 \pm 1426$ & $2774 \pm 1613$ & $2417 \pm 903$ \\
\hline Fósforo Total mg/m² & $8,13 \pm 2,7$ & $5,9 \pm 3,0$ & $4,3 \pm 0,9$ & $6,0 \pm 1,4$ & $5,7 \pm 1,9$ & $3,3 \pm 0,5$ & $30,7 \pm 10,8$ & $32,8 \pm 17,3$ \\
\hline Clorofila $a \mathrm{mg} / \mathrm{m}^{2}$ & $15,3 \pm 6,9$ & $21,8 \pm 13,9$ & $14,9 \pm 8,8$ & $25,3 \pm 5,4$ & $10,4 \pm 11,4$ & $9,7 \pm 7,4$ & $14,1 \pm 10,8$ & $16,7 \pm 12,9$ \\
\hline Respiración $\mathrm{mgO}_{2} / \mathrm{h} . \mathrm{m}^{2}$ & $3,16 \pm 0,35$ & $5,25 \pm 9,1$ & $0,5 \pm 0,9$ & $0,0 \pm 0,0$ & $39,5 \pm 8,8$ & $14,5 \pm 12,6$ & $28,5 \pm 24,7$ & $39,7 \pm 25,9$ \\
\hline Índice Autotrófico & $367,6 \pm 166,8$ & $141,3 \pm 38,9$ & $249,4 \pm 40,7$ & $154,2 \pm 59,6$ & $198,3 \pm 19,4$ & $294,9 \pm 218,4$ & $141,4 \pm 68,6$ & $129 \pm 72,8$ \\
\hline Lakatos \%Cenizas & $0,32 \pm 0,18$ & $0,75 \pm 0,24$ & $0,41 \pm 0,06$ & $0,72 \pm 0,3$ & $0,51 \pm 0,05$ & $0,51 \pm 0,4$ & $0,82 \pm 0,4$ & $1,13 \pm 0,9$ \\
\hline Lakatos \%Clorofila & $43,03 \pm 3,4$ & $34,9 \pm 15,3$ & $38,8 \pm 6,4$ & $50,5 \pm 0,4$ & $44,5 \pm 10,2$ & $55,0 \pm 4,4$ & $57,4 \pm 8,6$ & $53,6 \pm 4,3$ \\
\hline Fosfatasa nmolMUF/h.cm ${ }^{2}$ & $5510 \pm 3014$ & $5391 \pm 5699$ & $6270,8 \pm 2958$ & $8945 \pm 1900$ & $27173 \pm 4767$ & $28172 \pm 4236$ & $8036 \pm 4994$ & $5634 \pm 2568$ \\
\hline
\end{tabular}


Experimento 2. Valores medios y desvíos a tiempo inicial y tiempo final para cada uno de los tratamientos. En violeta los parámetros cuya variación se registró, en naranja los forzados en los tratamientos, en celeste los estimados en el agua y en verde los estimados en el perifiton.

\begin{tabular}{|c|c|c|c|c|c|c|c|c|}
\hline & \multicolumn{4}{|c|}{ Inicial } & \multicolumn{4}{|c|}{ Final } \\
\hline & Control & Húmicos & Fertilizante & $\mathbf{H}+\mathbf{F}$ & Control & Húmicos & Fertilizante & $\mathbf{H}+\mathbf{F}$ \\
\hline $\mathrm{pH}$ & $8,05 \pm 0,04$ & $8,05 \pm 0,05$ & $8,0 \pm 0,05$ & $8,0 \pm 0,02$ & $8,7 \pm 0,01$ & $8,6 \pm 0,09$ & $8,7 \pm 0,2$ & $8,4 \pm 0,1$ \\
\hline Temperatura ${ }^{\circ} \mathrm{C}$ & $20,1 \pm 0,9$ & $19,4 \pm 0,1$ & $19,3 \pm 0,06$ & $19,5 \pm 0,1$ & $24,1 \pm 0,2$ & $24,5 \pm 0,06$ & $24,4 \pm 0,2$ & $24,5 \pm 0,06$ \\
\hline Conductividad $\mu \mathrm{S} / \mathrm{cm}$ & $1495 \pm 45,1$ & $1464 \pm 38,1$ & $2190 \pm 0,0$ & $2230 \pm 55,7$ & $1508 \pm 61,4$ & $1514 \pm 47,8$ & $2416 \pm 40,4$ & $2426 \pm 90,7$ \\
\hline Amonio $\mu \mathrm{gN}-\mathrm{NH}_{4}{ }^{+} / 1$ & $14,5 \pm 4,3$ & $10,7 \pm 3,8$ & $509,3 \pm 97$ & $519,7 \pm 23$ & $9,0 \pm 2,3$ & $10,1 \pm 5,2$ & $244 \pm 184$ & $494 \pm 339$ \\
\hline Nitritos $\mathrm{mgN}-\mathrm{NO}_{2}^{-} / \mathrm{l}$ & $0,03 \pm 0,02$ & $0,03 \pm 0,02$ & $0,08 \pm 0,02$ & $0,14 \pm 0,06$ & $0,01 \pm 0,01$ & $0,02 \pm 0,002$ & $0,3 \pm 0,05$ & $0,4 \pm 0,09$ \\
\hline Nitratos $\mathrm{mgN}-\mathrm{NO}_{3}{ }^{-} / 1$ & $0,13 \pm 0,08$ & $0,5 \pm 0,1$ & $4,8 \pm 1,1$ & $4,3 \pm 0,5$ & $0,05 \pm 0,001$ & $0,03 \pm 0,01$ & $8,3 \pm 0,9$ & $12,7 \pm 6,1$ \\
\hline Cloruros mgCl-/l & $80,9 \pm 7,1$ & $86 \pm 2,9$ & $244,4 \pm 10,3$ & $250,6 \pm 4,1$ & $92,2 \pm 2,7$ & $93,0 \pm 3,9$ & $284,5 \pm 11$ & $282,5 \pm 12,4$ \\
\hline Peso Seco g/l & $16,7 \pm 7,53$ & $22,5 \pm 5,8$ & $17,8 \pm 2,6$ & $27,4 \pm 1,4$ & $13,9 \pm 4,6$ & $16,9 \pm 4,8$ & $10,1 \pm 3,0$ & $16,0 \pm 7,9$ \\
\hline PS Orgánico g/l & $4,7 \pm 4,5$ & $7,9 \pm 1,5$ & $5,1 \pm 1,3$ & $8,5 \pm 0,8$ & $5,0 \pm 0,9$ & $8,1 \pm 2,9$ & $4,7 \pm 0,5$ & $8,3 \pm 3,1$ \\
\hline
\end{tabular}




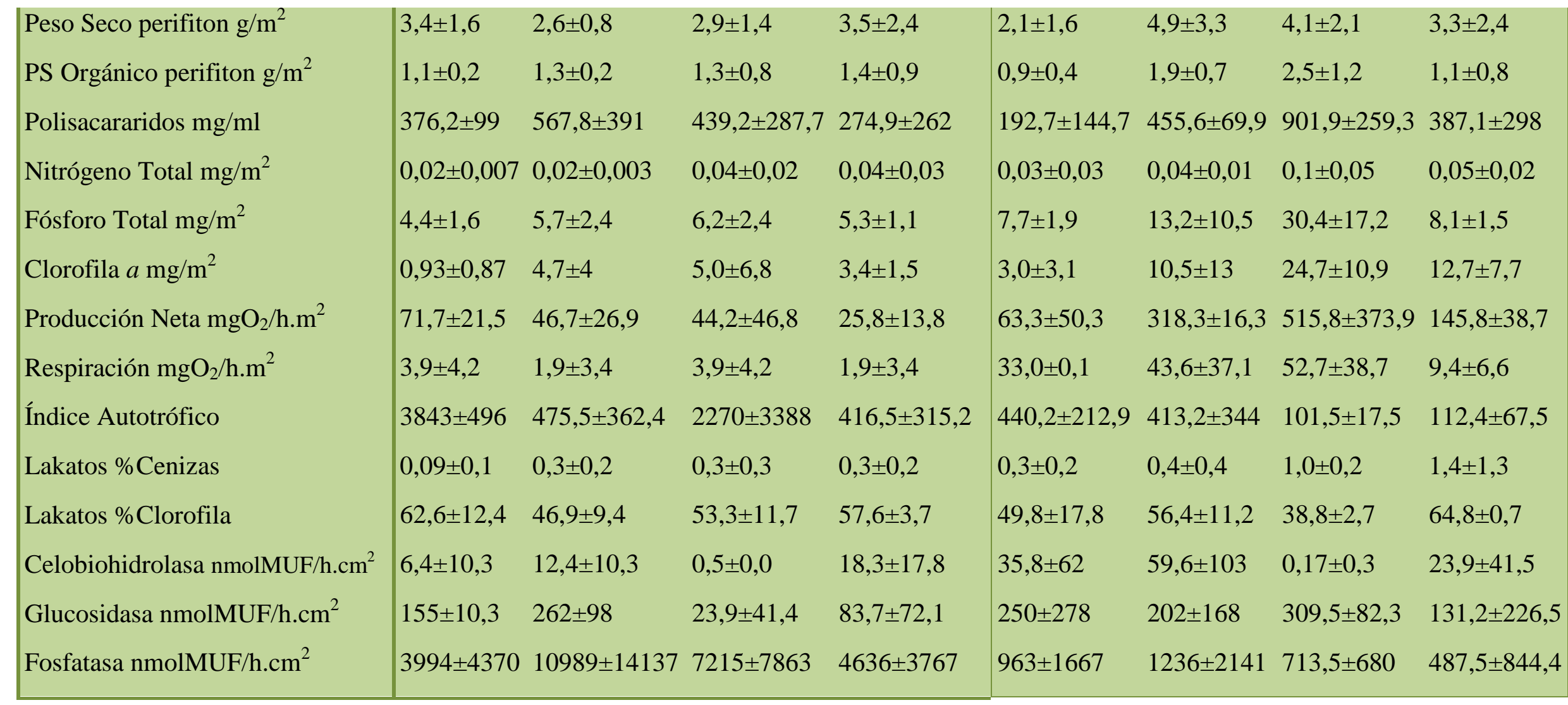


Experimento 3. Valores medios y desvíos a tiempo inicial y tiempo final para cada uno de los tratamientos. En violeta los parámetros cuya variación se registró, en naranja los forzados en los tratamientos, en celeste los estimados en el agua y en verde los estimados en el perifiton

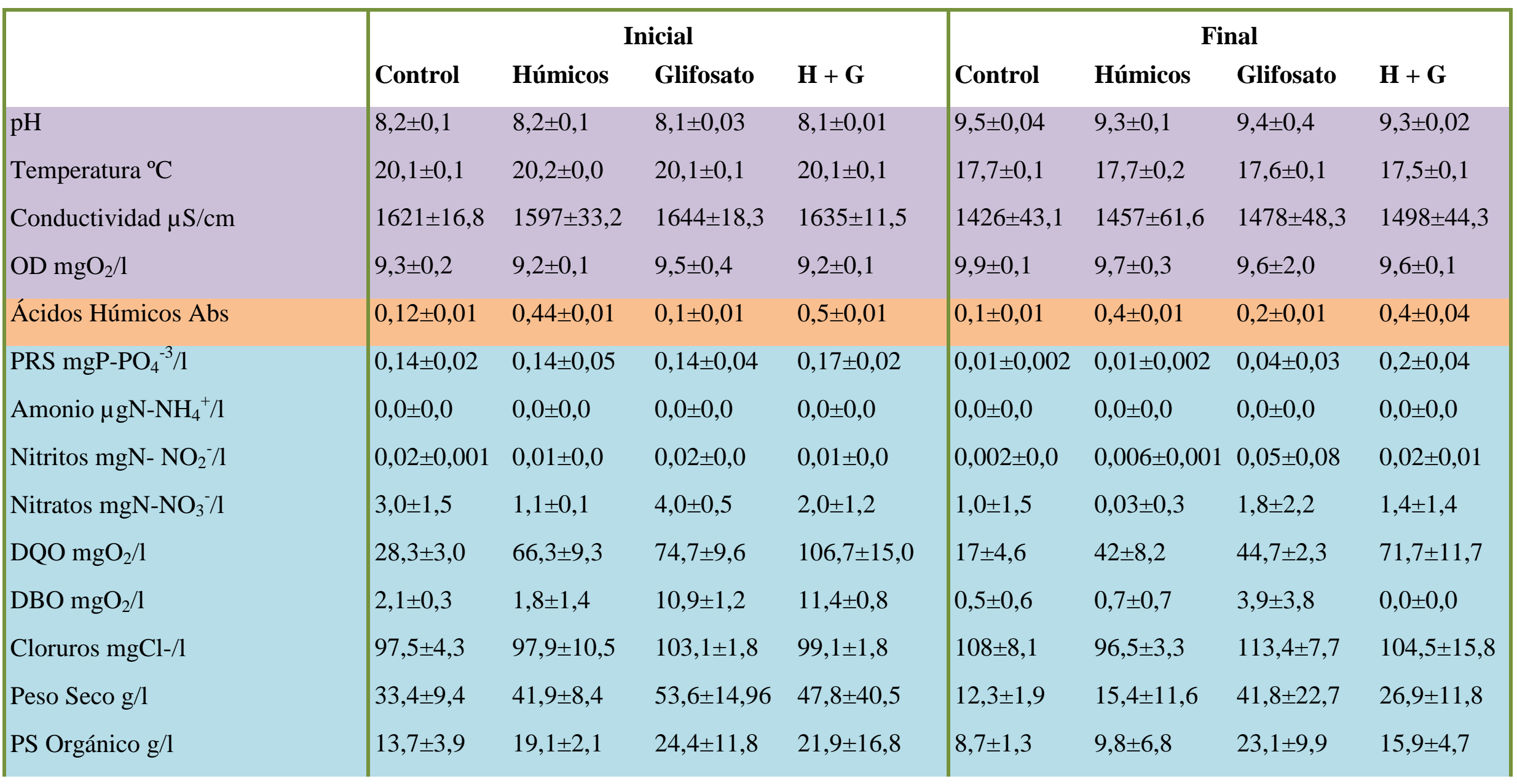




\begin{tabular}{|c|c|c|c|c|c|c|c|c|}
\hline Peso Seco perifiton $\mathrm{g} / \mathrm{m}^{2}$ & $2,8 \pm 2,2$ & $1,8 \pm 0,4$ & $5,9 \pm 6,7$ & $3,2 \pm 1,4$ & $7,0 \pm 2,7$ & $3,9 \pm 2,3$ & $8,9 \pm 7,0$ & $3,6 \pm 0,4$ \\
\hline PS Orgánico perifiton $\mathrm{g} / \mathrm{m}^{2}$ & $2,7 \pm 2,2$ & $1,7 \pm 0,4$ & $4,8 \pm 4,9$ & $2,6 \pm 1,0$ & $4,5 \pm 1,8$ & $2,7 \pm 1,7$ & $6,2 \pm 4,8$ & $2,7 \pm 0,4$ \\
\hline Polisacararidos mg/ml & $917,8 \pm 286$ & $1810 \pm 641$ & $1728 \pm 140$ & $1688 \pm 203$ & $2932 \pm 190$ & $4203 \pm 230$ & $4657 \pm 203$ & $3993 \pm 570$ \\
\hline Fósforo Total mg/m² & $7,2 \pm 4,8$ & $6,3 \pm 2,5$ & $8,3 \pm 1,3$ & $7,0 \pm 2,7$ & $7,0 \pm 0,5$ & $6,6 \pm 3,0$ & $18,8 \pm 5,4$ & $10,2 \pm 2,4$ \\
\hline Clorofila $a \mathrm{mg} / \mathrm{m}^{2}$ & $6,2 \pm 2,1$ & $6,2 \pm 3,2$ & $13,2 \pm 7,0$ & $13,9 \pm 4,1$ & $12,3 \pm 4,0$ & $9,7 \pm 7,5$ & $30,6 \pm 7,6$ & $15,6 \pm 9,3$ \\
\hline Respiración $\mathrm{mgO}_{2} / \mathrm{h} \cdot \mathrm{m}^{2}$ & $14,8 \pm 8,3$ & $9,9 \pm 9,1$ & $28,6 \pm 23,7$ & $18,9 \pm 13,8$ & $30,1 \pm 9,8$ & $30,1 \pm 23,6$ & $55,5 \pm 27,3$ & $18,7 \pm 10,1$ \\
\hline Índice Autotrófico & $867,6 \pm 359$ & $484,4 \pm 198,4$ & $418 \pm 286$ & $299,9 \pm 168,5$ & $273,5 \pm 216$ & $246,2 \pm 174,5$ & $51,6 \pm 23,7$ & $118,7 \pm 52,5$ \\
\hline Lakatos \%Cenizas & $0,13 \pm 0,05$ & $0,23 \pm 0,07$ & $0,32 \pm 0,2$ & $0,4 \pm 0,2$ & $0,5 \pm 0,3$ & $0,6 \pm 0,5$ & $2,3 \pm 1,3$ & $1,0 \pm 0,6$ \\
\hline Lakatos \%Clorofila & $6,9 \pm 8,5$ & $4,3 \pm 0,9$ & $10,2 \pm 11,2$ & $14,3 \pm 13,9$ & $36,8 \pm 4,6$ & $31,5 \pm 8,1$ & $29,2 \pm 7,3$ & $22,9 \pm 10,4$ \\
\hline Fosfatasa nmolMUF/h.cm ${ }^{2}$ & $92,0 \pm 173,1$ & $1088 \pm 1336$ & $6776 \pm 2824$ & $1961 \pm 660$ & $8380 \pm 2020$ & $6466 \pm 1907$ & $11114 \pm 8002$ & $3911 \pm 1361$ \\
\hline
\end{tabular}

